\title{
Análise de fatores intervenientes nas características dimensionais de segmentos rodoviários sob a óptica da compatibilidade veículo-via
}

Tese apresentada à Escola de Engenharia de São Carlos da Universidade de São Paulo, como parte dos requisitos para obtenção de título de Doutor em Engenharia Civil.

Área de Concentração: Transportes

Orientador: Prof Dr. João Alexandre Widmer

São Carlos

2007 


\section{AGRADECIMENTOS}

Ao Prof Dr. João Alexandre Widmer, pela orientação, incentivo e confiança depositada no desenvolvimento deste trabalho.

Ao CNPq, pela concessão de uma bolsa de estudo e financiamento da coleta de dados.

A todos os professores que contribuíram para enriquecer este trabalho com seuse conhecimentos, em especial ao Dr. Felipe Issa Kabbach Jr., Dr.a Maria Alice Prudêncio Jacques, Dr.a Suelly Helena de Araújo Barroso, Dr José Leomar Fernandes Jr., Dr. Jorge Barbosa Soares, Dr. Manoel Henrique Alba Sória e Dr. Glauco Tulio Pessa Fabbri.

Aos colegas do Departamento de Transportes da EESC-USP, Vivianne, Leandro, Cassiano, Serginho, Karênina, Celane, Xaxá, Manoel, Vítor, Márcia Lika, dentre outros, pela amizade e apoio, que me foram muito importantes para a realização desta pesquisa.

Aos colegas do Curso de Engenharia Civil da Universidade Federal do Ceará no Cariri, em especial aos professores Dr. Ary Ferreira da Silva e Dr.a Vilma Maria Sudério, pela compreensão e apoio.

Aos professores do DET - UFC, em especial à Dr.a Elisabeth Moreira e ao Dr. Felipe Loureiro, pelo incentivo para ingressar no curso de doutorado.

Aos funcionários do DER-SP, em especial ao Sr. Aprígio, e do DERT-CE, na pessoa do engenheiro Ms. Joacy de Souza Jr, pela presteza em disponibilizar dados fundamentais para a concretização deste trabalho. Agradeço também à engenheira Sueli Rodrigues e ao engenheiro Ms. Marcos Timbó Gomes, pelo empréstimo de equipamentos para a coleta de dados em campo.

Aos amigos Bosco, Júlio e Marcos, pela amizade em todos os momentos.

Aos meus familiares, sobretudo aos meus pais Aécio e Tereza Aquino, pela dedicação e amor. 


\section{RESUMO}

PEREIRA NETO, W. A. Análise de Fatores Intervenientes nas Características Dimensionais de Segmentos Rodoviários sob a Óptica da Compatibilidade Veículo-Via. 2007. 190p. Tese (Doutorado) - Escola de Engenharia de São Carlos, Universidade de São Paulo.

O setor rodoviário no Brasil é o maior responsável pelo transporte de passageiros e de cargas. A indústria de veículos de carga tem realizado modificações nas características dos veículos e a tendência neste mercado é o aumento na capacidade de transporte, obtida com a fabricação de veículos com maiores dimensões, com um maior número de eixos, bem como a utilização de combinações de veículos de carga (CVCs). Estas alterações atendem uma exigência do mercado, que é o aumento da produtividade nos serviços de transporte. Para uma operação segura, entretanto, se faz necessário garantir a compatibilidade entre os veículos e a malha rodoviária ofertada para absorver este tráfego. O objetivo principal deste trabalho é investigar as características e padrões dos veículos que trafegam nas rodovias brasileiras, visando à proposição de parâmetros de projeto geométrico compatíveis, contemplando os aspectos da interação dos veículos e da via, com ênfase para os veículos de grande porte, e em particular os veículos do tipo CVC. São propostos ajustes nos padrões técnicos estabelecidos pelo DNER, atual DNIT, de forma a adequar a geometria das rodovias às características e restrições dos veículos em operação. Foi realizado ainda um estudo de caso para um conjunto de trechos de rodovias no Estado de São Paulo e no Estado do Ceará, com características técnicas diferentes, onde trafegam CVCs de diversas configurações com restrições, permitindo que sejam identificados os ajustes necessários na geometria para adequação ao tráfego, bem como orientar a concepção de outros projetos.

Palavras-chave: Rodovias. Projeto Geométrico. Veículos Longos. Compatibilidade. Classificação viária. 


\begin{abstract}
PEREIRA NETO, W. A. Analysis of Intervening Factors on Highway Geometric Design According the Compatibility between Vehicles and Roads. 2007. 190p. Tese (Doutorado) - Escola de Engenharia de São Carlos, Universidade de São Paulo.

In Brazil the majority of passenger and goods transportation is carried out by the highway transportation system. Vehicle industry does a continuous job of designing new models in order to increase capacities, producing bigger vehicles, with more axles, as well as Long Combination Vehicles (LCVs). These modifications aim to attend a market demand that is looking for better productivity figures for transportations services. However, to assure a good level of safety in the operation of these vehicles, it is necessary a guarantee of compatibility of them with the roads where they will circulate. The main objective of this thesis is the research of the characteristics and standards of vehicles traveling on Brazilian roads, in order to analyze design parameters, considering the interaction between vehicles and roads. The problem of the flow of large vehicles, in particular LCVs, is emphasized. Adjustments on the design standards, established by the DNER (presently named DNIT), are proposed with the intention of adequate the road geometry to the vehicles characteristics and restrictions. A case study was carried out for a set of highway segments of the states of São Paulo and Ceará. These segments present different technical characteristics and are traversed, with some restrictions, by different types of LCVs. This study allows not only the identification of necessary adjustment on the road geometry to hold up the existing traffic flow, but also the design of new projects standards.
\end{abstract}

Keywords: Highways. Geometric Design. Long Vehicles. Compatibility. Road Classification. 


\section{LISTA DE ILUSTRAÇÕES}

Figura 1.1: Composição dos Veículos de Carga na Frota Brasileira. ................................2

Figura 3.1: Comprimento Mínimo das Curvas Verticais Convexas, Calculado com Base nos Veículos de Passeio $\left(\mathrm{h}_{1}=1,1 \mathrm{~m}\right)$.

Figura 3.2: Comprimento Mínimo das Curvas Verticais Convexas, Calculado com Base em Caminhões $\left(\mathrm{h}_{1}=2,4 \mathrm{~m}\right)$. 54

Figura 3.3: Distância de Visibilidade em Curva Horizontal.............................................55

Figura 3.4: Condições de Velocidade Assumidas Pelo Modelo de Glennon para a Ultrapassagem de Automóveis e Caminhões. 66

Figura 3.5: Comparação dos Valores de Distância de Visibilidade de Ultrapassagem Calculados pelo Modelo de Glennon e outros Modelos.

Figura 3.6: Tipos de Arraste Verificados em Caminhões Executando Conversões. Fonte: Adaptado de FHWA (2000). 69

Figura 3.7: Componentes do Cálculo da Sobrelargura em Curvas Circulares. .70

Figura 3.8: Deslocamento observado no centro de gravidade em função das forças que atuam no veículo ao percorrer a curva. .78

Figura 3.9: Triângulo de Visibilidade Recomendado para Interseções Controladas pela Sinalização "Parada Obrigatória" na Via Secundária .86

Figura 4.1: Fluxograma dos Parâmetros Investigados dos Veículos e da Via para o Atendimento das Condições Operacionais. .96

Figura 4.2: Folga Lateral dos Veículos - Classe 0 - Veículo de Projeto CO............... 101

Figura 4.3: Folga Lateral dos Veículos - Classe 0 - Veículo de Projeto O. ................ 101

Figura 4.4: Folga Lateral dos Veículos - Classe 0 - Veículo de Projeto SR. .............. 101

Figura 4.5: Folga Lateral dos Veículos - Classe I - Veículo de Projeto CO. .............. 102

Figura 4.6: Folga Lateral dos Veículos - Classe I - Veículo de Projeto O .................. 102

Figura 4.7: Folga Lateral dos Veículos - Classe I - Veículo de Projeto SR ................ 103

Figura 4.8: Folga Lateral dos Veículos - Classe II - Veículo de Projeto CO.............. 103

Figura 4.9: Folga Lateral dos Veículos - Classe II - Veículo de Projeto O................. 104

Figura 4.10: Folga Lateral dos Veículos - Classe II - Veículo de Projeto SR............ 104

Figura 4.11: Folga Lateral dos Veículos - Classe III - Veículo de Projeto CO.......... 104 
Figura 4.12: Folga Lateral dos Veículos - Classe III - Veículo de Projeto O.............. 105

Figura 4.13: Folga Lateral dos Veículos - Classe III - Veículo de Projeto SR............ 105

Figura 4.14: Folga Lateral dos Veículos - Classe IV - Veículo de Projeto CO........... 105

Figura 4.15: Folga Lateral dos Veículos - Classe IV - Veículo de Projeto O. ............ 106

Figura 4.16: Folga Lateral dos Veículos - Classe IV - Veículo de Projeto SR. .......... 106

Figura 4.17: Extensão de Travessia Considerada na Simulação para Cálculo da Distância de Visibilidade em Interseções. ............................................................. 119

Figura 4.18: Interseções do Tipo Trevo Vazado Simples e Trevo Vazado com Faixas de Aceleração e Desaceleração. 120

Figura 5.1: Localização do Trecho das Rodovias SP 333 (entre SP 300 e SP 304) e SP304. 138

Figura 5.2: Localização do Trecho das Rodovias SP 333 (Serrana - Cajuru), SP 225 e SP 310. 138

Figura 5.3: Localização do Trecho da Rodovia SP 147. 139

Figura 5.4: Localização do Trecho da Rodovia CE 232. 139

Figura 5.5: Localização do Trecho das Rodovias CE 456 e CE 377. 139

Figura 5.6: Localização do Trecho da Rodovia CE 040. 140

Figura 5.7: SP 310 - Trecho Montanhoso com Sobrelarguras nas Curvas Horizontais. 144

Figura 5.8: SP 333 (SP 300 - SP 304) - Acostamentos em Mal Estado de Conservação.

Figura 5.9: SP 333 (SP 300 - SP 304) - Acostamentos com Desnível Acentuado...... 146

Figura 5.10: SP 333 (Serrana - Cajuru) - Pista com Acostamento sem Pavimento..... 146

Figura 5.11: SP 147 - Pista sem Acostamento.

Figura 5.12: SP 147 - Curva com Acostamento Direito Adequado para Acomodar o Veículo sem Invasão da Faixa de Tráfego Oposta, mas Acostamento Esquerdo Insuficiente. Foto: Autor. 148

Figura 5.13: SP 147 -Trecho Curvo sobre Ponte, sem Acostamento. 148

Figura 5.14: CE 232 - Rodovia com Acostamento Pavimentado e Largura Suficiente em Todas as Curvas para Acolher o Arraste dos Veículos. 149

Figura 5.15: CE 377 - Rodovia com Curvas de Raio Reduzido, com Acostamentos Estreitos e sem Pavimento. 150 
Figura 6.1: Procedimentos para Verificar a Adequação de Parâmetros Importantes da Geometria de Rodovias às Condições dos Veículos. 162

Figura A.1: Tipos Comuns de Conexão entre a Unidade Tratora e a Primeira Unidade Rebocada de CVCs. 183

Figura A.2: Tipos de Conexão entre as Unidades Rebocadas de uma CVC 184 


\section{LISTA DE TABELAS}

Tabela 1.1: Evolução da Frota de Caminhões por Tipo de Veículo. ................................ 3

Tabela 2.1: Quadro Resumo das Classes de Rodovias Rurais........................................ 16

Tabela 2.2: Relação entre as Classes Funcionais e as Classes Técnicas de Projeto. .......18

Tabela 2.3: Velocidade Operacional Utilizada em Rodovias, de acordo com sua

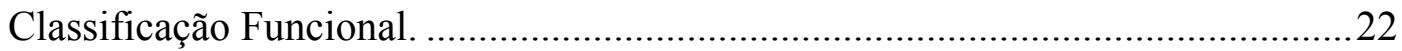

Tabela 2.4: Rampas Máximas Admissíveis em Sistemas de Classificação Funcional...23

Tabela 2.5: Rampas Máximas Admissíveis em Outros Paises (em \%). ..........................24

Tabela 2.6: Largura das Faixas de Tráfego e dos Acostamentos de Rodovias em

Sistemas de Classificação Funcional. .....................................................................26

Tabela 2.7: Largura das Faixas de Tráfego e dos Acostamentos de Rodovias em Sistemas de Classificação Funcional de Outros Paises.............................................22

Tabela 2.8: Superelevação Máxima de Rodovias em Sistemas de Classificação

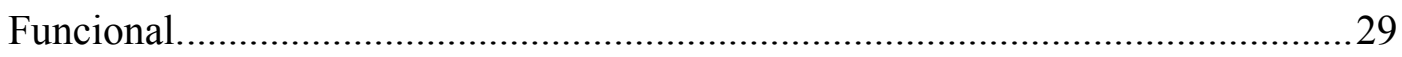

Tabela 2.9: Superelevação Máxima Admitida em Função da Velocidade de Projeto das

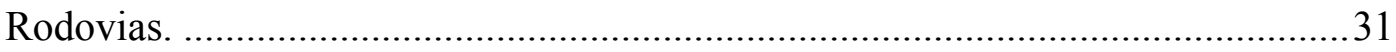

Tabela 3.1: Comparação dos Veículos de Projeto do DNER com Veículos de mesma

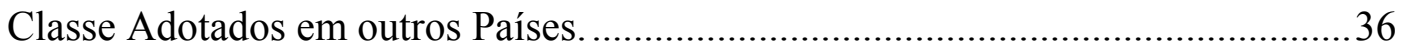

Tabela 3.2: Representação Pictográfica dos Veículos Estudados...................................39

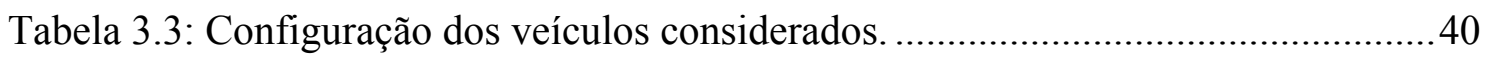

Tabela 3.4: Distância de Visibilidade de Parada para Veículos de Passeio e Caminhões.

Tabela 3.5: Comparação dos Valores de $K_{\min }$ para Curvas Verticais Convexas $(D<$ $\left.L v_{\min }\right)$ com Base nos Parâmetros de Veículos de Passeio e de Caminhões..............51

Tabela 3.6: Valores de Afastamento Lateral Mínimo em Curvas Horizontais para os Parâmetros Mínimos das Classes de Projeto do DNER ............................................58

Tabela 3.7: Comparação dos Valores de Distância de Visibilidade de Ultrapassagem Calculados pelo Modelo de Glennon e Outros Modelos ........................................66

Tabela 3.8: Valores do Gabarito Lateral do Veículo de Projeto em Movimento ............72 Tabela 3.9: Espaço de Segurança dos Veículos nos Trechos em Tangente e nas Curvas 
Tabela 3.10: Fator de Atrito Lateral $f_{\max }$ Adotado no Projeto de Curvas Horizontais... 76 Tabela 3.11: Intervalo de Tempo na Via Principal Aceito para Manobras de Veículos Parados na Via Secundária $\left(\mathrm{t}_{\mathrm{g}}\right)$. .87

Tabela 3.12: Comprimento das Faixas de Aceleração em Interseções, Adotado pelo DNIT para Greides Inferiores a 2\%, Incluindo Taper. .89

Tabela 3.13: Comprimento das Faixas de Aceleração em Interseções, Adotado pela AASHTO para Greides Inferiores a 2\%, Incluindo Taper. .90

Tabela 3.14: Comprimento das Faixas de Aceleração em Interseções, Adotado pelo DNIT para Greides Ascendentes, Incluindo Taper. .90

Tabela 3.15: Comprimento das Faixas de Aceleração em Interseções, Adotado pelo

DNIT para Greides Descendentes, Incluindo Taper. 91

Tabela 3.16: Comprimento das Faixas de Aceleração em Interseções, Adotado pela AASHTO para Greides Ascendentes, Incluindo Taper. 91

Tabela 3.17: Comprimento das Faixas de Aceleração em Interseções, Adotado pela AASHTO para Greides Descendentes, Incluindo Taper. 92

Tabela 4.1: Dimensões Básicas dos Veículos Considerados (m) 97

Tabela 4.2: Sobrelarguras Exigidas para as Condições Mínimas das Classes de Projeto do DNER (Plano (P), Ondulado (O) e Montanhoso (M), em metros). .98

Tabela 4.3: Compatibilidade das Sobrelarguras Calculadas com Base nos Veículos de Projeto do DNER, por Classe de Rodovia e Terreno (Plano (P), Ondulado (O) e Montanhoso (M)). 107

Tabela 4.4: Compatibilidade das Sobrelarguras em Curvas Horizontais, Considerando as Simulações de Alguns Veículos de Projeto..... 109

Tabela 4.5: Margens de Segurança para a Ocorrência de Escorregamento em Curvas Horizontais, Dados os Parâmetros Mínimos das Classes Técnicas do DNER. .... 112 Tabela 4.6: Margens de Segurança para a Ocorrência da Tombamento em Curvas Horizontais, Dados Parâmetros Mínimos das Classes Técnicas do DNER 112

Tabela 4.7: Margens de Segurança para a Ocorrência de Escorregamento e Tombamento em Curvas Horizontais, Dados os Parâmetros Mínimos das Classes Técnicas do DNER 113

Tabela 4.8: Comprimentos Críticos Calculados para as Rampas Máximas das Classes de Projeto do DNER, Considerando Caminhões Típicos Brasileiros (em metros)... 117 
Tabela 4.9: Intervalo de Tempo na Via Principal Aceito para Manobra de Travessia de Veículos Parados na Via Secundária - Greide de 1\% 121

Tabela 4.10: Intervalo de Tempo na Via Principal Aceito para Manobra de Travessia de Veículos Parados na Via Secundária - Greide de 2\% 122

Tabela 4.11: Intervalo de Tempo na Via Principal Aceito para Manobra de Travessia de Veículos Parados na Via Secundária - Greide de 3\% 122

Tabela 4.12: Distância de Visibilidade em Interseções, segundo o Veículo de Projeto O (DNER) e Veículos Simulados com Comprimento de 12,2 m. 124

Tabela 4.13: Distância de Visibilidade em Interseções, segundo o Veículo de Projeto RE (DNIT) e Veículos Simulados.com Comprimento de 19,8 m

Tabela 4.14: Distância de Visibilidade em Interseções Segundo o Veículo de Projeto RE (DNIT) e Veículos Simulados com Comprimento de $25 \mathrm{~m}$. 125

Tabela 4.15: Distância de Visibilidade em Interseções Segundo o Veículo de Projeto RE (DNIT) e Veículos Simulados com Comprimento de $30 \mathrm{~m}$. 125

Tabela 4.16: Velocidade Atingida por Veículo que se Inseriu na Via Principal, após um Intervalo equivalente ao Gap Necessário para a Transposição da Via. 127

Tabela 4.17: Velocidade de Equilíbrio dos Veículos Simulados para o Terreno Plano e algumas Rampas Ascendentes.

Tabela 4.18: Comprimento da Faixa de Aceleração para os Veículos de Carga, Incluindo Taper - Rampas Ascendentes de 2\% (em metros). 129

Tabela 4.19: Comprimento da Faixa de Aceleração para os Veículos de Carga, Incluindo Taper - Rampas Ascendentes de 4\% (em metros).............................. 130

Tabela 4.20: Comprimento da Faixa de Aceleração para os Veículos de Carga, Incluindo Taper - Rampas Ascendentes de 6\% (em metros). 131

Tabela 4.21: Comprimento da Faixa de Aceleração para os Veículos de Carga em Rampas Descendentes, Incluindo Taper - Veículo 1 - 3,16 cv/t (em metros)..... 132 Tabela 4.22: Comprimento da Faixa de Aceleração para os Veículos de Carga em Rampas Descendentes, Incluindo Taper - Veículo 2 - 4,67 cv/t (em metros)..... 132 Tabela 4.23: Comprimento da Faixa de Aceleração para os Veículos de Carga em Rampas Descendentes, Incluindo Taper - Veículo 3 - 6,97 cv/t (em metros)..... 133 Tabela 4.24: Comprimento da Faixa de Aceleração para os Veículos de Carga em Rampas Descendentes, Incluindo Taper - Veículo 4 - 7,42 cv/t (em metros)..... 133 
Tabela 4.25: Comprimento da Faixa de Aceleração para os Veículos de Carga em Rampas Descendentes, Incluindo Taper - Veículo 5 - 9,76 cv/t (em metros)..... 134 Tabela 4.26: Comprimento da Faixa de Aceleração para os Veículos de Carga em Rampas Descendentes, Incluindo Taper - Veículo 6 - 13,15 cv/t (em metros)... 134

Tabela 5.1: Características Técnicas dos Trechos Pesquisados. 141

Tabela 5.2: Compatibilidade da Largura das Pistas nas Curvas Horizontais para o Tráfego de Veículos. 143

Tabela 5.3: Velocidade-Limite Estimada para a Ocorrência de Instabilidade Lateral do Veículo - Curva com Menor Margem de Segurança do Trecho. 152

Tabela 5.4: Extensão do Trecho onde o Veículo Trafega com uma Redução de

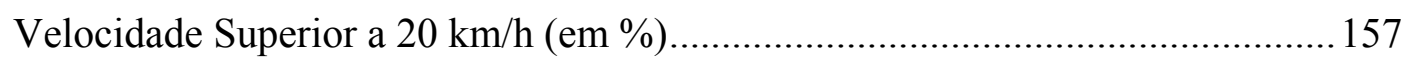

Tabela A.1: Representação Pictográfica dos Veículos Estudados. 182 


\section{LISTA DE ABREVIATURAS E SIGLAS}

AASHTO - American Association of State Highway and Transportation Officials

ABS - Antilock Break System

AET - Autorização Especial de Trânsito

AUSTROADS - Australian and New Zealand Road Transport and Traffic Authorities

AVSR - Australian Vehicle Standards Rules

BRTE - Bureau of Transport and Regional Economics

CBR - Commonwealth Bureau of Roads

CVC - Combinação de Veículo de Carga

CNT - Confederação Nacional do Transporte

CONTRAN - Conselho Nacional de Trânsito

CTB - Código de Trânsito Brasileiro

DENATRAN - Departamento Nacional de Trânsito

DER - Departamento de Estradas de Rodagem

DERT - Departamento de Edificações Rodovias e Transportes

DNER - Departamento Nacional de Estradas de Rodagem

DNIT - Departamento Nacional de Infra-Estrutura de Transportes

FHWA - Federal Highway Administration

HCM - Highway Capacity Manual

MUTCD - Manual on Uniform Traffic Control Devices for Streets and Highways

NAASRA - National Association of Australian State Road Authorities

NRTC - National Road Transport Commission

NTC -- National Transportation Commission

PBS - Performance Based Standards

PBT - Peso Bruto Total

PBTC - Peso Bruto Total Combinado

PNTC - Plano Nacional de Contagem de Trânsito

SAE - Society of Automotive Engineers

SARM - Saskatchewan Association of Rural Municipalities

STAA - Surface Transportation Assistance Act 
TAC - Transportation Association of Canada

TRB - Transportation Research Board

US DOT - United States Department of Transportation

VMD - Volume Médio Diário

VMDA - Volume Médio Diário Anual

WHI - Western Highway Institute 


\section{SUMÁRIO}

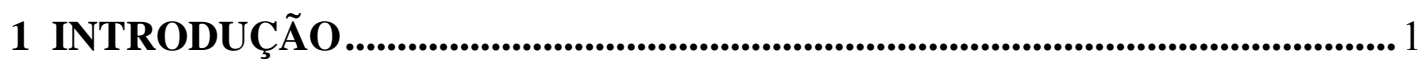

1.1 Considerações Iniciais........................................................................ 1

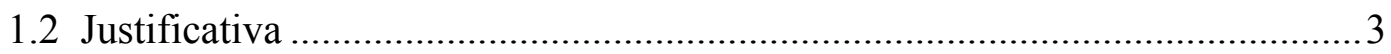

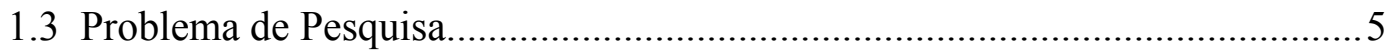

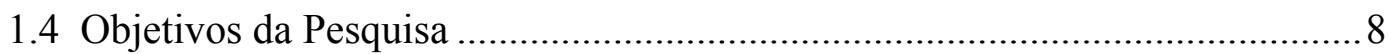

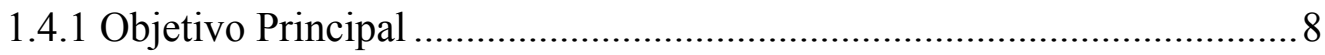

1.4.2 Objetivos Específicos................................................................. 8

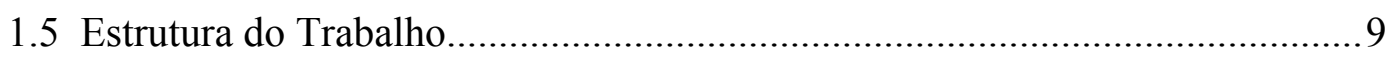

2 SISTEMAS DE CLASSIFICAÇÃO DE RODOVIAS RURAIS ...................... 10

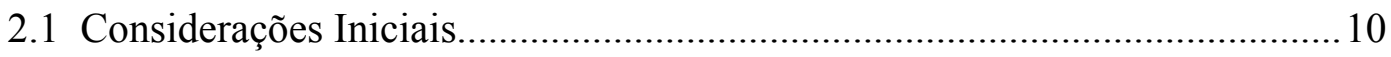

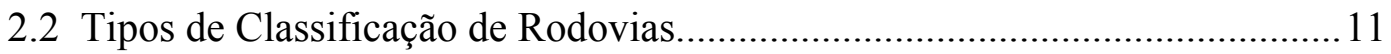

2.3 Os Sistemas de Classificação de Rodovias em Alguns Países.......................... 13

2.4 O Sistema de Classificação de Rodovias no Brasil........................................ 15

2.4.1 Principais Características ................................................................. 16

2.4.2 As Classes de Projeto do DNER (atual DNIT) .....................................19

2.5 Parâmetros de Projeto Utilizados na Concepção de Rodovias Rurais .............21

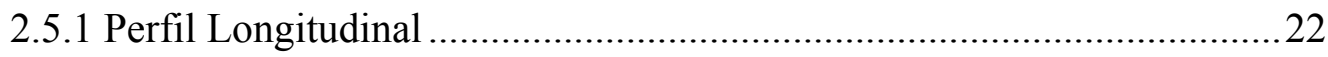

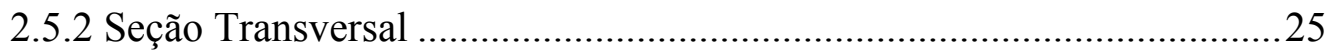

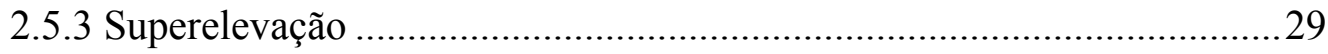

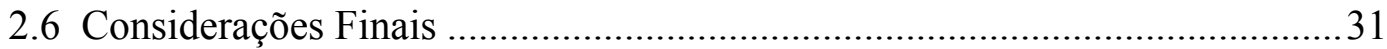

3 ASPECTOS DA INTERAÇÃO VEÍCULO - VIA NA CONCEPÇÃO DO PROJETO GEOMÉTRICO DE RODOVIAS ..................................................... 32

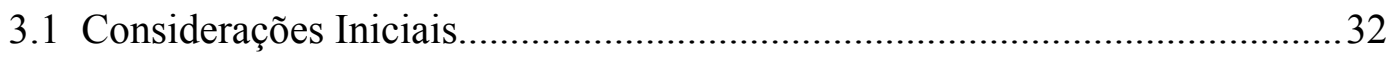

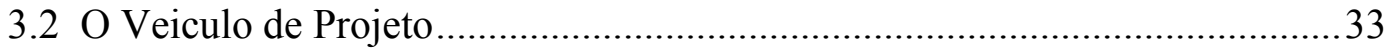

3.3 Principais Influências dos Veículos de Projeto na Concepção de Segmentos

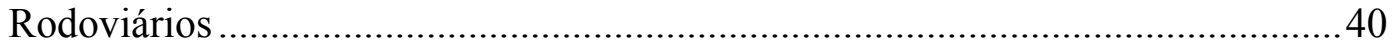

3.3.1 Distância de Visibilidade de Parada..........................................................40

3.3.2 Distância de Visibilidade para Tomada de Decisão................................ 48

3.3.3 Distância de Visibilidade em Curvas Verticais Convexas........................48

3.3.4 Distância de Visibilidade em Curvas Horizontais ...................................54 
3.3.5 Distância de Visibilidade de Ultrapassagem..........................................59

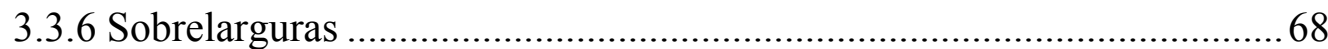

3.3.7 Estabilidade dos Veículos em Curvas Horizontais ................................ 74

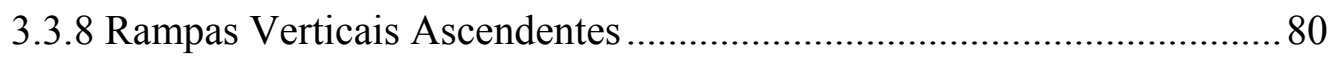

3.3.9 Rampas Verticais Descendentes .................................................... 83

3.3.10 Distância de Visibilidade para Interseções em Nível ...........................84

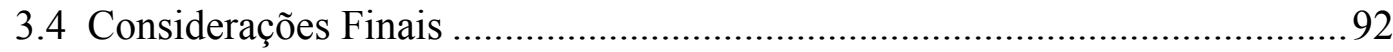

4 PROPOSTA DE ADEQUAÇÃO DE PARÂMETROS DE PROJETO PARA

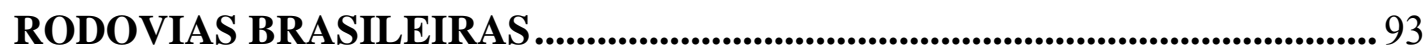

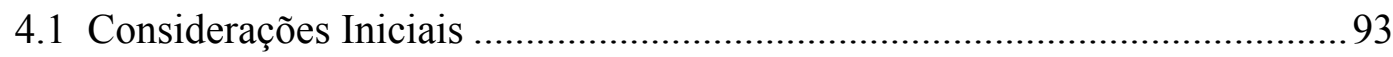

4.2 Parâmetros Investigados para Verificar o Atendimento de Condições

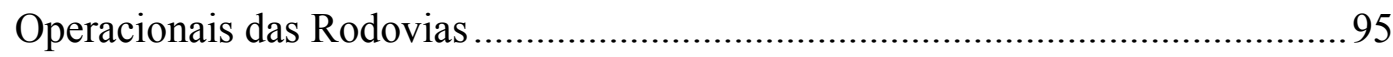

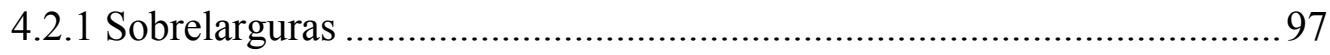

4.2.2 Estabilidade nas Curvas Horizontais .................................................. 110

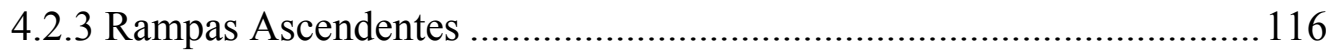

4.2.4 Distância de Visibilidade em Interseções ............................................. 118

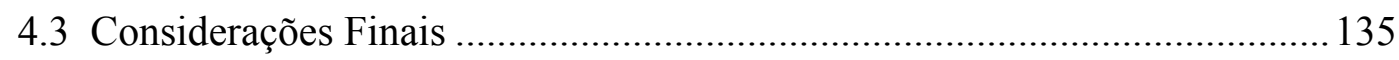

5 ESTUDO DE CASO _.......................................................................... 136

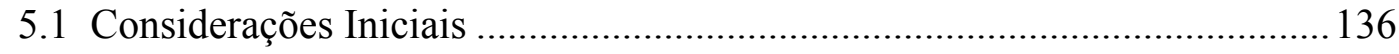

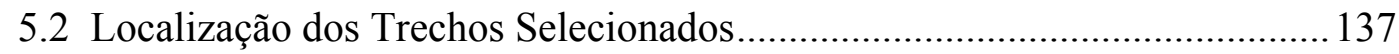

5.3 Características Técnicas dos Trechos Selecionados …................................ 140

5.4 Avaliação das Sobrelarguras dos Trechos Investigados ............................... 143

5.5 Avaliação da Estabilidade nas Curvas Horizontais dos Trechos Investigados 151

5.6 Avaliação das Rampas Ascendentes dos Trechos Estudados ...................... 155

6 ANÁLISE DOS RESULTADOS ................................................................. 160

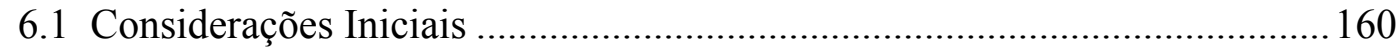

6.2 Procedimentos para Verificar a Adequação de Parâmetros de Geometria de

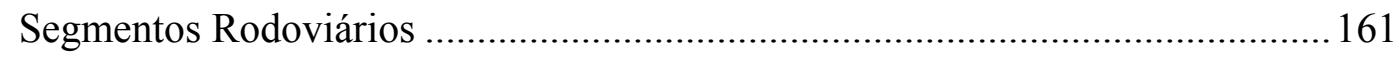

7 CONCLUSÕES E RECOMENDAÇÕES....................................................... 164

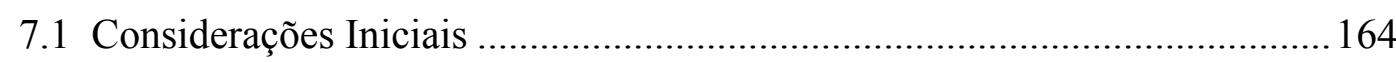


7.2 Conclusões Quanto à Investigação de Parâmetros de Projeto Ordinariamente Baseados em Veículos de Passeio 165

7.3 Conclusões Quanto à Investigação dos Veículos de Projeto Brasileiros...... 166

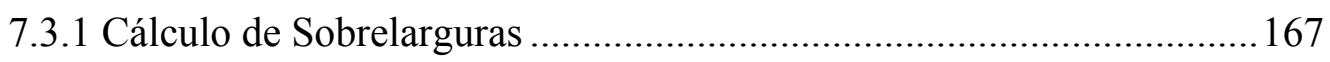

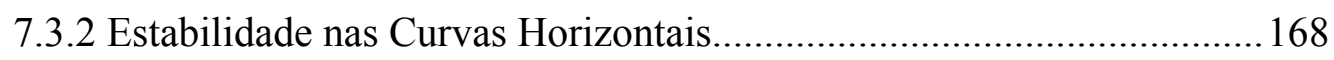

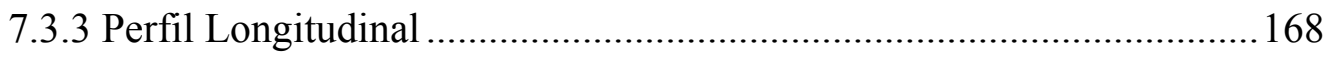

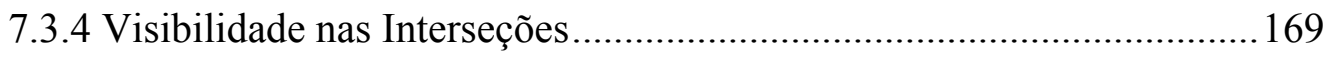

7.4 Conclusões Obtidas no Estudo de Caso ....................................................... 169

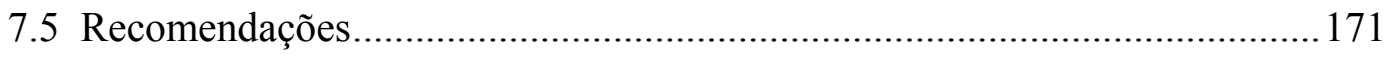

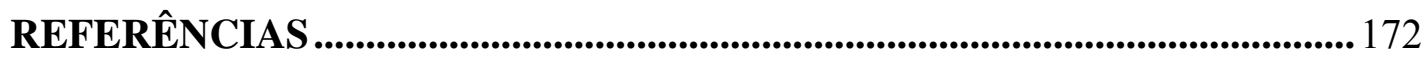

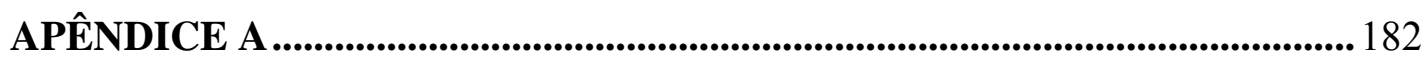

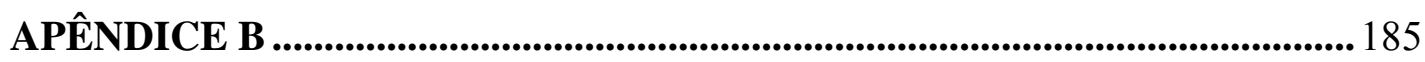





\section{INTRODUÇÃO}

\subsection{Considerações Iniciais}

O Brasil, assim como outros países da América Latina, investiu, a partir da década de 1950 e mais intensamente até os anos 1970, boa parcela de recursos públicos na implantação de sua rede rodoviária e de outras infra-estruturas de transporte. $O$ desenvolvimento experimentado pelo setor de transporte rodoviário foi marcado por forte priorização, sobrepondo-se aos demais modos da matriz nacional de transportes. Isto pode ser justificado, entre outras razões, por oferecer vantagens como grande flexibilidade e mobilidade, além da existência de aspectos associados à conjuntura econômica, com a implantação da indústria automobilística nos anos 1950 e a determinação política dos governos da época.

O setor rodoviário no Brasil é responsável por cerca de 96,2\% do transporte de passageiros e $61,8 \%$ das cargas transportadas (CNT, 2006). A atual infra-estrutura rodoviária brasileira é composta de aproximadamente 1.610.076 quilômetros de rodovias, de cujo total, 196.094 quilômetros são de rodovias pavimentadas (CNT, 2005). Dentre as rodovias pavimentadas $29 \%$ são de jurisdição federal, $59 \%$ estadual e $12 \%$ municipal. Por esta infra-estrutura trafega uma frota de 2,048 milhões de caminhões, 353.583 ônibus e 198.393 micro-ônibus (DENATRAN, 2006).

A indústria de veículos de carga tem realizado modificações nas características dos veículos e a tendência neste mercado é o aumento na capacidade de transporte. Acréscimos nas dimensões dos caminhões, seja pela fabricação de veículos mais altos e mais longos, com maior número de eixos, seja com a utilização de combinações de veículos, é a estratégia adotada para elevar a capacidade dos veículos. Estas alterações atendem a uma exigência do mercado, o aumento da produtividade nos serviços de transporte (WIDMER; SETTI, 1998). A utilização de veículos de maior porte permite 
transportar maiores volumes de carga sem uma elevação nos custos com a mão-de-obra. Além disso, existe uma economia de escala em virtude da redução nos gastos com os combustíveis, uma vez que o aumento no seu consumo é bem menor do que a carga adicional transportada, levando a melhores resultados quando considerado o consumo por tonelada-quilômetro transportada.

A Figura 1.1 apresenta dados de composição da frota brasileira de veículos de carga, segundo a classificação proposta pelo Código de Trânsito Brasileiro (BRASIL, 1999a), dados estes referentes ao cadastro de veículos do Departamento Nacional de Trânsito (DENATRAN, 2004) e que revelam participação importante dos veículos longos na frota nacional de veículos pesados.

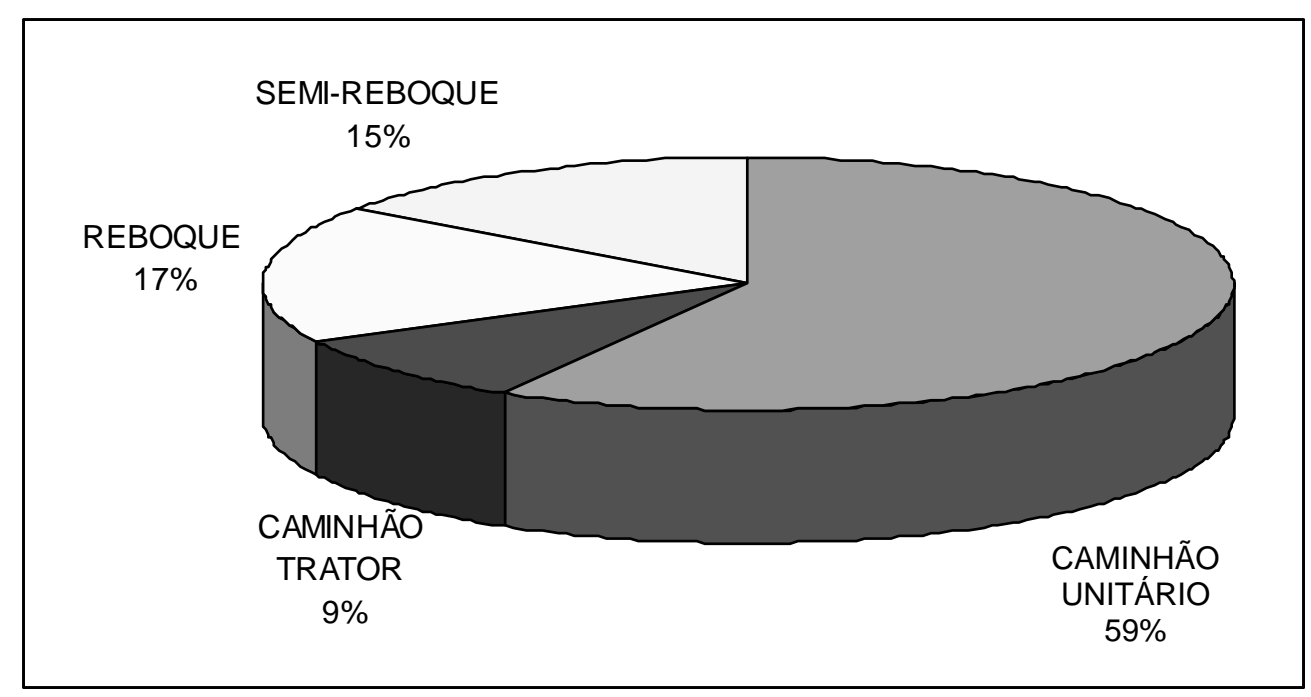

Figura 1.1: Composição dos Veículos de Carga na Frota Brasileira. Fonte: DENATRAN (2006).

A frota de veículos brasileiros, considerando o período de 1985 a 2002, apresentou taxa média de crescimento anual de 3,4\%, liderado pelos veículos comerciais leves, com aumento anual de 4,1\%, seguido pelos automóveis, com 3,6\%, e pelos ônibus, com 2,4\%, enquanto os caminhões permaneceram com um volume praticamente estabilizado (DNIT, 2005). Como mostra a Tabela 1.1, entretanto, se observados os tipos de veículos da frota de caminhões, é verificada uma substituição dos veículos médios e leves por veículos de maior capacidade, com peso bruto total variando entre 15 e 45 toneladas. Os veículos pesados e articulados, que em 1985 
representavam 7,6\% dos veículos de carga, no ano de 2002 já correspondiam a $21,9 \%$ da frota de caminhões.

Tabela 1.1: Evolução da Frota de Caminhões por Tipo de Veículo.

\begin{tabular}{|c|c|c|c|c|c|c|c|}
\hline \multirow{2}{*}{$\begin{array}{c}\text { TIPO DE } \\
\text { CAMINHÃO }\end{array}$} & \multirow{2}{*}{ CLASSIFICAÇÃO } & \multicolumn{6}{|c|}{ PARTICIPAÇÃO NA FROTA DE CAMINHÕES (\%) } \\
\hline & & 1985 & 1990 & 1995 & 2000 & 2001 & 2002 \\
\hline $\begin{array}{l}\text { Semileves } \\
\text { Leves }\end{array}$ & $\begin{array}{l}2 \text { eixos simples com } \\
\text { rodagem simples } \\
(3,5 \mathrm{t}<\mathrm{PBT}<10 \mathrm{t})\end{array}$ & 42,5 & 42,6 & 40 & 37,2 & 36,6 & 37,4 \\
\hline Médios & $\begin{array}{l}\text { Eixos simples com } \\
\text { rodagem simples ou dupla } \\
\quad(10 \mathrm{t}<\mathrm{PBT}<15 \mathrm{t})\end{array}$ & 45 & 44,1 & 42,7 & 41,4 & 41,1 & 39,3 \\
\hline $\begin{array}{l}\text { Semipesados } \\
\text { Pesados }\end{array}$ & $\begin{array}{l}\text { Eixos simples com rodagem simples e } \\
\text { eixo em tandem duplo ou triplo } \\
(15 \mathrm{t}<\mathrm{PBT}<40 \mathrm{t})\end{array}$ & 7,6 & 9,0 & 13,2 & 19,1 & 20,5 & 21,9 \\
\hline Articulados & $\begin{array}{l}\text { Semi-Reboques e Reboques } \\
\quad(15 \mathrm{t}<\mathrm{PBT}<45 \mathrm{t})\end{array}$ & & & & & & \\
\hline Diversos & - & 4,9 & 4,3 & 4,1 & 2,3 & 1,8 & 1,4 \\
\hline
\end{tabular}

Fonte: (DNIT, 2005).

\subsection{Justificativa}

As mudanças ocorridas na frota dos veículos produzem repercussões na operação do tráfego, originando a necessidade de adequação da infra-estrutura viária às solicitações destes veículos. O padrão das rodovias deve acompanhar esta evolução, ajustando-se às alterações ocorridas nos veículos, de forma a estabelecer novos valores para os parâmetros de geometria viária, de acordo com as demandas originadas pelo tráfego. Como a homologação de novos veículos é da responsabilidade de instituições do governo, assim como é do governo, seja na esfera estadual ou federal, a incumbência de prover e/ou fiscalizar a infra-estrutura rodoviária, é fundamental haver o diálogo e entendimento entre estes agentes, de forma a dirigir essas transformações sem comprometer a segurança e eficiência do sistema de transporte. A inobservância deste aspecto pode causar danos, como a elevação nos índices de acidentes e maior deterioração da infra-estrutura viária.

Um instrumento fundamental para o adequado funcionamento de uma malha rodoviária é o seu sistema de classificação, onde as vias são hierarquizadas e são estabelecidos padrões técnicos a serem obedecidos. Este sistema deve garantir que uma via de determinada classe atenda à função que lhe é outorgada, acolhendo 
adequadamente os veículos que dela fazem uso. Para cumprir este papel, é fundamental que o sistema de classificação esteja atualizado, de forma a ser capaz de estabelecer a compatibilidade das classes de rodovia para os diversos veículos que fazem uso do sistema viário, por meio da definição de padrões técnicos mínimos adequados.

Tornar a infra-estrutura compatível para a circulação de veículos com maiores dimensões, mais pesados e na maioria das vezes com maiores restrições operacionais, significa conceber projetos de padrão mais elevado, que, por sua vez, demandam maior aporte financeiro. A redução dos custos de transporte obtidos com a operação deste tipo de veículo deve, por sua vez, ser compatível com o ônus de ofertar uma infra-estrutura mais cara. Seguindo este raciocínio, a regulamentação de veículos com maior capacidade, sejam eles unitários ou combinações, deveria ser precedida anteriormente por um estudo detalhado da compatibilidade entre os parâmetros de geometria e as características operacionais destes veículos, de forma a identificar possíveis danos causados à infra-estrutura, os impactos gerados à segurança viária e os custos associados às intervenções necessárias.

No caso do Brasil, esta problemática não recebe a devida atenção. $\mathrm{O}$ que se observa é uma carência em estudos desta natureza, sendo normalmente permitida a operação de veículos que atendam apenas a alguns requisitos associados à segurança viária. Isto resulta na existência de veículos de elevada complexidade utilizando as rodovias sob condições operacionais adversas.

As mudanças ocorridas na frota de veículos pesados não se restringem a um aumento de capacidade de carga, sendo observadas também inovações na tecnologia destes veículos, que contribuíram principalmente para um ganho de potência, elevando seu desempenho em termos de velocidade e aceleração. Essa é uma tendência verificada também em outros países. McLean, Tziots e Gunatillake (2002) citam um fato importante: há 25 anos os veículos articulados na Austrália viajavam a uma velocidade correspondente a $80 \%$ da velocidade dos automóveis. Por conta desta diferença, admitia-se que parâmetros de projeto geométrico como a distância de visibilidade de frenagem e o raio das curvas, dimensionados em função do $85^{\circ}$ percentil da velocidade dos automóveis, eram adequados para o tráfego de veículos de carga. Como estes parâmetros de geometria são determinados em função da variável velocidade ao 
quadrado, acreditava-se que o diferencial de velocidade entre os veículos de passeio e de carga poderia mais do que compensar o desempenho inferior dos caminhões nas curvas e nos processos de desaceleração.

O surgimento de inovações tecnológicas, entretanto, e a conseqüente elevação na potência dos veículos de carga, além de melhorias no desempenho aerodinâmico como a utilização de pneus com menor resistência interna ao rolamento - contribuíram para uma elevação na velocidade dos caminhões, deixando-a muito próxima da velocidade dos automóveis. Atualmente a diferença entre o $85^{\circ}$ percentil da velocidade dos automóveis e dos caminhões nas rodovias australianas é menor do que 5\%, de forma que não se pode mais assumir a existência de uma compensação do pior desempenho dos veículos de carga nas frenagens e nos trechos em curva. A adoção de parâmetros de geometria com base em veículos de passeio pode, portanto, representar sérios riscos à operação de veículos pesados, devendo ser substituída pela utilização de um veículo de carga para permitir a concepção de vias seguras.

\subsection{Problema de Pesquisa}

O presente ensaio irá investigar o problema da incompatibilidade de veículos pesados com as características geométricas de segmentos rodoviários brasileiros. A pesquisa aqui abordada trará como contributo uma revisão de várias questões relacionadas à interação dos veículos com a infra-estrutura viária. Serão investigadas várias configurações de veículos em circulação nas rodovias brasileiras, e, com base nas suas características técnicas e restrições operacionais, serão identificados padrões de geometria mais adequados, levando à proposição de mudanças nas diretrizes atuais de projeto para rodovias brasileiras.

Um dos aspectos mais importantes nesta investigação consiste em avaliar os parâmetros de geometria das vias associados à segurança viária. Dados de acidentes nos Estados Unidos indicam que veículos longos, especialmente os veículos combinados, apresentam taxas de colisões com vítimas fatais aproximadamente $11 \%$ superiores quando comparadas aos acidentes observados em veículos simples (US DOT, 2000). Análises indicam que a causa principal dos acidentes envolvendo veículos longos é a utilização de uma infra-estrutura que foi projetada para veículos de menor porte e que é 
incompatível com a operação de veículos maiores (DONALDSON, 1986). Esta incompatibilidade está associada principalmente a aspectos geométricos, como os raios utilizados nas curvas, sobrelarguras, superelevações e distâncias de visibilidade que, à medida que são mal projetados, ocasionam problemas como:

(a) a invasão de faixas adjacentes - em trechos de curvas com raios pequenos e valores de sobrelargura insuficientes, os veículos de maior porte podem invadir faixas de tráfego adjacentes, aumentando o risco de colisões laterais com outros veículos ou mesmo expulsar outros veículos das faixas de rolamento;

(b) risco de colisão durante ultrapassagens - em rodovias de pista simples, a ultrapassagem de veículos de maior comprimento ocasiona a necessidade de maiores distâncias de visibilidade de ultrapassagem;

(c) instabilidade lateral dos veículos - em trechos de curvas com raios pequenos, com valores de superelevação insuficientes, ou onde se verificam velocidades operacionais elevadas, há riscos de ocorrência de escorregamento lateral ou tombamento dos veículos, especialmente em veículos com centro de gravidade alto, como é observado em alguns veículos de carga;

(d) risco de colisão nas interseções em nível - a operação de veículos mais longos exige maiores tempos de cruzamento nas interseções, demandando brechas (lacunas) maiores, para que seja possível a estes veículos transpor a interseção ou realizar conversões com segurança. A existência de distâncias de visibilidade maiores nesses cruzamentos é importante para permitir aos motoristas da via secundária avaliar com segurança o melhor momento para manobrar o veículo. Da mesma forma, é importante que o veículo da via principal perceba com a antecedência necessária a existência de uma interseção na via, adequando assim sua velocidade, de forma a permitir a parada do veículo em situações de emergência; e

(e) risco de colisão em curvas - a inobservância da distância de visibilidade nas curvas, tanto para as curvas verticais convexas como para as curvas horizontais, pode resultar na impossibilidade de o veículo desviar ou parar diante de obstáculos, elevando o risco de colisões.

Os pontos há pouco destacados foram abordados sob a óptica da segurança viária. Existem ainda outros aspectos, como a declividade e extensão dos greides, a 
existência de faixas de tráfego adicionais, de faixas de aceleração e desaceleração, que, além de estarem relacionados à segurança viária, possuem interferência importante nos aspectos operacionais, como a capacidade da via e seu nível de serviço, enfoque este que, apesar de não fazer parte do escopo deste trabalho, deve ser destacado.

Com relação aos desgastes causados à infra-estrutura, a vida útil do pavimento é fortemente influenciada pelo peso por eixo, pois, à medida que as cargas são elevadas, os danos causados ao pavimento crescem numa escala exponencial. Neste aspecto, alguns veículos de carga, em especial as combinações de veículos de carga (CVCs), podem apresentar vantagens sobre os demais, uma vez que normalmente utilizam configurações de eixos do tipo tandem duplo e triplo, que, de acordo com o que regulamenta a "Lei da Balança" (BRASIL, 2006a), possuem cargas máximas para estes grupamentos de eixos mais favoráveis à conservação do pavimento do que os valores admitidos em eixos isolados. Por outro lado, em obras de arte como pontes e viadutos, onde o peso bruto total combinado (PBTC) é o aspecto a ser considerado, poderá haver solicitações de cargas superiores aos valores calculados em projeto, comprometendo sua estabilidade e segurança.

O padrão geométrico das rodovias deve ser estabelecido em função das características dos veículos que nela trafegam como (DNER, 1999):

(a) a largura das pistas de rolamento e dos acostamentos, que é influenciada pela largura dos veículos;

(b) a largura dos canteiros, a extensão das faixas de espera e as dimensões dos estacionamentos, que são influenciadas pelo comprimento dos veículos;

(c) o cálculo da sobrelargura das pistas principais, a determinação da largura e dos raios mínimos internos das pistas dos ramos, que são influenciados pela distância entre os eixos e a configuração dos acoplamentos dos veículos;

(d) os valores de rampa máxima admissível, a necessidade de implantação de faixa adicional em subidas e a determinação dos fatores de equivalência veicular para cálculo da capacidade da rodovia, que são função da relação potência/massa dos veículos; e

(e) o gabarito vertical para redes aéreas, viadutos, túneis e elementos da sinalização vertical, que têm seu valor condicionado à altura admissível dos veículos. 
Um aspecto que demonstra a importância em estabelecer e atender aos critérios de um sistema de classificação de rodovias diz respeito a garantir a continuidade de um padrão geométrico ao longo da infra-estrutura viária. À medida que o motorista se defronta com os elementos da infra-estrutura viária, como, por exemplo, a largura das faixas de tráfego, a existência de acostamentos, de separadores físicos de tráfego, a configuração das curvas horizontais com seus raios, superelevações e sobrelarguras, é adotado um comportamento na forma de operar o veículo que, segundo o julgamento do motorista, é compatível com as condições existentes na via. Quando uma rodovia não possui uma continuidade em seu padrão geométrico, apresentando trechos com características diferentes, a expectativa do motorista é violada, originando situações de risco e potencializando a ocorrência de acidentes, que poderão ter maior severidade se envolverem veículos pesados. A existência deste padrão, premissa associada à consistência do traçado, permite que a compatibilidade entre a infra-estrutura e os veículos seja avaliada de forma mais precisa.

\subsection{Objetivos da Pesquisa}

\subsubsection{Objetivo Principal}

O objetivo principal deste trabalho é investigar as características e padrões dos veículos de grande porte e, em particular, os veículos rodoviários de carga do tipo CVC que trafegam nas rodovias brasileiras, contemplando os aspectos da interação de os veículos com a via, para analisar a compatibilidade de parâmetros de projeto geométrico com uma operação segura do tráfego.

\subsubsection{Objetivos Específicos}

(a) fazer uma análise comparativa dos parâmetros de projeto geométrico propostos no manual brasileiro e nas diretrizes vigentes de outros paises, enfocando o tratamento dado aos veículos pesados;

(b) investigar aspectos da interação veículo-via e seus impactos para a obtenção de parâmetros de projeto compatíveis com a operação de veículos pesados; 
(c) levantar as características técnicas e operacionais de veículos pesados que operem nas rodovias brasileiras;

(d) identificar restrições operacionais que os veículos pesados estão sujeitos, dadas as atuais diretrizes vigentes;

(e) propor medidas para adequar as condições operacionais dos veículos de carga em segmentos rodoviários brasileiros;

(f) realizar um estudo de caso para um conjunto de trechos de rodovias brasileiras com características técnicas diferentes, onde trafegam veículos pesados de configurações diversas sujeitos a restrições operacionais.

\subsection{Estrutura do Trabalho}

Este ensaio é estruturado em sete capítulos, incluindo o presente, de caráter introdutório. O módulo 2 apresenta os sistemas de classificação de rodovias rurais utilizados no Brasil e em outros países, comparando suas características funcionais e padrões técnicos, destacando o tratamento dado aos veículos de maior porte. O capítulo 3 traz uma revisão bibliográfica de vários parâmetros utilizados no projeto geométrico de rodovias, com ênfase nas diferenças verificadas no comportamento dos veículos de passeio e de carga. No segmento 4 são abordadas as diretrizes de projeto geométrico de rodovias adotadas no Brasil, sendo avaliadas as condições operacionais a que veículos representativos da frota estão sujeitos, tomando como referência o padrão mínimo das classes técnicas de projeto. Em função deste diagnóstico, serão identificados os veículos compatíveis com o padrão técnico das vias, sendo também propostos ajustes, visando a atender aos veículos que trafegam com restrições. O capítulo 5 traz um estudo de caso, contemplando alguns trechos de rodovias brasileiras, onde são identificadas as restrições e suas causas, sendo propostas opções de intervenção. Com base no diagnóstico obtido no estudo de caso, o módulo 6 apresenta uma análise destes resultados e propõe procedimentos para verificar a adequação da geometria das rodovias às restrições dos veículos. O segmento 7 consiste de conclusões tiradas a partir das partes precedentes, juntamente com algumas recomendações para futuros trabalhos. Segue-se a lista de obras/autores que estearam, teórica e empiricamente, a investigação. 


\section{SISTEMAS DE CLASSIFICAÇÃO DE RODOVIAS RURAIS}

\subsection{Considerações Iniciais}

Neste capitulo serão apresentados alguns sistemas de classificação de rodovias, usualmente utilizados como base para a definição do padrão geométrico das rodovias. $\mathrm{O}$ manual de projeto geométrico brasileiro e alguns manuais de outros paises serão analisados, sendo observada a abordagem dada aos veículos de carga. Foram utilizados, alem do manual brasileiro, os manuais dos Estados Unidos, Canadá, Austrália e Nova Zelândia, escolha justificada pelo fato de se tratarem de paises com importante participação do modo rodoviário no transporte de cargas, onde é permitida a operação de veículos de grande capacidade.

O estabelecimento de um sistema de classificação de rodovias é importante para proporcionar um grau de uniformidade na rede viária, especialmente quando as vias cruzam fronteiras administrativas de territórios heterogêneos, que muitas vezes possuem significativas diferenças econômicas, como é verificado no Brasil. Como a capacidade de investimento dos diversos estados da Federação é bastante desigual, é necessário determinar uma padronização com valores mínimos recomendados para esta infra-estrutura, de forma a melhor regulamentar sua utilização.

A classificação das vias permite a definição e o planejamento da rede viária, onde as vias possuem padrões funcionais e técnicos determinados de forma a atender adequadamente às necessidades de deslocamento. Cada classe de via deve possuir um padrão capaz de atender aos volumes de tráfego previstos, de forma a oferecer condições satisfatórias de conforto e segurança. O nível de atendimento a estas condições está subordinado às restrições de ordem econômica e ambiental, que influenciarão notadamente a escolha da classe de rodovia a ser implantada. 


\subsection{Tipos de Classificação de Rodovias}

Existem várias formas de classificação para as rodovias, relacionadas aos diferentes sistemas operacionais, classes funcionais ou tipos de geometria, tendo sido aplicados diferentes tipos de classificação com propósitos diversos em muitos países (LAMM; PSARIANOS; MAILAENDER, 1999). Dentre estes sistemas de classificação, se destacam os sistemas de classificação funcional e técnica. O sistema funcional determina grupos de vias em função do tipo de serviço que estas prestam, relacionado essencialmente a dois papeis principais numa rede viária: prover mobilidade e acessibilidade aos usuários. A taxinomia técnica, por sua vez, está relacionada mais diretamente ao padrão geométrico da via, isto é, à designação dos elementos geométricos que garantirão serem atendidas satisfatoriamente as atribuições determinadas para a rodovia. O Manual brasileiro estabelece um sistema de classificação técnica, que será detalhada posteriormente, sendo esta correlacionada à classificação funcional. Em outros países como Estados Unidos e Canadá, entretanto, não é proposto explicitamente um sistema de classificação técnica, sendo a configuração geométrica das vias estabelecida diretamente para as classes funcionais.

As classes funcionais das rodovias seguem internacionalmente um padrão semelhante. De modo geral, as vias de mais alta hierarquia atendem aos deslocamentos de maior extensão, sendo definido para estas vias um padrão técnico mais elevado, de forma a garantir um nível de serviço de maior qualidade para atender às viagens de maior duração e são responsáveis pelo atendimento de elevados volumes de tráfego. Estas vias, denominadas normalmente de arteriais, se caracterizam por permitir velocidades operacionais mais elevadas, sendo priorizada maior mobilidade nos deslocamentos em detrimento das oportunidades de acesso, outorgadas às vias de hierarquia inferior. À medida que se desce na escala hierárquica, têm-se, portanto, vias com crescente ganho de acessibilidade e gradual restrição na mobilidade, revelando o caráter complementar que elas desempenham na rede viária para atender às pretensões de deslocamento.

Além das funções relacionadas ao tráfego veicular, como mobilidade e acessibilidade, uma rede viária possui outros elementos não relacionados especificamente ao tráfego, como o uso e ocupação do entorno, que interagem com os 
demais, originando conflitos que precisam ser gerenciados. Uma classificação funcional considerando estas inter-relações é proposta por Lamm, Psarianos e Mailaender (1999), que estabelece cinco categorias de vias:

(a) Grupo A - compreende os Sistemas Arteriais Principais e Secundários Rurais, utilizados essencialmente para ligar cidades e outros pólos. Estas vias têm como finalidade prover mobilidade, e como estão localizadas fora das áreas construídas, as funções de acesso e facilidades para pedestres não possuem relevância.

(b) Grupo B - trata-se de vias do Sistema Arterial, localizadas em áreas suburbanas, com baixa concentração de construções, prevalecendo a função de ofertar mobilidade ao tráfego motorizado. Nas vias deste grupo, não existe uma segregação entre o tráfego veicular e o não veicular, como ocorre nas vias do Grupo A, sendo possível a existência de equipamentos, como calçadas, para pedestres ou ciclofaixas junto aos acostamentos.

(c) Grupo $\mathrm{C}$ - consiste nas vias arteriais localizadas em áreas urbanas com alta densidade de construções em seu entorno. Sua função principal é ofertar mobilidade, apesar de prover acesso às edificações adjacentes. Para atender ao volumes de pedestres e ciclistas, é comum a existência de equipamentos, como calçadas em ambos os lados da via, faixas de ciclista e estacionamentos. A existência de conflitos entre os usuários justifica a adoção de medidas como a utilização de velocidades mais baixas, assim como ações visando a integrar este tipo de via ao espaço urbano, procurando reduzir os impactos do tráfego no meio ambiente, primando pela qualidade de vida dos habitantes.

(d) Grupo D - é composto de todas as vias urbanas cuja função principal é prover acesso. A existência de elevados volumes de pedestres e ciclistas compartilhando espaço com veículos que acessam a área justifica a separação destes fluxos de forma a reduzir os riscos de acidentes.

(e) Grupo E - consiste em todas as vias locais onde os pedestres são os usuários principais, tendo uso principalmente para acesso a áreas residenciais. O tráfego de passagem não faz uso destas vias, e as oportunidades de acesso são apenas parcialmente permitidas. A existência de um volume de até 250 veículos/hora nestas áreas não produz conflitos com o tráfego de pedestres. 


\subsection{Os Sistemas de Classificação de Rodovias em Alguns Países}

O sistema de classificação funcional adotado nos Estados Unidos pela American Association of State Highway and Transportation Officials (AASHTO) é utilizado como parâmetro por vários outros países. Pelo fato de áreas urbanas e rurais apresentarem características diferentes com relação à densidade e tipos de uso do solo, das vias e dos padrões das viagens, é proposta uma classificação diferenciada para os sistemas funcionais urbanos e rurais (AASHTO, 2004). Nesta diferenciação, consideradas como áreas urbanas são as localidades mais densamente povoadas, com população de 5000 pessoas ou superior e as áreas rurais correspondem àquelas fora das fronteiras urbanas.

No sistema funcional rural, são identificadas as categorias arterial, coletora e local. As vias arteriais se subdividem em duas classes: arteriais principais, responsáveis pelos deslocamentos intra e interestaduais, atendendo áreas urbanas com populações acima de 50.000 habitantes; e arteriais secundárias, integrando serviços interestaduais e intermunicipais. As vias coletoras apresentam a mesma subdivisão, onde as coletoras principais ligam cidades não atendidas pelas arteriais secundárias e as coletoras secundárias têm o papel de fazer conexão com as vias locais. As vias locais cumprem a função de complementar as viagens e garantir maior acesso ao solo lindeiro.

O sistema de classificação funcional na Austrália foi originalmente desenvolvido pela National Association of Australian State Road Authorities (NAASRA) (BRTE, 2003) em parceria com a Commonwealth Bureau of Roads (CBR), tendo sido publicada pela primeira vez em 1968. Ao longo do tempo, essa classificação foi alvo de revisões para se adequar às modificações operadas na configuração da malha viária, sendo atualmente publicada pela Australian and New Zealand Road Transport and Traffic Authorities (AUSTROADS) e sendo adotada em regiões da Austrália e da Nova Zelândia (BRTE, 2003). Este sistema de classificação propõe, como nos demais, uma distinção entre rodovias urbanas e rurais. Admite-se que, quando a população de uma cidade atinge a marca de 40.000 habitantes, o transporte é objeto de uma mudança em seus padrões, passando de uma função local, no entorno de seus arredores, para uma cobertura de alcance regional, caracterizando uma área urbana. O sistema é composto de nove classes, sendo cinco classes para áreas rurais e quatro para áreas urbanas. 
O sistema de classificação rural proposto pela AUSTROADS (AUSTROADS, 2002) segue o mesmo padrão anteriormente relatado, com as vias de Classe 1, 2 e 3 definidas como arteriais e aquelas de Classe 4 e 5 como vias locais. As vias de Classe 1 apresentam a função de garantir mobilidade e ligar os centros urbanos mais importantes e mais densamente povoados. As classes intermediárias, 2 e 3, atendem com a mesma finalidade às regiões menos povoadas e correspondem à classe coletora na classificação da AASHTO. Já as Classes 4 e 5 cumprem o papel de promover a acessibilidade ao sistema viário, sendo denominadas de vias locais rurais.

O Manual de projeto geométrico de vias rurais utilizado na Austrália e Nova Zelândia (AUSTROADS, 2002) apresenta ainda uma divisão das rodovias em três grupos, em função de sua velocidade: rodovias de velocidades elevada, intermediária e baixa. No grupo de rodovias de velocidade elevada, estão aquelas com velocidade operacional de $100 \mathrm{~km} / \mathrm{h}$ ou maior, onde, normalmente, esta velocidade não é limitada pela geometria da via, mas sim por uma série de outros fatores, como o grau de risco que os motoristas estão dispostos a aceitar e o nível de fiscalização para o cumprimento dos limites de velocidade regulamentada, além do próprio desempenho dos veículos. As rodovias de velocidade intermediária são aquelas com velocidade de projeto entre 80 $\mathrm{km} / \mathrm{h}$ e $99 \mathrm{~km} / \mathrm{h}$, tendo sua velocidade operacional normalmente limitada pela geometria da via. O raio destas vias nos trechos em curva é normalmente superior a $160 \mathrm{~m}$. As vias de baixa velocidade correspondem àquelas projetadas com velocidades de $79 \mathrm{~km} / \mathrm{h}$ ou inferior, com curvas de raios inferiores a $150 \mathrm{~m}$.

No Canadá, as províncias possuem certa autonomia no estabelecimento da classificação funcional de suas rodovias, com algumas diferenças, como, por exemplo, quanto ao porte das populações atendidas (ALBERTA INFRASTRUCTURE, 1994). A província de Saskatchewan possui um sistema de classificação funcional, no qual, além dos aspectos mobilidade e acessibilidade, foram incorporados fatores de ordem social e econômica ao sistema de classificação (SARM, 1999). Nesse sistema, foram estabelecidas sete classes funcionais, onde existem classes de vias com funções como: fazer a conexão entre hospitais regionais e hospitais de base, reservas indígenas, parques nacionais, áreas industriais, além de classes com funções mais específicas, como cobrir rotas de ônibus escolares e prover acesso às áreas residenciais. 
Apesar da diversidade na classificação funcional nas rodovias do Canadá, existem iniciativas para se estabelecer um padrão para a concepção dos projetos geométricos das rodovias canadenses, como nas publicações desenvolvidas pela Transportation Association of Canada (TAC). A classificação proposta pela TAC (TAC, 1999) estabelece uma subdivisão das classes de rodovias rurais, entre vias locais, coletoras, arteriais e expressas. Esta subdivisão é estabelecida em função de dois parâmetros: a velocidade de projeto da via e a existência ou não de separação física entre os fluxos de tráfego. Desta forma, consoante a combinação destes parâmetros, são estabelecidas quarenta e quatro subclasses para as rodovias rurais.

\subsection{O Sistema de Classificação de Rodovias no Brasil}

No artigo 60 do Código de Trânsito Brasileiro (CTB) as vias são classificadas de acordo com sua utilização, ou seja, consoante uma classificação funcional. Nesse sistema as vias são divididas em dois grupos: rurais e urbanas. As rurais são classificadas como rodovias ou estradas. A distinção é feita considerando apenas o material de revestimento, pois rodovias são vias rurais pavimentadas enquanto as estradas são vias rurais não pavimentadas. Já as vias urbanas são classificadas como vias de trânsito rápido, arterial, coletora ou local, sem alusão ao tipo de revestimento.

O Departamento Nacional de Estradas e Rodagens (DNER), atual Departamento Nacional de Infra-estrutura de Transportes (DNIT), propõe em seu Manual de Projeto Geométrico de Rodovias Rurais (DNER, 1999) um sistema funcional para as vias rurais que consiste em agrupar rodovias em sistemas e classes, de acordo com o tipo de serviço que elas prestam e as funções que exercem, principalmente no que tange às funções de mobilidade e acessibilidade. Esse Manual tem forte influência do Manual da AASHTO, publicado no ano de 1994 (AASHTO, 1994).

As rodovias rurais brasileiras seguem o padrão americano, sendo enquadradas em três sistemas funcionais: arterial, coletor e local. O sistema arterial é responsável por proporcionar alto nível de mobilidade e é dividido nos subsistemas principal, primário e secundário. São considerados nesta subdivisão o tipo de viagem (internacional, interregional, interestadual ou intra-estadual) e a população das cidades atendidas pela infra-estrutura. O sistema coletor tem como função atender ao tráfego intermunicipal e 
centros geradores de tráfego de menor porte, atuando de forma complementar ao sistema arterial, formando uma rede contínua que proporciona mobilidade e acesso dentro de uma área específica e se subdivide em sistema primário e secundário. $\mathrm{O}$ sistema local, por sua vez, é constituído de rodovias de pequena extensão, destinadas essencialmente a garantir acessibilidade ao tráfego intramunicipal de áreas rurais e de pequenas localidades às rodovias de nível superior pertencentes ao Sistema Coletor Secundário.

\subsubsection{Principais Características}

A Tabela 2.1 apresenta de forma resumida as características das classes de rodovias brasileiras (DNER, 1999).

Tabela 2.1: Quadro Resumo das Classes de Rodovias Rurais.

\begin{tabular}{|c|c|c|c|c|c|}
\hline $\begin{array}{c}\text { SISTEMA } \\
\text { FUNCIONAL }\end{array}$ & $\begin{array}{c}\text { FUNÇÃO } \\
\text { PRINCIPAL }\end{array}$ & $\begin{array}{c}\text { SUB- } \\
\text { SISTEMA }\end{array}$ & ATENDE & $\begin{array}{c}\text { EXTENSÃO } \\
\text { MÉDIA DAS } \\
\text { VIAGENS }(\mathrm{km})\end{array}$ & $\begin{array}{l}\text { VELOCIDADE } \\
\text { OPERACIONAL } \\
(\mathrm{km} / \mathrm{h})\end{array}$ \\
\hline \multirow{3}{*}{$\begin{array}{l}\text { Sistema } \\
\text { Arterial }\end{array}$} & \multirow{3}{*}{$\begin{array}{l}\text { Proporcionar } \\
\text { alto nível de } \\
\text { mobilidade } \\
\text { para grandes } \\
\text { volumes de } \\
\text { tráfego. }\end{array}$} & Principal & $\begin{array}{c}\text { Cidades com } \\
\text { população acima } \\
\text { de } 150.000 \text { hab. e } \\
\text { as capitais dos } \\
\text { estados }\end{array}$ & 120 & 60 a 120 \\
\hline & & Primário & $\begin{array}{c}\text { Cidades com } \\
\text { população em } \\
\text { torno de } 50.000 \\
\text { hab. }\end{array}$ & 80 & 50 a 100 \\
\hline & & Secundário & $\begin{array}{c}\text { Cidades com } \\
\text { população acima } \\
\text { de } 10.000 \text { hab. }\end{array}$ & 60 & 40 a 80 \\
\hline \multirow{2}{*}{$\begin{array}{l}\text { Sistema } \\
\text { Coletor }\end{array}$} & \multirow{2}{*}{$\begin{array}{c}\text { Proporcionar } \\
\text { mobilidade e } \\
\text { acesso } \\
\text { dentro de } \\
\text { uma área } \\
\text { específica. }\end{array}$} & Primário & $\begin{array}{c}\text { Cidades com } \\
\text { população acima } \\
\text { de } 5.000 \text { hab. }\end{array}$ & 50 & 30 a 70 \\
\hline & & Secundário & $\begin{array}{c}\text { Centros com } \\
\text { população acima } \\
\text { de } 2.000 \text { hab. }\end{array}$ & 35 & 30 a 60 \\
\hline Sistema Local & $\begin{array}{l}\text { Proporcionar } \\
\text { acesso }\end{array}$ & - & $\begin{array}{l}\text { Tráfego intra- } \\
\text { municipal de } \\
\text { áreas rurais e } \\
\text { pequenas } \\
\text { localidades } \\
\text { conectando as } \\
\text { rodovias de nível } \\
\text { superior }\end{array}$ & 20 & 20 a 50 \\
\hline
\end{tabular}

Fonte: (DNER, 1999). 
A classificação funcional é um critério importante para a definição do padrão técnico a ser implantado em uma via. As características técnicas da via devem ser capazes de oferecer um nível de serviço compatível com a função da via, dados o volume e a composição do tráfego (AASHTO, 2004). Este padrão técnico está intimamente associado à configuração geométrica, que, por sua vez, é condicionada por diversos parâmetros, como a velocidade de projeto, as rampas máximas, a largura das faixas de tráfego e acostamentos, entre outros. Os valores adotados para estes parâmetros recebem influência das características topográficas da região. Normalmente os manuais consideram três tipos de terreno, classificados em função de seu relevo: plano, ondulado e montanhoso. Para permitir a viabilidade econômica de projetos em terrenos que apresentem maiores dificuldades na construção das rodovias, é adotado menor rigor nos valores de certos parâmetros de projeto para os terrenos ondulados e montanhosos.

Apesar de os sistemas de classificação funcional de rodovias seguirem uma orientação comum, pautada nas funções de acessibilidade e mobilidade ofertadas, os valores adotados nos parâmetros de projeto apresentam algumas variações, existindo abordagens diferentes para sua determinação. A AASHTO e a TAC estabelecem diretamente as faixas de velocidade de projeto das classes funcionais. Com base nestas velocidades, são determinados alguns parâmetros, como as distâncias de visibilidade e os raios das curvas horizontais. Outros parâmetros, como rampas máximas, larguras das faixas de tráfego e dos acostamentos são definidos em função da velocidade, mas recebem influência da classe da via; ou seja, rodovias com velocidades de projeto iguais podem apresentar padrões diferentes para rampas máximas e larguras de faixa em função da classe a que pertencem. O Manual de projeto geométrico da AUSTROADS utiliza outra abordagem, onde os parâmetros de geometria da via são definidos para várias velocidades de projeto, sem fazer menção à classificação funcional.

No Brasil, com o objetivo de definir os parâmetros de projeto das rodovias, foi proposta outra classificação, denominada classificação técnica, na qual são estabelecidos os valores a serem adotados na concepção dos projetos. Esta classificação é correlacionada à classificação funcional, como mostra a Tabela 2.2. 
Tabela 2.2: Relação entre as Classes Funcionais e as Classes Técnicas de Projeto.

\begin{tabular}{lcc}
\hline \multicolumn{1}{c}{ SISTEMA } & SUBSISTEMA & CLASSE \\
\hline Sistema & Principal & Classes 0 e I \\
Arterial & Primário & Classe I \\
& Secundário & Classe I e II \\
\hline Sistema & Primário & Classe II e III \\
Coletor & Secundário & Classe III e IV \\
\hline Sistema Local & - & Classe III e IV \\
\hline
\end{tabular}

Fonte: (DNER, 1999).

Para o enquadramento de uma rodovia em uma dada classe técnica os principais critérios utilizados são (DNER, 1999):

(a) a posição hierárquica dentro da classificação funcional. Esta hierarquização proposta pela classificação funcional é normalmente respeitada na definição das classes técnicas, mesmo que os volumes atuais não as justifiquem. É admitido que, com o tempo, seja estabelecido maior fluxo de tráfego no Sistema Local Coletor - Arterial, de forma que a infra-estrutura deve ser projetada para atender demandas que serão alocadas na rede de acordo com o sistema idealizado pela classificação funcional;

(b) volume médio diário (VMD) do tráfego. Trata-se do volume de tráfego misto, nas condições usuais das rodovias brasileiras. Dados levantados no Plano Nacional de Contagem de Trânsito (PNTC) do DNER no ano de 1996 são ordinariamente utilizados nos projetos como estimativa da classificação deste tráfego;

(c) o nível de serviço. Seguindo a metodologia proposta pelo Highway Capacity Manual (TRB, 2000), é considerado o volume horário de projeto, normalmente sendo tomado o volume estimado para o décimo ano após a abertura do projeto; e

(d) outros condicionantes, cujo mais importante é o aspecto econômico, representado pelo custo de construção da via. Este custo é fortemente influenciado pelo tipo de relevo, uma vez que o tipo de terreno influenciará diretamente o traçado, bem como a magnitude das intervenções necessárias à implantação da infra-estrutura. 


\subsubsection{As Classes de Projeto do DNER (atual DNIT)}

As classes de projeto definidas pelo DNER foram estabelecidas de acordo com a função que estas rodovias desempenham, dos volumes de tráfego e associadas ao grau de dificuldade de implantação da infra-estrutura em virtude da natureza do terreno. $\mathrm{O}$ atual sistema de classificação técnica no País é dividido em cinco classes, a saber: Classes 0, I, II, III e IV (DNER, 1999). A Classe 0 corresponde à rodovia de mais elevado padrão técnico, com pista dupla, controle total de acesso de veículos e bloqueio total de pedestres. São as vias expressas. O critério utilizado para o enquadramento de uma rodovia nesta classe é principalmente quando há volumes de tráfego elevados e o tráfego do décimo ano de abertura implicar uma rodovia de pista simples operando:

(a) no nível de serviço inferior ao $\mathrm{C}$, no caso de terreno plano com excelentes condições de visibilidade (VMD acima de 5500 veículos) e em terrenos levemente ondulados com más condições de visibilidade (VMD acima de 1900 veículos); e

(b) no nível de serviço inferior ao D, no caso de terreno fortemente ondulado ou montanhoso com excelentes condições de visibilidade (VMD acima de 2600 veículos) ou com más condições de visibilidade (VMD acima de 1000 veículos).

Além do critério nível de serviço, a proposição de uma rodovia como Classe 0 é indicada quando se tem por objetivo garantir exclusivamente a função mobilidade ao tráfego de passagem, ficando o tráfego local atendido por outras vias da região. Outra condição para que seja proposta uma via de Classe 0 decorre da existência de atritos entre as atividades desenvolvidas nas áreas adjacentes à faixa de domínio da rodovia e o tráfego de passagem, ocasionando problemas de ordem operacional e de segurança, exigindo maior controle dos acessos locais para veículos e pedestres.

A Classe I é subdividida em função de a rodovia possuir pista dupla (Classe IA) ou pista simples (Classe I-B). Na Classe I-A estão agrupadas as vias com controle parcial de acesso e correspondem às rodovias arteriais com grande demanda de tráfego, com volumes e condições semelhantes às descritas na Classe 0 , mas que possuem maior tolerância às interferências causadas pela existência de acessos mais freqüentes. As vias de Classe I-B devem absorver os volumes de tráfego projetados para 10 anos após a abertura do tráfego dentro dos seguintes limites: 
(a) como limite inferior, é estabelecido um VMD de 1400 veículos ou um volume horário de projeto de 200 veículos, que corresponde ao nível $\mathrm{C}$ em regiões montanhosas com visibilidade excelente, e ao nível B em regiões planas com más condições de visibilidade; e

(b) como limite superior, é estabelecido um VMD de 5500 veículos, caso se trate de regiões planas com excelentes condições de visibilidade (nível de serviço C), um VMD de 1900 veículos em terrenos levemente ondulados com más condições de visibilidade (nível de serviço C), um VMD de 2600 veículos para regiões fortemente onduladas com excelentes condições de visibilidade (nível de serviço D) ou um VMD de 1000 veículos para o caso de regiões montanhosas com más condições de visibilidade (nível de serviço D).

Para volumes de tráfego mais elevados do que este limite a rodovia deve ser enquadrada na Classe I-A.

A Classe II corresponde às rodovias de pista simples, suportando um VMD que varia de 700 a 1400 veículos, com nível de serviço variando do nível A ao $\mathrm{D}$, em função do relevo da região.

$\mathrm{Na}$ Classe III estão agrupadas as rodovias de pista simples com VMD entre 300 e 700 veículos, com nível de serviço variando de A até D.

As vias de Classe IV normalmente não são pavimentadas e fazem parte do sistema local que compreende as estradas vicinais e rodovias pioneiras. São subdivididas na Classe IV-A para as vias com VMD de 50 a 200 veículos no ano de abertura do projeto e na Classe IV-B, com VMD de até 50 veículos.

Os dados de VMD ora mencionados dizem respeito a volumes de tráfego misto, isto é, formados pelas diversas configurações de veículos, admitidas as condições ordinárias das rodovias brasileiras. Para cada uma destas classes e em função da topografia do terreno, são definidos parâmetros de projeto como: velocidade diretriz da via, raios mínimos de curvatura horizontal, rampas máximas, distância de visibilidade de parada, largura das faixas de rolamento, dos acostamentos e dos canteiros centrais, entre outros aspectos. 


\subsection{Parâmetros de Projeto Utilizados na Concepção de Rodovias Rurais}

O parâmetro de projeto geométrico básico para a concepção de uma rodovia é a velocidade de projeto, dada sua influência em diversos outros aspectos da geometria de uma via, como os raios das curvas horizontais, a declividade e extensão das rampas, as distâncias de visibilidade, entre outros. Considerando as classes funcionais definidas nos manuais pesquisados, foram comparados os valores estabelecidos para a velocidade de projeto e outros parâmetros de geometria da via.

A Tabela 2.3 mostra as classes funcionais e as velocidades de projeto adotadas para a concepção de rodovias nos Estados Unidos, Canadá e Brasil. Como o Manual da AUSTROADS não menciona as velocidades a serem adotadas para as classes funcionais, não foi incluído na comparação. O Canadá é o único dos países estudados que não estabelece diferenças de velocidade em função do tipo de terreno. São utilizados, entretanto, intervalos de velocidade bastante elásticos para suas classes funcionais, permitindo, embora sem uma determinação clara, adequar a velocidade às restrições na topografia da região. Uma peculiaridade observada neste sistema é a possibilidade de existirem rodovias classificadas como vias locais com velocidades de até $110 \mathrm{~km} / \mathrm{h}$, o que não se coaduna com o caráter de acessibilidade que este tipo de via deve proporcionar.

As velocidades apresentadas para as Classes Local e Coletora pela AASHTO referem-se aos valores mínimos admissíveis, podendo ser utilizadas velocidades mais elevadas. Já os valores de velocidade estabelecidos no Manual brasileiro são referentes a intervalos fixos, característicos das classes de rodovias adotadas no Brasil. Comparando os dados destes dois países, é verificado que as velocidades adotadas no Brasil são semelhantes aos valores mínimos da AASHTO para a situação de relevo plano. No caso de relevo ondulado e montanhoso, as velocidades propostas pelo DNER são em sua maioria inferiores aos valores mínimos adotados pela AASHTO. Esta tendência revela que, no Brasil, a existência de condições de relevo menos favoráveis justifica maior redução do padrão técnico da rodovia, e isto pode ser entendido como uma forma de reduzir os custos de implantação da infra-estrutura, coerente com sua menor capacidade de investimento. 
Tabela 2.3: Velocidade Operacional Utilizada em Rodovias, de acordo com sua Classificação Funcional.

\begin{tabular}{|c|c|c|c|c|c|}
\hline \multirow{2}{*}{ PAÍS } & \multirow{2}{*}{$\begin{array}{c}\text { CLASSE } \\
\text { FUNCIONAL }\end{array}$} & \multirow{2}{*}{$\begin{array}{c}\text { CLASSE } \\
\text { TÉCNICA }\end{array}$} & \multicolumn{3}{|c|}{ VELOCIDADE DE PROJETO (km/h) } \\
\hline & & & PLANO & ONDULADO & MONTANHOSO \\
\hline \multirow{4}{*}{$\begin{array}{l}\text { Estados Unidos } \\
\text { (AASHTO-2004) }\end{array}$} & Local & - & 50 a 80 & 30 a 60 & 30 a 50 \\
\hline & Coletora & - & 60 a 100 & 50 a 80 & 30 a 60 \\
\hline & Arterial & - & 100 a 120 & 80 a 100 & 60 a 80 \\
\hline & Freeway & - & $\geq 110$ & $\geq 110$ & $\geq 80$ \\
\hline \multirow{4}{*}{$\begin{array}{c}\text { Canadá } \\
\text { (TAC-1999) }\end{array}$} & Local & - & 50 a 110 & 50 a 110 & 50 a 110 \\
\hline & Coletora & - & 60 a 110 & 60 a 110 & 60 a 110 \\
\hline & Arterial & - & 80 a 130 & 80 a 130 & 80 a 130 \\
\hline & Freeway & - & 100 a 130 & 100 a 130 & 100 a 130 \\
\hline \multirow{4}{*}{$\begin{array}{c}\text { Brasil } \\
\text { (DNER-1999) }\end{array}$} & Local & III e IV & 60 a 80 & 40 a 60 & 30 a 40 \\
\hline & Coletora & II, III e IV & 60 a 100 & 40 a 70 & 30 a 50 \\
\hline & $\begin{array}{l}\text { Arterial Primária } \\
\text { e Secundária }\end{array}$ & I e II & 100 & 70 a 80 & 50 a 60 \\
\hline & Arterial Principal & 0 e I & 100 a 120 & 80 a 100 & 60 a 80 \\
\hline
\end{tabular}

Fontes: (AASHTO, 2004), (TAC, 1999) e (DNER, 1999).

Antes de apresentar outros parâmetros de projeto geométrico da via, é interessante mencionar que, enquanto no Manual do DNER é determinado para cada classe técnica e tipo de terreno apenas um valor para a velocidade de projeto, a AASHTO propõe um intervalo de velocidades. Desta forma, cada classe de rodovia e terreno do Manual do DNER possui apenas um valor possível para parâmetros como largura de faixa e rampas máximas. A AASHTO, por sua vez, estabelece alguns valores possíveis para estes parâmetros, determinados em função da velocidade utilizada, permitindo assim um maior grau de liberdade para a concepção geométrica da via.

\subsubsection{Perfil Longitudinal}

A Tabela 2.4 apresenta os valores de rampas máximas admissíveis para as classes de rodovia e tipos de terreno, respeitando os valores de velocidade recomendados na Tabela 2.3. Analisando o perfil longitudinal das rodovias, o Canadá é comparativamente o mais conservador na adoção de limites para o valor das rampas máximas, enquanto os Estados Unidos apresentam os limites mais elevados, especialmente nos trechos com terreno montanhoso. O Brasil e a Austrália utilizam valores intermediários. Observando os valores estabelecidos para as velocidades e 
rampas máximas das rodovias em terrenos ondulados e montanhosos, vê-se que o Brasil, comparativamente aos Estados Unidos, adota uma atitude mais conservadora, definindo velocidades de projeto menores e rampas máximas de menor declividade do que o proposto pela AASHTO.

Tabela 2.4: Rampas Máximas Admissíveis em Sistemas de Classificação Funcional.

\begin{tabular}{|c|c|c|c|c|}
\hline \multirow{2}{*}{ PAÍS } & \multirow{2}{*}{$\begin{array}{c}\text { CLASSE } \\
\text { FUNCIONAL }\end{array}$} & \multicolumn{3}{|c|}{ RAMPA MÁXIMA (\%) } \\
\hline & & PLANO & ONDULADO & MONTANHOSO \\
\hline \multirow{4}{*}{$\begin{array}{l}\text { Estados Unidos } \\
\text { (AASHTO-2004) }\end{array}$} & Local & 5 a 7 & 6 a 11 & 10 a 16 \\
\hline & Coletora & 5 a 7 & 6 a 9 & 8 a 12 \\
\hline & Arterial & 3 & 4 a 5 & 7 a 8 \\
\hline & Freeway & 3 & 4 & 5 a 6 \\
\hline \multirow{4}{*}{$\begin{array}{c}\text { Canadá } \\
\text { (TAC-1999) }\end{array}$} & Local & - & 5 a 7 & 7 a 11 \\
\hline & Coletora & - & 5 a 6 & 7 a 10 \\
\hline & Arterial & - & 3 a 4 & 5 a 7 \\
\hline & Freeway & - & 3 & 5 \\
\hline \multirow{4}{*}{$\begin{array}{c}\text { Brasil } \\
(\text { DNER-1999) }\end{array}$} & Local & 4 a 6 & 6 a 8 & 8 a 10 \\
\hline & Coletora & 3 a 6 & 5 a 8 & 7 a 10 \\
\hline & $\begin{array}{c}\text { Arterial Primária e } \\
\text { Secundária }\end{array}$ & 3 & 4,5 a 5 & 6 a 7 \\
\hline & Arterial Principal & 3 & 4 a 4,5 & 5 a 6 \\
\hline \multirow{3}{*}{$\begin{array}{c}\text { Austrália } \\
\text { (AUSTROADS-2002) }\end{array}$} & $\begin{array}{l}\text { Via de Baixa } \\
\text { Velocidade }\end{array}$ & 6 a 8 & 7 a 9 & 9 a 10 \\
\hline & $\begin{array}{c}\text { Via de Velocidade } \\
\text { Intermediária } \\
\end{array}$ & 3 a 6 & 4 a 7 & 6 a 9 \\
\hline & Via de Alta Velocidade & 3 a 5 & 4 a 6 & - \\
\hline
\end{tabular}

Fontes: (AASHTO, 2004), (TAC, 1999), (DNER, 1999) e (AUSTROADS, 2002).

Um aspecto fundamental para permitir analisar os aspectos velocidade de projeto e rampa máxima destes sistemas de classificação é conhecer a relação massa/potência representativa dos veículos desses países. Melo (2002) verificou que a relação massa/potência dos caminhões brasileiros varia entre 100 e $380 \mathrm{~kg} / \mathrm{kW}$, valores significativamente maiores do que a média considerada nos veículos norte-americanos, de $120 \mathrm{~kg} / \mathrm{kW}$. Estes valores revelam pior desempenho dos veículos brasileiros em termos de suas velocidades e capacidade de aceleração. Considerando este fato, a definição de rampas menos íngremes e de velocidades de projeto mais baixas para as classes de rodovias brasileiras, se comparadas às classes correspondentes do sistema americano, possui justificativa coerente. 
A Tabela 2.5 apresenta os limites de rampa máxima adotados em outros paises, com valores relacionados às velocidades de projeto consideradas. Comparando tais valores com as rampas máximas admitidas para as rodovias brasileiras, são observados valores acima do limite de 10\% adotado pelo DNER em alguns países com Áustria e Suíça. A utilização de rampas mais íngremes nestes países se deve a existência de formações de relevo bastante acidentado, onde o alto custo de implantação da infraestrutura justifica a adoção de limites mais elevados.

Tabela 2.5: Rampas Máximas Admissíveis em Outros Paises (em \%).

\begin{tabular}{cccccccccccc}
\hline PAIS & \multicolumn{1}{c}{ VELOCIDADE DE PROJETO $(\mathrm{km} / \mathrm{h})$} & \multirow{2}{*}{ 类 } \\
& 40 & 50 & 60 & 70 & 80 & 90 & 100 & 110 & 120 & 130 & 140 \\
\hline Alemanha & - & - & 8 & 7 & 6 & 5 & 4,5 & - & 4 & - & - \\
Áustria & & & & & & & & & & & \\
sem faixa adicional & 9 & 8 & 7 & 6 & 5 & - & 4 & - & 3 & - & - \\
com faixa adicional & 12 & 11 & 10 & 9 & 8 & - & 6 & - & 5 & - & - \\
França & - & - & 7 & - & 6 & - & 5 & - & - & - & - \\
Grécia & - & 11 & 10 & 9 & 8 & 7 & 5 & 4,5 & 4 & 3 & - \\
Itália & 10 & 10 & 7 & 7 & 6 & 5 & 5 & 5 & 5 & 5 & 5 \\
Japão & 7 & 6 & 5 & - & 4 & - & 3 & - & 2 & - & - \\
Suíça & 12 & - & 10 & - & 8 & - & 6 & - & 4 & - & - \\
\hline
\end{tabular}

Fonte: Lamm, Psarianos e Mailaender (1999).

Outro parâmetro de projeto importante a ser considerado, juntamente com a rampa máxima, é o seu comprimento crítico, que pode ser definido como o comprimento máximo de uma rampa de subida, na qual um caminhão carregado possa operar sem que haja uma redução inaceitável de sua velocidade (AASHTO, 2004). O comprimento crítico das rampas ascendentes está condicionado não apenas pela sua declividade, mas também recebe influência da velocidade do veículo na entrada da rampa e especialmente da relação massa/potência do veículo.

A AASHTO estabelece comprimentos críticos de rampas para caminhões com relação massa/potência de $120 \mathrm{~kg} / \mathrm{kW}$, assumindo uma velocidade no início da rampa de $110 \mathrm{~km} / \mathrm{h}$ e recomenda também que a redução de velocidade deve se limitar a 15 $\mathrm{km} / \mathrm{h}$ no final dos trechos em rampa. A TAC utiliza uma relação massa/potência de 180 $\mathrm{kg} / \mathrm{kW}$ e assume uma velocidade de entrada na rampa igual a $95 \mathrm{~km} / \mathrm{h}$, considerando também uma redução de velocidade da ordem de $15 \mathrm{~km} / \mathrm{h}$ para a determinação da 
extensão dos trechos críticos. A AUSTROADS utiliza como veículo representativo um semi-reboque com relação massa/potência de $164 \mathrm{~kg} / \mathrm{kW}$ e uma velocidade inicial de $100 \mathrm{~km} / \mathrm{h}$.

No Brasil, os critérios e métodos utilizados para a determinação da necessidade, localização e extensão de faixas adicionais em trechos de subida se baseiam em parâmetros utilizados em outros países, especialmente os dos Estados Unidos (DNER, 1999). O próprio Manual brasileiro reconhece a inadequação desta prática, citando que as curvas de desaceleração e as velocidades consideradas pela AASHTO não correspondem ao comportamento observado na frota brasileira, confirmando a necessidade de se estabelecer um tratamento mais adequado para representar a realidade dos veículos nacionais.

\subsubsection{Seção Transversal}

Com relação às características da seção transversal da via, mais especificamente a largura das faixas e dos acostamentos, a AASHTO e a TAC estabelecem valores para a largura das faixas de tráfego em cada classe funcional de rodovia, considerando para isto dois parâmetros: a velocidade operacional e o volume horário de tráfego.

Para a largura dos acostamentos, a TAC utiliza os mesmos parâmetros, enquanto a AASHTO considera apenas o volume horário de tráfego. Para a AUSTROADS, as larguras de faixas de tráfego e acostamentos são determinadas apenas em função do volume médio diário anual (VMDA) do tráfego, e seus valores são diferenciados para dois tipos de rodovias: rodovias sem separação física dos fluxos e rodovias com separação física dos fluxos, sem fazer menção às classes funcionais especificadamente. No Manual do DNER são propostas larguras de faixas de tráfego e acostamentos, sendo estes valores diferenciados em função da classe de rodovia e da topografia do terreno, sem estabelecer uma relação direta com os volumes de tráfego atendidos e o veículo de projeto.

A Tabela 2.6 mostra que, com relação às faixas de tráfego, os diversos países citados adotam valores semelhantes, com larguras variando entre 3,0 e 3,6 m, e, no caso do Canadá, chegando a até $3,7 \mathrm{~m}$. Considerando-se as larguras adotadas para cada 
classe funcional, o Brasil é o país que permite menores larguras para as rodovias coletoras, com uma largura de faixa de 3,0 m, enquanto os outros países adotam como valor mínimo 3,3 m para esta classe de via. Para as vias de padrão mais elevado, a largura da faixa de tráfego no Brasil chega a 3,6 m, equiparando-se ao padrão internacional.

Tabela 2.6: Largura das Faixas de Tráfego e dos Acostamentos de Rodovias em Sistemas de Classificação Funcional.

\begin{tabular}{|c|c|c|c|}
\hline PAÍS & CLASSE FUNCIONAL & $\begin{array}{l}\text { LARGURA DAS } \\
\text { FAIXAS DE } \\
\text { TRÁFEGO (m) } \\
\end{array}$ & $\begin{array}{c}\text { LARGURA DO } \\
\text { ACOSTAMENTO } \\
(\mathrm{m})\end{array}$ \\
\hline \multirow{4}{*}{$\begin{array}{l}\text { Estados Unidos } \\
\text { (AASHTO-2004) }\end{array}$} & Local & 3,0 a 3,6 & 1,0 \\
\hline & Coletora & 3,3 a 3,6 & 1,5 a 3,0 \\
\hline & Arterial & 3,5 a 3,6 & 2,5 a 3,0 \\
\hline & Freeway & 3,6 & $\begin{array}{c}\text { Direito: } 3,0 \\
\text { Central: } 1,5 \text { a } 2,5\end{array}$ \\
\hline \multirow{4}{*}{$\begin{array}{c}\text { Canadá } \\
\text { (TAC-1999) }\end{array}$} & Local & 3,0 a 3,7 & 1,0 \\
\hline & Coletora & 3,3 a 3,7 & 1,5 a 3,0 \\
\hline & Arterial & 3,5 a 3,7 & 2,5 a 3,0 \\
\hline & Freeway & 3,7 & $\begin{array}{c}\text { Direito:3,0 } \\
\text { Central: } 1,5 \text { a } 2,5\end{array}$ \\
\hline \multirow{4}{*}{$\begin{array}{c}\text { Brasil } \\
\text { (DNER-1999) }\end{array}$} & Local & 3,0 a 3,5 & 0,8 a 2,5 \\
\hline & Coletora & 3,0 a 3,6 & 0,8 a 2,5 \\
\hline & Arterial Primária e Secundária & 3,3 a 3,6 & 2,5 a 3,0 \\
\hline & Arterial Principal & 3,6 & $\begin{array}{l}\text { Direito: } 2,5 \text { a } 3,5 \\
\text { Central: } 0,5 \text { a } 3,0 \\
\end{array}$ \\
\hline \multirow{2}{*}{$\begin{array}{c}\text { Austrália } \\
\text { (AUSTROADS-2002) }\end{array}$} & $\begin{array}{l}\text { Vias sem Separação Física dos } \\
\text { Fluxos }\end{array}$ & 3,1 a 3,5 & 1,5 a 2,5 \\
\hline & $\begin{array}{l}\text { Vias com Separação Física dos } \\
\text { Fluxos }\end{array}$ & 3,5 & $\begin{array}{c}\text { Direito: } 2,5 \text { a } 3,0 \\
\text { Central: } 1,0 \\
\end{array}$ \\
\hline
\end{tabular}

Fontes: (AASHTO, 2004), (TAC, 1999), (DNER, 1999) e (AUSTROADS, 2002).

Em estudo desenvolvido por Prem et al. (1999), foram investigadas as larguras de faixa necessárias para acomodar veículos de carga na Austrália. Foi utilizado um modelo computacional, validado por ensaios de campo, onde foram considerados os efeitos da irregularidade longitudinal do pavimento, declividade transversal das pistas e velocidade no comportamento do veículo quanto aos deslocamentos laterais verificados entre o veículo-trator e as unidades rebocadas. Dentre os resultados obtidos, considerando veículos similares da frota brasileira, foram indicadas larguras mínimas para as faixas de tráfego de $2,8 \mathrm{~m}$, se considerados veículos do tipo semi-reboque de 19 m e larguras mínimas de 2,9 m para bitrens de $25 \mathrm{~m}$. Como os veículos no estudo citado possuem largura regulamentada de $2,5 \mathrm{~m}$, isto é, $0,10 \mathrm{~m}$ abaixo do limite adotado no Brasil, pode-se admitir que rodovias com faixas de tráfego de no mínimo 3,0 m, 
condição atendida pelas Classes 0 a IV-A, se mostram compatíveis para os trechos em tangente.

Existem ainda, dentre as classes de rodovia do DNER, as vias de Classe IV-B, onde são permitidas faixas de tráfego com largura de até 2,5 m. Este caso constitui uma classe técnica à parte, na qual são enquadradas vias não pavimentadas, portanto, não sendo consideradas rodovias segundo o CTB. São em sua maioria, estradas vicinais, com VMD inferior a 50 veículos e que não serão objeto da presente pesquisa.

Para os acostamentos, enquanto em outros países são adotadas larguras mínimas de $1 \mathrm{~m}$, no Brasil são admitidos valores de até $0,8 \mathrm{~m}$. Para estabelecer a largura adequada de um acostamento, é necessário conhecer a função que este dispositivo exerce na via. O CTB define acostamento como "a parte da via diferenciada da pista de rolamento destinada à parada ou estacionamento de veículos, em caso de emergência, e à circulação de pedestres e bicicletas, quando não houver local apropriado para este fim”. (BRASIL, 1999a). O Manual do DNER cita que todas as vias devem possuir acostamento e que a condição ideal é a existência de uma largura capaz de abrigar o veículo de projeto e uma pessoa trabalhando ao seu lado.

Outra atribuição para o acostamento é estabelecida pelo Manual do DNER quando este cita que "a existência de acostamento pavimentado contribui para reduzir a necessidade de sobrelargura nas pistas de rolamento", dando ao acostamento uma função adicional de suprir a inexistência ou insuficiência de sobrelarguras. Conforme é mencionado no Manual, podem ser desprezadas as sobrelarguras que não atingirem o valor de 0,40 m por pista de tráfego (DNER,1999).

O trabalho de Downs Junior e Wallace (1982) identificou as larguras de acostamento aceitáveis para que este atenda às suas funções, sendo consideradas as seguintes larguras mínimas: (i) 0,6 m para acomodar o deslocamento lateral dos veículos nas tangentes e suprir déficits nas sobrelarguras dos trechos em curva, (ii)1,2 m para o tráfego de pedestres e ciclistas, (iii) 1,8 m para paradas de emergência e (iv) 2,4 $\mathrm{m}$ para o reparo de veículos. Como pode ser observado, a largura de $0,80 \mathrm{~m}$ de acostamento, estabelecida para rodovias de Classe IV-A, é suficiente para garantir o atendimento de apenas a primeira função mencionada. Se considerada a função de 
permitir o estacionamento do veículo para reparos, apenas as rodovias de Classe 0 e I apresentam larguras de acostamento compatíveis em todos os tipos de relevo.

A Tabela 2.7 apresenta valores para as larguras da seção transversal das rodovias de outros países. As larguras das faixas de tráfego utilizadas nas rodovias locais e coletoras de países da Europa, especialmente na Alemanha e Holanda, apontam para valores ainda menores que os limites utilizados pelo DNER. Entretanto, vale ressaltar que os países europeus estabelecem limites mais conservadores para as dimensões dos veículos de carga. Por outro lado, se forem observadas as larguras das faixas de tráfego nas rodovias de mais elevado padrão, são propostos valores de até 3,75 m nestes países. Quanto aos acostamentos, vários países como China, Espanha, Holanda e Suíça estabelecem larguras mínimas inferiores aos limites estabelecidos pelo DNER.

Tabela 2.7: Largura das Faixas de Tráfego e dos Acostamentos de Rodovias em Sistemas de Classificação Funcional de Outros Paises.

\begin{tabular}{|c|c|c|c|}
\hline PAÍS & CLASSE FUNCIONAL & $\begin{array}{c}\text { LARGURA DAS } \\
\text { FAIXAS DE } \\
\text { TRÁFEGO }(\mathrm{m})\end{array}$ & $\begin{array}{c}\text { LARGURA DO } \\
\text { ACOSTAMENTO } \\
(\mathrm{m})\end{array}$ \\
\hline \multirow{3}{*}{ Alemanha } & Local e Coletora & 2,75 a 3,25 & 1,0 a 1,5 \\
\hline & Arterial & 3,25 a 3,5 & 2,0 \\
\hline & Freeway & 3,5 a 3,75 & 2,0 a 2,5 \\
\hline \multirow{3}{*}{ China } & Local e Coletora & 3,5 & 0,5 a 1,5 \\
\hline & Arterial & 3,75 & 0,75 a 2,5 \\
\hline & Freeway & 3,5 a 3,75 & 2,0 a 3,25 \\
\hline \multirow{3}{*}{ Espanha } & Local e Coletora & 3,0 a 3,25 & 0,5 a 2,0 \\
\hline & Arterial & 3,0 a 3,5 & $1,5 \mathrm{a} 2,5$ \\
\hline & Freeway & 3,5 a 3,75 & $\begin{array}{l}\text { Direito: } 2,5 \text { a } 3,0 \\
\text { Central: } 0,5 \text { a } 1,0\end{array}$ \\
\hline \multirow{3}{*}{ França } & Local e Coletora & 3,5 & 2,5 \\
\hline & Arterial & 3,5 & 2,5 \\
\hline & Freeway & 3,5 & 3,0 \\
\hline \multirow{3}{*}{ Holanda } & Local e Coletora & 2,75 a 3,25 & 0,15 a 0,45 \\
\hline & Arterial & 3,10 a 3,25 & 0,20 a 0,45 \\
\hline & Freeway & 3,50 & 1,25 \\
\hline \multirow{3}{*}{ Portugal } & Local e Coletora & 3,0 & 1,5 a 2,5 \\
\hline & Arterial & 3,75 & 2,5 \\
\hline & Freeway & 3,75 & $\begin{array}{l}\text { Direito:3,0 } \\
\text { Central: } 1,0\end{array}$ \\
\hline \multirow{3}{*}{ Suíça } & Local e Coletora & 3,15 a 3,65 & sem acostamento \\
\hline & Arterial & 3,45 a 3,75 & 0,5 a 1,5 \\
\hline & Freeway & 3,75 a 4,0 & 1,0 a 2,5 \\
\hline
\end{tabular}

Fonte: Lamm, Psarianos e Mailaender (1999). 


\subsubsection{Superelevação}

A superelevação das pistas, recurso utilizado no projeto de vias, com a finalidade de criar uma componente da força peso para contrabalançar o efeito das forças que atuam no veículo ao executar trajetórias curvas, é outro parâmetro de projeto que tem seus valores de utilização limitados. Como limite inferior, o DNER recomenda utilizar uma superelevação de $2 \%$, de forma a permitir melhor drenagem das águas pluviais. Quanto ao limite superior, são estabelecidos valores máximos, uma vez que a adoção de valores muito elevados pode implicar a ocorrência de deslizamento ou tombamento de veículos que, por alguma razão, tenham que operar a baixas velocidades, especialmente quando são veículos com elevado centro de gravidade.

Algumas situações relacionadas à ocorrência de fatores climáticos, como a presença de gelo ou neve, bem como o uso do solo adjacente, são restritivas para a adoção de limites mais elevados para as superelevações. Para evitar a utilização de valores excessivos de superelevação e a ocorrência de acidentes, os manuais e normas de projeto geométrico estabelecem valores máximos de superelevação, como mostra a Tabela 2.8 .

Tabela 2.8: Superelevação Máxima de Rodovias em Sistemas de Classificação Funcional.

\begin{tabular}{ccc}
\hline PAÍ́S & CLASSE FUNCIONAL & $\begin{array}{c}\text { SUPERELEVAÇÃO } \\
\text { MÁXIMA (\%) }\end{array}$ \\
\hline \multirow{2}{*}{ Estados Unidos } & Local & 12 \\
(AASHTO-2004) & Coletora & 12 \\
& Arterial & 12 \\
Freeway & $6 \mathrm{a} 12$ \\
\hline Canadá & Local & \\
(TAC-1999) & Coletora & 6 \\
& Arterial & 8 \\
Brasil & Freeway & 8 \\
(DNER-1999) & Local & 8 e 10 \\
& Coletora & $8 \mathrm{e} 10$ \\
\hline Austrália & Arterial Primária e Secundária & 10 \\
(AUSTROADS-2002) & Arterial Principal & 7 \\
\hline
\end{tabular}

Fontes: (AASHTO, 2004), (TAC, 1999), (DNER, 1999) e (AUSTROADS, 2002). 
O Manual do DNER considera que valores máximos de superelevação de 10\% são próprios para rodovias de padrão elevado, onde as condições físicas favoreçam elevadas velocidades e fluxo ininterrupto, sendo recomendada sua adoção em rodovias de Classe 0 em geral e Classe I em regiões planas e onduladas. Nas rodovias de padrão intermediário, e ainda naquelas de elevado padrão, mas sujeitas a fatores que reduzam a velocidade média - como, por exemplo, o relevo da região - é recomendada a utilização de superelevações máximas de $8 \%$, valor proposto para as rodovias de Classe I em terreno montanhoso e para as demais classes de projeto em geral.

A Tabela 2.9 mostra os limites de superelevação adotados em outros países (CARDOSO et al., 1997) e estão relacionadas às velocidades de projeto consideradas. Os valores entre parênteses são aplicados apenas em condições excepcionais. Como pode se verificar, existe uma tendência oposta ao estabelecido no Manual brasileiro.

O DNER admite que sejam utilizadas superelevações máximas mais altas para as rodovias de padrão mais elevado, e portanto para velocidades de projeto mais altas, assim como menores superelevações para as demais vias. Já os valores propostos pelos outros países seguem uma lógica inversa, sendo reduzidas as superelevações máximas admitidas para as rodovias com maiores velocidade de projeto. A prática adotada nesses países se mostra mais coerente, uma vez que resulta na utilização de raios de curvas mais elevados para as vias de maior padrão técnico, contribuindo para a concepção de traçados mais suaves. Vale ressaltar que a utilização de raios mais elevados resulta em vantagens, como a redução da necessidade de sobrelargura nas curvas e melhor condição de visibilidade para os motoristas.

A influência climática é outro aspecto marcante na determinação das superelevações máximas, como pode ser observado nos limites adotados em países como Canadá, Suécia e Finlândia, onde a ocorrência de neve e gelo reduz o atrito na superfície pneu/pavimento, potencializando o escorregamento dos veículos para o interior das curvas, levando à adoção de limites mais baixos para este parâmetro. 
Tabela 2.9: Superelevação Máxima Admitida em Função da Velocidade de Projeto das Rodovias.

\begin{tabular}{|c|c|c|c|c|c|c|c|c|c|c|c|}
\hline \multirow{2}{*}{ PAÍS } & \multicolumn{11}{|c|}{ VELOCIDADE DE PROJETO (km/h) } \\
\hline & 40 & 50 & 60 & 70 & 80 & 90 & 100 & 110 & 120 & 130 & 140 \\
\hline Alemanha & \multicolumn{11}{|c|}{$7 \%$} \\
\hline Áustria & \multicolumn{6}{|c|}{$7 \%$} & \multicolumn{5}{|c|}{$6 \%$} \\
\hline Espanha & \multicolumn{6}{|c|}{$7 \%$} & $6 \%$ & \multicolumn{4}{|c|}{$5 \%$} \\
\hline Finlândia & \multicolumn{2}{|c|}{$7 \%$} & \multicolumn{3}{|c|}{$6 \%$} & \multicolumn{3}{|c|}{$5 \%$} & \multicolumn{3}{|c|}{$4 \%$} \\
\hline França & \multicolumn{11}{|c|}{$7 \%$} \\
\hline Holanda & \multicolumn{11}{|c|}{$7(8) \%$} \\
\hline Inglaterra & \multicolumn{11}{|c|}{$5(7) \%$} \\
\hline Itália & \multicolumn{11}{|c|}{$7 \%$} \\
\hline Irlanda & \multicolumn{11}{|c|}{$6(7) \%$} \\
\hline Portugal & \multicolumn{11}{|c|}{$6(8) \%$} \\
\hline Suécia & \multicolumn{11}{|c|}{$6 \%$} \\
\hline Suíça & \multicolumn{11}{|c|}{$7 \%$} \\
\hline
\end{tabular}

Fonte: (CARDOSO et al., 1997).

\subsection{Considerações Finais}

Os parâmetros de projeto há pouco mencionados são estabelecidos nos manuais de projeto e são baseados principalmente na classificação funcional adotada no sistema viário. Outros parâmetros de projeto, por sua vez, são relacionados às características dos veículos, sejam físicas ou operacionais. Estas questões serão tratadas com maior profundidade no Capítulo 3. 


\section{ASPECTOS DA INTERAÇÃO VEÍCULO - VIA NA CONCEPÇÃO DO PROJETO GEOMÉTRICO DE RODOVIAS}

\subsection{Considerações Iniciais}

$\mathrm{O}$ ato de projetar a geometria de uma via de forma adequada está condicionado a uma correta compreensão dos elementos que interagem com a via: o motorista e o veículo. Enquanto o motorista apresenta características inerentes à sua condição humana, como as limitações de visão, os tempos necessários para a percepção e reação, bem como sua capacidade de processar informações - características que não mudam significativamente ao longo das gerações - os veículos experimentam marcantes transformações, impulsionadas pelos avanços tecnológicos das últimas décadas e pela busca em atender as exigências de um mercado competitivo.

Analisando o contexto internacional, encontra-se como marco no crescimento da frota de veículos de grande porte a implantação do Surface Transportation Assistance Act (STAA) em 1982, legislação federal americana que elevou os limites de peso e dimensões dos veículos de carga articulados e autorizou sua circulação nas rodovias interestaduais e em outras rodovias principais dos Estados Unidos. As transformações ocorridas na frota de veículos tornaram necessária a investigação dos impactos gerados na segurança viária, sendo determinado pelo Congresso Americano seu monitoramento, levando essa discussão para a comunidade técnica e científica, o que resultou na realização de eventos, como o Symposium on Geometric Design for Large Trucks (1986), que atestaram a necessidade de conhecer as características dos veículos e, sobretudo, adaptar o projeto das vias de forma a considerar suas restrições operacionais.

A incorporação de novos veículos à composição da frota conferiu caráter dinâmico à classificação e ao projeto das vias. Veículos com maiores restrições operacionais resultam em maiores exigências no padrão técnico das vias, cabendo assim 
ajustes nas vias e ao mesmo tempo modificações na concepção de novas vias. No Brasil observa-se a homologação de vários veículos, acompanhada apenas da imposição de medidas restritivas, especialmente relacionadas aos horários autorizados para a circulação destes, bem como da obrigatoriedade de emprego de dispositivos de segurança. O resultado disto é a obsolescência do atual sistema de classificação das vias e das diretrizes utilizadas para o projeto de novas rodovias.

\subsection{O Veiculo de Projeto}

O papel do veículo de projeto neste contexto ganhou maior relevância à medida que a operação de veículos mais complexos foi autorizada. A não-utilização de um veículo representativo do tráfego para a definição dos parâmetros de geometria resulta numa infra-estrutura com restrições que comprometem não apenas seu desempenho e segurança, mas também dos demais veículos que compartilham da via.

A AASHTO define veículo de projeto como aquele representativo das dimensões, peso e características operacionais de uma determinada classe de veículos. A escolha deste veículo deve ser tal que ele tenha dimensões e raios de giro mínimos superiores ao da maioria dos veículos daquela classe. Para a TAC, a escolha desse veículo deve ser baseada em função das características da frota de veículos e não nas dimensões do maior veículo de uma classe nem em valores médios ou nas dimensões legais máximas. A AUSTROADS, por sua vez, considera que o veículo de projeto deve ser capaz de acolher com segurança e conforto pelo menos $85 \%$ dos veículos que operam na rodovia.

Os veículos usualmente utilizados para o projeto de uma rodovia devem ser definidos de forma criteriosa. A frota de veículos é normalmente marcada por intensa heterogeneidade, existindo veículos com diferentes características geométricas, mecânicas e desempenhos operacionais diversos. Portanto, esta definição deve estar amparada em um conhecimento profundo da frota de veículos e de seu comportamento. Havendo um elenco de veículos de projeto consistente, cabe escolher aquele mais adequado para garantir uma operação segura da via. Escolher simplesmente o veículo mais complexo, medida que no primeiro momento pode ser entendida como favorável à segurança, pode configurar uma escolha incorreta, uma vez que não se pode primar tão- 
somente pela eficiência técnica do projeto, mas também considerar a eficiência econômica a ele associada.

A escolha de um veículo de projeto deve ser embasada em aspectos como o volume e composição do tráfego atendido, a classe de via a ser construída, e com ela características como sua velocidade de projeto, seção transversal, concordância horizontal e vertical. Estas variáveis fornecerão subsídios para se estabelecer a natureza e dimensão das restrições que serão impostas aos demais veículos da frota portadores de maior nível de complexidade.

A AASHTO define quatro classes gerais de veículos: (i) veículos de passeio, que envolvem também vans e camionetas e demais veículos utilitários e esportivos; (ii) ônibus, sejam eles urbanos com dois eixos ou articulados e ainda os veículos intermunicipais de três eixos; (iii) caminhões, sejam unitários ou combinações; e (iv) veículos recreativos, incluindo veículos rebocando lanchas ou acessórios outros de lazer. Para estas classes, foi estabelecido um total de dezenove veículos de projeto, permitindo assim melhor condição de escolher um veículo representativo da frota.

A TAC utiliza as classes de veículos de passeio, caminhões e ônibus semelhantemente à AASHTO, num total de onze veículos de projeto, mas não contempla uma classe para veículos recreativos, nem inclui veículos que circulam apenas mediante permissões especiais de tráfego.

A AUSTROADS utiliza três classes de veículos básicos para projeto: (i) veículos de passeio, (ii) ônibus e caminhões unitários e (iii) semi-reboques. No Território australiano, os veículos de carga de acesso irrestrito possuem como dimensões máximas: 2,5 $\mathrm{m}$ de largura, 4,3 $\mathrm{m}$ de altura e $12,5 \mathrm{~m}$ de comprimento, no caso de veículos simples, e $19 \mathrm{~m}$, no caso de veículos combinados (NTC, 2005). Para o caso geral, o Manual propõe a utilização do veículo semi-reboque como padrão para o dimensionamento da seção transversal das vias, ou seja, dos parâmetros como largura de faixa, dos acostamentos e sobrelarguras, enquanto que o veículo de passeio é utilizado para os parâmetros relacionados à geometria horizontal e vertical. Além desses veículos de projeto, o Manual da AUSTROADS recomenda que sejam consideradas outras configurações de veículos caso a demanda na via justifique a adoção de um 
veículo de projeto mais complexo. São propostos para estes casos outros doze veículos de projeto mais complexos (AUSTROADS, 1995).

O Manual de projeto geométrico brasileiro, por sua vez, define quatro veículostipo: (i) veículos leves, que incluem automóveis, vans, utilitários e similares - VP; (ii) veículos comerciais não articulados, incluindo caminhões e ônibus, normalmente com dois eixos e seis rodas - CO; (iii) veículos não articulados de maior dimensão, como ônibus e caminhões longos de três eixos - O; e (iv) veículos articulados compostos de uma unidade tratora simples e um semi-reboque - SR. Como a escolha do veículo de projeto orientará o dimensionamento geométrico da via, os veículos com características ou dimensões semelhantes ou mais favoráveis que estes veículos-tipo irão operar em condições adequadas. Veículos com as configurações mais desfavoráveis, todavia, irão operar com restrições. Neste grupo está inserida a maioria das combinações de veículos homologadas nos últimos anos.

No Brasil, onde há considerável participação de veículos comerciais rígidos como os ônibus e caminhões convencionais - o veículo $\mathrm{CO}$ é utilizado normalmente como o veículo de projeto. A adoção de um veículo simples como o VP como veículo de projeto se justifica em casos especiais, como o atendimento a áreas de lazer como as áreas de preservação ambiental, onde seja permitido apenas o tráfego de carros de passeio. Neste caso, procura-se minimizar os impactos no meio-ambiente e ao mesmo tempo são reduzidos os custos de construção. Ainda assim, no entanto, devem ser projetadas condições geométricas mínimas para permitir o trânsito de veículos de carga, ainda que em horários apropriados e em caráter precário, de forma a assegurar o suprimento e serviços, bem como para permitir a passagem de veículos especiais, como ambulâncias e carros de bombeiros (LEE, 2005). Já as vias que dão acesso a terminais de carga e centros de distribuição, onde existe uma participação mais intensa de veículos longos, o veículo de projeto é o veículo SR.

A última publicação do Manual de Projeto de Interseções (DNIT, 2005) no Brasil apresenta um veículo de projeto além dos quatro veículos propostos no Manual de projeto das rodovias. Trata-se de um reboque com extensão de 19,80 m, cuja utilização como veículo de projeto é recomendada para interseções de vias expressas com vias arteriais com volume de tráfego expressivo, nas interseções que dão acesso a 
áreas industriais, plantações de cana-de-açúcar, áreas de corte de madeira e outras atividades com utilização relevante de veículos do tipo reboque.

A Tabela 3.1 apresenta as características dos cinco veículos de projeto utilizados no Brasil, incluindo o veículo RE, comparados com veículos de projeto de outros países, pertencentes à mesma categoria de veículo. Como em alguns dos manuais consultados existe mais de uma configuração de veículo de uma mesma categoria, foi escolhido o veículo mais complexo da categoria, de acordo com os dados disponíveis nestes manuais.

Tabela 3.1: Comparação dos Veículos de Projeto do DNER com Veículos de mesma Classe Adotados em outros Países.

\begin{tabular}{|c|c|c|c|c|}
\hline VEÍCULOS DE PROJETO & $\begin{array}{c}\text { COMPRIMENTO } \\
(\mathrm{m})\end{array}$ & $\begin{array}{c}\text { ALTURA } \\
(\mathrm{m})\end{array}$ & $\begin{array}{c}\text { LARGURA } \\
(\mathrm{m})\end{array}$ & $\begin{array}{c}\text { RAIO MÍNIMO }\left(180^{\circ}\right) \\
\text { Roda Externa Dianteira }(\mathrm{m})\end{array}$ \\
\hline \multicolumn{5}{|l|}{ CARRO DE PASSEIO } \\
\hline AASHTO (P) & 5,8 & 1,3 & 2,1 & 7,3 \\
\hline $\mathrm{TAC}(\mathrm{P})$ & 5,6 & - & 2,0 & 6,3 \\
\hline AUSTROADS & 5,0 & - & - & 6,3 \\
\hline DNER (VP) & 5,8 & - & 2,1 & 7,3 \\
\hline \multicolumn{5}{|l|}{ CAMINHÃO - 2 EIXOS } \\
\hline AASHTO (SU) & 9,2 & 3,4 a 4,1 & 2,4 & 12,8 \\
\hline TAC (MSU) & 10,0 & - & 2,6 & 11,1 \\
\hline AUSTROADS & 12,5 & 4,3 & 2,5 & - \\
\hline DNER $(\mathrm{CO})$ & 9,1 & 4,4 & 2,6 & 12,8 \\
\hline \multicolumn{5}{|l|}{ CAMINHÃO - 3 EIXOS } \\
\hline TAC (HSU) & 11,5 & - & 2,6 & 14,1 \\
\hline AUSTROADS & 12,5 & 4,3 & 2,5 & - \\
\hline DNER $(\mathrm{O})$ & 12,2 & 4,4 & 2,6 & 12,8 \\
\hline \multicolumn{5}{|l|}{ ÔNIBUS - 2 EIXOS } \\
\hline AASHTO (CITY-BUS) & 12,2 & 3,2 & 2,6 & 12,8 \\
\hline TAC (B-12) & 12,2 & - & 2,4 & 12,9 \\
\hline AUSTROADS & 12,5 & 4,3 & 2,5 & - \\
\hline DNER (CO) & 9,1 & 4,4 & 2,6 & 12,8 \\
\hline \multicolumn{5}{|l|}{ ÔNIBUS - 3 EIXOS } \\
\hline AASHTO (BUS-14) & 13,7 & 3,7 & 2,6 & 13,7 \\
\hline TAC (I-BUS) & 14,0 & - & 2,4 & 13,9 \\
\hline AUSTROADS & 12,5 & 4,3 & 2,5 & - \\
\hline DNER (O) & 12,2 & 4,4 & 2,6 & 12,8 \\
\hline \multicolumn{5}{|l|}{ SEMI REBOQUE } \\
\hline AASHTO (WB-20) & 22,4 & 4,1 & 2,6 & 13,7 \\
\hline TAC (WB-20) & 22,7 & - & 2,6 & 14,3 \\
\hline AUSTROADS & 19 & 4,3 & 2,5 & - \\
\hline DNER (SR) & 16,8 & 4,4 & 2,6 & 13,7 \\
\hline \multicolumn{5}{|l|}{ REBOQUE } \\
\hline AASHTO (WB30-T) & 31,9 & 4,1 & 2,6 & 13,7 \\
\hline TAC (ATD) & 24,5 & - & 2,6 & 12,3 \\
\hline AUSTROADS & 53,5 & 4,3 & 2,5 & - \\
\hline DNIT (RE) & 19,8 & 4,4 & 2,6 & 13,7 \\
\hline
\end{tabular}

Fontes: (AASHTO, 2004), (TAC, 1999), (DNER, 1999) e (AUSTROADS, 2002). 
Comparando os valores dos parâmetros apresentados para cada categoria de veículo, têm-se os veículos de projeto brasileiros apresentando menor comprimento do que os demais na maioria dos casos, como é verificado nos caminhões e ônibus de dois eixos, especialmente quando considerados os semi-reboques e reboques. Considerando este quadro e observando o porte dos veículos que hoje trafegam nas rodovias brasileiras, onde são encontrados veículos unitários com comprimento de $14 \mathrm{~m}$ e tráfego irrestrito, assim como outras configurações de veículos mais longos, chegando a comprimentos de até $30 \mathrm{~m}$, têm-se um indício importante da necessidade de uma revisão nos veículos de projeto. A atual classificação não reflete as características básicas da frota circulante e ao se desconsiderar a participação de veículos mais complexos, são acarretados problemas como insuficiência nos valores de sobrelargura nas curvas, assim como nas distâncias de visibilidade das interseções, comprometendo a segurança viária.

Tradicionalmente, os elementos da geometria relacionados aos processos de frenagem, ao comportamento dos veículos nas curvas horizontais e aos processos de ultrapassagem são determinados com base nos veículos de passeio. Esta prática tem recebido diversas críticas e é objeto de pesquisas. Nos Estados Unidos, a partir da implantação do STAA, com a elevação dos limites nas dimensões e carga dos veículos, uma série de investigações foi realizada, relacionando as dimensões dos veículos, seu desempenho e os parâmetros utilizados no projeto geométrico de vias. Estes estudos tiveram maior ênfase na interface dos veículos com a geometria das interseções, resultando na especificação de novos padrões de projeto para estes dispositivos.

Com relação aos parâmetros de projeto ao longo dos trechos das rodovias, entretanto, os padrões se mantiveram baseados nos veículos de passeio. Na Austrália, pesquisas foram desenvolvidas visando à determinação de alguns destes parâmetros de projeto geométrico utilizando como base os veículos de carga. No atual Manual da AUSTROADS, alguns elementos de projeto são propostos com base no desempenho de caminhões, como é o caso das distâncias de visibilidade de parada, de ultrapassagem e também a definição de fatores de atrito transversal para o traçado das curvas horizontais, que são determinados considerando a estabilidade dos veículos de carga. 
Alguns trabalhos foram desenvolvidos abordando aspectos técnicos referentes aos impactos gerados nas rodovias quando da circulação de veículos longos. Quanto aos aspectos que afetam à infra-estrutura, é válido mencionar os trabalhos de Fabbri et al. (1990) e Fernandes Júnior (1994), que estudaram os efeitos das CVCs nos pavimentos, bem como estudos desenvolvidos sobre os impactos destes veículos em obras de arte, como viadutos e pontes (DEBS; MALITE; MUNAIAR NETO, 2004).

Quanto à operação do tráfego, no trabalho de Machado Neto (1995) foi desenvolvido um estudo do tempo de ultrapassagem de veículos unitários e composições de veículos de carga. Demarchi (1995) investigou os tempos e as distâncias de visibilidade em interseções em nível e as implicações na capacidade da via, dada a operação de veículos de grande porte. Demarchi (2000a) estudou também a influência de veículos pesados na capacidade e nível de serviço em rodovias de pista dupla. Russo (1995) abordou o problema da sobrelargura nas interseções durante a operação em baixas velocidades e o problema do arraste observado nas CVCs. Costa (1997) analisou a compatibilidade do gabarito de caminhões com a geometria de interseções urbanas. Melo (2002) estudou a utilização de faixas adicionais para aclives em rodovias brasileiras para caminhões típicos da frota de veículos.

Para esta pesquisa, serão considerados, além dos veículos de projeto existentes nos manuais brasileiros (DNER, 1999; DNIT, 2005), quinze veículos representativos da frota e que operam, em sua maioria, de forma irrestrita nas rodovias do Brasil. A Tabela 3.2 mostra os pictogramas destes veículos e a Tabela 3.3 apresenta as características básicas dos veículos unitários e das combinações de veículos que serão considerados. Para a identificação dos veículos considerados será empregada a nomenclatura proposta por Widmer (2004). O Apêndice A apresenta novamente os pictogramas desses veículos, assim como ilustrações das conexões entre a unidade tratora e as unidades rebocadas das CVCs. 
Tabela 3.2: Representação Pictográfica dos Veículos Estudados.

\begin{tabular}{|c|c|}
\hline VEÍCULO & PICTOGRAMA \\
\hline CO(DNER), e U2 & 8 \\
\hline $\begin{array}{c}\text { O(DNER), O3(ROD) } \\
\text { e U3 }\end{array}$ & (4) \\
\hline $\begin{array}{l}\text { O2(URB), O2(ROD), } \\
\text { CO(DNER) }\end{array}$ & 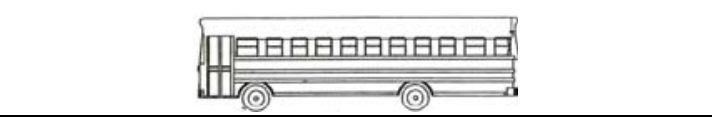 \\
\hline O3(ROD) e U3 & 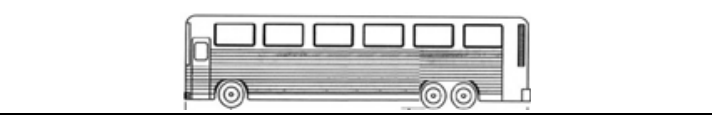 \\
\hline $\mathrm{O} 2 \mathrm{~S} 1$ & 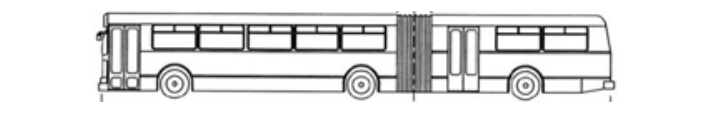 \\
\hline O2S1B1 & 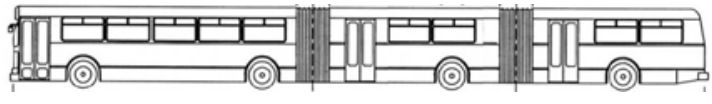 \\
\hline SR(DNER) & OHLOT T \\
\hline RE(DNIT) & $\mathrm{O}^{\mathrm{In}} \mathrm{O}$ \\
\hline $2 \mathrm{~S} 1$ & tor T \\
\hline $\begin{array}{l}2 \mathrm{~S} 2(20 \mathrm{~m}) \mathrm{e} \\
2 \mathrm{~S} 2(22,4 \mathrm{~m})\end{array}$ & बतन \\
\hline $2 \mathrm{~S} 3$ & (1) \\
\hline $3 \mathrm{~S} 2 \mathrm{~B} 2(20 \mathrm{~m})$ e $3 \mathrm{~S} 2 \mathrm{~B} 2(26 \mathrm{~m})$ & बत्न \\
\hline 3S3B3 & 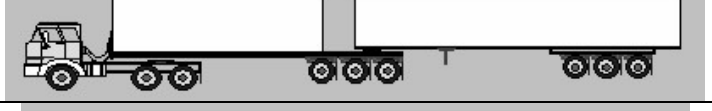 \\
\hline $3 \mathrm{~S} 2 \mathrm{~A} 2 \mathrm{~S} 2$ & क्न \\
\hline
\end{tabular}


Tabela 3.3: Configuração dos veículos considerados.

\begin{tabular}{cccc}
\hline VEÍCULO & $\begin{array}{c}\text { NÚMERO } \\
\text { DE EIXOS }\end{array}$ & $\begin{array}{c}\text { COMPRIMENTO } \\
\text { TOTAL }(\mathrm{m})\end{array}$ & NOMENCLATURA \\
\hline Veículo Projeto “CO”- & 2 & 9,10 & CO(DNER) \\
Veículo Projeto “O”- DNER & 3 & 12,20 & O(DNER) \\
Ônibus Urbano 2 eixos & 2 & 12,10 & O2(URB) \\
Ônibus Rodoviário & 2 & 13,40 & O2(ROD) \\
Ônibus Rodoviário & 3 & 13,95 & O3(ROD) \\
Caminhão Unitário & 2 & 14 & U2 \\
Caminhão Unitário & 3 & 14 & U3 \\
Veículo Projeto “SR”- DNER & 5 & 16,80 & SR(DNER) \\
Veículo Projeto "RE”- DNIT & 5 & 19,80 & RE(DNIT) \\
Ônibus Articulado & 3 & 18 & O2S1 \\
Ônibus Biarticulado & 4 & 25 & O2S1B1 \\
Semi-reboque & 3 & 18,15 & $2 \mathrm{~S} 1$ \\
Semi-reboque & 4 & 20 & $2 \mathrm{~S} 2(20 \mathrm{~m})$ \\
Cegonheiro & 4 & 22,4 & $2 \mathrm{~S} 2(22,4 \mathrm{~m})$ \\
Semi-reboque & 5 & 18,15 & $2 \mathrm{~S} 3$ \\
Bi-trem & 7 & 20 & $3 \mathrm{~S} 2 \mathrm{~B} 2(20 \mathrm{~m})$ \\
Bi-trem & 7 & 26 & $3 \mathrm{~S} 2 \mathrm{~B} 2(26 \mathrm{~m})$ \\
Bi-trem & 9 & 26 & $3 \mathrm{~S} 3 \mathrm{~B} 3$ \\
Rodotrem & 9 & 30 & $3 \mathrm{~S} 2 \mathrm{~A} 2 \mathrm{~S} 2$ \\
\hline
\end{tabular}

\subsection{Principais Influências dos Veículos de Projeto na Concepção de Segmentos Rodoviários}

Considerando a interação veículo-via, serão apresentados a seguir os principais fatores intervenientes no projeto geométrico das vias, condicionados às características dos veículos e suas restrições operacionais. Serão abordados inicialmente os parâmetros que de ordinário são determinados com base nos veículos de passeio e em seguida aqueles determinados com a utilização de outros veículos de projeto.

\subsubsection{Distância de Visibilidade de Parada}

A distância de visibilidade de parada é um elemento importante para o projeto geométrico de curvas horizontais, curvas verticais e das interseções em nível. Ela é composta de duas parcelas, sendo a primeira referente à distância percorrida durante o tempo de percepção e reação do motorista, e a segunda corresponde à distância percorrida durante o processo de frenagem. Sua determinação é função de três aspectos 
principais: o veículo, o pavimento e o motorista - sendo os dois primeiros intimamente associados ao processo de frenagem, envolvendo: (i) a tecnologia do sistema de freios convencional ou Antilock Break System (ABS), (ii) a carga do veículo e sua distribuição e (iii) a pressão dos pneus e seu estado de conservação, em especial a profundidade das trilhas dos pneus, que, associada às características de atrito do pavimento, são fundamentais na frenagem (FITZPATRICK, 1992).

A importância do motorista está relacionada especialmente ao tempo de percepção e reação e sua altura de visão, além de aspectos subjetivos, como habilidade, experiência e treinamento. Os estudos expressos na literatura convergem para um tempo de percepção e reação de 2,5 seg, apesar dos valores pesquisados apresentarem uma elevada dispersão (TRIGGS; HARRIS, 1982). Segundo pesquisas desenvolvidas por Frambo, Fitzpatrick e Koppa (1997), este valor excede o $90^{\circ}$ percentil dos tempos de percepção e reação dos motoristas, justificando sua adoção pela maioria dos manuais de projeto de vias. Considerando especificamente os caminhões, é verdadeiro afirmar que, por se tratarem de motoristas profissionais, este tempo de percepção e reação pode ser menor do que no restante da população. Os sistemas de freio a ar, historicamente utilizados em combinações de veículos de carga, todavia, possuem uma defasagem inerente de 0,5 seg na aplicação dos freios, de forma que é apropriada a utilização do valor de 2,5 seg também para os motoristas de caminhões (HARWOOD; TORBIC; RICHARD, 2003).

A AASHTO tem adotado distâncias de visibilidade de parada com base nos automóveis. A justificativa para isto é o fato que, apesar dos caminhões apresentarem pior desempenho nos processos de frenagem, e com isto resultar em maiores distâncias de frenagem, existe uma compensação nestes veículos, uma vez que a maior altura de visão do motorista proporciona maior distância de visibilidade. A própria AASHTO, entretanto, em seu Manual, recomenda que sejam providos maiores valores de distância de visibilidade para os trechos em declive, especialmente no final de rampas negativas, onde a velocidade dos caminhões se equipara à dos automóveis e a maior altura de visão dos motoristas não constitui vantagem significativa.

O cálculo da distância de visibilidade de parada utilizada pela AASHTO é determinado para a condição de frenagem com rodas travadas e pavimento molhado, ou 
seja, os coeficientes utilizados para a determinação do atrito longitudinal da interface pneu-pavimento são estabelecidos em favor da segurança, abaixo do observado para a situação de pavimento seco. Até o Manual publicado em 1994 (AASHTO, 1994), era apresentada uma tabela com valores de fatores de atrito longitudinal em função da velocidade do veículo, variando entre 0,40 para a velocidade de projeto de $30 \mathrm{~km} / \mathrm{h}$ e 0,28 para a velocidade de $120 \mathrm{~km} / \mathrm{h}$. Os valores das distâncias de visibilidade utilizados pelo DNER e pela TAC seguem esta orientação, com fatores de atrito praticamente iguais ao proposto pela AASHTO.

Pesquisas desenvolvidas na década 1980 (OLSON et al., 1984) revelaram a inadequação em se considerar o processo de frenagem com rodas travadas em caminhões, uma vez que este é irreal e perigoso, dificultando o controle direcional dos veículos e causando muitas vezes a invasão de faixas adjacentes, elevando assim o risco de colisões. Fancher (1986) desenvolveu um modelo teórico relacionando distância de parada para semi-reboques trafegando em pavimento molhado com os valores de resistência a derrapagem. Os resultados indicaram valores de desaceleração da ordem de $0,23 \mathrm{~g}$ a $0,3 \mathrm{~g}$ para a velocidade de $32 \mathrm{~km} / \mathrm{h}$ e da ordem de $0,17 \mathrm{~g}$ a $0,23 \mathrm{~g}$ para a velocidade de $96 \mathrm{~km} / \mathrm{h}$. O trabalho de Fancher (1986) generalizou os resultados dos testes de distância de parada desenvolvidos por Olson et al. (1984). Segundo esses testes, foi observado que, para uma dada condição de pavimento, os semi-reboques demandam uma distância de parada igual a 1,4 vez a distância requerida pelos automóveis. Como a distância de parada é inversamente proporcional à desaceleração média, pode-se então dividir a taxa de desaceleração assumida para os automóveis pelo fator 1,4. A vantagem desta prática é a utilização do mesmo grau de risco existente na adoção dos valores de desaceleração dos automóveis, sem a necessidade de assumir valores para a resistência à derrapagem (MCLEAN; TZIOTS; GUNATILLAKE, 2002).

Widmer (2002b) aponta a necessidade de incorporar um fator de eficiência de frenagem à equação da AASHTO, de forma a considerar o rendimento do sistema de freios dos veículos. Utilizando uma modelagem simples de corpos rígidos, Limpert (1992) encontrou alguns valores para a eficiência de frenagem de várias configurações de veículos de carga, vazios ou carregados, considerando diferentes valores para o fator de atrito, todos para a situação de movimento retilíneo. $\mathrm{O}$ modelo teórico considerou 
veículos dos tipos: caminhões unitários, semi-reboques, rodotrens e bitrens, que apresentaram resultados de eficiência de frenagem variando de 0,61 a 0,97 para veículos vazios e de 0,65 a 0,97 para veículos carregados. Calculando as distâncias de visibilidade com base no Manual do DNER e os fatores de eficiência de frenagem, têmse aumentos nas distâncias de até $47 \%$, valor próximo ao proposto nos estudos de Fancher (1986).

Nas duas últimas edições do Manual da AASHTO (AASHTO, 2001, 2004) foi estabelecido valor único de taxa de desaceleração para os veículos, independentemente da velocidade e igual a $3,4 \mathrm{~m} / \mathrm{s}^{2}$, que corresponde a um fator de atrito longitudinal da ordem de 0,35. Este valor foi obtido a partir de estudo desenvolvido por Frambo, Fitzpatrick e Koppa (1997) e representa o $10^{\circ}$ percentil da taxa de desaceleração dos veículos de passeio. Esta taxa de desaceleração representa um valor de frenagem controlada que é confortável para os passageiros e permite manter o veículo na sua faixa de tráfego, mesmo em situação de pavimento molhado. Os valores adotados continuam sendo propostos com base em veículos de passeio e são utilizados também para caminhões. Esta prática é justificada pelo fato de haver dados indicando que veículos de carga providos de sistema de freios ABS alcançam taxas de desaceleração em frenagens controladas próximas destes valores (AASHTO, 2004). Estatísticas do ano de 1992 mostravam que aproximadamente $42 \%$ dos semi-reboques americanos possuíam este sistema de freio e as projeções indicam que em curto prazo a quase totalidade dos veículos será dotada desta tecnologia (HARWOOD; TORBIC; RICHARD, 2003).

A equação (3.1) para cálculo da distância de visibilidade de parada proposta pela AASHTO (2004) é:

$$
D=0,278 \cdot V \cdot t+\frac{V^{2}}{254 \cdot\left[\left(\frac{a}{9,81}\right) \pm 0,01 \cdot G\right]}
$$

onde:

$D=$ distância de visibilidade de parada $(\mathrm{m})$

$V=$ velocidade do veículo $(\mathrm{km} / \mathrm{h})$ 
$t=$ tempo de reação, geralmente adotado $t=2,5 \mathrm{seg}$

$a=$ taxa de desaceleração $\left(\mathrm{m} / \mathrm{s}^{2}\right)$

$\mathrm{G}=$ declividade de rampa (\%), sendo positiva para declives e negativa para aclives

O Manual do DNER, assim como os da TAC e AUSTROADS, utilizam equações equivalentes, semelhante ao proposto pela AASHTO até o Manual de 1994, utilizando o parâmetro $f$, referente ao fator de atrito e admitindo um tempo de percepção e reação de 2,5 seg, conforme mostrado na equação 3.2:

$D=0,7 \cdot V+\frac{V^{2}}{[255 \cdot(f+i)]}$

onde:

$D=$ distância de visibilidade de parada $(\mathrm{m})$

$V=$ velocidade do veículo $(\mathrm{km} / \mathrm{h})$

$f=$ fator de atrito, estabelecido para a velocidade considerada

$i=$ greide $(\mathrm{m} / \mathrm{m})$, sendo positiva no sentido ascendente e negativo no sentido descendente.

A determinação de valores diferentes para as distâncias de visibilidade em veículos de passeio e veículos de carga tem sido adotada em alguns manuais. O Canadá utiliza as distâncias de visibilidade de frenagem para a situação de rodas travadas, entretanto apenas para veículos de passeio e veículos de carga providos de sistema ABS de freios, visando a evitar a ocorrência da perda do controle direcional dos veículos de carga. Para os veículos de carga com sistema de freios convencional, é proposta a utilização das distâncias de visibilidade mais elevadas.

A AUSTROADS propõe a utilização de fatores de atrito longitudinal diferentes para automóveis e caminhões com base nas pesquisas desenvolvidas por Donaldson (1986) e Fancher (1986). Estes trabalhos sugerem que as distâncias de visibilidade disponíveis, em razão da maior altura de visão dos motoristas de caminhões, não 
compensam seu pior desempenho nas frenagens. As razões principais citadas pelo Manual da AUSTROADS para a utilização de distâncias de visibilidade diferentes para os caminhões são (AUSTROADS, 2002):

(a) o pior desempenho de frenagem observado nos veículos descarregados, uma vez que o sistema de suspensão e os pneus do veículo contribuem com uma eficiência máxima de frenagem apenas quando o veículo está carregado;

(b) veículos com carga mal distribuída entre os eixos podem ocasionar o deslizamento de um dos eixos lateralmente, criando uma situação de instabilidade nos demais eixos, podendo resultar em perdas na eficiência de frenagem da ordem de $15 \%$;

(c) a frenagem ineficiente dos veículos articulados, pois uma parcela aproximada de $50 \%$ não apresenta o desempenho de frenagem requerido; e

(d) os pneus dos caminhões são projetados com a função principal de resistência ao desgaste e isto resulta em pneus com piores fatores de atrito em superfícies molhadas.

Os valores utilizados pela AUSTROADS foram obtidos a partir de estudos desenvolvidos por Harwood et al. (1990). A Australian Vehicle Standards Rules AVSR especifica como parâmetros mínimos de desempenho de desaceleração para os sistemas de freio dos veículos pesados o valor de 0,29 g, chegando ao valor máximo de 0,59 g (MCLEAN; TZIOTS; GUNATILLAKE, 2002).

A Tabela 3.4 mostra os valores calculados para a distância de visibilidade de parada, segundo os fatores de atrito longitudinal adotados em alguns países. Para o cálculo desses valores, foi utilizado um tempo de percepção e reação de 2,5 seg, declividade zero e distâncias em metros arredondadas para múltiplos de 5. 
Tabela 3.4: Distância de Visibilidade de Parada para Veículos de Passeio e Caminhões.

\begin{tabular}{cccccccc}
\hline \multirow{2}{*}{\begin{tabular}{c} 
VELOCIDADE $\begin{array}{c}c \\
\text { DE PROJETO } \\
(\mathrm{km} / \mathrm{h})\end{array}$ \\
\cline { 2 - 7 }
\end{tabular}} & AASHTO & \multicolumn{3}{c}{ DNER } & \multicolumn{2}{c}{ TAC } & \multicolumn{2}{c}{ AUSTROADS } \\
\cline { 2 - 7 } & & $\begin{array}{c}\text { Distância } \\
\text { Mínima }\end{array}$ & $\begin{array}{c}\text { Distância } \\
\text { Desejada }\end{array}$ & Auto & Caminhão & Auto & Caminhão \\
\hline 30 & 35 & 30 & 30 & 30 & - & - & - \\
40 & 50 & 45 & 45 & 45 & 60 & - & - \\
50 & 65 & 60 & 65 & 65 & 85 & 55 & 70 \\
60 & 85 & 75 & 85 & 85 & 105 & 75 & 95 \\
70 & 105 & 90 & 110 & 115 & 135 & 95 & 120 \\
80 & 130 & 110 & 140 & 140 & 155 & 115 & 145 \\
90 & 160 & 130 & 175 & 170 & 190 & 145 & 175 \\
100 & 185 & 155 & 210 & 210 & 235 & 175 & 215 \\
110 & 220 & 180 & 255 & 250 & 260 & 210 & 260 \\
120 & 250 & 205 & 310 & 290 & - & 250 & 315 \\
130 & 285 & - & - & 330 & - & 285 & 370 \\
\hline
\end{tabular}

Fontes: (AASHTO, 2004), (TAC, 1999), (DNER, 1999) e (AUSTROADS, 2002).

O valor de desaceleração proposto atualmente pela AASHTO é o mesmo para automóveis e caminhões e resulta em distâncias de visibilidade semelhantes aos valores propostos no Manual de 1994 para as velocidades até $60 \mathrm{~km} / \mathrm{h}$. Por outro lado, para velocidades maiores, as distâncias de visibilidade foram reduzidas em até $18 \%$, em virtude da utilização de taxa única de desaceleração. A TAC e o DNER ainda utilizam valores de fator de atrito longitudinal com base na orientação do Manual da AASHTO de 1994. Para os caminhões, entretanto, a TAC estabelece distâncias de visibilidade diferenciadas para os veículos providos de sistema de freio convencional. O Manual do DNER admite a utilização de duas distâncias de visibilidade de parada, uma obtida com base nas velocidades de projeto, denominada distância de visibilidade desejável e outra considerando valores de velocidades médias, denominada distância de visibilidade mínima. O Manual exige que seja adotada ao menos a distância mínima, permitindo ainda que seja considerada a situação de greide nulo. A justificativa para isto consiste na alegação de que existem margens de segurança nos fatores de atrito adotados nos processos de frenagem que permitem desprezar a existência de greides.

Considerando as distâncias de visibilidade estabelecidas pela TAC para caminhões, são observados valores até $33 \%$ superiores (para $V=40 \mathrm{~km} / \mathrm{h}$ ) às distâncias desejáveis recomendadas pelo DNER, e até $52 \%$ superiores (para $V=100 \mathrm{~km} / \mathrm{h}$ ), se 
considerada a adoção das distâncias mínimas propostas. Para os veículos com sistema de freio ABS, a TAC recomenda que sejam consideradas as mesmas distâncias calculadas para automóveis. A AUSTROADS também apresenta distância de visibilidade de parada diferenciada para automóveis e caminhões. As distâncias propostas para os caminhões são até $12 \%$ superiores aos valores utilizados no Brasil, quando consideradas as distâncias pretendidas, e até $44 \%$ superiores em relação à adoção das distâncias mínimas.

Comparando as distâncias de visibilidade de parada ora apresentadas, e levando em conta a tecnologia de frenagem utilizada nos países citados, observa-se que no Brasil são assumidas menores margens de segurança para os processos de frenagem dos veículos de carga, elevando o risco para a ocorrência de acidentes. Apesar de não haver disponíveis dados oficiais, estima-se que apenas 3\% dos caminhões brasileiros são providos de sistema ABS de freios. Diante deste prognóstico tão díspar das estatísticas americanas, é recomendada a adoção de distâncias com base no desempenho de frenagem dos caminhões para o projeto de vias cuja participação destes veículos no tráfego seja significativa. A adoção de distâncias mínimas de visibilidade, adicionada ao fato de ser desconsiderada a influência dos greides, única exigência imposta no Manual, compromete as condições de segurança, especialmente para os veículos de carga.

A utilização de distâncias mínimas de frenagem recai sobre uma discussão, a respeito da relação potência/massa dos caminhões brasileiros, que tem papel fundamental nas velocidades desenvolvidas por estes veículos. Apesar de existir o argumento de que os veículos brasileiros apresentam uma relação potência/massa em média mais baixa do que outros países, como os Estados Unidos, e que isto resulta num desempenho de velocidades mais baixas nos caminhões, é importante ressaltar que a frota nacional não possui inspeção técnica veicular e esta falta de controle resulta numa heterogeneidade no desempenho dos veículos, tanto nos processos de frenagem quanto em suas capacidades de aceleração, não sendo recomendado tratar a frota de veículos em função apenas de um valor médio de relação potência/massa. Considerando então que uma parte dos caminhões brasileiros é capaz de desenvolver velocidades elevadas, e ainda a existência dos trechos em declive, onde esta velocidade pode alcançar valores 
ainda superiores, é importante estabelecer condições seguras para a frenagem destes veículos, baseadas na velocidade de projeto da via.

\subsubsection{Distância de Visibilidade para Tomada de Decisão}

Além da distância de visibilidade de parada, o Manual do DNER segue recomendação da AASHTO (1994) e sugere a adoção da distância de visibilidade para tomada de decisão. Este parâmetro corresponde à distância necessária para que o motorista perceba uma situação inesperada ou de risco, tendo tempo suficiente para avaliar esta condição, escolher o caminho a percorrer e a velocidade a empregar, permitindo assim manobrar o veículo com segurança.

São propostas duas distâncias de tomada de decisão, referentes às manobras de parada e de desvio de obstáculos. Para a parada simples são propostas distâncias semelhantes ao utilizado na distância de visibilidade de parada tratada há pouco. No caso da distância prevista para permitir desviar o veículo, são propostos valores significativamente maiores, de 21 a 156\% superiores às distâncias de visibilidade de parada. Embora sua utilização não seja obrigatória, conforme menciona o Manual do DNER, a maior visibilidade proporcionada por este critério de projeto, além de dotar os pontos críticos da via de uma maior segurança, forneceria distâncias de visibilidade compatíveis com a parada dos veículos pesados.

\subsubsection{Distância de Visibilidade em Curvas Verticais Convexas}

A concordância vertical dos greides de uma rodovia é obtida através da utilização de curvas verticais. Para as curvas convexas, é observada uma limitação na distância de visibilidade do motorista, de forma que, para garantir a segurança dos veículos, é necessário que estas distâncias sejam iguais ou superiores à distância de visibilidade de parada $(D)$. Para determinar este parâmetro, são consideradas outras variáveis, como a altura de visão do motorista e a altura do obstáculo. A altura de visão do motorista é mais crítica para os veículos de passeio. A altura utilizada pela TAC e pela AUSTROADS é de 1,05 m, valor que, de acordo com estudos realizados no Canadá, é menor do que $99 \%$ dos valores observados em motoristas de automóvel (TAC, 1999). A AASHTO utiliza uma altura de 1,08 m e o DNER, de 1,10 m. Para os 
ônibus ou caminhões simples a TAC recomenda o valor 1,8 m e, nos caminhões longos e combinações, valores entre 1,9 m e 2,4 m são adotados. A AASHTO propõe altura de 2,33 m e a AUSTROADS de 2,4 m, enquanto o Manual do DNER não estabelece valores para este parâmetro. Quanto à altura de visão de outros tipos de veículos comerciais, vale ressaltar que parte dos ônibus rodoviários modernos possui uma configuração em que a poltrona do motorista está localizada a uma menor distância do chassi do veículo, proporcionando altura de visão mais próxima do observado em automóveis do que o verificado em caminhões.

Com relação à altura do obstáculo, utilizado para a determinação da configuração das curvas verticais convexas, a AASHTO estabeleceu, a partir do Manual de 2001 uma altura de $600 \mathrm{~mm}$, julgando ser um valor representativo da dimensão de um objeto capaz de causar riscos para o motorista e que pode ser reconhecido a tempo de parar o veículo antes de uma colisão. As versões anteriores do Manual da AASHTO propunham uma altura de $150 \mathrm{~mm}$, valor que ainda é utilizado pelo DNER. Estudos de acidentes realizados por Frambo, Fitzpatrick e Koppa (1997), apontando que praticamente inexistem acidentes envolvendo obstáculos com altura entre 100 e 150 mm, motivaram a elevação deste valor para $600 \mathrm{~mm}$, que é também considerado um valor conservador quando relacionado à altura da lanterna traseira dos veículos. Os manuais da TAC e da AUSTROADS determinam um intervalo de valores para este parâmetro, em função do objeto a ser considerado, variando de zero, para o caso da sinalização horizontal, até $380 \mathrm{~mm}$ para a TAC e $600 \mathrm{~mm}$ para a AUSTROADS, representando a altura da lanterna traseira dos veículos.

A AASHTO (2004), assim como os demais manuais pesquisados, determina valores mínimos para o comprimento da concordância vertical, denominado de $L v_{\min }$, para atender esta condição de visibilidade. Este valor pode ser expresso pelo fator $K$, que relaciona o comprimento da curva $\left(L v_{\min }\right)$ com a diferença algébrica dos greides, sendo determinado conforme as equações 3.3 e 3.4 .

(a) Se $D<L v_{\min }$, tem-se:

$$
K_{\min }=\frac{D^{2}}{200 \cdot\left(\sqrt{h_{1}}+\sqrt{h_{2}}\right)^{2}}
$$


(b) Se $D>L v_{\min }$, tem-se:

$$
K_{\min }=\frac{2 D}{\delta_{i}}-\left[\frac{200 \cdot\left(\sqrt{h_{1}}+\sqrt{h_{2}}\right)^{2}}{\delta_{i}^{2}}\right]
$$

onde:

$K_{\min }=$ comprimento da curva necessário para uma mudança de $1 \%$ no greide $(\mathrm{m})$

$\delta_{i}=$ diferença algébrica dos greides $(\%)$

$h_{1}=$ altura da vista do motorista em relação à pista $(\mathrm{m})$

$h_{2}=$ altura do obstáculo (m).

Considerando que as distâncias de visibilidade de parada são mais elevadas para veículos de carga do que para automóveis, este parâmetro contribui para elevar os comprimentos mínimos das curvas verticais. Por outro lado, o parâmetro altura de vista do motorista, maior para os veículos de carga, contribui para sua redução, cabendo verificar se existe ou inexiste uma compensação que permita continuar adotando os comprimentos mínimos das curvas com base nos veículos de passeio, como atualmente tem sido praticado no Manual do DNER. A Tabela 3.4 apresenta os valores de $K_{\min }$ calculados, utilizando os parâmetros recomendados nos manuais de projeto geométrico para automóveis e caminhões, com suas respectivas alturas de visão do motorista, altura dos obstáculos e distâncias de visibilidade de parada. No caso do DNER, foi usada para os caminhões a distância de visibilidade de parada dos automóveis com uma majoração de $40 \%$, de acordo com o proposto na pesquisa de Olson et al. (1984). Foram também calculados valores de $K_{\min }$ para distâncias de visibilidade mínima, com base nos valores de velocidade média adotados pelo DNER no lugar das velocidades de projeto. Estes valores de $K_{\min }$ estão apresentados entre parênteses na Tabela 3.5. Pode-se observar que os valores de $K_{\min }$ calculados dadas as condições assumidas nos quatro manuais de projeto são bastante díspares. A principal razão para este fato é a influência do parâmetro altura do obstáculo. O valor adotado pelo DNER, de 0,15 m, resulta nos maiores valores de $K_{\min }$ em comparação aos demais manuais, mesmo com o DNER utilizando distâncias de visibilidade de parada menores, baseadas em veículos de 
passeio. Esta constatação permite afirmar que, dado o conservadorismo adotado no Manual do DNER, as curvas verticais convexas proporcionam condições de visibilidade bastante superiores aos demais manuais, indicando também que, caso sejam considerados obstáculos de $0,20 \mathrm{~m}$ a $0,60 \mathrm{~m}$, valores utilizados nos outros manuais, os valores de $K_{\min }$ adotados pelo DNER atendem com folga, tanto para as condições operacionais dos automóveis, como para os caminhões.

Tabela 3.5: Comparação dos Valores de $K_{\min }$ para Curvas Verticais Convexas $(D<$ $\left.L v_{\min }\right)$ com Base nos Parâmetros de Veículos de Passeio e de Caminhões.

\begin{tabular}{|c|c|c|c|c|c|c|c|c|}
\hline \multirow{5}{*}{$\begin{array}{c}\text { VELOCIDADE } \\
\text { PROJETO } \\
(\mathrm{km} / \mathrm{h})\end{array}$} & \multicolumn{8}{|c|}{$K_{\min }$} \\
\hline & \multicolumn{2}{|c|}{ AASHTO } & \multicolumn{2}{|c|}{ TAC } & \multicolumn{2}{|c|}{ AUSTROADS } & \multicolumn{2}{|c|}{ DNER } \\
\hline & Auto & Caminhão & Auto & Caminhão & Auto & Caminhão & Auto & Caminhão \\
\hline & $\begin{array}{c}\mathrm{h}_{1} \\
1,08 \mathrm{~m}\end{array}$ & $\begin{array}{c}\mathrm{h}_{1} \\
2,33 \mathrm{~m} \\
\end{array}$ & $\begin{array}{c}\mathrm{h}_{1} \\
1,05 \mathrm{~m} \\
\end{array}$ & $\begin{array}{c}\mathrm{h}_{1} \\
2,40 \mathrm{~m} \\
\end{array}$ & $\begin{array}{c}\mathrm{h}_{1} \\
1,05 \mathrm{~m} \\
\end{array}$ & $\begin{array}{c}\mathrm{h}_{1} \\
2,40 \mathrm{~m} \\
\end{array}$ & $\begin{array}{c}\mathrm{h}_{1} \\
1,10 \mathrm{~m} \\
\end{array}$ & $\begin{array}{c}\mathrm{h}_{1} \\
2,40 \mathrm{~m} \\
\end{array}$ \\
\hline & $\begin{array}{c}\mathrm{h}_{2} \\
0,60 \mathrm{~m}\end{array}$ & $\begin{array}{c}\mathrm{h}_{2} \\
0,60 \mathrm{~m}\end{array}$ & $\begin{array}{c}\mathrm{h}_{2} \\
0,38 \mathrm{~m}\end{array}$ & $\begin{array}{c}\mathrm{h}_{2} \\
0,38 \mathrm{~m}\end{array}$ & $\begin{array}{c}\mathrm{h}_{2} \\
0,20 \mathrm{~m}\end{array}$ & $\begin{array}{c}\mathrm{h}_{2} \\
0,20 \mathrm{~m}\end{array}$ & $\begin{array}{c}\mathrm{h}_{2} \\
0,15 \mathrm{~m}\end{array}$ & $\begin{array}{c}\mathrm{h}_{2} \\
0,15 \mathrm{~m}\end{array}$ \\
\hline 20 & 1 & 1 & - & - & - & - & - & - \\
\hline 30 & 2 & 2 & 2 & - & - & - & $2(2)$ & $2(2)$ \\
\hline 40 & 4 & 3 & 4 & 4 & - & - & $5(5)$ & $5(5)$ \\
\hline 50 & 7 & 4 & 7 & 8 & 7 & 5 & $10(9)$ & $10(9)$ \\
\hline 60 & 11 & 7 & 13 & 12 & 12 & 8 & $18(14)$ & $19(15)$ \\
\hline 70 & 17 & 11 & 23 & 20 & 20 & 13 & $29(20)$ & $32(21)$ \\
\hline 80 & 26 & 16 & 36 & 26 & 31 & 19 & $48(29)$ & $51(32)$ \\
\hline 90 & 39 & 24 & 53 & 39 & 46 & 28 & $74(41)$ & $78(44)$ \\
\hline 100 & 52 & 32 & 80 & 59 & 67 & 41 & $107(58)$ & $115(63)$ \\
\hline 110 & 74 & 45 & 110 & 73 & 98 & 63 & $164(79)$ & $170(85)$ \\
\hline 120 & 95 & 58 & 150 & - & 139 & 90 & $233(102)$ & $251(110)$ \\
\hline 130 & 124 & 76 & 200 & - & 197 & 126 & - & - \\
\hline
\end{tabular}

Comparando-se por outro lado os valores de $K_{\min }$ de cada manual separadamente, isto é, para uma mesma altura de obstáculo, pode se observado que, para o caso da AASHTO, a maior altura de visão do motorista de caminhão resultou numa redução significativa nos valores de $K_{\min }$ em relação aos valores tomados com base nos veículos de passeio. Como neste caso é admitido um desempenho de frenagem nos caminhões semelhante ao verificado nos automóveis, em virtude da tecnologia dos seus sistemas de freios, a vantagem da maior altura de visão destes motoristas é totalmente convertida numa redução no valor de $K_{\text {min }}$. Para a TAC e a AUSTROADS, foi verificada uma compensação das maiores distâncias de visibilidade de parada dos caminhões pela maior altura de visão proporcionada por esses veículos, resultando na 
obtenção de menores valores de $K_{\min }$ do que os obtidos para os veículos de passeio. Desta forma, dados as condições assumidas nestes três manuais, pode-se concluir que estabelecer valores de $K_{\min }$ em curvas verticais convexas $\left(D<L v_{\min }\right)$ com base no comportamento dos veículos de passeio não representa risco para os caminhões.

Quanto aos resultados obtidos com os parâmetros do DNER, foi observado que existe uma compensação para as velocidades mais baixas, entre 30 e $60 \mathrm{~km} / \mathrm{h}$, com uma tendência dos veículos de carga exigirem valores de $K_{\min }$ um pouco superiores à medida que esta velocidade se eleva. Em razão, porém, de estas diferenças serem de pequena dimensão, uma análise de sensibilidade no fator de majoração das distâncias de frenagem dos caminhões mostrou que, se considerado um fator próximo ao utilizado, em torno de $35 \%$, passa a ser verificada uma compensação em todas as faixas de velocidade, sendo obtidos valores de $K_{\min }$ iguais, tanto na simulação de automóveis como de caminhões. Considerando-se as margens de segurança conservadoras nas taxas de desaceleração utilizadas para o cálculo das distâncias de visibilidade de parada, pode-se admitir que, também neste caso, a prática de estabelecer comprimentos mínimos de curvas verticais convexas $\left(D<L v_{\min }\right)$ com base nos veículos de passeio não compromete a segurança viária.

Além do critério de menor distância de visibilidade, apresentado há instantes, para a determinação dos valores de $K_{\min }$ nas curvas verticais, existem dois outros critérios considerados no Manual do DNER. O primeiro leva em conta um valor de máxima aceleração centrífuga admissível, sendo baseado num critério de conforto e calculado através da equação 3.5 .

$$
K_{\min }=\frac{V^{2}}{1296 a}
$$

onde:

$V=$ velocidade de projeto $(\mathrm{km} / \mathrm{h})$

$a=$ aceleração centrifuga admissível, igual a 1,5\% g (aceleração da gravidade) para rodovias de elevado padrão e $5 \%$ g para rodovias de reduzido padrão. 
O outro critério, denominado de critério do mínimo valor absoluto é utilizado com o intuito de permitir ao motorista perceber a alteração de declividade longitudinal, sendo utilizado como comprimento mínimo da curva vertical $\left(L v_{\min }\right)$ o valor correspondente a $0,6 . \mathrm{V}_{\mathrm{p}}$, onde $\mathrm{V}_{\mathrm{p}}$ é a velocidade de projeto em $\mathrm{km} / \mathrm{h}$.

As Figuras 3.1 e 3.2 apresentam os comprimentos mínimos das curvas verticais convexas, respectivamente para automóveis e caminhões, para os casos de, $D<L v_{\min } \mathrm{e}$ $D>L v_{\text {min }}$, considerando ainda os outros dois critérios utilizados pelo Manual do DNER. As distâncias de visibilidade de parada e alturas do motorista e do obstáculo seguiram a orientação do DNER.

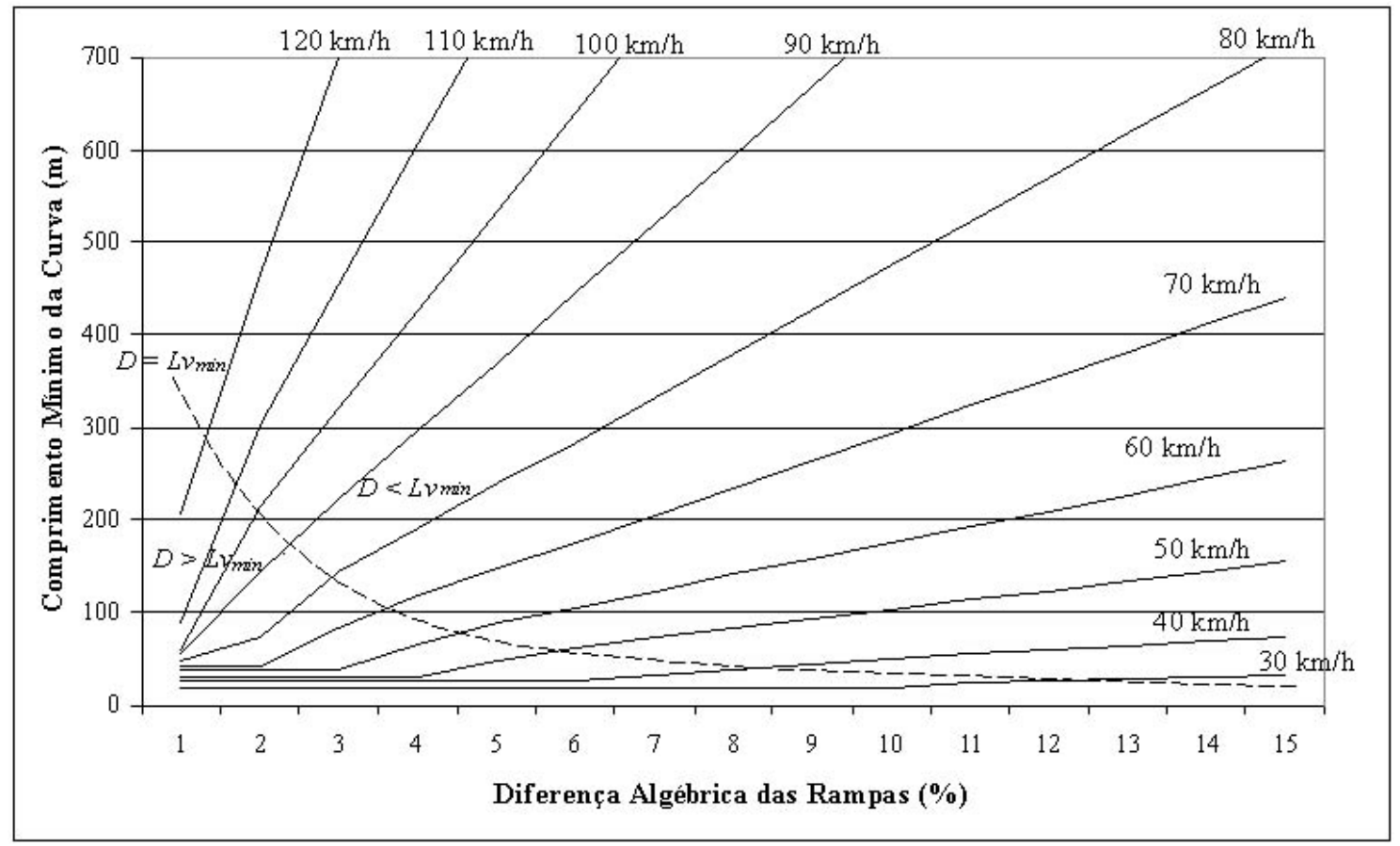

Figura 3.1: Comprimento Mínimo das Curvas Verticais Convexas, Calculado com Base nos Veículos de Passeio $\left(\mathrm{h}_{1}=1,1 \mathrm{~m}\right)$. 


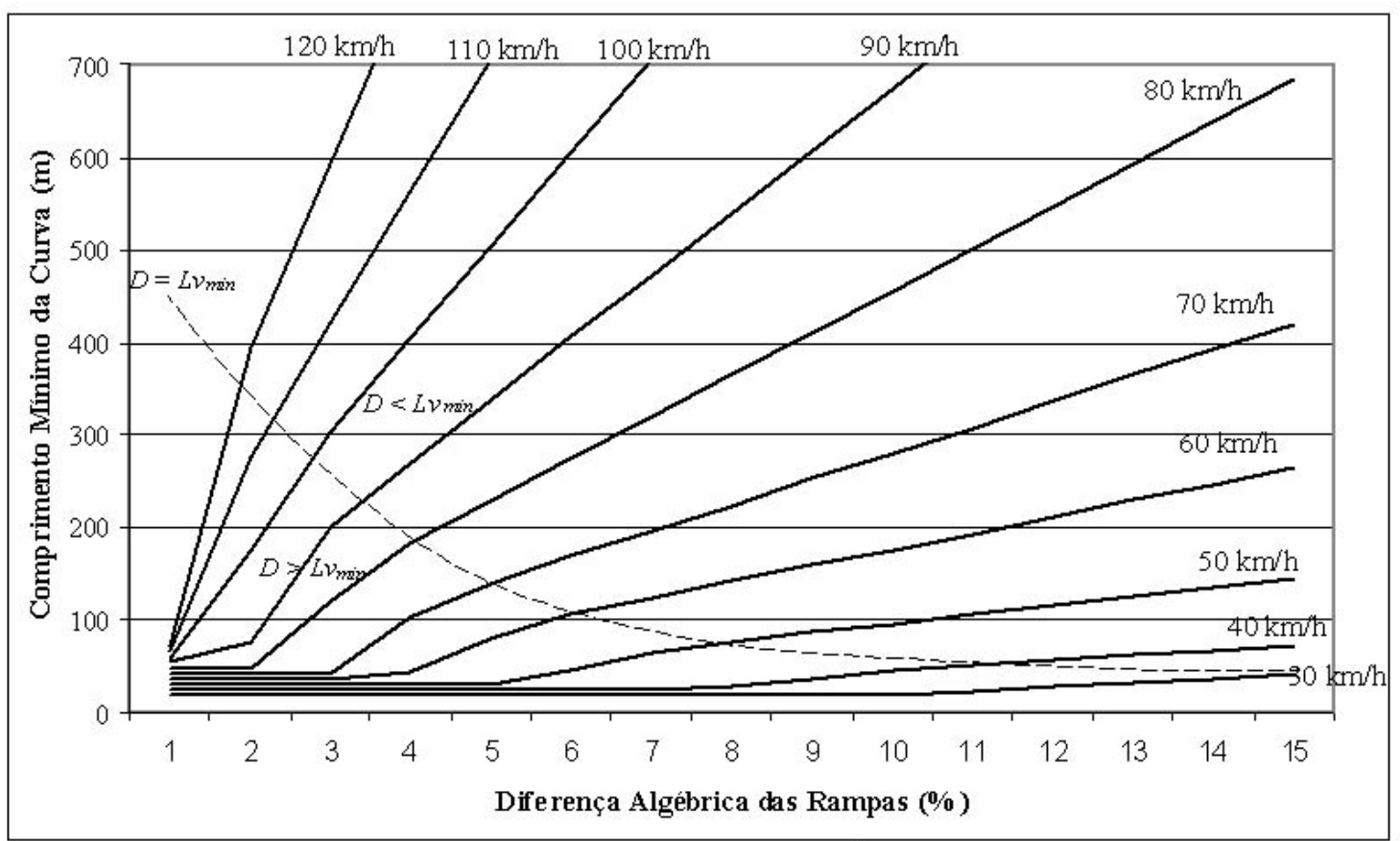

Figura 3.2: Comprimento Mínimo das Curvas Verticais Convexas, Calculado com Base em Caminhões $\left(h_{1}=2,4 \mathrm{~m}\right)$.

Os valores observados nos gráficos mostram que, de um modo geral, não existe compensação da maior altura de visão dos veículos de carga ante suas maiores distâncias de frenagem, se admitida a majoração de $40 \%$ nas distâncias de frenagem dos caminhões. A análise de sensibilidade, contudo, mostrou que se esta majoração for da ordem de $30 \%$, os valores de $K_{\min }$ são os mesmos, tanto para os veículos de passeio como de carga, revelando que, também para as curvas verticais convexas $\left(D>L v_{\min }\right)$, desde que admitida uma redução nas margens de segurança, podem ser calculados comprimentos mínimos com base em veículos de passeio.

\subsubsection{Distância de Visibilidade em Curvas Horizontais}

Obstáculos, como, por exemplo, taludes, em trechos com curvas horizontais, podem obstruir as condições de visibilidade dos veículos, como ilustrado na Figura 3.3. A distância de visibilidade disponível está condicionada ao raio da curva horizontal e ao afastamento entre o obstáculo e a via. Para garantir condições mínimas de segurança, ela deve ser igual à distância de visibilidade de frenagem. 

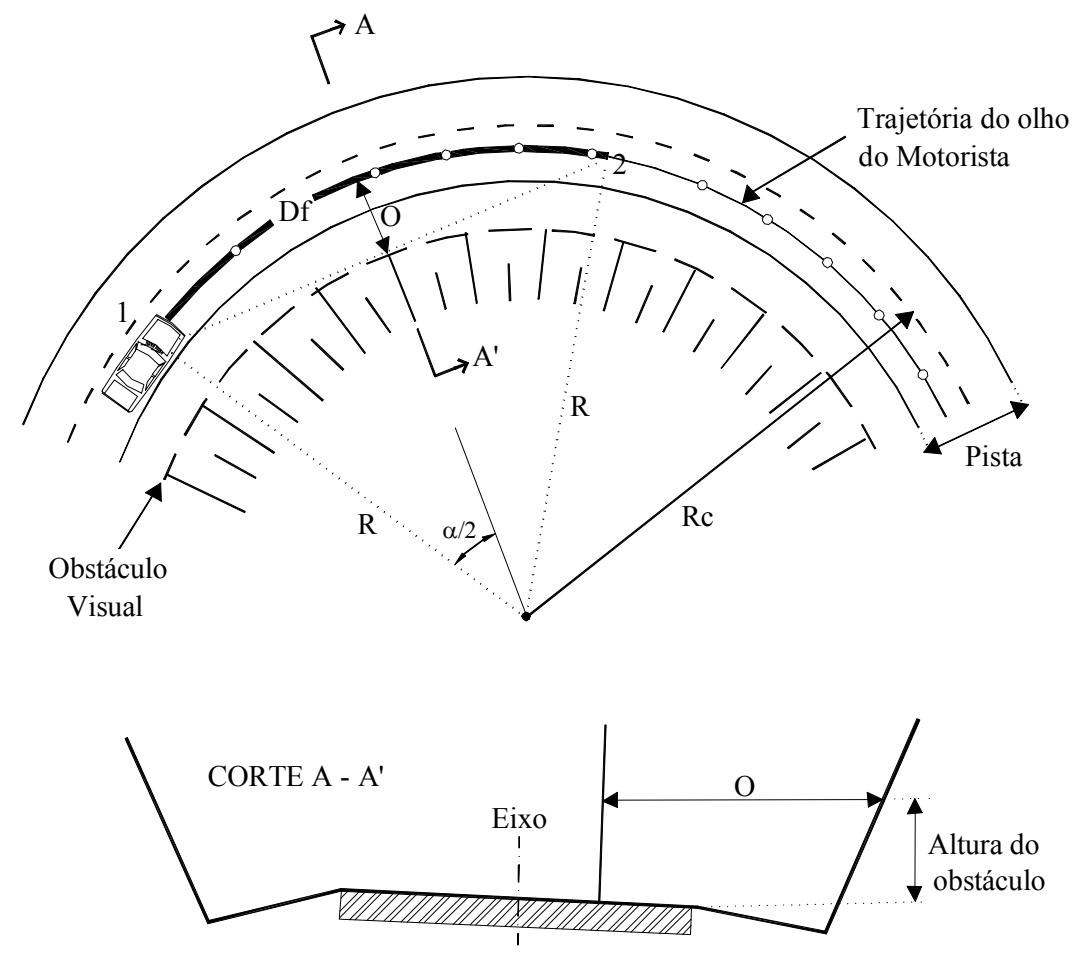

Figura 3.3: Distância de Visibilidade em Curva Horizontal. Fonte: Adaptado de Pontes Filho (1998).

Para determinados valores de raio da curva e distância de visibilidade de frenagem, pode-se determinar o afastamento lateral mínimo dos obstáculos nos trechos de curva horizontal (MCLEAN; TZIOTS; GUNATILLAKE, 2002), dado pela equação 3.6. O Esta distância é medida a partir do eixo da faixa de tráfego mais interna da curva horizontal e deve ser aplicada para os casos em que o desenvolvimento da curva circular é maior do que a distância de visibilidade de parada necessária.

$O=R_{c}\left[1-\cos \left(\frac{28,65 \cdot D_{f}}{R_{c}}\right)\right]$

onde:

$O=$ afastamento lateral mínimo $(\mathrm{m})$

$R_{C}=$ raio da curva horizontal $(\mathrm{m}) \approx R$, onde $R$ corresponde ao raio do eixo da faixa de tráfego interna 
$D_{f}=$ distância de visibilidade de parada $(\mathrm{m})$.

Para os veículos de passeio, um obstáculo com altura inferior a $0,75 \mathrm{~m}$ não obstrui a visibilidade (PIMENTA; OLIVEIRA, 2004). Para obstáculos maiores que este limite, porém, é necessário assegurar condições de visibilidade. Com uma altura de visão mais elevada, em torno de 2,4 m, os veículos de carga estão em posição vantajosa. Portanto, para obstáculos com altura ente $0,75 \mathrm{~m}$ e 2,4 m, o afastamento lateral mínimo pode ser estabelecido com base nos parâmetros dos veículos de passeio. Já para os obstáculos acima desta altura, situação que pode ocorrer por exemplo em curvas existentes em seções de corte, é recomendável utilizar afastamentos calculados com base nos veículos de carga, uma vez que a variável distância de visibilidade de parada destes veículos é maior.

Um aspecto importante que deve ser considerado na frenagem em curvas horizontais é a diminuição do atrito longitudinal na interface pneu-pavimento, provocando distâncias de frenagem maiores do que nos trechos em tangente. Esta redução da força de atrito longitudinal decorre do surgimento de outra componente, na transversal, como reação à força centrífuga nos trechos em curva. A equação proposta por Krempel (1965) estabelece relação entre os coeficientes destas duas forças, como mostram as equações 3.7 e 3.8. O fator de multiplicação da equação 3.8 procura considerar todas as influências específicas dos pneus.

$$
\begin{aligned}
& \left(\frac{f_{R}}{f_{R \max }}\right)^{2}+\left(\frac{f_{T}}{f_{T_{\max }}}\right)^{2} \leq 1 \\
& f_{R \max }=0.925 \cdot f_{T_{\max }}
\end{aligned}
$$

onde:

$f_{R}=$ fator de atrito disponível na direção radial (lateral)

$f_{R \max }=$ fator de atrito máximo na direção radial (lateral)

$f_{T}=$ fator de atrito disponível na direção tangencial 
$f_{T \max }=$ fator de atrito máximo na direção tangencial, que corresponde ao valor máximo para efeito de projeto.

O Manual da TAC aponta para acréscimos ainda menores, sendo utilizada a equação 3.8 (OLSON et al., 1984), que tem similaridade com a equação 3.7:

$$
f^{2}=f_{t}{ }^{2}-\left(\frac{V^{2}}{127 \cdot R}-e\right)^{2}
$$

onde:

$f=$ fator de atrito tangencial disponível para frenagem

$f_{t}=$ fator de atrito tangencial máximo da interface pneu-pavimento

$V=$ velocidade de projeto $(\mathrm{km} / \mathrm{h})$

$R=$ raio da curva horizontal $(\mathrm{m})$

$\mathrm{e}=$ superelevação $(\mathrm{m} / \mathrm{m})$.

Os resultados calculados com o uso da equação 3.9 para determinação do fator de atrito disponível para frenagem levaram à obtenção das distâncias de visibilidade de parada entre $3 \%$ a $9 \%$ superiores às distâncias obtidas para os trechos em tangente (TAC, 1999).

Para determinar os afastamentos laterais mínimos, foram tomados como base os valores do fator de atrito tangencial máximos permitidos, que são propostos no Manual do DNER e que variam de 0,40 para a velocidade de $30 \mathrm{~km} / \mathrm{h}$ e 0,27 para a velocidade de $120 \mathrm{~km} / \mathrm{h}$. Aplicando estes valores na equação 3.8, foi estimado o fator de atrito máximo na direção radial. A partir deste valor, juntamente com os fatores de atrito lateral adotados pelo DNER, foi determinado o fator de atrito disponível na direção tangencial por intermédio da equação 3.7. Foram, então, calculadas as distâncias de visibilidade (desejável e mínima) e os respectivos afastamentos laterais para as classes técnicas do DNER. 
Os resultados estão mostrados na Tabela 3.6. Comparando as distâncias de visibilidade de parada calculadas para as curvas horizontais, os valores se mostraram entre 3 e $11 \%$ superiores aos observados nos trechos em tangente. Observando então os afastamentos mínimos calculados com base nestas distâncias e os valores de afastamento recomendados no Manual do DNER, onde não são consideradas as perdas de atrito longitudinal na curva, são observadas diferenças que variam até $3 \mathrm{~m}$. A Tabela 3.5 mostra também os afastamentos laterais para as distâncias de visibilidade dos caminhões. Neste caso, foi utilizado o fator 1,4 proposto por Olson et al. (1984) sobre as distâncias de visibilidade dos automóveis em trechos tangentes, valores que convergem com os resultados obtidos na pesquisa de Widmer (2002), admitindo-se ainda que este fator seja suficiente também para compensar o fenômeno de redução do atrito tangencial nas curvas.

Tabela 3.6: Valores de Afastamento Lateral Mínimo em Curvas Horizontais para os Parâmetros Mínimos das Classes de Projeto do DNER.

\begin{tabular}{|c|c|c|c|c|c|c|c|c|c|c|c|c|c|}
\hline \multirow[t]{2}{*}{$\begin{array}{c}\text { RODOVIA } \\
\text { Classe } \\
\text { (Relevo) }\end{array}$} & \multirow[t]{2}{*}{$\begin{array}{c}\mathrm{V}_{\mathrm{P}} \\
(\mathrm{km} / \mathrm{h})\end{array}$} & \multirow[t]{2}{*}{$\underset{\text { Vproj }}{f_{\mathrm{T}}}$} & \multirow[t]{2}{*}{$\underset{\text { Vmed }}{f_{\mathrm{T}}}$} & \multicolumn{2}{|c|}{$\begin{array}{c}\text { DVP NA } \\
\text { CURVA } \\
\text { AUTO } \\
(\mathrm{m})\end{array}$} & \multicolumn{2}{|c|}{$\begin{array}{c}\text { DVP } \\
\text { NA CURVA } \\
\text { VEÍCULOS } \\
\text { DE CARGA } \\
(\mathrm{m}) \\
\end{array}$} & \multicolumn{2}{|c|}{$\begin{array}{l}\text { AFAST. } \\
\text { LATERAL } \\
\text { DNER } \\
(\mathrm{m})\end{array}$} & \multicolumn{2}{|c|}{$\begin{array}{c}\text { AFAST. } \\
\text { LATERAL } \\
\text { AUTO } \\
(\mathrm{m})\end{array}$} & \multicolumn{2}{|c|}{$\begin{array}{l}\text { AFAST. } \\
\text { LATERAL } \\
\text { CAM. } \\
(\mathrm{m})\end{array}$} \\
\hline & & & & Mín. & Des. & Mín. & Des. & Mín. & Des. & Mín. & Des. & Mín. & Des. \\
\hline $0(\mathrm{P})$ & 120 & 0,24 & 0,28 & 210 & 320 & 290 & 445 & 10 & 21 & 10 & 23 & 19 & 45 \\
\hline $0(\mathrm{O})$ & 100 & 0,24 & 0,27 & 170 & 235 & 240 & 325 & 9 & 16 & 10 & 19 & 20 & 38 \\
\hline $0(\mathrm{M})$ & 80 & 0,26 & 0,27 & 120 & 155 & 170 & 215 & 7 & 12 & 9 & 14 & 17 & 27 \\
\hline $\mathrm{I}(\mathrm{P})$ & 100 & 0,24 & 0,27 & 170 & 235 & 240 & 325 & 9 & 16 & 10 & 19 & 20 & 38 \\
\hline $\mathrm{I}(\mathrm{O})$ & 80 & 0,26 & 0,27 & 120 & 155 & 170 & 215 & 7 & 12 & 9 & 14 & 17 & 27 \\
\hline $\mathrm{I}(\mathrm{M})$ & 60 & 0,29 & 0,30 & 80 & 95 & 110 & 130 & 6 & 7 & 6 & 8 & 11 & 16 \\
\hline $\mathrm{II}(\mathrm{P})$ & 100 & 0,24 & 0,27 & 170 & 235 & 240 & 325 & 8 & 15 & 10 & 18 & 19 & 35 \\
\hline $\mathrm{II}(\mathrm{O})$ & 70 & 0,26 & 0,28 & 100 & 125 & 140 & 175 & 6 & 9 & 7 & 11 & 14 & 21 \\
\hline $\mathrm{II}(\mathrm{M})$ & 50 & 0,30 & 0,31 & 60 & 70 & 85 & 95 & 6 & 7 & 6 & 7 & 10 & 14 \\
\hline $\mathrm{III}(\mathrm{P})$ & 80 & 0,26 & 0,27 & 120 & 155 & 170 & 215 & 7 & 11 & 8 & 13 & 15 & 24 \\
\hline $\mathrm{III}(\mathrm{O})$ & 60 & 0,29 & 0,30 & 80 & 95 & 110 & 130 & 6 & 7 & 6 & 8 & 11 & 16 \\
\hline III(M) & 40 & 0,32 & 0,33 & 45 & 50 & 65 & 70 & 5 & 5 & 5 & 6 & 9 & 11 \\
\hline $\mathrm{IV}(\mathrm{P})$ & 60 & 0,29 & 0,30 & 80 & 95 & 110 & 130 & 6 & 7 & 6 & 8 & 11 & 16 \\
\hline $\mathrm{IV}(\mathrm{O})$ & 40 & 0,31 & 0,33 & 45 & 50 & 65 & 70 & 5 & 5 & 5 & 6 & 9 & 11 \\
\hline $\operatorname{IV}(\mathrm{M})$ & 30 & 0,34 & 0,34 & 30 & 30 & 45 & 45 & 4 & 4 & 5 & 5 & 9 & 9 \\
\hline
\end{tabular}

A decisão acerca de qual destes valores de afastamento lateral apresentados na Tabela 3.5 deve ser utilizado no projeto de curvas horizontais deve levar em conta aspectos como segurança e economia, restando também outras soluções, como a 
elevação do raio da curva e a redução da velocidade de projeto do trecho em curva considerado.

\subsubsection{Distância de Visibilidade de Ultrapassagem}

Nas rodovias de pista simples, a realização de ultrapassagens é condicionada, entre outros aspectos, à existência de distâncias de visibilidade que permitam ao veículo que trafega em maior velocidade visualizar, na faixa de tráfego oposta, um trecho da via com espaço suficiente para ultrapassar veículos mais lentos com segurança, sem interferir na velocidade de veículos da faixa de fluxo oposto. Esta extensão de via é chamada distância de visibilidade de ultrapassagem e depende essencialmente da velocidade de projeto da via, da velocidade relativa entre os veículos e de seus comprimentos. Assim, a participação das CVCs no tráfego veicular é uma questão importante a ser analisada quanto à segurança viária. Ainda que a malha rodoviária ofereça vias de elevado padrão técnico, com faixas múltiplas de tráfego, a operação destes veículos não ocorre exclusivamente nestas vias, uma vez que sua circulação permanece existindo em rodovias de pista simples, que garantem acessibilidade a terminais de carga, armazéns e outros pontos de origem e destino das viagens.

Existe ainda a influência de outros fatores nos processos de ultrapassagem, relacionados ao comportamento dos motoristas, como a decisão por concluir ou abortar uma ultrapassagem em face do surgimento de um veículo na faixa de tráfego oposta e ainda aspectos inerentes aos veículos como a altura de visão do motorista, sua capacidade de aceleração e frenagem. Vários aspectos devem ser considerados quanto à interação dos veículos no tráfego e as implicações no comportamento dos motoristas. Gattis, Alguire e Townsend (1997) e Romana (1999) verificaram aumento na quantidade de ultrapassagens quando a brecha entre os veículos se reduz a valores inferiores a $3 \mathrm{seg}$. Existem várias situações que podem resultar nesta redução, como a existência de veículos de carga com pequena capacidade de aceleração e velocidade, valendo ressaltar que esta característica está associada diretamente à relação potência/massa dos veículos, não obrigatoriamente guardando relação com a existência de CVCs no tráfego. Outra situação que pode resultar na elevação das ultrapassagens é a regulamentação de velocidades diferenciadas para o tráfego de veículos de passeio e 
carga. Esta prática, adotada em algumas rodovias brasileiras, é citada por alguns autores como responsável inclusive pela elevação no número de acidentes (STOKES; MCCASLAND, 1986).

O fluxo de veículos na faixa de tráfego oposta exerce importante influência quanto ao tipo de ultrapassagem realizada, repercutindo no impacto das CVCs nos processos de ultrapassagens. Quando este fluxo é pequeno, cresce o número de oportunidades para a realização de flying passes, isto é, manobras nas quais o veículo que realiza a ultrapassagem não reduz sua velocidade ao se aproximar do veículo a ser ultrapassado, permitindo assim transpor o veículo mais lento com maior velocidade relativa. Nestes casos, a maior extensão das CVCs tem menor impacto nas distâncias de ultrapassagem necessárias. À medida que se eleva o fluxo de tráfego na corrente oposta, este tipo de manobra se torna mais raro, dando lugar a ultrapassagens do tipo delayed pass, em que o veículo reduz sua velocidade a um valor semelhante à do veículo a ser ultrapassado, seguindo este veículo até obter uma oportunidade de realizar a manobra. Nesta situação, a maior dimensão dos veículos longos tem repercussões maiores nos processos de ultrapassagem, uma vez que demandará maior tempo de exposição na faixa de tráfego oposta, elevando o risco de fracasso da ultrapassagem. Kaub (1990) verificou, a partir de observações no comportamento de ultrapassagens nos Estados Unidos, que, quando o fluxo no sentido oposto aumenta da faixa de 285 a 435 veículos/hora para 400 a 590 veículos/hora, o número de tentativas de ultrapassagens se reduz em $76 \%$ e o de ultrapassagens abortadas sobe de $0,8 \%$ para $7 \%$, revelando a importante influência desta variável.

O cálculo das distâncias de visibilidade de ultrapassagem utilizadas nas rodovias de pista simples, constante nos manuais de projeto geométrico, não leva em consideração aspectos como os volumes de tráfego e suas implicações, sendo estas questões relacionadas mais propriamente à capacidade e ao nível de serviço da via. Como pode ser concluído, entretanto, para avaliar os reais impactos das CVCs no tráfego, é importante recorrer a modelos de ultrapassagem que considerem, dentre outros aspectos, os volumes de tráfego. Hanley e Forkenbrock (2005) propuseram um modelo incorporando esta variável, além de outras, como o comportamento do motorista e o comprimento e desempenho dos veículos. Foi utilizado um modelo 
estocástico, mais apropriado à natureza probabilística das variáveis consideradas, em vez da adoção de valores médios para os parâmetros considerados. Os resultados apontaram para uma elevação significativa das distâncias de ultrapassagem envolvendo caminhões, à medida que seus comprimentos são maiores, especialmente quando os volumes de tráfego na faixa oposta são elevados. Este tipo de análise é uma ferramenta importante para mensurar os impactos observados em determinado trecho de rodovia diante da operação de veículos longos, orientando assim a autorização ou não para o tráfego de CVCs.

Em se tratando dos aspectos relacionados estritamente ao projeto geométrico da via, a AASHTO estabeleceu um critério para o cálculo da distância de visibilidade de ultrapassagem, que tem se mantido inalterado desde a publicação em 1965, sendo utilizado por diversos países, inclusive o Brasil. Este critério é embasado nos resultados de pesquisas de campo realizadas entre 1938 e 1941 e que foram revalidados em 1958 (HARWOOD; TORBIC; RICHARD, 2003). Esses estudos resultaram, após uma série de observações do comportamento dos motoristas durante manobras de ultrapassagem, na formação de quatro grupos de velocidades, sendo validados valores para parâmetros como taxas de aceleração e espaços de segurança em cada grupo estudado. Pelo modelo da AASHTO, são identificadas quatro distâncias no processo de ultrapassagem:

(a) $d_{1}=$ abrange a distância percorrida durante o tempo de percepção e reação do motorista que realiza a ultrapassagem e também durante o processo de aceleração inicial do veículo até a ocupação da faixa de tráfego oposta;

(b) $d_{2}=$ abrange a distância percorrida pelo veículo na faixa de tráfego oposta;

(c) $d_{3}=$ espaço de segurança entre o veículo que concluiu a ultrapassagem e o veículo que se aproxima na faixa de tráfego oposta; e

(d) $d_{4}=$ abrange a distância percorrida pelo veículo que trafega na faixa de tráfego oposta durante a ocupação desta para a realização da ultrapassagem, sendo adotado um valor igual a $2 / 3 \mathrm{~d}_{2}$.

A AASHTO estabelece o critério de que as ultrapassagens são abortadas apenas quando o veículo avista a aproximação de outro veículo vindo em sua direção, antes de ter completado $1 / 3$ da distância total que percorreria na faixa de tráfego oposta. Esta suposição é bastante criticada, em razão do seu conservadorismo. É considerada 
também uma velocidade relativa de $15 \mathrm{~km} / \mathrm{h}$ entre o veículo que realiza a ultrapassagem e o veículo que é ultrapassado, sendo admitida uma taxa de aceleração entre 2,25 e 2,41 $\mathrm{km} / \mathrm{h} / \mathrm{s}$. Para velocidades operacionais de 50 e $110 \mathrm{~km} / \mathrm{h}$, as distâncias de ultrapassagem calculadas variam entre 317 e 726 m (AASHTO, 2004), sendo considerada sempre uma manobra realizada entre veículos de passeio e do tipo delayed pass.

Além da distância de visibilidade de ultrapassagem, critério considerado no projeto geométrico, visando a oferecer oportunidades de ultrapassagem aos veículos em rodovias de pista simples, existe outro aspecto, relacionado à demarcação de zonas de proibição e permissão de ultrapassagem, que orienta os motoristas quando estas manobras podem ser executadas com segurança. O critério de demarcação destas zonas, estabelecido pela Federal Highway Administration (FHWA) no Manual on Uniform Traffic Control Devices for Streets and Highways (MUTCD), não utiliza os valores de distância de visibilidade recomendados pela AASHTO (2004), propondo outras distâncias, com base no $85^{\circ}$ percentil de velocidades em vez da velocidade de projeto, mas não esclarece como estas distâncias foram obtidas. Estes valores considerados no MUTCD correspondem exatamente aos valores outrora adotados pela AASHTO (AASHTO, 1940), que estabelecia parâmetros para a demarcação de zonas de ultrapassagem com base em valores ajustados envolvendo ultrapassagens do tipo flying pass e delayed pass (FHWA, 2003). As distâncias assim obtidas resultaram em valores significativamente menores do que os propostos atualmente pela AASHTO. No Brasil, a demarcação destas zonas, estabelecida no Manual de Sinalização Rodoviária (DNER, 2000), estabelece valores ainda menores do que o proposto pela MUTCD, onde é considerada uma distância de visibilidade correspondente à dupla distância de visibilidade de parada. Já o Manual de Sinalização Rodoviária do DER-SP segue a recomendação das distâncias de visibilidade propostas pelo MUTCD (DER-SP, 2006).

A definição das zonas de ultrapassagem inicia-se com a demarcação das zonas de proibição, e estas correspondem aos trechos da via onde o motorista não terá uma distância de visibilidade à sua frente bastante para a realização de uma ultrapassagem segura. Os trechos restantes correspondem às zonas de ultrapassagem permitida. Portanto, considerando o estabelecido pela MUTCD, um motorista pode iniciar uma ultrapassagem em qualquer ponto de segmento com ultrapassagem permitida, pois 
haverá espaço suficiente para concluir a manobra com segurança, mesmo que parte desta manobra ocorra em zona de proibição. Assim a zona de proibição é na verdade impeditiva para se dar início a novas ultrapassagens e não à concretização das ultrapassagens iniciadas anteriormente.

O modelo da AASHTO, assim como o considerado pela MUTCD para a determinação das distâncias de visibilidade, é alvo de críticas, seja pelo fato de estar validado em dados obtidos há cerca de 50 anos, estando desatualizado diante das intensas inovações na tecnologia dos veículos ao longo deste período, mas especialmente por não considerar ultrapassagens envolvendo veículos longos. Vários estudos independentes foram publicados a partir de 1970, questionando as premissas utilizadas neste modelo e sugerindo correções em seus valores, como, por exemplo, os trabalhos desenvolvidos por Weaver e Glennon (1971), van Valkenburg e Michael (1971), Harwood e Glennon (1976) e Lieberman (1982). Esses estudos incorporaram o conceito de ponto crítico, também chamado de ponto sem retorno, para o cálculo da distância de visibilidade de ultrapassagem. Este ponto pode ser definido como a posição ocupada pelo veículo que realiza a ultrapassagem, de forma que as distâncias de visibilidade requeridas para abortar a ultrapassagem ou para concluí-la são iguais (HARWOOD; GLENNON, 1976). Admitindo que o motorista só tome a decisão pela conclusão ou não da ultrapassagem ao atingir o ponto crítico, são obtidas menores distâncias de ultrapassagem do que os valores propostos pela AASHTO. Até então, os modelos não consideravam explicitamente a influência do comprimento dos veículos longos nos processos de ultrapassagem, até que Glennon (1988) propôs um novo modelo considerando esta variável. Neste modelo são admitidas as seguintes suposições:

(a) a decisão por abortar uma ultrapassagem prolonga-se até a posição crítica, sendo considerada a distância de visibilidade de ultrapassagem a partir deste ponto;

(b) foram adotadas velocidades relativas variáveis entre o veículo que realiza a ultrapassagem e o veículo ultrapassado. Este valor é determinado em função da velocidade de projeto e foi obtido com base em observações em campo;

(c) a distância percorrida pelo veículo que realizará a ultrapassagem durante o tempo de percepção e aceleração inicial é o espaço referente ao tempo de $1 \mathrm{seg}$, 
considerando a velocidade relativa entre este veículo e o veículo que é ultrapassado. Esta suposição aproxima-se do conceito de flying pass;

(d) o veículo que realiza a ultrapassagem, assim como o que se aproxima na faixa de tráfego oposta, viajam na velocidade de projeto. No caso do veículo que realiza a ultrapassagem, é considerado que a velocidade de projeto é atingida no ponto crítico ou antes do mesmo;

(e) a taxa de desaceleração no caso de ultrapassagens abortadas é da ordem de 2,4 $\mathrm{m} / \mathrm{s}^{2}$.

As equações 3.10 e 3.11 são propostas no modelo de Glennon:

$$
\begin{aligned}
& \Delta_{C}=L_{P}+0,88 m\left[\frac{\left(0,54 m+L_{I}+L_{P}\right)}{0,88(2 V-m)}-\sqrt{\frac{0,73 V\left(0,54 m+L_{I}+L_{P}\right)}{1,97 d(2 V-m)}}\right] \\
& P S D_{C}=1,2 V\left[0,89+\frac{L_{P}-\Delta_{C}}{0,6 m}\right]
\end{aligned}
$$

onde:

$\Delta_{C}=$ separação crítica, que consiste na distância entre a frente do veículo que realiza a ultrapassagem e a frente do veículo que é ultrapassado no instante da posição crítica (m) $P S D_{C}=$ distância de visibilidade de ultrapassagem crítica (m) $V=$ velocidade do veículo que ultrapassa e do veículo no sentido oposto do tráfego $(\mathrm{km} / \mathrm{h})$, assumidas como idênticas

$m=$ diferencial de velocidade entre o veículo que ultrapassa e o veículo que é ultrapassado $(\mathrm{km} / \mathrm{h})$

$d=$ taxa de desaceleração utilizada para abortar a ultrapassagem $\left(\mathrm{m} / \mathrm{s}^{2}\right)$

$\mathrm{L}_{\mathrm{P}}=$ comprimento do veículo que realiza a ultrapassagem $(\mathrm{m})$

$\mathrm{L}_{\mathrm{I}}=$ comprimento do veículo que é ultrapassado (m). 
Dentre as críticas a este modelo está o fato de as suposições utilizadas consistirem em situações difíceis de se observar no tráfego (HARWOOD; TORBIC; RICHARD, 2003). De acordo com Glennon, porém, suas suposições também são aplicáveis a situações ordinárias de ultrapassagem, por serem compensadas pelos valores conservadores utilizados para as taxas de desaceleração e para a velocidade diferencial considerada entre o veículo que realiza a ultrapassagem e o que é ultrapassado. Posteriormente ao modelo de Glennon, Rillet, Hutchinson e Whitney (1990) propuseram um modelo mais complexo, alterando algumas das suposições propostas por Glennon. Nesse modelo, foram estabelecidas velocidades mínimas para o veículo que aborta a ultrapassagem retornar à sua faixa de tráfego, além de ser considerado também no cálculo da distância de visibilidade uma parcela referente à distância percorrida pelo veículo antes de atingir o ponto crítico. Outra diferença proposta neste modelo é considerar que o veículo que realiza a ultrapassagem pode atingir a velocidade de projeto após o ponto crítico. Assumidas estas suposições, obteve-se um modelo bastante complexo, que não admite uma solução analítica, sendo resolvido por interação em virtude do resultado obtido depender da velocidade assumida no ponto crítico, como observou Machado Neto (1995).

Para a abordagem proposta neste trabalho, será realizada uma análise de sensibilidade, conforme propuseram Harwood, Torbic e Richard (2003), considerando as distâncias de visibilidade obtidas mediante o Modelo de Glennon para automóveis e caminhões, adaptando o comprimento dos veículos para os valores admitidos na frota brasileira. A Tabela 3.7 apresenta os valores obtidos para as distâncias de visibilidade de ultrapassagem. No caso de ultrapassagens realizadas por caminhões, dada a inexistência de dados de velocidades destes veículos nestas manobras, foi utilizada uma versão ajustada do modelo de Glennon (HARWOOD; TORBIC; RICHARD, 2003), sendo admitida a idéia de que o diferencial de velocidade entre os caminhões e o veículo ultrapassado corresponde à metade do valor observado quando a ultrapassagem é realizada por veículos de passeio. Para tanto, foram mantidas as velocidades do veículo ultrapassado e do veículo no sentido de tráfego oposto, reduzindo a velocidade do veículo que realiza a ultrapassagem uma fração de m/2, como ilustra a Figura 3.4. Desta forma, a variável $\mathrm{V}$ das equações 3.10 e 3.11 é substituída pelo termo $0,5\left(\mathrm{~V}_{\mathrm{p}}+\right.$ $\mathrm{V}_{\mathrm{o}}$ ), onde $\mathrm{V}_{\mathrm{p}}$ é a velocidade do veículo que realiza a ultrapassagem e $\mathrm{V}_{\mathrm{o}}$ é a velocidade 
do veículo no sentido oposto. Outro ajuste utilizado foi a adoção de uma taxa de desaceleração menor, de $1,5 \mathrm{~m} / \mathrm{s}^{2}$ para os caminhões (HARWOOD; TORBIC; RICHARD, 2003). Os valores foram calculados para um veículo com $30 \mathrm{~m}$ de comprimento, representando a maior extensão de veículo homologado no Brasil.

Tabela 3.7: Comparação dos Valores de Distância de Visibilidade de Ultrapassagem Calculados pelo Modelo de Glennon e Outros Modelos

\begin{tabular}{cccccccc}
\hline \multirow{2}{*}{$\begin{array}{c}\text { VELOCIDADE } \\
\begin{array}{c}\text { DE PROJETO } \\
(\mathrm{km} / \mathrm{h})\end{array}\end{array}$} & $\begin{array}{c}\text { DNER } \\
(\mathrm{m})\end{array}$ & $\begin{array}{c}\text { AASHTO } \\
(\mathrm{m})\end{array}$ & $\begin{array}{c}\text { MUTCD } \\
(\mathrm{m})\end{array}$ & $\begin{array}{c}\text { Auto } \\
\text { ultrapassando } \\
\text { Auto } \\
(\mathrm{m})\end{array}$ & $\begin{array}{c}\text { Auto } \\
\text { ultrapassando } \\
\text { Caminhão } \\
(\mathrm{m})\end{array}$ & $\begin{array}{c}\text { Caminhão } \\
\text { ultrapassando } \\
\text { Auto } \\
(\mathrm{m})\end{array}$ & $\begin{array}{c}\text { Caminhão } \\
\text { ultrapassando } \\
\text { Caminhão } \\
(\mathrm{m})\end{array}$ \\
\hline 30 & & & & 83 & 85 & 86 & 118 \\
40 & 180 & 200 & - & 119 & 128 & 145 & 182 \\
50 & 270 & 270 & 140 & 154 & 168 & 195 & 244 \\
60 & 350 & 345 & 160 & 185 & 206 & 246 & 305 \\
70 & 420 & 410 & 180 & 219 & 245 & 296 & 366 \\
80 & 490 & 485 & 210 & 219 & 281 & 347 & 426 \\
90 & 560 & 540 & 245 & 249 & 319 & 397 & 486 \\
100 & 620 & 615 & 280 & 282 & 353 & 446 & 545 \\
110 & 680 & 670 & 320 & 309 & 386 & 495 & 603 \\
120 & 730 & 730 & 355 & 336 & 362 & 545 & 663 \\
\hline
\end{tabular}

1 - MODELO DE GLENNON - Automóvel realizando ultrapassagem

$\longrightarrow \mathrm{Vp}=\mathrm{VP} \longrightarrow \mathrm{Vu}=\mathrm{VP}-\mathrm{m} \quad-\quad \mathrm{Vo=}$

2 - MODELO DE GLENNON AJUSTADO - Caminhão realizando ultrapassagem

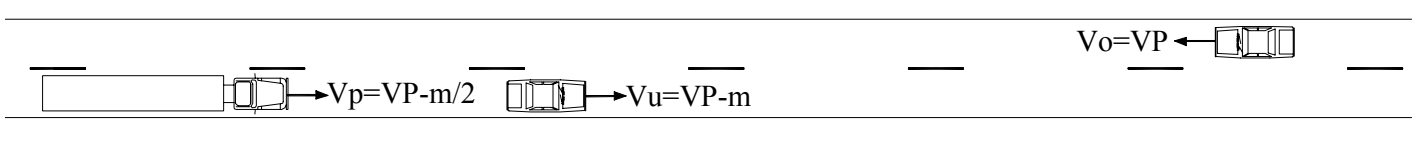

$\begin{aligned} \text { Obs: } \mathrm{VP} & =\text { Velocidade de projeto } \\ \mathrm{Vo} & =\text { Velocidade do veículo no sentido oposto } \\ \mathrm{Vp} & =\text { Velocidade do veículo que realiza a ultrapassagem } \\ \mathrm{Vu} & =\text { Velocidade do veículo que é ultrapassado }\end{aligned}$

Figura 3.4: Condições de Velocidade Assumidas Pelo Modelo de Glennon para a Ultrapassagem de Automóveis e Caminhões. 


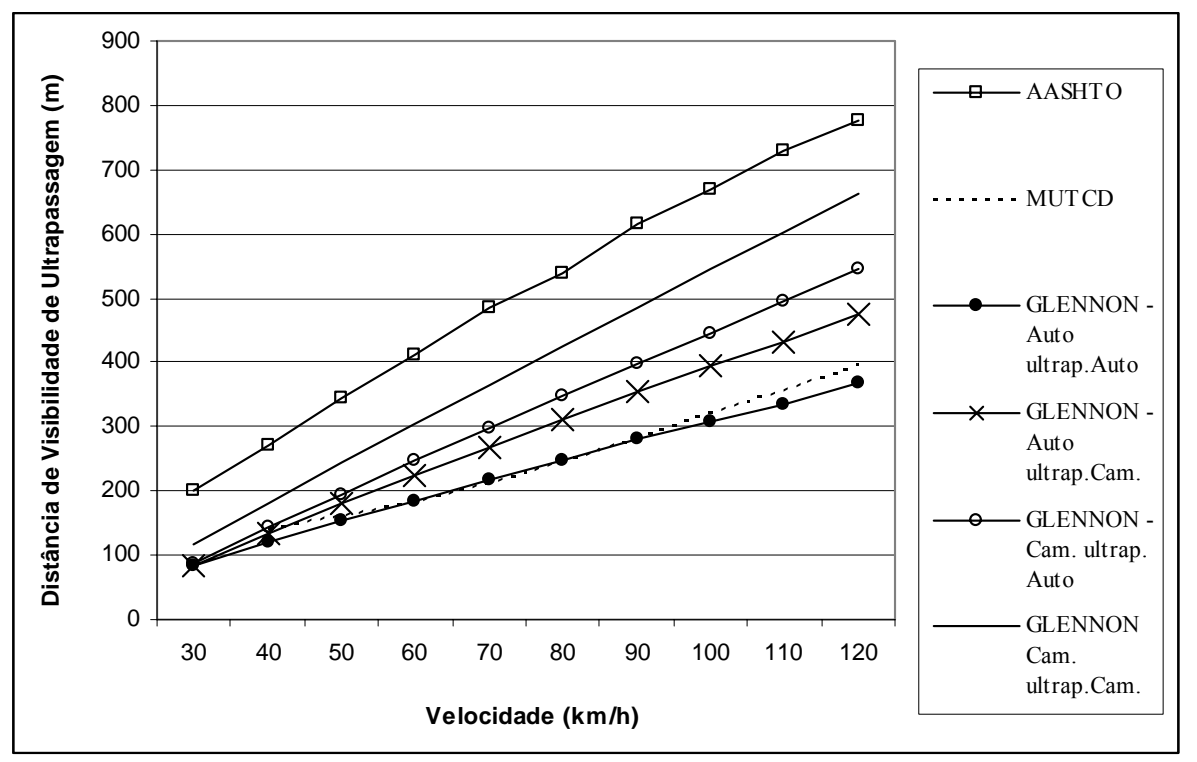

Figura 3.5: Comparação dos Valores de Distância de Visibilidade de Ultrapassagem Calculados pelo Modelo de Glennon e outros Modelos.

Como pode ser observado na Figura 3.5, os valores estabelecidos pela MUTCD são próximos daqueles propostos por Glennon para ultrapassagens entre automóveis, enquanto os demais tipos de ultrapassagem determinados por Glennon assumem valores progressivamente maiores. Mesmo para a situação mais crítica, ou seja, caminhões ultrapassando caminhões, são obtidos resultados significativamente inferiores aos propostos pela AASHTO para veículos de passeio. Esta constatação revela o caráter conservador do modelo da AASHTO e este é o argumento utilizado para se manter os padrões estabelecidos pela AASHTO como medida capaz de permitir uma ultrapassagem segura para outros tipos de veículo e não apenas para os veículos de passeio, como argumenta o Manual da TAC (TAC, 1999).

Fancher, Baretek e Russo (1995) analisaram os valores da distância de visibilidade de ultrapassagem com base em um modelo, que, conforme o proposto por Glennon, desconsidera a distância $\mathrm{d}_{1}$ do modelo da AASHTO, assemelhando-se à condição de flying pass. Na proposta de Fancher, não é considerada relevante a forma como o veículo chega ao ponto de início da ultrapassagem, sendo na realidade considerado como ponto inicial da análise o local onde o motorista toma a decisão de completar ou abortar a ultrapassagem. A abordagem utilizada permitiu comparar como se comportam as distâncias de visibilidade diante de mudanças em variáveis como os 
comprimentos dos veículos, as brechas consideradas entre o veículo que realiza a ultrapassagem e o veículo ultrapassado, a velocidade relativa entre os veículos e o espaço de segurança adotado entre o veículo que realiza a ultrapassagem e o veículo que se aproxima na faixa de tráfego oposta. Este tipo de análise é um instrumento importante para se comparar modelos reconhecidamente conservadores, como o modelo da AASHTO, com modelos menos conservadores, como o proposto por Glennon (1988), Liu e Herman (1996) e Wang e Cartmell (1998), trazendo à discussão os padrões de segurança admitidos, orientando a definição do cenário mais coerente com a situação real que deve ser considerada para a determinação das distâncias de ultrapassagem.

\subsubsection{Sobrelarguras}

Ao desenvolver uma curva, os veículos apresentam comportamento diferente do observado em trechos retos. As rodas dianteiras dos veículos não seguem a mesma trajetória das rodas traseiras, aumentando o espaço necessário para a execução de curvas, fenômeno denominado de arraste. A magnitude deste arraste aumenta para veículos com maior distância entre eixos e para curvas com raios menores. A sobrelargura é o recurso utilizado para proporcionar aos veículos maior espaço na faixa de tráfego, de forma a acomodá-los nas curvas, evitando a invasão de faixas adjacentes ou a colisão com obstáculos no entorno da via. Os veículos pesados, especialmente as combinações, apresentam normalmente piores condições de manobrabilidade, devendo, portanto, orientar o dimensionamento das sobrelarguras.

O comportamento dos veículos nas curvas ou conversões é ainda alvo da interferência da velocidade com que a manobra está sendo executada. Quando a manobra é realizada a baixa velocidade, as rodas do eixo traseiro seguem uma trajetória mais adentro da trajetória seguida pelo eixo dirigível, ocorrendo o chamado arraste positivo, como ilustra a Figura 3.6. Este comportamento do veículo é influenciado pela distância entre o pino-rei e o centro do eixo ou do grupo de eixos traseiros nos semireboques e conexões tipo B e pelo comprimento da barra de conexão entre unidades de conexão do tipo A (ver ilustração no Apêndice A). Para combinações de mais de um semi-reboque ou reboque, as conexões também influenciam este comportamento. 
Quando o veículo executa uma conversão a alta velocidade, é observada a tendência da traseira do veículo se mover para fora da trajetória descrita pelo eixo dirigível em virtude da influência da aceleração lateral, configurando o chamado arraste negativo. Este comportamento é influenciado pelo espaçamento entre os eixos, pela velocidade do veículo e pelo raio de curvatura. Russo (1995) desenvolveu amplo estudo do comportamento dos veículos em interseções, situação dominada pela ocorrência do arraste positivo, investigando a operação de onze tipos de veículos de carga, entre veículos unitários e CVCs em interseções reais e genéricas. Seu trabalho exprime a noção de que, para velocidades acima de $16 \mathrm{~km} / \mathrm{h}$, existe maior probabilidade da ocorrência do arraste negativo, o qual compensará em parte o arraste positivo. Diferentemente do observado nas interseções em nível, a velocidade nas curvas horizontais supera este valor, caracterizando a ocorrência do arraste negativo. Este arraste, em geral de menor amplitude do que o arraste positivo, não terá seus efeitos considerados na presente investigação, sendo admitida a idéia de que os espaços de segurança utilizados no cálculo das sobrelarguras são suficientes para compensar sua ocorrência. Neste trabalho, serão calculados os valores de sobrelargura exigidos por veículos que compõem a frota nacional, comparando-os aos valores obtidos com base nos veículos de projeto do DNER, verificando-se, como efeito, a existência de compatibilidade entre estes veículos.
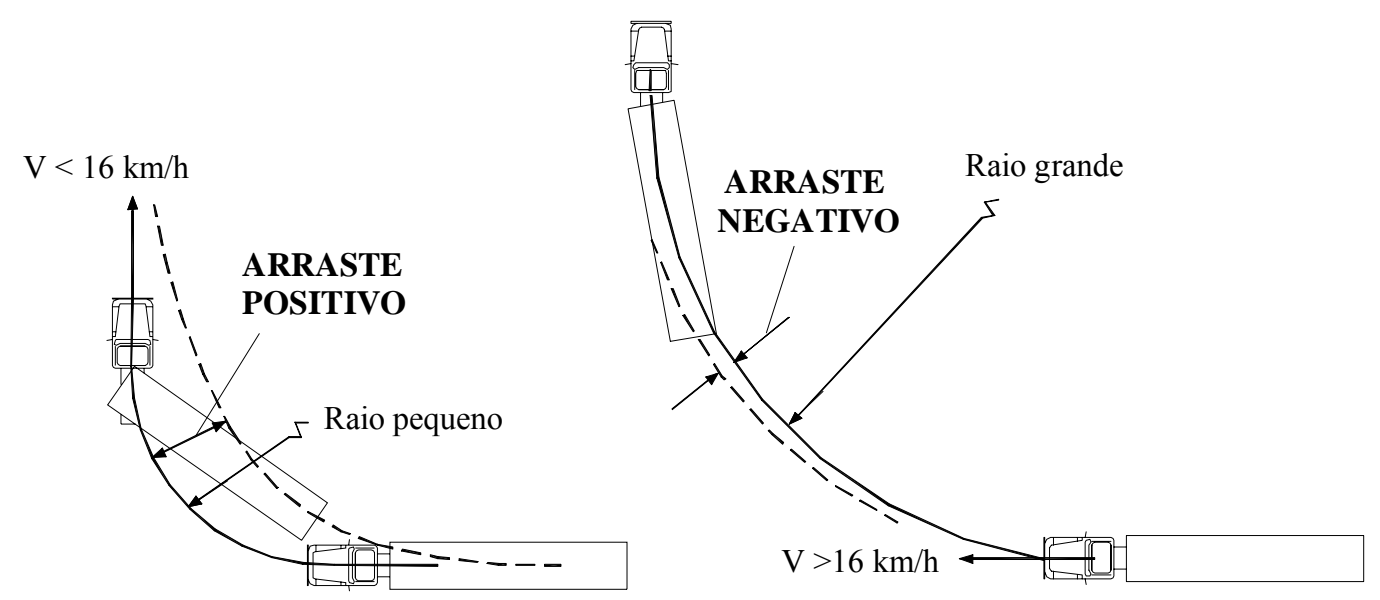

— Trajetória traçada pelo eixo dirigível

-_- Trajetória traçada pelo eixo traseiro

Figura 3.6: Tipos de Arraste Verificados em Caminhões Executando Conversões. Fonte: Adaptado de FHWA (2000). 
A largura total de uma pista no trecho em curva, bem como suas componentes estão ilustradas na Figura 3.7 e são expressas pelas equações 3.12 a 3.15. Estas equações utilizadas no Manual do DNER seguem as mesmas recomendações propostas pela AASHTO.

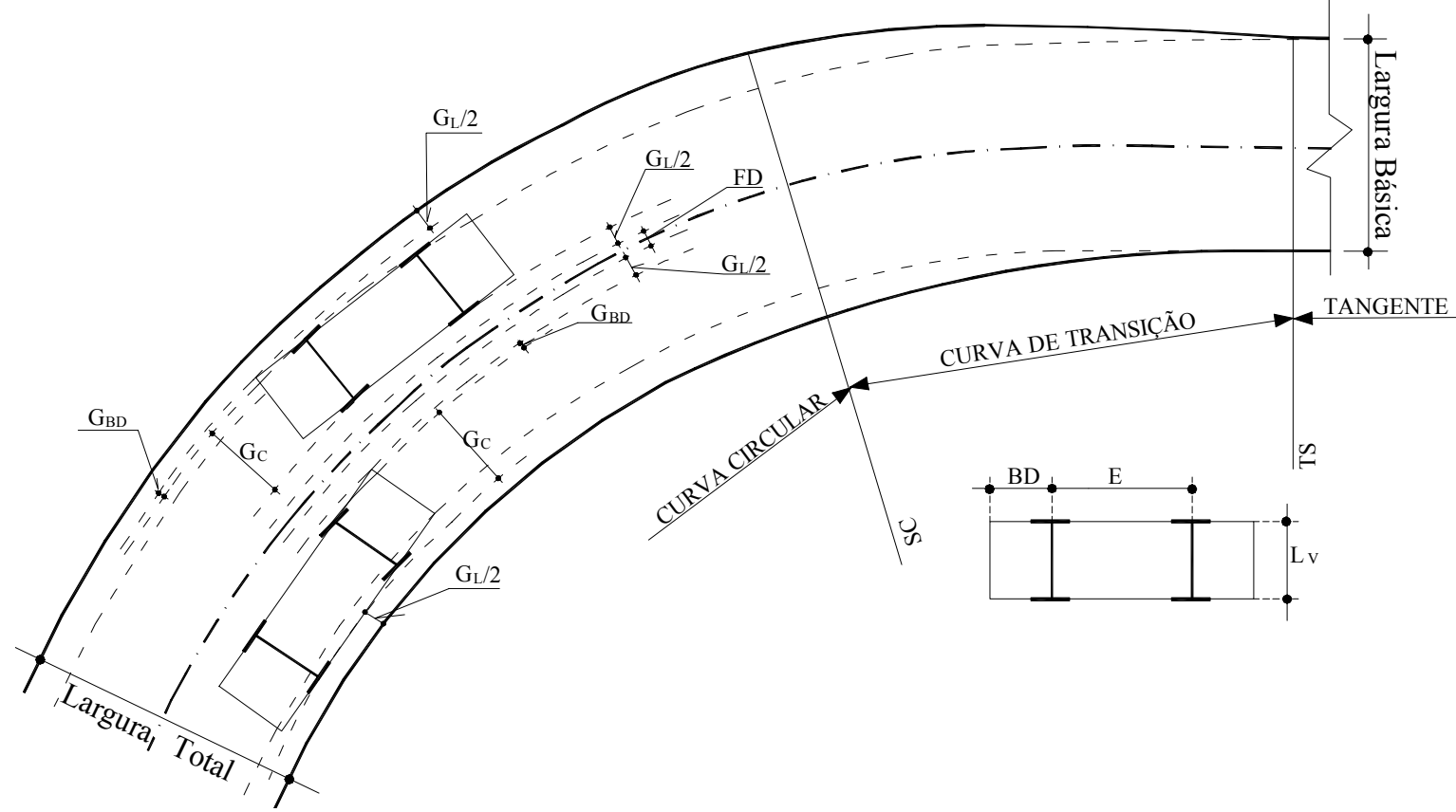

Figura 3.7: Componentes do Cálculo da Sobrelargura em Curvas Circulares.

Fonte: Adaptado de DNER (1999).

$$
\begin{aligned}
& L_{T}=\left[2\left(G_{C}+G_{L}\right)+G_{B D}\right]+F D \\
& G_{C}=L_{V}+\left(R-\sqrt{R^{2}-E^{2}}\right) \\
& G_{B D}=\sqrt{\left[R^{2}+B D(2 E+B D)\right]-R} \\
& F D=\frac{V}{10 \sqrt{R}}
\end{aligned}
$$


onde:

$L_{T}=$ Largura total no trecho em curva para uma pista com duas faixas de rolamento $(\mathrm{m})$

$G_{C}=$ Gabarito estático do veículo de projeto em curva (m)

$G_{L}=$ Gabarito (folga) lateral do veículo de projeto em movimento (m)

$G_{B D}=$ Gabarito requerido pelo percurso do balanço dianteiro do veículo de projeto em curva $(\mathrm{m})$

$F D=$ Folga dinâmica $(\mathrm{m})$

$L_{V}=$ Largura física do veículo de projeto (m)

$E=$ Distância entre eixos do veículo de projeto (m)

$R=$ Raio da curva $(\mathrm{m})$

$B D=$ Balanço dianteiro $(\mathrm{m})$

$V=$ Velocidade diretriz $(\mathrm{km} / \mathrm{h})$.

No caso do estudo de CVCs, a equação 3.13 deve ser substituída pela equação 3.16, conhecida como fórmula do WHI-SAE, utilizada admitindo-se a condição de curva em regime estacionário (WIDMER, 2002a).

$$
G_{C}=L_{V}+\left(R-\sqrt{R^{2}-\sum_{i=1}^{n} \pm\left(E_{i}^{2}\right)}\right)
$$

onde:

$E_{i}=$ i-ésima distância entre pontos notáveis do veículo, medidos a partir do ponto médio do eixo dianteiro do veículo trator e formando segmentos de retas que afetam a curva de arraste (m). O termo $E i^{2}$ recebe sinal positivo, quando o i-ésimo segmento contribui para o aumento da sobrelargura, e negativo caso contrário. 
$n$ = número de segmentos notáveis da composição.

Os valores utilizados para a componente $G_{L}$ são estabelecidos em função da largura da pista de rolamento, como mostra a Tabela 3.8.

Tabela 3.8: Valores do Gabarito Lateral do Veículo de Projeto em Movimento

\begin{tabular}{cc}
\hline LARGURA BÁSICA & GABARITO LATERAL \\
$\mathrm{L}_{\mathrm{B}}(\mathrm{m})$ & 0,60 \\
6,0 a 6,4 & 0,75 \\
6,6 a 6,8 & 0,90 \\
7,0 a 7,2 &
\end{tabular}

Observando a equação 3.12, têm-se duas variáveis relacionadas à varredura do veículo, $G_{C}$ e $G_{B D}$, e outras duas $G_{L}$ e FD, que irão compor os espaços de segurança. Para avaliar a compatibilidade dos veículos considerados com relação às sobrelarguras projetadas com base nos veículos de projeto do DNER, serão verificados os espaços de segurança, sendo admitida a utilização destas folgas para acomodar a sobrelargura adicional exigida pelos veículos mais complexos do que o veículo de projeto.

O espaço de segurança está relacionado à fricção lateral de que os veículos são objeto, quando em movimento, estando estreitamente associado às condições de segurança e conforto proporcionadas pela rodovia. Nos trechos em tangente, corresponde à diferença entre as larguras da faixa de tráfego e do veículo. Nos trechos em curva ele corresponde à soma das componentes da folga dinâmica (equação 3.15) e do gabarito lateral (Tabela 3.8). Os espaços de segurança nas diversas classes de rodovia, considerando suas condições técnicas mínimas e uma largura de 2,6 m dos veículos de carga, estão mostrados na Tabela 3.9 e são referentes às folgas disponíveis em cada lateral do veículo. 
Tabela 3.9: Espaço de Segurança dos Veículos nos Trechos em Tangente e nas Curvas

\begin{tabular}{llcc}
\hline \multirow{2}{*}{ CLASSE } & RELEVO & $\begin{array}{c}\text { ESPAÇO DE } \\
\text { SEGURANÇA } \\
\text { NAS RETAS (m) }\end{array}$ & $\begin{array}{c}\text { ESPAÇO DE } \\
\text { SEGURANÇA NAS } \\
\text { CURVAS (m) }\end{array}$ \\
\hline \multirow{3}{*}{ Classe 0 } & Plano & 0,50 & 0,58 \\
& Ondulado & 0,50 & 0,58 \\
& Montanhoso & 0,50 & 0,59 \\
\hline \multirow{3}{*}{ Classe I } & Plano & 0,50 & 0,58 \\
& Ondulado & 0,50 & 0,59 \\
Classe II & Montanhoso & 0,50 & 0,51 \\
& Plano & 0,50 & 0,58 \\
& Ondulado & 0,45 & 0,58 \\
\multirow{3}{*}{ Classe III } & Montanhoso & 0,35 & 0,51 \\
& Plano & 0,45 & 0,58 \\
& Ondulado & 0,35 & 0,51 \\
\multirow{2}{*}{ Classe IV } & Montanhoso & 0,35 & 0,52 \\
& Plano & 0,20 & 0,43 \\
& Ondulado & 0,20 & 0,44 \\
\hline
\end{tabular}

Para verificar a condição operacional dos veículos em uma curva horizontal, foi proposta a utilização de uma variável, que será denominada aqui de folga lateral efetiva $\left(F L_{E}\right)$. Esta variável consiste na diferença observada entre a varredura do veículo de projeto, considerado no cálculo da sobrelargura da curva, e a varredura do veículo investigado. Este resultado, somado ao espaço de segurança da classe de rodovia, determina a folga disponível nas laterais do veículo para este realizar a curva, conforme apresentado na equação 3.17 .

$$
F L_{E}=\frac{\left[\left(2 G_{C}+G_{B D}\right)_{V P}-\left(2 G_{C}+G_{B D}\right)_{V E}+(F D+2 G L)_{C L A S S E}\right]}{4}
$$

onde:

$F L_{E}=$ Folga Lateral Efetiva em cada lateral do veículo (m)

$\left(2 G_{C}+G_{B D}\right)_{V P}=$ Varredura do Veículo de Projeto na curva (m)

$\left(2 G_{C}+G_{B D}\right)_{V E}=$ Varredura do Veículo Estudado na curva (m)

$(F D+2 G L)_{C L A S S E}=$ Espaço de Segurança da classe de rodovia $(\mathrm{m})$. 
Para identificar a compatibilidade de um dado veículo com a sobrelargura numa curva, serão admitidos como limite mínimo para a folga lateral efetiva $\left(\mathrm{FL}_{\mathrm{E}}\right)$ os valores de espaço de segurança das rodovias de Classe IV-A, que variam entre 0,43 e 0,45 m, sendo considerado para a análise proposta o valor de $0,40 \mathrm{~m}$. Nos casos em que a folga lateral efetiva for igual ou superior a este valor, a rodovia será considerada compatível para o tráfego do veículo.

Nos demais casos, será considerada a utilização dos acostamentos para acomodar o veículo. Segundo Downs Junior e Wallace (1982), um acostamento deve possuir largura mínima de 0,6 m para ser utilizado com esta finalidade, condição que é atendida quando consideradas as larguras mínimas especificadas no Manual de projeto do DNER para qualquer classe de rodovia. Além da largura do acostamento, é necessário que este seja pavimentado e que não exista um desnível acentuado com relação ao pavimento das pistas de rolamento. A utilização de acostamentos que possuam degraus pode resultar numa elevação na aceleração lateral dos veículos que trafegam no lado externo das curvas, uma vez que a superelevação na curva é parcial ou totalmente anulada. Este fato pode comprometer a estabilidade lateral do veículo e elevar o risco da ocorrência de tombamento. Como estas duas exigências não são asseguradas para as classes de rodovia, o tráfego de veículos com uso do acostamento dependerá do atendimento destas condições. Portanto, nos casos em que há larguras de acostamento suficientes para acomodar o veículo, a via será considerada compatível, com restrições, dada a necessidade de avaliar a condição geral do acostamento. Nos casos em que a largura do acostamento for incapaz de acomodar o veículo, a rodovia será julgada incompatível.

\subsubsection{Estabilidade dos Veículos em Curvas Horizontais}

Os parâmetros das curvas horizontais são definidos com o objetivo de garantir uma condição de equilíbrio de forças que atuam no veículo ao longo de sua trajetória. Considerando o veículo como um corpo rígido desenvolvendo um movimento circular uniforme, tem-se a atuação da força de atrito lateral entre o pneu e o pavimento e a superelevação existente na curva, que irão promover a força centrípeta necessária para balancear a força inercial. Quando esta condição de equilíbrio é rompida, a resultante 
das forças deixa de ser nula, ocasionando dois possíveis tipos de instabilidade lateral: o escorregamento lateral ou o tombamento do veículo. Estudos da interface pneupavimento mostraram que os valores máximos do fator de atrito lateral, para a situação de pneus novos e pavimento molhado, variam entre 0,5 para a velocidade de $30 \mathrm{~km} / \mathrm{h}$ e 0,35 para a velocidade de $100 \mathrm{~km} / \mathrm{h}$ (AASHTO, 2004). Isto significa, que considerando apenas o fenômeno da derrapagem, numa pista sem superelevação, tem-se sua ocorrência caso a aceleração centrífuga ultrapasse os valores de $0,5 \mathrm{~g}$ ou $0,35 \mathrm{~g}(\mathrm{~g}$ corresponde à aceleração gravitacional) para as velocidades de $30 \mathrm{~km} / \mathrm{h}$ e $100 \mathrm{~km} / \mathrm{h}$, respectivamente. Com o objetivo de evitar o risco de derrapagens e ainda para proporcionar maior conforto ao motorista ao realizar uma curva, são estabelecidos valores máximos admissíveis para este fator de atrito.

Para o dimensionamento das curvas horizontais, são determinados valores de raio em função da velocidade de projeto, das superelevações utilizadas e de um valor de fator de atrito lateral admissível. A equação 3.18 representa esta equação de equilíbrio e é utilizada para a determinação de valores de raios mínimos (AASHTO, 2004):

$$
R_{\min }=\frac{V^{2}}{127\left(e_{\max }+f_{\max }\right)}
$$

onde:

$R_{\min }=$ raio mínimo da curva (m)

$V=$ velocidade do veículo $(\mathrm{km} / \mathrm{h})$

$e_{\max }=$ superelevação máxima admissível

$f_{\max }=$ fator de atrito lateral máximo admissível.

As análises aqui realizadas irão considerar esta situação mais crítica para avaliar os impactos, especialmente nos caminhões, embora os manuais de projeto geométrico recomendem a utilização de menores valores de atrito, em benefício do maior conforto e segurança dos motoristas. A AASHTO propõe a utilização de valores para $f_{\max }$ com base 
em veículos de passeio, cujos valores foram determinados em ensaios identificando o nível de aceleração lateral que causa a sensação de desconforto do motorista. Foram identificados nesses testes valores de fator de atrito lateral entre 0,15 e 0,21, dependendo das faixas de velocidade, garantido relativa margem de segurança, se comparados aos valores-limites de atrito para causar o escorregamento.

A Tabela 3.10 mostra os valores do fator de atrito lateral utilizados nos manuais de projeto geométrico. A AUSTROADS é a única das referências pesquisadas que faz distinção entre os valores utilizados para veículos de passeio e caminhões, onde são observados valores de $f$ para automóveis superiores aos atribuídos para os caminhões na faixa de velocidades entre 50 e $90 \mathrm{~km} / \mathrm{h}$.

Tabela 3.10: Fator de Atrito Lateral $f_{\max }$ Adotado no Projeto de Curvas Horizontais.

\begin{tabular}{cccccc}
\hline $\begin{array}{c}\text { VELOCIDADE } \\
(\mathrm{km} / \mathrm{h})\end{array}$ & AASHTO & DNER & TAC & \multicolumn{2}{c}{ AUSTROADS } \\
\cline { 5 - 6 } 15 & 0,40 & - & - & - & - \\
20 & 0,35 & - & - & - & - \\
30 & 0,28 & 0,20 & - & - & - \\
40 & 0,23 & 0,18 & 0,17 & - & - \\
50 & 0,19 & 0,16 & 0,16 & 0,30 & 0,21 \\
60 & 0,17 & 0,15 & 0,15 & 0,24 & 0,17 \\
70 & 0,15 & 0,15 & 0,15 & 0,19 & 0,14 \\
80 & 0,14 & 0,14 & 0,14 & 0,16 & 0,13 \\
90 & 0,13 & 0,14 & 0,13 & 0,13 & 0,12 \\
100 & 0,12 & 0,13 & 0,12 & 0,12 & 0,12 \\
110 & 0,11 & 0,12 & 0,10 & 0,12 & 0,12 \\
120 & 0,09 & 0,11 & 0,09 & 0,11 & 0,11 \\
130 & 0,08 & - & 0,08 & - & - \\
\hline Fontes: (AASHTO, 2004), (TAC, 1999), (DNER, 1999) e (AUSTROADS, 2002).
\end{tabular}

Ao considerar, por sua vez, o fenômeno de tombamento, a estabilidade lateral é expressa em termos da aceleração lateral-limite de tombamento $\left(a c_{\max }\right)$, em unidade de $g$ (aceleração em decorrência da gravidade), obtida a partir da equação (3.19) e corresponde à aceleração lateral, paralela à superfície da via, no princípio do tombamento do veículo.

$$
a c_{\max }=\frac{t}{2 h} g
$$

onde: 
$a c_{\max }=$ aceleração lateral limite de tombamento $\left(\mathrm{m} / \mathrm{s}^{2}\right)$

$t=$ bitola do veículo $(\mathrm{m})$

$g=$ aceleração da gravidade $\left(\mathrm{m} / \mathrm{s}^{2}\right)$

$h=$ altura do centro de gravidade do veículo (m).

Matematicamente, a relação $\mathrm{t} / 2 \mathrm{~h}$ da equação 3.19 equivale ao valor de $f_{\max }$ apresentado na equação 3.18 , devendo os valores de $f_{\max }$ admitidos no projeto das curvas horizontais assumir valores inferiores aos limiares, tanto para a derrapagem como para o tombamento dos veículos. Como os caminhões possuem centro de gravidade mais elevado, estes apresentam valores de aceleração lateral-limite de tombamento inferiores ao encontrado nos automóveis. Enquanto nos veículos de passeio são necessários valores em sua maioria superiores a 1,5 g (PREM et al., 2001) para a ocorrência de tombamento, estudos apontam que, em caminhões, podem ser observados valores pequenos, como 0,25 g (WINKLER et al., 2000), revelando que, enquanto os automóveis estão mais susceptíveis a uma derrapagem, os caminhões com elevado centro de gravidade são mais propensos ao fenômeno do tombamento.

\section{Aceleração Lateral-Limite de Tombamento}

O tombamento de veículos de carga constitui importante causa de acidentes envolvendo caminhões. Estatísticas nos Estados Unidos, no período de 1992 a 1996, indicaram que, embora apenas 4,4\% dos acidentes envolvendo semi-reboques decorrem de tombamentos, este tipo de ocorrência é responsável por $58 \%$ das mortes verificadas nos condutores destes veículos, revelando a severidade deste tipo de acidente (WINKLER et al., 2000).

O tombamento em caminhões é particularmente perigoso pela dificuldade de ser pressentido. Enquanto nos veículos de passeio a aceleração lateral-limite de tombamento é atingida em situações extremas, próximas à condição de perda do controle direcional do veículo, nos caminhões, ela pode ocorrer com o veículo sendo guiado sem que haja essa percepção. Além disso o limiar de tombamento dos veículos comerciais muda regularmente à medida que cargas de densidades diferentes são 
transportadas, dificultando ao motorista discernir a estabilidade do veículo. Nas CVCs, a condição de instabilidade pode ocorrer em apenas uma das unidades rebocadas, como, por exemplo, em situações nas quais a direção do veículo é alterada de forma abrupta, na tentativa de evitar a colisão com algum obstáculo. Este tipo de ocorrência pode precipitar o tombamento do último veículo da combinação.

A equação 3.19 aplica-se para a condição de estabilidade de um corpo rígido, que não corresponde à realidade observada em um caminhão. As forças que atuam no veículo ao realizar uma curva e a própria distribuição longitudinal e transversal da carga produzem deformações nos pneus, deflexões do sistema de suspensão e na estrutura do chassi, ocasionando um deslocamento no seu centro de gravidade. A Figura 3.8 ilustra a diferença entre considerar o caminhão como um corpo rígido e a situação real. No segundo caso, o limiar de tombamento, inicialmente superestimado, deve ser corrigido, como mostra a equação 3.20 , onde a componente $\Delta y$ corresponde ao deslocamento ocorrido no centro de gravidade do veículo em relação ao eixo da bitola.

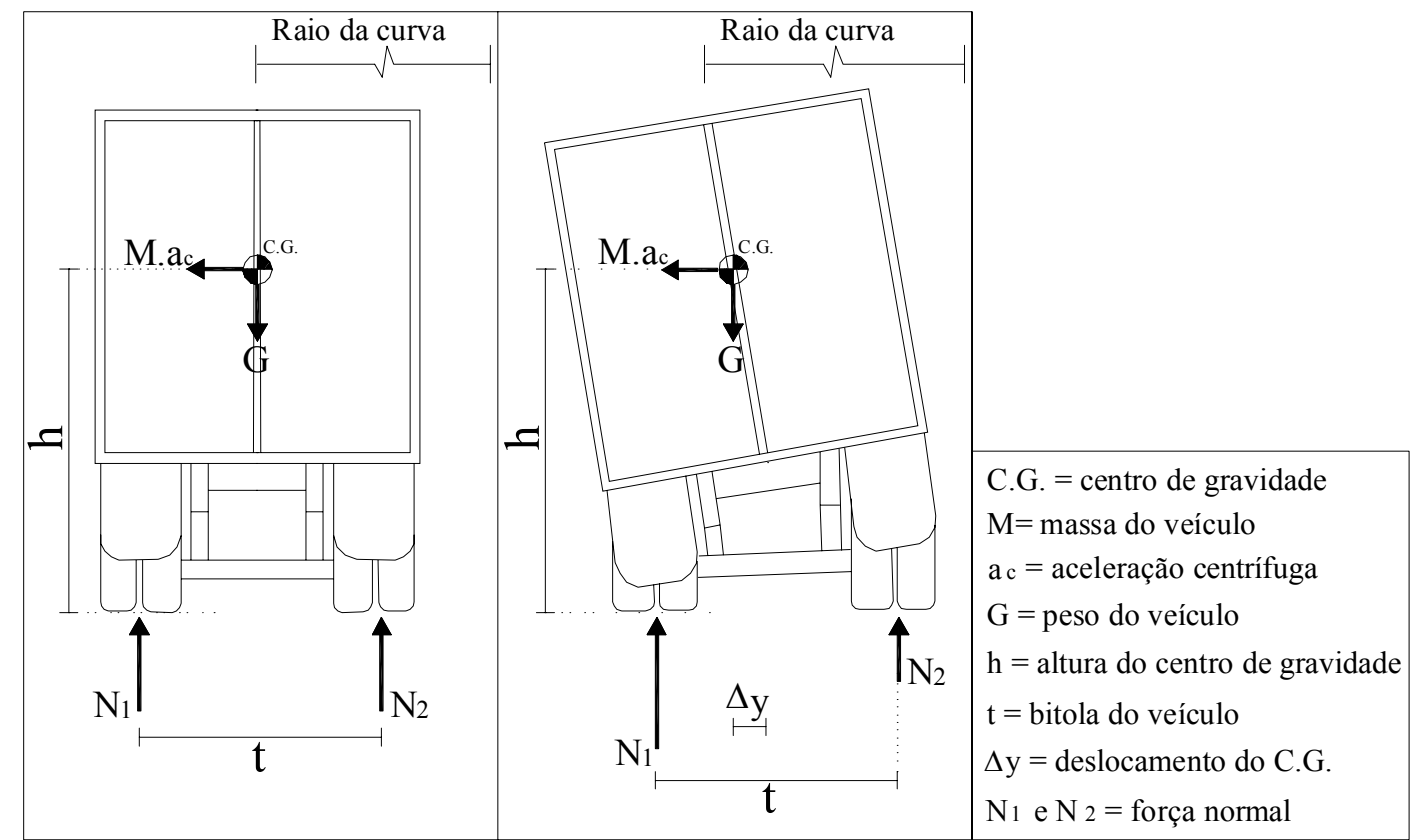

Figura 3.8: Deslocamento observado no centro de gravidade em função das forças que atuam no veículo ao percorrer a curva. Fonte: Adaptado de Winkler et al. (2000).

$$
a_{c_{\max }}=\left(\frac{t-2 \Delta y}{2 h}\right) g
$$


Winkler et al. (2000) estimam que o somatório das deflexões que ocorrem no veículo resulta em um deslocamento lateral no seu centro de gravidade capaz de reduzir a condição de estabilidade para um valor correspondente a $60 \%$ do observado, caso o veículo fosse perfeitamente rígido, com base em estudos realizados para a determinação dos valores do limiar de tombamento em caminhões, alguns envolvendo ensaios de simulação física com a utilização de tilt table. Nesse ensaio, o veículo é posicionado em uma plataforma gradualmente inclinada, levando ao surgimento de uma componente da força gravitacional, paralela à superfície da plataforma. Esta força é utilizada para simular a ação da força centrífuga que atua no veículo ao executar uma curva, sendo gradualmente elevada até que o veículo atinja o limiar do tombamento. Ervin, Macadam e Burnes (1986) determinaram valores de $a c_{\max }$ para veículos combinando situações com diferentes volumes e densidades de carga, sendo a situação mais crítica observada para o veículo com uma carga homogênea, cuja densidade permita carregar o veículo com a máxima capacidade em seu peso e volume, resultando em um $a c_{\max }$ em torno de 0,25 g. El-Gindy e Woodrooffe (1990) encontraram caminhões madeireiros no Canadá com um limiar de tombamento variando entre $0,23 \mathrm{~g}$ e $0,31 \mathrm{~g}$. Winkler et al. (2000) citam o caso de veículos-tanque que transportam gases liquefeitos apresentando limiares de tombamento da ordem de 0,26 g. No transporte de cargas líquidas, vale ressaltar o fato de que veículos-tanque carregados abaixo de sua capacidade são sujeitos a deslocamentos laterais do líquido transportado, resultando em mudanças na posição do centro de gravidade do veículo, reduzindo assim o limiar de tombamento.

Outro aspecto a ser considerado além do valor numérico da $a c_{\max }$ é o tempo que esta força atua sobre o veículo. Em estudo desenvolvido por Cooperrider, Thomas e Hammound (1990), considerando a condição de estabilidade de um veículo rígido ao longo de uma trajetória curva, os resultados indicaram que a aceleração necessária para provocar o tombamento de um veículo é função de sua duração. Foi observado que, se o valor da aceleração lateral corresponder ao limiar de tombamento, é necessário que esta aceleração seja aplicada indefinidamente para que o veículo tombe. Por outro lado, se esta aceleração ultrapassar em 10\% o limiar de tombamento, esta condição será atingida em apenas $1 \mathrm{seg}$, e, se ultrapassar em $20 \%$, o mesmo ocorrerá em aproximadamente 0,6 seg. 
A utilização de curvas de transição oferece melhores condições operacionais para os veículos, trazendo benefícios, como menor necessidade de afastamento lateral para garantir a visibilidade de curvas horizontais, além de reduzir o risco de o veículo sair da pista (DONALDSON, 1986), contribuindo assim com sua estabilidade. É, porém, improvável que a utilização de curvas de transição seja capaz de prover maior redução nos acidentes envolvendo tombamento. Apesar de as curvas de transição permitirem a implantação gradual de superelevação na pista assim como da aceleração radial do veículo, da tangente até o ponto de curvatura, a distribuição da superelevação nas curvas circulares simples, onde são normalmente implantados $2 / 3$ da superelevação antes do ponto de curvatura e 1/3 na curva propriamente dita, não constitui prática que produza riscos significativos. Simulações de caminhões em curvas horizontais realizadas em computador (HARWOOD et al., 1990) mostraram que a distribuição da superelevação desta forma resulta apenas em uma pequena redução na aceleração lateral, em torno de $0,01 \mathrm{~g}$ se comparada à utilização de curvas de transição. Estudos de campo e simulações confirmam que, mesmo nas curvas horizontais sem transição, os motoristas tendem a seguir uma trajetória em espiral (HARWOOD; MASON, 1994). Desta forma, no trecho da curva onde a superelevação ainda não foi inteiramente implantada, o motorista, via de regra, ainda está desenvolvendo um raio superior ao da curva.

Todos estes aspectos demonstram a importância de projetar curvas horizontais considerando margens de segurança entre o limiar de tombamento dos veículos que irão operar na via, representado por seu valor de $a c_{\max }$, e o valor do fator de atrito lateral considerado no projeto das curvas horizontais. $\mathrm{O}$ valor deste atrito poderá ser alterado em função de variáveis como a velocidade que o veículo desempenha na curva, a condição dos pneus e do pavimento e a trajetória que o motorista segue ao desenvolver a curva, devendo haver folgas que garantam que o valor de $a c_{\max }$ não seja atingido.

\subsubsection{Rampas Verticais Ascendentes}

A capacidade de rampa de um veículo, ou seja, a velocidade que determinado veículo é capaz de manter em uma rampa ascendente contínua, é a característica mais importante para determinar sua compatibilidade com o perfil longitudinal de uma 
estrada. Esta capacidade é determinada pelas resistências ao movimento: resistências ao rolamento, aerodinâmica e de rampa e principalmente pela relação potência/massa do veículo. A escolha de um veículo de projeto para se projetar adequadamente o traçado vertical de uma rodovia deve ser feita mediante a definição de uma relação potência/massa que represente os veículos que compõem o tráfego. Esta escolha orientará aspectos como a extensão máxima das rampas e a necessidade de construção de faixas adicionais de subida.

A modelagem do desempenho de caminhões em rampas pode ser feita de três maneiras: por modelos empíricos, econométricos e de simulação (SAFWAT; WALTON, 1986). O modelo empírico é obtido a partir de ensaios de campo, em que a velocidade do veículo é monitorada em diferentes declividades e extensões de rampa. Apresenta resultados satisfatórios, mas é bastante trabalhoso e possui a restrição de se obter um modelo limitado às condições existentes nos testes. O modelo econométrico envolve a coleta de dados de desempenho de veículos diversos, bem como de suas características físicas, e ainda características dos motoristas, da via e do meio ambiente. Mediante regressão múltipla, estes dados são utilizados para produzir uma equação que relacione todos os fatores relevantes ao desempenho do veículo. O modelo de simulação, por sua vez, é focado nas características do motor e nas resistências ao movimento, apresentando como vantagem a possibilidade de permitir uma análise das diversas combinações entre estas variáveis. Para qualquer um dos métodos citados, é importante a coleta de dados, seja para calibração ou ajuste de seus parâmetros.

Melo (2002) determinou curvas de desempenho para caminhões brasileiros utilizando um modelo de simulação proposto por Demarchi (2000b), após sua calibração e validação mediante observações em campo. Foram estabelecidas curvas para sete caminhões típicos da frota nacional, com relação massa/potência variando de 100 a $380 \mathrm{~kg} / \mathrm{kW}(13,4$ a 3,5 cv/t). Estes veículos e as curvas de desempenho encontradas servirão como parâmetro para comparar os resultados com a utilização do simulador TRUPER (DEMARCHI, 2004) nesta pesquisa. O TRUPER utiliza como dados de entrada as especificações do veículo, como a potência nominal do motor, a eficiência de transmissão, o peso total do veículo e do(s) eixo(s) trator(es), além de outros parâmetros, como pode ser verificado no Apêndice B. Estas informações, 
juntamente com o perfil longitudinal (extensão e declividade das rampas), são utilizadas em equações de desempenho para modelar o comportamento do veículo em termos de sua velocidade e aceleração. As equações de desempenho utilizadas são baseadas principalmente no método J2188 da SAE (1996), sendo que alguns dos coeficientes utilizados nestas equações foram adaptados para as condições brasileiras.

A existência de rampas extensas e de elevada declividade nas rodovias pode resultar na necessidade da implantação de faixas adicionais de subida. Estas faixas são propostas visando a reduzir os problemas causados pelos veículos de carga com baixo desempenho nas rampas. Entre os critérios normalmente considerados para determinar a necessidade de faixas adicionais, estão a diminuição observada na velocidade dos caminhões, a redução do nível de serviço da via, e ainda aspectos relacionados às características do tráfego, como o volume e percentagem de caminhões. Esses fatores são determinantes para a análise de custo-benefício utilizada na avaliação econômica para a implantação das faixas adicionais. A AASHTO propõe como limite para a redução de velocidade o valor de $15 \mathrm{~km} / \mathrm{h}$, com base em estudos de acidentes envolvendo caminhões, realizados na década de 1970 (GLENNON, 1970). Alguns estudos contribuíram para orientar a decisão de implantar faixas adicionais, considerando a realidade brasileira. Kabbach Júnior (1993) investigou os critérios tradicionalmente utilizados para avaliar a necessidade das faixas adicionais ascendentes em rodovias de pista simples, sendo propostos ajustes e adaptações às condições brasileiras. $\mathrm{O}$ método sugerido baseou-se em três critérios, considerando o desempenho dos veículos pesados, a capacidade viária nas rampas e uma avaliação econômica, permitindo analisar as condições operacionais do fluxo de tráfego, assim como atestar a viabilidade econômica da implantação de faixas adicionais. No trabalho de Melo (2002), foram investigadas as diferenças de velocidade entre caminhões e automóveis e sua relação com a ocorrência de acidentes em rodovias do Estado de São Paulo. O estudo conclui que devem ser utilizados valores-limites para a redução de velocidade da ordem de $20 \mathrm{~km} / \mathrm{h}$ nas rodovias de pista simples e $35 \mathrm{~km} / \mathrm{h}$ nas rodovias de pista dupla. Estes valores foram obtidos considerando os mesmos índices de envolvimento de caminhões em acidentes estabelecidos pela AASHTO, quando propôs a redução de 15 $\mathrm{km} / \mathrm{h}$ (MELO, 2002). 
Com base neste diferencial de velocidade, é possível determinar o comprimento crítico das rampas para cada classe de rodovia, considerando as inclinações máximas das rampas e sua velocidade de projeto. Além da variável comprimento crítico, a velocidade de entrada na rampa é outro parâmetro importante para a verificação da necessidade de implantação de faixas adicionais. Um valor razoável para este parâmetro é utilizar a velocidade média de percurso, quando o início da rampa ocorre num trecho plano (HARWOOD; TORBIC; RICHARD, 2003). Quando porém esta situação não é verificada, e especialmente quando ocorre a existência de rampas ascendentes sucessivas, é necessário utilizar outro valor para a velocidade a ser considerada. Uma forma de tratar esta questão é a utilização de simuladores de desempenho dos veículos, considerando o perfil longitudinal de todo o trecho, e não apenas avaliando as curvas verticais, isoladamente. Para a análise do estudo de caso proposto neste trabalho, será utilizado o simulador TRUPER com esta finalidade, considerando veículos típicos da frota brasileira.

\subsubsection{Rampas Verticais Descendentes}

Além da importância do desempenho dos veículos nos trechos em aclive, o estudo dos veículos nas rampas descendentes deve ser considerado, orientando a implantação, quando necessário, de faixas adicionais. Nestes casos, assim como ocorre nas rampas em aclive, os veículos de carga apresentam comportamento diferente do restante do tráfego. Desta vez, por motivos relacionados à segurança, intimamente associadas ao desempenho do sistema de freios, os veículos de carga necessitam operar a velocidades mais baixas, ocasionando, de forma semelhante ao observado nos trechos de aclive, a formação de pelotões. Resumidamente o problema central da descida de caminhões em trechos de declive extensos é a ocorrência do fade. O fade, segundo a NBR 5532 (ASSOCIAÇÃO BRASILEIRA DE NORMAS TÉCNICAS, 1990), consiste em um processo mediante o qual ocorre perda no atrito entre os componentes de sistemas de freios, lona e tambor ou pastilha e disco, em função, principalmente, de temperaturas elevadas ocasionadas pela fricção entre estes componentes, resultando em perdas de eficiência no sistema de freios, interferindo no desempenho de frenagem dos veículos e comprometendo sua segurança. 
Lucas (2004) investigou o comportamento dos veículos em rampas verticais descendentes, partindo das características do veículo, da massa transportada, da velocidade do veículo e ainda do comprimento e extensão da rampa. Com base nessas variáveis, foram geradas curvas de desempenho dos veículos nos declives, permitindo determinar a velocidade que o veículo poderá utilizar. Esse trabalho consistiu ainda de um estudo de caso considerando várias configurações de veículos e seu desempenho em greides com comprimento variando de 1000 a $12000 \mathrm{~m}$ e declividades de 1 a $12 \%$. Dentre os resultados obtidos, pôde-se concluir que a temperatura do sistema de freios está intimamente relacionada com a potência de frenagem gerada pelo motor do veículo. Assim, quanto maior for a relação potência de frenagem/PBTC, menor será a necessidade de utilização dos freios de serviço e, portanto, menor a temperatura atingida pelo sistema de frenagem, permitindo aos veículos operar com limites de velocidade mais elevados. Esta mesma tendência foi verificada quando considerada a relação massa total de frenagem/massa total transportada. Para os quocientes mais elevados, foi comprovada maior capacidade de absorção de calor pelo sistema de freios e, por conseguinte, melhor desempenho operacional do veículo. $\mathrm{O}$ estudo do comportamento dos caminhões nas rampas verticais descendentes já foi investigado com profundidade no trabalho de dissertação de Lucas (2004), não sendo necessário retomar este tema na presente pesquisa.

\subsubsection{Distância de Visibilidade para Interseções em Nível}

Apesar de o foco desta pesquisa ser a investigação da compatibilidade veículo-via nos segmentos de rodovia, existe um aspecto importante relacionado às interseções e que tem interferência significativa na segurança de um segmento rodoviário. Trata-se das interseções em nível, que devem ser localizadas de forma a prover uma distância de visibilidade suficiente para que os veículos que chegam às aproximações possam ajustar sua velocidade ou parar, quando preciso. É necessário também garantir uma distância de visibilidade para que um veículo posicionado na via secundária possa identificar uma brecha na via principal e transpor esta via ou nela se inserir com segurança.

Nesta pesquisa, este parâmetro será investigado sendo considerado apenas o efeito do tempo de travessia de veículos longos nas interseções em nível. Não serão analisadas 
as diferentes configurações geométricas das interseções nem os espaços ocupados pelos veículos nas interseções para a realização de manobras de conversão, assunto já tratado no trabalho de Russo (1995).

A AASHTO estabelece que, para cada aproximação da via secundária, deve existir um triângulo de visibilidade que proporcione estas distâncias, determinadas em função do tipo de controle de tráfego no cruzamento (AASHTO, 2004). O método utilizado para estabelecer as distâncias de visibilidade em interseções foi atualizado no Manual da AASHTO de 2001, sendo esta orientação utilizada também no Brasil na publicação do Manual de Projeto de Interseções (DNIT, 2005).

Para as interseções sem controle, a AASHTO cita dados de observações em campo que indicam redução na velocidade operacional dos veículos, ao se aproximarem deste tipo de cruzamento, da ordem de 50\%, mesmo para os casos em que inexiste risco potencial de conflito com outros veículos (AASHTO, 2004). Admitindo este comportamento dos motoristas e considerando o cálculo das distâncias de visibilidade com base na velocidade de projeto da via, têm-se, então, distâncias de visibilidade de parada com quase o dobro do valor necessário para a frenagem de automóveis. Mesmo admitindo as distâncias de visibilidade de parada dos caminhões $40 \%$ superiores à distância dos automóveis, como estimou Fancher (1986), persistem as distâncias compatíveis para os caminhões.

Para as interseções controladas pela sinalização "Parada Obrigatória" na via secundária, a AASHTO estabelece o triângulo de visibilidade, conforme mostrado na Figura 3.9. 


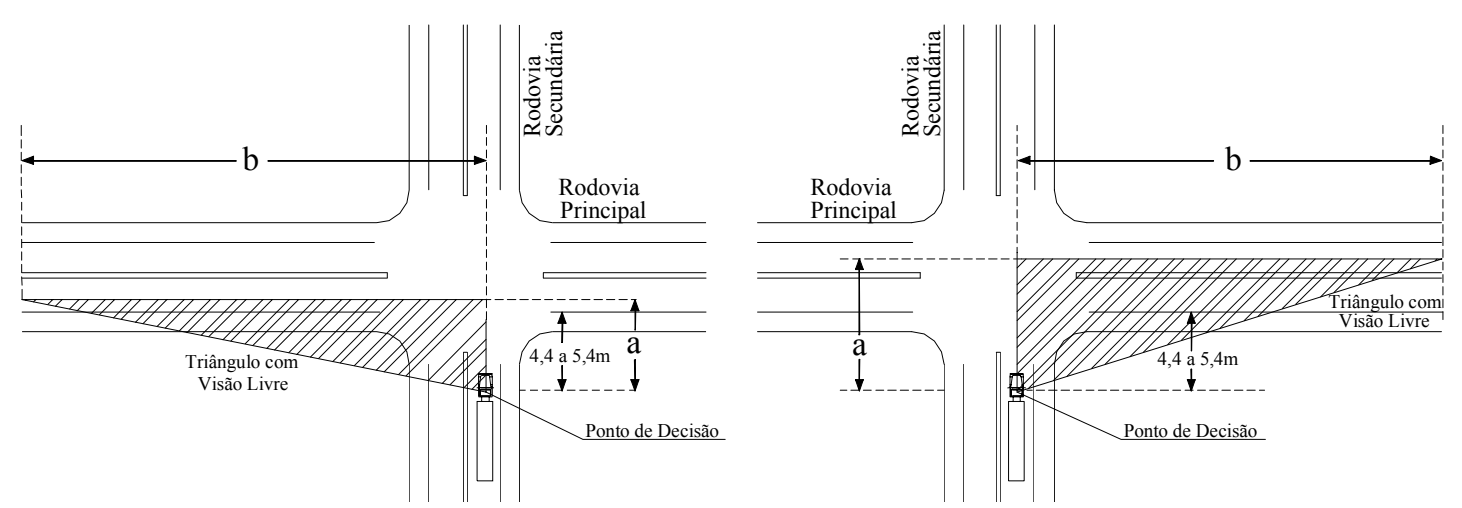

Figura 3.9: Triângulo de Visibilidade Recomendado para Interseções Controladas pela Sinalização "Parada Obrigatória" na Via Secundária .

Fonte: Adaptado de AASHTO (2004).

A distância "a" corresponde à distância percorrida pelo veículo da via secundária, entre o ponto de decisão e o ponto de cruzamento com uma das correntes da via principal. O ponto de decisão consiste no ponto de partida do veículo na rodovia secundária, partindo do repouso para realizar a manobra. Este ponto deve estar localizado a uma distância de 4,4 m a 5,4 m do bordo da faixa de tráfego da via principal (DNIT, 2005). A distância "b" corresponde à trajetória percorrida pelo veículo da rodovia principal entre o instante em que o veículo da via secundária parte do ponto de decisão e o instante que ele transpõe a via principal ou nela se insere. Para o cálculo da distância "b", a AASHTO utiliza dados coletados em campo, cujo o intervalo de tempo considerado correspondeu às brechas aceitas na corrente de tráfego para que os veículos parados na via secundária realizassem a monobra de travessia ou conversão. Estes tempos são estabelecidos para grupos de veículos, classificados em função de seus comprimentos, não sendo feita menção às suas capacidades de aceleração. A Tabela 3.11 mostra os valores destas brechas adotadas pela AASHTO e DNIT, onde são considerados greides ascendentes de até 3\% e pistas com duas faixas de tráfego, sendo propostas correções para greides de maior declividade e rodovias com mais de duas faixas de tráfego. É verificado um acréscimo de 1 seg nos intervalos de tempo entre manobras de travessia ou giro à direita e a manobra de giro à esquerda. 
Tabela 3.11: Intervalo de Tempo na Via Principal Aceito para Manobras de Veículos Parados na Via Secundária $\left(\mathrm{t}_{\mathrm{g}}\right)$.

\begin{tabular}{|c|c|c|c|}
\hline \multicolumn{2}{|c|}{ VEÍCULO DE PROJETO } & \multicolumn{2}{|c|}{$\begin{array}{l}\text { INTERVALO DE TEMPO ACEITO PARA } \\
\text { MANOBRA (seg) }\end{array}$} \\
\hline $\begin{array}{c}\text { AASHTO } \\
\text { (AASHTO, 2004) }\end{array}$ & $\begin{array}{c}\text { DNIT } \\
\text { (DNIT, 2005) }\end{array}$ & GIRO À ESQUERDA & $\begin{array}{l}\text { GIRO À DIREITA E } \\
\text { TRAVESSIA }\end{array}$ \\
\hline Veículo de Passeio & $\begin{array}{l}\text { Veículo de Passeio } \\
\text { (Comp. igual a 5,8 m) }\end{array}$ & 7,5 & 6,5 \\
\hline Caminhão Unitário & $\begin{array}{c}\text { Caminhão e Ônibus } \\
\text { (Comp. entre } 9,1 \text { e } 12,2 \mathrm{~m} \text { ) }\end{array}$ & 9,5 & 8,5 \\
\hline CVCs & $\begin{array}{l}\text { Semi-Reboque e Reboque } \\
\text { (Comp. entre 16,8 e 19,8 m) }\end{array}$ & 11,5 & 10,5 \\
\hline
\end{tabular}

Fontes: (AASHTO, 2004) e (DNIT, 2005).

Com base nestes valores de brecha, a distância de visibilidade, correspondente à distância "b" da Figura 3.8, é calculada pela equação 3.21:

$D V I=0,278 \cdot V_{p} \cdot t_{g}$

onde:

$D V I=$ distância de visibilidade necessária ao longo da via principal (m)

$V_{p}=$ velocidade de projeto da via principal $(\mathrm{km} / \mathrm{h})$

$t_{g}=$ intervalo de tempo entre veículos da via principal aceitos por veículos procedentes da rodovia secundária $(\mathrm{seg})$.

Widmer e Setti (1998) apresentaram tempos de travessia para veículos de passeio e alguns caminhões, correspondentes ao $75^{\circ}$ percentil de amostras de dados coletados em interseções em rodovias de pista simples. Os resultados apontaram para intervalos de 4,6 seg para veículos de passeio, 9 seg para caminhões unitários de 13,2 m, 10,5 seg para semi-reboques de 18,15 m e 12,8 seg para CVCs de 19,8 m, compatíveis com a maioria dos valores apresentados na Tabela 3.10. A pesquisa encontrou ainda o valor de 15,6 seg para CVCs com extensão de $30 \mathrm{~m}$.

As brechas consideradas pelo DNIT abrangem três classes de veículos, definidas em função de seus comprimentos. As relações potência/massa da frota de veículos, entretanto, resultam em diferentes capacidades de aceleração, que terão importante 
influência nas distâncias de visibilidade requerida pelos veículos. A proposta deste trabalho é incluir a relação potência/massa na definição dos veículos de projeto. Será utilizado o simulador de desempenho TRUPER (DEMARCHI, 2004), considerando esta variável, além do comprimento do veículo e das distâncias de travessia, estabelecidas com base na largura das faixas de tráfego e dos acostamentos das classes técnicas de rodovias de pista simples.

\section{Interseções Providas de Faixas de Mudança de Velocidade}

Nas rodovias de alta velocidade de projeto, e especialmente naquelas com volumes de tráfego mais elevados, os manuais de projeto geométrico recomendam, além do atendimento às distâncias de visibilidade de parada mencionadas no item anterior, a adoção de faixas de mudança de velocidade. Estes dispositivos consistem em faixas auxiliares de tráfego, que têm por objetivo proporcionar espaço suficiente para os veículos que irão se inserir na via principal poderem elevar suas velocidades a valores próximos ao observado na corrente de tráfego desta via (faixas de aceleração). Outra finalidade é permitir os veículos que irão deixar a via principal reduzirem suas velocidades para um valor compatível com as características do ramo ou da via de conexão onde o veículo adentrará (faixas de desaceleração). Desta forma, são reduzidos os conflitos e interferências destes veículos com fluxo de tráfego direto da via principal, elevando a fluidez e a segurança viária. Para o estudo proposto, será analisada a configuração de faixas de aceleração, sendo verificadas as extensões recomendadas pelo Manual do DNIT e sua adequação, dado o desempenho de veículos pesados com diferentes relações potência/massa. Serão consideradas, além da velocidade da via principal, a velocidade do veículo no início da faixa de aceleração e a influência dos greides ascendentes e descendentes no desempenho destes veículos, sendo realizadas simulações com o TRUPER.

O Manual do DNIT estabelece as extensões das faixas de aceleração com base em veículos de passeio e reconhece que esta prática resulta em menor velocidade desenvolvida pelos caminhões no final da faixa auxiliar, dada sua menor capacidade de aceleração. O Manual argumenta que os caminhões, em razão do seu maior porte, intimidam os veículos de passeio, que tendem a ceder espaço, diminuindo sua 
velocidade e dando oportunidade para que estes veículos se insiram na via principal. Este argumento, todavia, não é consistente, uma vez que o comportamento dos motoristas não é único, não devendo ser generalizado, de forma que situações como estas podem resultar em acidentes de colisão entre os veículos. Para os casos em que existe uma importante participação de veículos pesados no tráfego, o Manual recomenda que sejam consideradas maiores extensões para as faixas de aceleração, apesar de não especificar que valores seriam estes.

A Tabela 3.12 apresenta os comprimentos necessários para as faixas de aceleração, recomendadas pelo DNIT (2005), incluindo a extensão do taper, e são determinados em função da velocidade do veículo no início da faixa auxiliar, admitindo que este atinja a velocidade média da via no final dessa faixa. Essas distâncias correspondem aos mesmos valores recomendados pela versão anterior do Manual do DNER (1974) e são recomendados para greides variando entre 0 e $2 \%$. A AASHTO (2004) considera taxas de aceleração mais conservadoras para os veículos, de forma que, mesmo adotando uma velocidade no final da faixa de aceleração em torno de 10 $\mathrm{km} / \mathrm{h}$ inferior às velocidades consideradas pelo DNIT, propõe maiores comprimentos para as faixas de aceleração (ver Tabela 3.13) que o observado no Manual do DNIT. A justificativa do Manual brasileiro para adoção de comprimentos inferiores ao determinado pela AASHTO é sustentada em razões econômicas, sendo assumida ainda a idéia de que os valores propostos pelo DNIT são satisfatórios para as condições de tráfego do país (DNIT, 2005).

Tabela 3.12: Comprimento das Faixas de Aceleração em Interseções, Adotado pelo DNIT para Greides Inferiores a 2\%, Incluindo Taper.

\begin{tabular}{cccccccccc}
\hline \multirow{2}{*}{$\begin{array}{c}\text { VELOCIDADE } \\
\text { DIRETRIZ }\end{array}$} & $\begin{array}{c}\text { VELOCIDADE NO } \\
\text { FIM DA FAIXA DE } \\
(\mathrm{km} / \mathrm{h})\end{array}$ & \multicolumn{4}{c}{ COMPRIMENTO DA FAIXA DE ACELERAÇÃO (m) } \\
\cline { 3 - 9 } & $\begin{array}{c}\text { ACELERAÇÃO } \\
(\mathrm{km} / \mathrm{h})\end{array}$ & 0 & 20 & 30 & 40 & 50 & 60 & 70 & 80 \\
\hline 40 & 38 & 60 & 50 & 40 & - & - & - & - & - \\
50 & 46 & 90 & 70 & 60 & 45 & - & - & - & - \\
60 & 54 & 130 & 110 & 100 & 70 & 55 & - & - & - \\
70 & 62 & 180 & 150 & 140 & 120 & 90 & 60 & - & - \\
80 & 71 & 230 & 210 & 200 & 180 & 140 & 100 & 70 & - \\
90 & 79 & 280 & 250 & 240 & 220 & 190 & 140 & 100 & 80 \\
100 & 86 & 340 & 310 & 290 & 280 & 240 & 200 & 170 & 110 \\
110 & 92 & 390 & 360 & 350 & 320 & 290 & 250 & 200 & 160 \\
120 & 98 & 430 & 400 & 390 & 360 & 330 & 290 & 240 & 200 \\
\hline
\end{tabular}

Fonte: (DNIT, 2005). 
Tabela 3.13: Comprimento das Faixas de Aceleração em Interseções, Adotado pela AASHTO para Greides Inferiores a 2\%, Incluindo Taper.

\begin{tabular}{|c|c|c|c|c|c|c|c|c|c|}
\hline \multirow{3}{*}{$\begin{array}{l}\text { VELOCIDADE } \\
\text { DIRETRIZ } \\
(\mathrm{km} / \mathrm{h})\end{array}$} & \multirow{3}{*}{$\begin{array}{c}\text { VELOCIDADE NO } \\
\text { FIM DA FAIXA DE } \\
\text { ACELERAÇÃO } \\
(\mathrm{km} / \mathrm{h})\end{array}$} & \multicolumn{8}{|c|}{ COMPRIMENTO DA FAIXA DE ACELERAÇÃO (m) } \\
\hline & & \multicolumn{8}{|c|}{ Velocidade no Início da Faixa de Aceleração $(\mathrm{km} / \mathrm{h})$} \\
\hline & & 0 & 20 & 30 & 40 & 50 & 60 & 70 & 80 \\
\hline 50 & 37 & 150 & 140 & 120 & - & - & - & - & - \\
\hline 60 & 45 & 185 & 170 & 155 & 135 & 135 & - & - & - \\
\hline 70 & 53 & 240 & 220 & 200 & 180 & 155 & - & - & - \\
\hline 80 & 60 & 290 & 270 & 255 & 235 & 205 & 155 & - & - \\
\hline 90 & 67 & 350 & 335 & 315 & 295 & 265 & 215 & 125 & - \\
\hline 100 & 74 & 435 & 415 & 395 & 375 & 345 & 295 & 200 & 13 \\
\hline 110 & 81 & 520 & 500 & 480 & 460 & 430 & 380 & 290 & 21 \\
\hline 120 & 88 & 635 & 620 & 605 & 580 & 550 & 500 & 415 & 33 \\
\hline
\end{tabular}

Fonte: (AASHTO, 2004).

Quanto à influência das rampas ascendentes superiores a 2\% e para o caso de rampas descendentes o Manual do DNIT recomenda a adoção de fatores de ajustamento para a extensão das faixas de aceleração, que resultam nos comprimentos apresentados nas Tabelas 3.14 e 3.15. A AASHTO também determina fatores de ajustamento para a ocorrência de greides para a faixa de velocidades de projeto entre 60 e $120 \mathrm{~km} / \mathrm{h}$, entretanto considera outros valores que resultam nos comprimentos apresentados nas Tabelas 3.16 e 3.17. Estes valores serão comparados posteriormente com os resultados obtidos no TRUPER para os veículos simulados.

Tabela 3.14: Comprimento das Faixas de Aceleração em Interseções, Adotado pelo DNIT para Greides Ascendentes, Incluindo Taper.

\begin{tabular}{|c|c|c|c|c|c|c|c|}
\hline \multirow{4}{*}{$\begin{array}{c}\text { VELOCIDADE } \\
\text { DIRETRIZ } \\
(\mathrm{km} / \mathrm{h})\end{array}$} & \multicolumn{7}{|c|}{ COMPRIMENTO DA FAIXA DE ACELERACCÃO (m) } \\
\hline & \multicolumn{7}{|c|}{ Velocidade no Início da Faixa de Aceleração $(\mathrm{km} / \mathrm{h})$} \\
\hline & 20 & 30 & 40 & 50 & 60 & 70 & 80 \\
\hline & \multicolumn{7}{|c|}{ Rampas Ascendentes de 3\% e 4\% } \\
\hline 40 & 60 & 48 & - & - & - & - & - \\
\hline 50 & 84 & 72 & 54 & - & - & - & - \\
\hline 60 & 143 & 130 & 91 & 77 & - & - & - \\
\hline 70 & 195 & 182 & 156 & 126 & 84 & - & - \\
\hline 80 & 294 & 280 & 252 & 210 & 150 & 105 & - \\
\hline 90 & 350 & 336 & 308 & 285 & 210 & 150 & 128 \\
\hline 100 & 465 & 435 & 420 & 384 & 340 & 289 & 198 \\
\hline 110 & 540 & 525 & 480 & 464 & 425 & 340 & 288 \\
\hline \multirow[t]{2}{*}{120} & 600 & 585 & 540 & 528 & 493 & 408 & 360 \\
\hline & \multicolumn{7}{|c|}{ Rampas Ascendentes de 5\% e 6\% } \\
\hline 40 & 65 & 56 & - & - & - & - & - \\
\hline 50 & 91 & 84 & 63 & - & - & - & - \\
\hline 60 & 154 & 150 & 105 & 82,5 & - & - & - \\
\hline 70 & 210 & 210 & 180 & 144 & 102 & - & - \\
\hline 80 & 294 & 300 & 270 & 238 & 180 & 133 & - \\
\hline 90 & 375 & 384 & 352 & 342 & 280 & 210 & 176 \\
\hline 100 & 496 & 493 & 476 & 456 & 440 & 408 & 275 \\
\hline 110 & 684 & 700 & 640 & 638 & 650 & 560 & 480 \\
\hline 120 & 800 & 819 & 828 & 825 & 870 & 768 & 700 \\
\hline
\end{tabular}

Fonte: (DNIT, 2005). 
Tabela 3.15: Comprimento das Faixas de Aceleração em Interseções, Adotado pelo DNIT para Greides Descendentes, Incluindo Taper.

\begin{tabular}{|c|c|c|c|c|c|c|c|}
\hline \multirow{4}{*}{$\begin{array}{l}\text { VELOCIDADE } \\
\text { DIRETRIZ } \\
(\mathrm{km} / \mathrm{h})\end{array}$} & \multicolumn{7}{|c|}{ COMPRIMENTO DA FAIXA DE ACELERAÇÃO (m) } \\
\hline & \multicolumn{7}{|c|}{ Velocidade no Início da Faixa de Aceleração (km/h) } \\
\hline & 20 & 30 & 40 & 50 & 60 & 70 & 80 \\
\hline & \multicolumn{7}{|c|}{ Rampas Descendentes de 3\% e 4\% } \\
\hline 40 & 40 & 40 & - & - & - & - & - \\
\hline 50 & 49 & 45 & 45 & - & - & - & - \\
\hline 60 & 77 & 70 & 55 & 55 & - & - & - \\
\hline 70 & 98 & 91 & 78 & 60 & 60 & - & - \\
\hline 80 & 137 & 130 & 117 & 91 & 70 & 70 & - \\
\hline 90 & 150 & 144 & 132 & 114 & 84 & 80 & 80 \\
\hline 100 & 186 & 174 & 168 & 144 & 120 & 102 & 85 \\
\hline 110 & 216 & 210 & 192 & 174 & 150 & 120 & 96 \\
\hline \multirow[t]{2}{*}{120} & 240 & 234 & 216 & 198 & 174 & 144 & 120 \\
\hline & \multicolumn{7}{|c|}{ Rampas Descendentes de $5 \%$ e $6 \%$} \\
\hline 40 & 30 & 40 & - & - & - & - & - \\
\hline 50 & 42 & 45 & 45 & - & - & - & - \\
\hline 60 & 66 & 60 & 55 & 55 & - & - & - \\
\hline 70 & 90 & 84 & 72 & 60 & 60 & - & - \\
\hline 80 & 116 & 110 & 99 & 77 & 70 & 70 & - \\
\hline 90 & 138 & 132 & 121 & 105 & 80 & 80 & 80 \\
\hline 100 & 155 & 145 & 140 & 120 & 100 & 85 & 85 \\
\hline 110 & 180 & 175 & 160 & 145 & 125 & 100 & 90 \\
\hline 120 & 200 & 195 & 180 & 165 & 145 & 120 & 100 \\
\hline
\end{tabular}

Fonte: (DNIT, 2005).

Tabela 3.16: Comprimento das Faixas de Aceleração em Interseções, Adotado pela AASHTO para Greides Ascendentes, Incluindo Taper.

\begin{tabular}{|c|c|c|c|c|c|c|c|}
\hline \multirow{4}{*}{$\begin{array}{l}\text { VELOCIDADE } \\
\text { DIRETRIZ } \\
(\mathrm{km} / \mathrm{h})\end{array}$} & \multicolumn{7}{|c|}{ COMPRIMENTO DA FAIXA DE ACELERACC̃̃O (m) } \\
\hline & & loci & o Iní & Faix & Acele & $(\mathrm{km} /$ & \\
\hline & 20 & 30 & 40 & 50 & 60 & 70 & 80 \\
\hline & \multicolumn{7}{|c|}{ Rampas Ascendentes de 3\% e 4\% } \\
\hline 60 & - & - & 149 & - & - & - & - \\
\hline 70 & - & - & 207 & 181 & - & - & - \\
\hline 80 & - & - & 293 & 263 & 188 & - & - \\
\hline 90 & - & - & 377 & 353 & 278 & 143 & - \\
\hline 100 & - & - & 518 & 498 & 439 & 277 & 162 \\
\hline 110 & - & - & 645 & 634 & 583 & 430 & 315 \\
\hline \multirow[t]{2}{*}{120} & - & - & 825 & 826 & 787 & 643 & 531 \\
\hline & \multicolumn{7}{|c|}{ Rampas Ascendentes de $5 \%$ e $6 \%$} \\
\hline 60 & - & - & 158 & - & - & - & - \\
\hline 70 & - & - & 225 & 194 & - & - & - \\
\hline 80 & - & - & 308 & 286 & 214 & - & - \\
\hline 90 & - & - & 418 & 405 & 340 & 164 & - \\
\hline 100 & - & - & 575 & 575 & 541 & 354 & 190 \\
\hline 110 & - & - & 830 & 838 & 844 & 650 & 465 \\
\hline 120 & _- & _ & 1217 & 1240 & 1320 & 1130 & 948 \\
\hline
\end{tabular}

Fonte: (AASHTO, 2004). 
Tabela 3.17: Comprimento das Faixas de Aceleração em Interseções, Adotado pela AASHTO para Greides Descendentes, Incluindo Taper.

\begin{tabular}{|c|c|c|c|c|c|c|c|}
\hline \multirow{4}{*}{$\begin{array}{l}\text { VELOCIDADE } \\
\text { DIRETRIZ } \\
(\mathrm{km} / \mathrm{h})\end{array}$} & \multicolumn{7}{|c|}{ COMPRIMENTO DA FAIXA DE ACELERACÃO (m) } \\
\hline & & loc & no Iní & Fai & Acels & 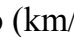 & \\
\hline & 20 & 30 & 40 & 50 & 60 & 70 & 80 \\
\hline & \multicolumn{7}{|c|}{ Rampas Descendentes de 3\% e 4\% } \\
\hline 60 & - & - & 122 & - & - & - & - \\
\hline 70 & - & - & 149 & 132 & - & - & - \\
\hline 80 & - & - & 184 & 165 & 132 & - & - \\
\hline 90 & - & - & 213 & 195 & 165 & 111 & - \\
\hline 100 & - & - & 261 & 243 & 213 & 156 & 114 \\
\hline 110 & - & - & 312 & 294 & 264 & 210 & 165 \\
\hline \multirow[t]{2}{*}{120} & - & - & 384 & 366 & 336 & 285 & 237 \\
\hline & \multicolumn{7}{|c|}{ Rampas Descendentes de $5 \%$ e $6 \%$} \\
\hline 60 & - & - & 117 & - & - & - & - \\
\hline 70 & - & - & 144 & 129 & - & - & - \\
\hline 80 & - & - & 170 & 153 & 126 & - & - \\
\hline 90 & - & - & 203 & 186 & 159 & 109 & - \\
\hline 100 & - & - & 233 & 218 & 193 & 145 & 110 \\
\hline 110 & - & - & 275 & 260 & 235 & 190 & 153 \\
\hline 120 & - & - & 335 & 320 & 295 & 253 & 213 \\
\hline
\end{tabular}

Fonte: (AASHTO, 2004).

\subsection{Considerações Finais}

A revisão bibliográfica dos vários aspectos da interação veículo-via aqui apresentados fundamentará a investigação, apresentada no Capítulo 4 , referente à compatibilidade de segmentos rodoviários projetados segundo o Manual brasileiro, para a operação de diversos pertencentes a frota nacional. Os resultados desta análise permitirão a proposição de ajustes nas diretrizes de projeto, com vistas a tornar compatível a operação dos veículos. 


\section{PROPOSTA DE ADEQUAÇÃO DE PARÂMETROS DE PROJETO PARA RODOVIAS BRASILEIRAS}

\subsection{Considerações Iniciais}

Conforme exposto no Capítulo 1, a proposta deste trabalho abrange uma análise dos parâmetros de projeto geométrico do sistema de classificação de rodovias adotado no Brasil, contextualizando os sistemas de classificação praticados em outros países e os trabalhos desenvolvidos pela comunidade científica acerca dos aspectos da interação veículo-via. Com base na revisão bibliográfica realizada, chegou-se às seguintes conclusões quanto ao atual sistema de classificação de rodovias brasileiro:

(a) a frota de veículos brasileiros veio ao longo dos anos apresentando uma tendência de elevação em suas dimensões, com a homologação e certificação de combinações de veículos de carga que chegam a apresentar comprimentos de até 30 m e PBT de 74 toneladas. Não houve, entretanto, uma atualização dos veículos de projeto utilizados para dimensionar as condições da via. Em comparação aos demais manuais estudados, é nítida a defasagem dos veículos de projeto utilizados no Brasil. É necessário, portanto, propor a inclusão de novos veículos de projeto no Manual brasileiro, representativos da frota em operação, de forma a que sejam projetadas vias com as condições de tráfego adequadas. Serão supridas por esta medida deficiências nos valores das sobrelarguras calculadas para as curvas horizontais, bem como nas distâncias de visibilidade nas interseções das vias;

(b) os parâmetros estabelecidos para a configuração das rampas verticais se limitam à determinação de declividades máximas para as classes de projeto em curso, sem especificar valores quanto à extensão destas rampas. As indefinições quanto ao veículo de projeto a ser considerado e sua respectiva relação potência/massa, bem como com relação às reduções de velocidade admissíveis para os caminhões nas rampas, não permitem que sejam estabelecidos valores para seus 
comprimentos críticos. Desta forma, a orientação de quando e onde construir dispositivos, como rampas adicionais, para trechos em aclive é uma questão que não é devidamente respondida. O próprio Manual reconhece a falta de uniformidade dos métodos e dos critérios adotados pelos projetistas no Brasil para prever a implantação e dimensionamento destes dispositivos. Apesar de citar a inadequação do uso dos parâmetros propostos pela AASHTO, dada a existência de realidades bastante díspares do observado no Brasil, esta é a única referência mencionada no Manual. Para contornar esta limitação, cabe incorporar às diretrizes de projeto de vias os resultados das pesquisas recentemente desenvolvidas para a realidade brasileira, como pode ser encontrado no trabalho de Melo (2002), permitindo a definição de veículos de projeto representativos da relação potência/massa existente na frota nacional. $\mathrm{O}$ comportamento destes veículos deve ser considerado no sistema de classificação, orientando o projeto das vias, de forma a definir comprimentos críticos e sinalizar a necessidade de implantação das faixas adicionais nos aclives. Uma dificuldade para a solução deste problema é o fato de que, mesmo de posse de curvas de desempenho representativas de caminhões brasileiros, há uma carência de dados consistentes de caracterização da frota nacional, onde se possa definir adequadamente qual curva de desempenho deve ser utilizada no projeto de um determinado trecho de rodovia;

(c) para a condição de estabilidade dos veículos nas curvas horizontais, o Manual segue a orientação da AASHTO, que propõe valores de fatores de atrito lateral com base nos veículos de passeio, prática questionada pelo fato de os veículos de carga apresentarem condições mais críticas e que, portanto, deveriam orientar esta definição. Para a análise da ocorrência do tombamento, é importante que sejam estabelecidos valores de desempenho mínimo para a aceleração laterallimite de tombamento nos veículos, garantindo a existência de um nível de segurança coerente com os valores de atrito lateral utilizados no projeto das rodovias brasileiras; e

(d) a revisão bibliográfica indicou que os estudos recentes apontam em direção ao uso de distâncias de frenagem com base em veículos de carga e não mais nos veículos de passeio, favorecendo, assim, a segurança viária. Esta prática é 
empregada em países como Austrália e Canadá. Nos Estados Unidos, apesar da manutenção de distâncias de frenagem idênticas para automóveis e caminhões, existe uma realidade diferente que justifica esse fato. A tecnologia dos veículos de carga, que em sua grande maioria possuem sistemas de freio ABS, aproxima o desempenho de frenagem dos automóveis e caminhões. No caso do Brasil, onde a quase totalidade da frota comercial é provida de sistemas de freio convencionais, manter a posição adotada nos Estados Unidos significa ir contra a segurança de tráfego dos veículos. Desta forma, é recomendado elevar os valores de distância de frenagem estabelecidos no Manual do DNER, aumentando também os valores dos parâmetros de projeto alvos de influência desta distância, como os valores de afastamento lateral mínimo, para garantir condições de visibilidade nas curvas horizontais.

\subsection{Parâmetros Investigados para Verificar o Atendimento de Condições Operacionais das Rodovias}

Para identificar as deficiências do atual sistema de classificação de rodovias e de suas diretrizes de projeto, e para propor sua adequação, visando a permitir a compatibilidade na operação de veículos pesados, serão utilizados os aspectos abordados no Capítulo 3.

Nesta análise, não serão consideradas as questões associadas à distância de visibilidade de parada nas curvas verticais convexas, que, conforme discutido anteriormente, se pode admitir uma compensação da maior altura de visão proporcionada pelos veículos pesados ante seu pior desempenho nas frenagens. Da mesma forma, considerando que as distâncias de visibilidade de ultrapassagem proposta pela AASHTO consistem em valores que, apesar de estarem baseados em veículos de passeio, foram obtidos a partir de suposições conservadoras, será admitido, conforme fazem alguns manuais de projeto geométrico (TAC, 1999), a noção de que estes valores possam ser utilizados para os processos de ultrapassagem envolvendo veículos longos. Desta forma, para a análise proposta, serão considerados os aspectos mostrados na Figura 4.1. 
Neste fluxograma, são apresentadas, no primeiro nível, as condições operacionais que a via oferece aos veículos, considerando quatro aspectos principais: sobrelarguras, rampas ascendentes, estabilidade em curvas horizontais e distâncias de visibilidade nas interseções. Cada um destes aspectos depende de outros elementos, que podem ser divididos em dois tipos. No primeiro, estão as características e padrões das vias, estabelecidos na sua classificação técnica, como os valores de raio mínimo, rampas máximas e largura das faixas de tráfego. No segundo grupo, estão as características dos veículos, representadas no fluxograma através do veículo de projeto, definindo aspectos como sua varredura nos trechos curvos, comprimento e relação potência/massa. É exatamente a interação destes dois grupos de elementos que permitirá ou não a existência de condições operacionais adequadas. Como visto, a compatibilidade de uma via depende, de um lado, das características técnicas desta via, e, do outro, do tipo de veículo que nela trafega.

Partindo deste fluxograma, serão investigados os quatro aspectos há instantes mencionados, considerando os padrões técnicos mínimos propostos nas classes de rodovia do DNER e as características, seja dos veículos de projeto considerados no Manual, seja de outros veículos representativos da frota nacional. Com base na análise dos resultados, serão propostas as modificações necessárias.

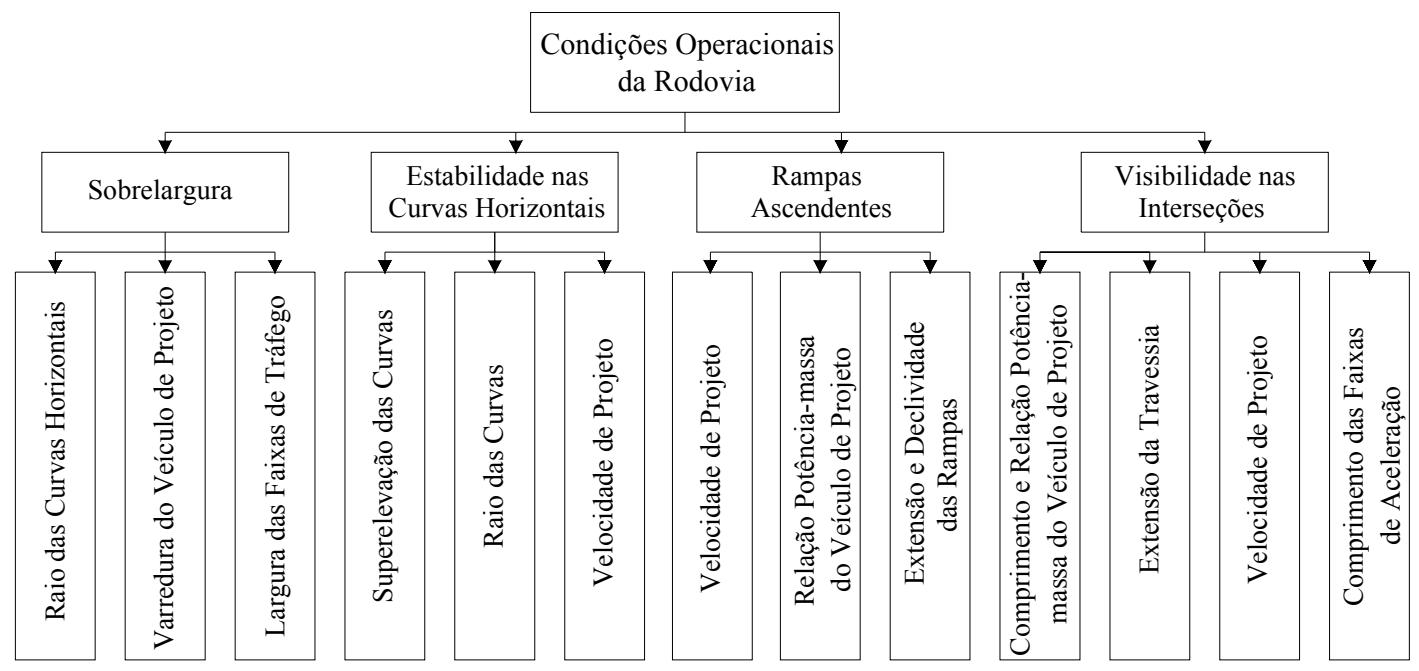

Figura 4.1: Fluxograma dos Parâmetros Investigados dos Veículos e da Via para o Atendimento das Condições Operacionais. 


\subsubsection{Sobrelarguras}

Para investigar a condição operacional da rodovia sob o aspecto das sobrelarguras, será observado o comportamento de veículos unitários e de combinações representativas da frota brasileira ao percorrerem curvas horizontais, considerando as características das classes de projeto do DNER. Estes resultados serão, pois, comparados com os valores de sobrelargura calculados com base na utilização dos veículos de projeto do DNER. Na Tabela 4.1, são apresentadas as dimensões básicas destes veículos: balanço dianteiro (BD), entre-eixos e balanço traseiro (BT), medidas estas que serão utilizados para o cálculo das sobrelarguras.

Tabela 4.1: Dimensões Básicas dos Veículos Considerados (m)

\begin{tabular}{|c|c|c|c|c|c|c|c|c|c|c|}
\hline \multirow[b]{2}{*}{ VEÍCULO } & \multicolumn{3}{|c|}{ VEÍCULO TRATOR } & \multicolumn{3}{|c|}{$\begin{array}{c}\text { UNIDADE } \\
\text { REBOCADA } 1\end{array}$} & \multicolumn{3}{|c|}{$\begin{array}{c}\text { UNIDADE } \\
\text { REBOCADA } 2\end{array}$} & \multirow{2}{*}{$\begin{array}{l}\text { COMP. } \\
\text { TOTAL }\end{array}$} \\
\hline & $\mathrm{BD}$ & $\begin{array}{l}\text { Entre } \\
\text { eixos }\end{array}$ & $\begin{array}{c}\text { BT } \\
* \text { Pós } 5^{a} \\
\text { Roda }\end{array}$ & $\mathrm{BD}$ & $\begin{array}{l}\text { Entre } \\
\text { eixos }\end{array}$ & $\begin{array}{l}\text { BT } \\
\text { Pós } 5^{\text {a }} \\
\text { Roda }\end{array}$ & $\mathrm{BD}$ & $\begin{array}{l}\text { Entre } \\
\text { eixos }\end{array}$ & $\begin{array}{l}\text { BT } \\
\text { Pós } 5^{\mathrm{a}} \\
\text { Roda }\end{array}$ & \\
\hline \multicolumn{11}{|c|}{ VEÍCULOS UNITÁRIOS } \\
\hline CO(DNER) & 1,20 & 6,10 & 1,80 & - & - & - & - & - & - & 9,10 \\
\hline O(DNER) & 2,10 & 7,60 & 2,50 & - & - & - & - & - & - & 12,20 \\
\hline O2(URB) & 2,60 & 6,00 & 3,50 & - & - & - & - & - & - & 12,10 \\
\hline O2(ROD) & 2,35 & 7,50 & 3,40 & - & - & - & - & - & - & 13,40 \\
\hline O3(ROD) & 2,35 & 7,45 & 4,15 & - & - & - & - & - & - & 13,95 \\
\hline $\mathrm{U} 2$ & 1,10 & 9,7 & 3,20 & - & - & - & - & - & - & 14,00 \\
\hline U3 & 1,10 & 8,75 & 4,15 & - & - & - & - & - & - & 14,00 \\
\hline \multicolumn{11}{|c|}{ VEÍCULOS COMBINADOS } \\
\hline SR(DNER) & 0,90 & 5,50 & 0,20 & 1,20 & 9,10 & 1,2 & - & - & - & 16,80 \\
\hline RE(DNIT) & 0,90 & 3,35 & 0,20 & 1,30 & 6,05 & 1,30 & 1,55 & 6,05 & 0,60 & 19,80 \\
\hline $\mathrm{O} 2 \mathrm{~S} 1$ & 2,60 & 5,50 & 2,20 & - & 4,50 & 3,20 & - & - & - & 18,00 \\
\hline O2S1B1 & 2,60 & 5,50 & 2,20 & - & 3,80 & 2,20 & - & 5,50 & 3,20 & 25,00 \\
\hline $2 \mathrm{~S} 1$ & 1,35 & 3,30 & 0,20 & 1,20 & 12,50 & 1,50 & - & - & - & 18,15 \\
\hline $2 \mathrm{~S} 2(20 \mathrm{~m})$ & 1,35 & 5,20 & 0,20 & 1,20 & 11,80 & 1,50 & - & - & - & 20,05 \\
\hline $2 \mathrm{~S} 2(22,4 \mathrm{~m})^{\wedge \wedge}$ & 1,35 & 3,30 & 0,20 & 2,00 & 14,10 & 4,15 & - & - & - & 22,40 \\
\hline $2 \mathrm{~S} 3$ & 1,35 & 3,7 & 0,20 & 1,20 & 7,0 & 4,70 & - & - & - & 18,15 \\
\hline 3S2B2(20m) & 1,30 & 5,20 & 0,00 & 1,30 & 6,10 & 0,20 & 0,80 & 5,00 & 2,00 & 19,80 \\
\hline $3 \mathrm{~S} 2 \mathrm{~B} 2(26 \mathrm{~m})^{* *}$ & 1,30 & 5,20 & 0,00 & 1,30 & 7,80 & 1,20 & 0,20 & 8,60 & 2,60 & 26,20 \\
\hline $3 \mathrm{~S} 3 \mathrm{~B} 3 * *$ & 1,30 & 5,20 & 0,00 & 1,30 & 7,80 & 1,20 & 0,20 & 7,20 & 4,00 & 26,20 \\
\hline $3 \mathrm{~S} 2 \mathrm{~A} 2 \mathrm{~S} 2 * *$ & 1,30 & 4,60 & 0,00 & 1,30 & 8,80 & 1,30 & 2,20 & 8,80 & 1,30 & 30,00 \\
\hline
\end{tabular}

\footnotetext{
* quando eixo traseiro trucado, o balanço é medido do centro entre os dois eixos

** veículos que trafegam com AET segundo Res. 211 do CONTRAN (Brasil, 2006b)

$\wedge^{\wedge}$ veículos que trafegam com AET segundo Res. 75 do CONTRAN (Brasil, 1999b)
} 
Para a análise proposta, será considerada a condição técnica mais crítica, sendo adotados os raios mínimos estabelecidos para as classes técnicas. Estes raios foram determinados a partir da velocidade de projeto da classe técnica e dos valores de $f_{\max } \mathrm{e}$ $e_{\text {max }}$ admitidos pelo Manual do DNER(1999), sendo calculados pela equação 3.18. As sobrelarguras foram determinadas pelas equações 3.12 a 3.16 e estão apresentadas na Tabela 4.2.

Tabela 4.2: Sobrelarguras Exigidas para as Condições Mínimas das Classes de Projeto do DNER (Plano (P), Ondulado (O) e Montanhoso (M), em metros).

\begin{tabular}{|c|c|c|c|c|c|c|c|c|c|c|c|c|c|}
\hline $\begin{array}{l}\text { CLASSE DA RODOVIA } \\
\text { (TERRENO) }\end{array}$ & $\begin{array}{c}0 \\
(\mathrm{P})\end{array}$ & $\begin{array}{l}\text { II } \\
(\mathrm{P})\end{array}$ & $\begin{array}{c}0 \\
(\mathrm{O}) \\
\mathrm{e} \\
\mathrm{I} \\
(\mathrm{P})\end{array}$ & $\begin{array}{l}\text { III } \\
(\mathrm{P})\end{array}$ & $\begin{array}{c}0 \\
(\mathrm{M}) \\
\mathrm{e} \\
\mathrm{I} \\
(\mathrm{O})\end{array}$ & $\begin{array}{c}\text { II } \\
(\mathrm{O})\end{array}$ & $\begin{array}{c}\mathrm{I} \\
(\mathrm{M})\end{array}$ & $\begin{array}{l}\text { III } \\
(\mathrm{O})\end{array}$ & $\begin{array}{c}\text { IVa } \\
(\mathrm{P})\end{array}$ & $\begin{array}{c}\text { II } \\
(\mathrm{M})\end{array}$ & $\begin{array}{c}\text { III } \\
(\mathrm{M})\end{array}$ & $\begin{array}{l}\text { IVa } \\
(\mathrm{O})\end{array}$ & $\begin{array}{l}\text { IVa } \\
(\mathrm{M})\end{array}$ \\
\hline $\mathrm{V}_{\mathrm{p}}(\mathrm{km} / \mathrm{h})$ & 120 & 100 & 100 & 80 & 80 & 70 & 60 & 60 & 60 & 50 & 40 & 40 & 30 \\
\hline$e_{\max }(\%)$ & 10 & 8 & 10 & 8 & 10 & 8 & 8 & 8 & 8 & 8 & 8 & 8 & 8 \\
\hline $\mathrm{R}_{\min }(\mathrm{m})$ & 540 & 375 & 345 & 230 & 210 & 170 & 125 & 125 & 125 & 80 & 50 & 50 & 25 \\
\hline LARGURA DA PISTA (m) & 7,2 & 7,2 & 7,2 & 7 & 7,2 & 7 & 7,2 & 6,6 & 6 & 6,6 & 6,6 & 6 & 6 \\
\hline CO(DNER) & 0,40 & 0,44 & 0,47 & 0,72 & 0,57 & $\mathbf{0 , 8 0}$ & $\mathbf{0 , 7 0}$ & 1,00 & 1,30 & 1,23 & 1,57 & 1,87 & 2,83 \\
\hline RE(DNIT) & 0,41 & 0,45 & 0,49 & 0,75 & 0,60 & 0,84 & 0,75 & 1,05 & 1,35 & 1,30 & 1,69 & 1,99 & 3,09 \\
\hline $\mathrm{O} 2$ (URB) & 0,43 & 0,47 & 0,51 & 0,79 & 0,64 & 0,89 & 0,81 & 1,11 & 1,41 & 1,40 & 1,86 & 2,16 & 3,39 \\
\hline $2 \mathrm{~S} 3$ & 0,44 & 0,50 & 0,54 & 0,83 & 0,68 & 0,94 & 0,89 & 1,19 & 1,49 & 1,52 & 2,04 & 2,34 & 3,81 \\
\hline $\mathrm{O} 2 \mathrm{~S} 1$ & 0,45 & 0,51 & 0,55 & 0,85 & 0,70 & 0,97 & 0,92 & 1,22 & 1,52 & 1,57 & 2,13 & 2,43 & 3,96 \\
\hline $\mathrm{O} 3$ & 0,46 & 0,52 & 0,56 & 0,86 & 0,71 & 0,98 & 2,76 & 1,24 & 1,54 & 1,61 & 2,19 & 2,49 & 4,07 \\
\hline O(DNER) & 0,46 & 0,52 & 0,56 & 0,86 & 0,71 & 0,98 & 0,94 & 1,24 & 1,54 & 1,61 & 2,19 & 2,49 & 4,08 \\
\hline $\mathrm{O} 2$ & 0,47 & 0,53 & 0,58 & 0,88 & 0,74 & 1,02 & 0,94 & 1,29 & 1,59 & 1,68 & 2,30 & 2,60 & 4,31 \\
\hline U3 & 0,48 & 0,55 & 0,59 & 0,90 & 0,77 & 1,05 & 0,99 & 1,33 & 1,63 & 1,75 & 2,41 & 2,71 & 4,57 \\
\hline $3 \mathrm{~S} 2 \mathrm{~B} 2(20 \mathrm{~m})$ & 0,50 & 0,57 & 0,62 & 0,95 & 0,81 & 1,11 & 1,03 & 1,41 & 1,71 & 1,87 & 2,62 & 2,92 & 5,01 \\
\hline $\mathrm{O} 2 \mathrm{~S} 1 \mathrm{~B} 1$ & 0,50 & 0,58 & 0,62 & 0,97 & 0,82 & 1,14 & 1,11 & 1,46 & 1,76 & 1,94 & 2,73 & 3,03 & 5,21 \\
\hline $\mathrm{U} 2$ & 0,51 & 0,60 & 0,64 & 0,99 & 0,85 & 1,16 & 1,18 & 1,48 & 1,78 & 1,98 & 2,79 & 3,09 & 5,36 \\
\hline SR(DNER) & 0,53 & 0,62 & 0,67 & 1,02 & 0,89 & 1,20 & 1,24 & 1,54 & 1,84 & 2,07 & 2,94 & 3,24 & 5,68 \\
\hline $3 \mathrm{~S} 3 \mathrm{~B} 3$ & 0,61 & 0,73 & 0,79 & 1,21 & 1,10 & 1,46 & 1,30 & 1,89 & 2,19 & 2,63 & 3,84 & 4,14 & 7,67 \\
\hline $2 \mathrm{~S} 1$ & 0,64 & 0,78 & 0,84 & 1,29 & 1,18 & 1,56 & 1,59 & 2,03 & 2,33 & 2,85 & 4,21 & 4,51 & 8,48 \\
\hline $3 \mathrm{~S} 2 \mathrm{~B} 2(26 \mathrm{~m})$ & 0,65 & 0,79 & 0,86 & 1,30 & 1,20 & 1,59 & 1,73 & 2,07 & 2,37 & 2,90 & 4,29 & 4,59 & 8,67 \\
\hline $2 \mathrm{~S} 2(20 \mathrm{~m})$ & 0,66 & 0,81 & 0,87 & 1,33 & 1,23 & 1,62 & 1,77 & 2,11 & 2,41 & 2,97 & 4,40 & 4,70 & 8,93 \\
\hline $3 \mathrm{~S} 2 \mathrm{~A} 2 \mathrm{~S} 2$ & 0,69 & 0,86 & 0,92 & 1,41 & 1,31 & 1,73 & 1,81 & 2,26 & 2,56 & 3,20 & 4,78 & 5,08 & 9,80 \\
\hline $2 \mathrm{~S} 2(22,4 \mathrm{~m})$ & 0,72 & 0,89 & 0,97 & 1,47 & 1,38 & 1,81 & 1,96 & 2,37 & 2,67 & 3,39 & 5,09 & 5,39 & 10,52 \\
\hline
\end{tabular}


O cálculo da sobrelargura do veículo SR(DNER) foi realizado conforme é apresentado no Manual de projeto geométrico. Em vez de o gabarito estático do veículo na curva ser calculado pela equação 3.13, utilizando-se as distâncias entre os pontos notáveis das combinações de veículo, o valor de sobrelargura foi determinado considerando-se o veículo como unitário e utilizando-se uma distância entre eixos fictícia $E$, onde $E^{2}=E_{1}{ }^{2}+E_{2}^{2}$, sendo $E_{1}$ a distância entre o eixo dianteiro do cavalo mecânico e o pivô de apoio do semi-reboque e $E_{2}$ a distância entre este pivô e o ponto médio entre os eixos traseiros do veículo. Considerando o veículo desta forma, as sobrelarguras foram calculadas para uma distância entre eixos de $10 \mathrm{~m}$ e balanço dianteiro (BD) de 1,2 $\mathrm{m}$, que resultaram em valores um pouco inferiores ao que seria obtido considerando os pontos notáveis do veículo separadamente. Os veículos estão apresentados em ordem crescente de sobrelarguras exigidas, e os resultados obtidos indicaram que:

(a) comparando as sobrelarguras demandadas pelos veículos em cada classe técnica de rodovia, percebe-se a existência de maior dispersão destes valores, à medida que é reduzido o padrão técnico da rodovia, uma vez que os raios de curva mínimos requeridos nessas rodovias são menores e é permitida a utilização de faixas de tráfego mais estreitas. Desta forma, os veículos mais complexos que o veículo de projeto utilizado para dimensionamento das sobrelarguras enfrentam maiores restrições, à medida que o padrão da rodovia diminui;

(b) veículos com maiores comprimentos totais não implicam necessariamente maiores valores de sobrelarguras requeridas. De modo geral, veículos com mais pontos de articulação e menores distâncias entre eixos da unidade tratora e das unidades rebocadas exigem menores sobrelarguras. Em particular, o bitrem de sete eixos e $20 \mathrm{~m}$ de comprimento, 3S2B2, é menos crítico do que a maioria das CVCs com uma ou duas unidades rebocadas;

(c) o caminhão unitário de $14 \mathrm{~m}$ de comprimento total, veículo U2, cujo tráfego irrestrito em todo o Território Nacional é permitido pela Resolução no 210 do CONTRAN (BRASIL, 2006a), requer sobrelarguras maiores do que os veículos de projeto CO e O do Manual do DNER; 
(d) o veículo de projeto $\mathrm{RE}(\mathrm{DNIT})$, quando consideradas as sobrelarguras requeridas, só é mais crítico do que o veículo de projeto $\mathrm{CO}$, não constituindo nova referência para o projeto geométrico de curvas horizontais;

(e) de modo geral, combinações do tipo cavalo mecânico mais semi-reboque(s) requerem sobrelarguras maiores do que combinações do tipo caminhãoplataforma mais reboque (romeu-e-julieta) de mesmo comprimento (v. SR(DNER) versus RE(DNIT)). A CVC do tipo 2S1 deveria ser utilizada no lugar do veículo SR(DNER), dado que seu tráfego é autorizado em todo o Território Nacional pela Resolução $n^{\circ} 210$, do CONTRAN; e

(f) o veículo mais crítico em termos de requisitos de sobrelargura é o cegonheiro, 2S2 $(22,4 \mathrm{~m})$, que hoje tem tráfego assegurado pela Resolução $\mathrm{n}^{\mathrm{o}} 75$, do CONTRAN (BRASIL, 1999b).

Foi utilizado o conceito proposto de folga lateral efetiva $\left(\mathrm{FL}_{\mathrm{E}}\right)$ para verificar a compatibilidade dos veículos nas curvas horizontais, a partir das sobrelarguras apresentadas na Tabela 4.2. Os resultados obtidos estão apresentados nas Figuras de 4.2 a 4.16, onde foram considerados os três veículos de projeto do DNER, CO, O e SR para as cinco classes técnicas de rodovias, nos três tipos de terreno. Foi empregada a notação $\mathrm{R}$ para os casos em que a compatibilidade do veículo está condicionada à utilização do acostamento e a letra I para indicar incompatibilidade do veículo, observada quando, mesmo com a utilização total do acostamento, não é garantido um espaço de segurança de 0,40 m. Nos demais casos, foi constatada uma condição de compatibilidade.

As Figuras de 4.2 a 4.4 mostram os valores de $\mathrm{FL}_{\mathrm{E}}$ dos veículos para uma rodovia de Classe 0, quando as sobrelarguras são calculadas com base nos veículos de projeto $\mathrm{CO}, \mathrm{O}$ e $\mathrm{SR}$. Os resultados mostram que em todos os tipos de relevo e para qualquer veículo de projeto os veículos apresentam uma folga lateral compatível. Apenas a CVC 2S2 $(22,4 \mathrm{~m})$ no relevo montanhoso e com o veículo de projeto $\mathrm{CO}$ (Figura 4.2) apresentou um valores de $\mathrm{FL}_{\mathrm{E}}$ abaixo de $0,40 \mathrm{~m}$, entretanto próximo deste limite. 


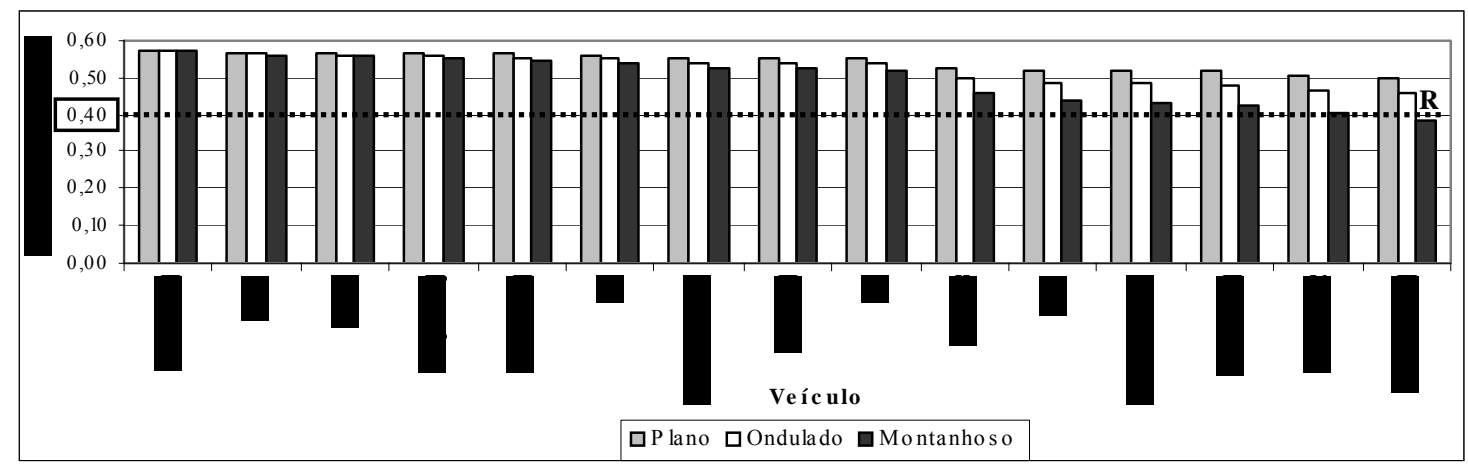

Figura 4.2: Folga Lateral dos Veículos - Classe 0 - Veículo de Projeto CO.

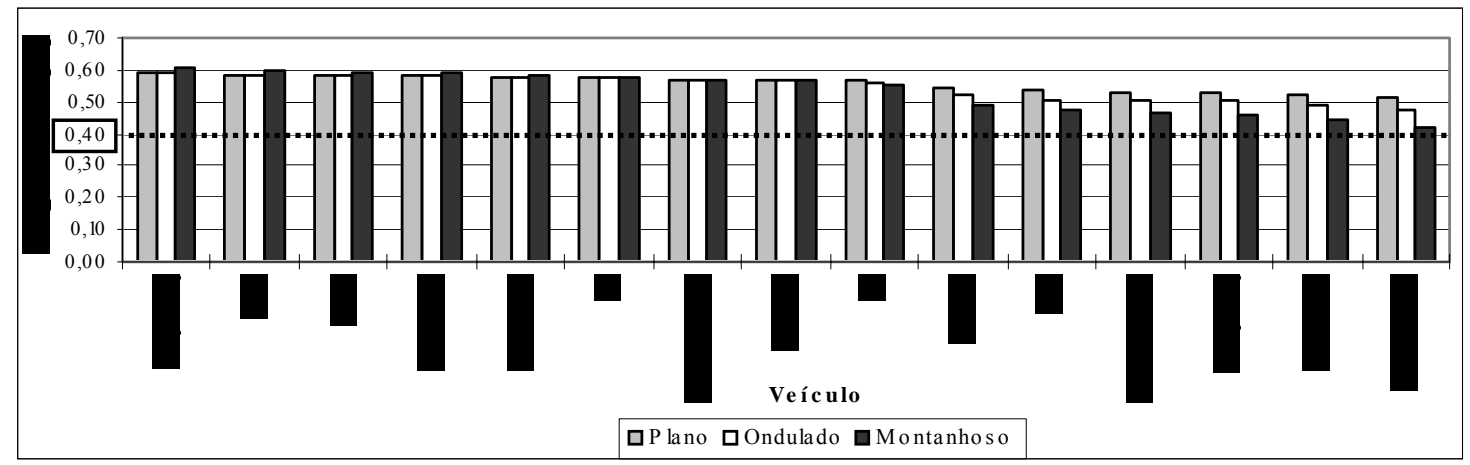

Figura 4.3: Folga Lateral dos Veículos - Classe 0 - Veículo de Projeto O.

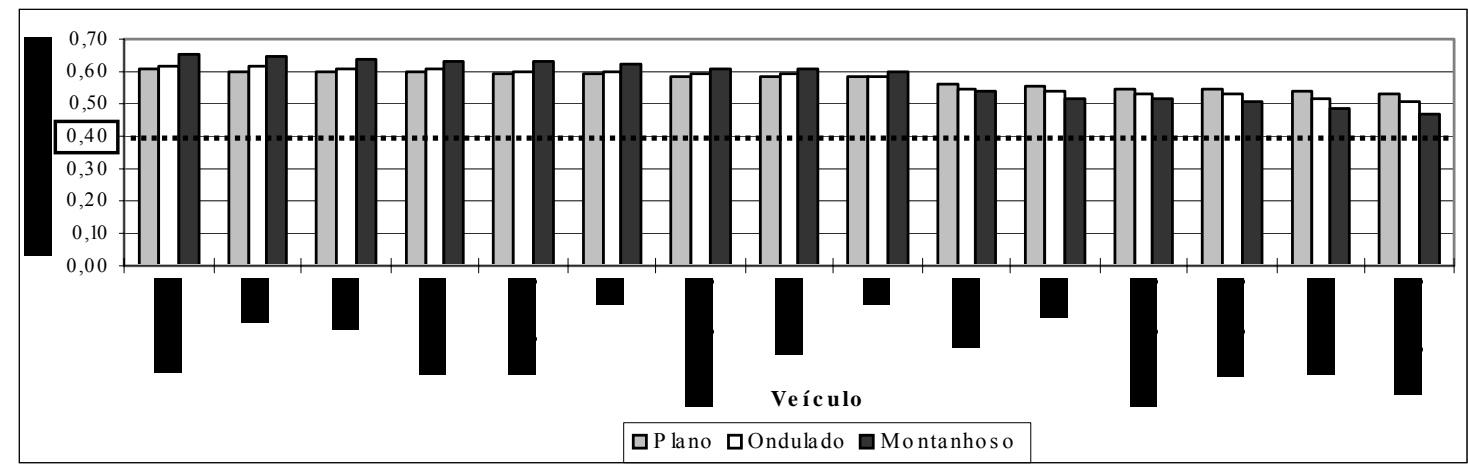

Figura 4.4: Folga Lateral dos Veículos - Classe 0 - Veículo de Projeto SR.

As Figuras 4.5 a 4.7 mostram os valores de $\mathrm{FL}_{\mathrm{E}}$ calculados para os veículos operando em rodovias de Classe I. Qualquer que seja o veículo de projeto considerado, as folgas laterais se mantêm em torno de $0,40 \mathrm{~m}$ ou acima para todos os veículos nos relevos plano e ondulado. Para o veículo de projeto $\mathrm{CO}$, no relevo montanhoso, têm-se restrições crescentes a partir da $\mathrm{CVC}$ 3S3B3, com a necessidade de utilização dos acostamentos para permitir um espaço de segurança de 0,40 m. 


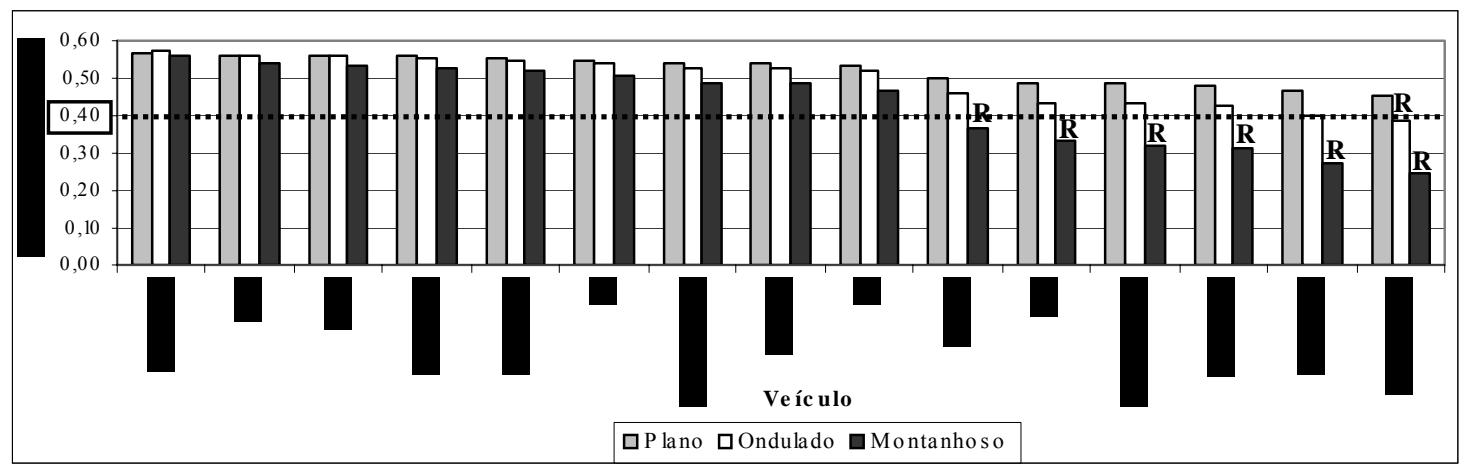

Figura 4.5: Folga Lateral dos Veículos - Classe I - Veículo de Projeto CO.

Quando são utilizados os veículos de projeto O e SR, o uso do acostamento ocorre apenas no terreno montanhoso, a partir do veículo $2 \mathrm{~S} 1$, quando utilizado o veículo de projeto $\mathrm{O}$ e apenas nos veículos 2S2A2S2 e 2S2(22,45m), quando utilizado o veículo SR. Considerando o caso de maior uso do acostamento, tem-se o veículo 2S2 $(22,45 \mathrm{~m})$ no relevo montanhoso e veículo de projeto $\mathrm{CO}$, ocorrendo uma invasão de apenas $20 \mathrm{~cm}$ do acostamento, valor este compatível com a largura mínima desta classe de projeto, que é de $2,5 \mathrm{~m}$ para o terreno montanhoso.

Os resultados mostram que, para as rodovias de Classe 0 e I, nos poucos casos de uso do acostamento, este cumpre a função apenas de garantir a manutenção de espaços de segurança de $0,40 \mathrm{~m}$, não havendo ocupação física do acostamento por qualquer um dos veículos pesquisados.

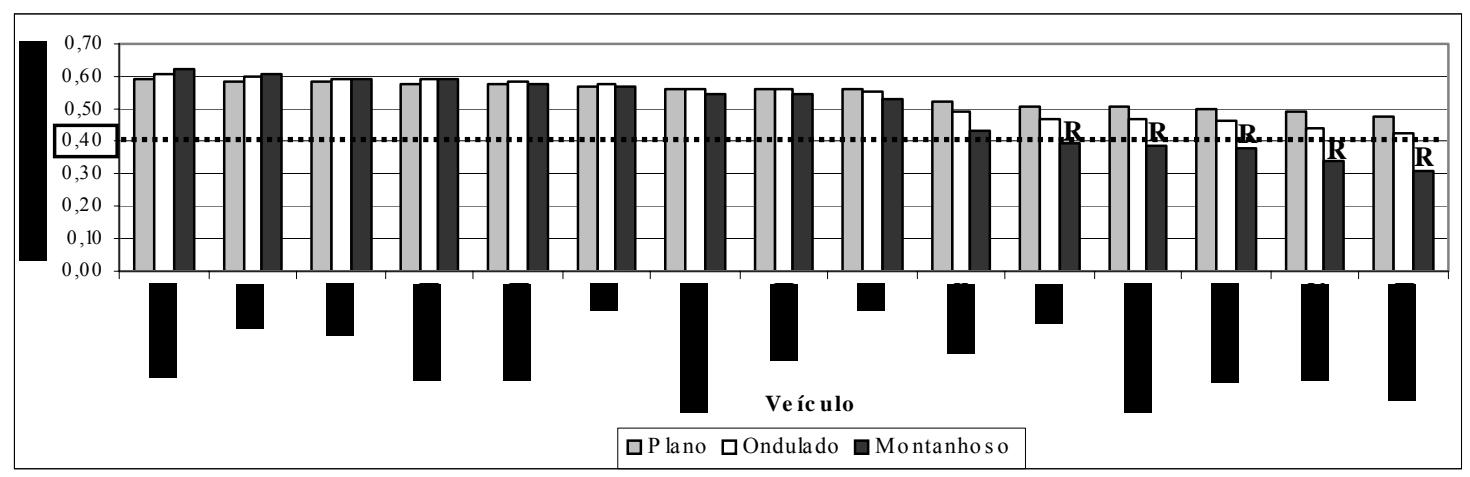

Figura 4.6: Folga Lateral dos Veículos - Classe I - Veículo de Projeto O 


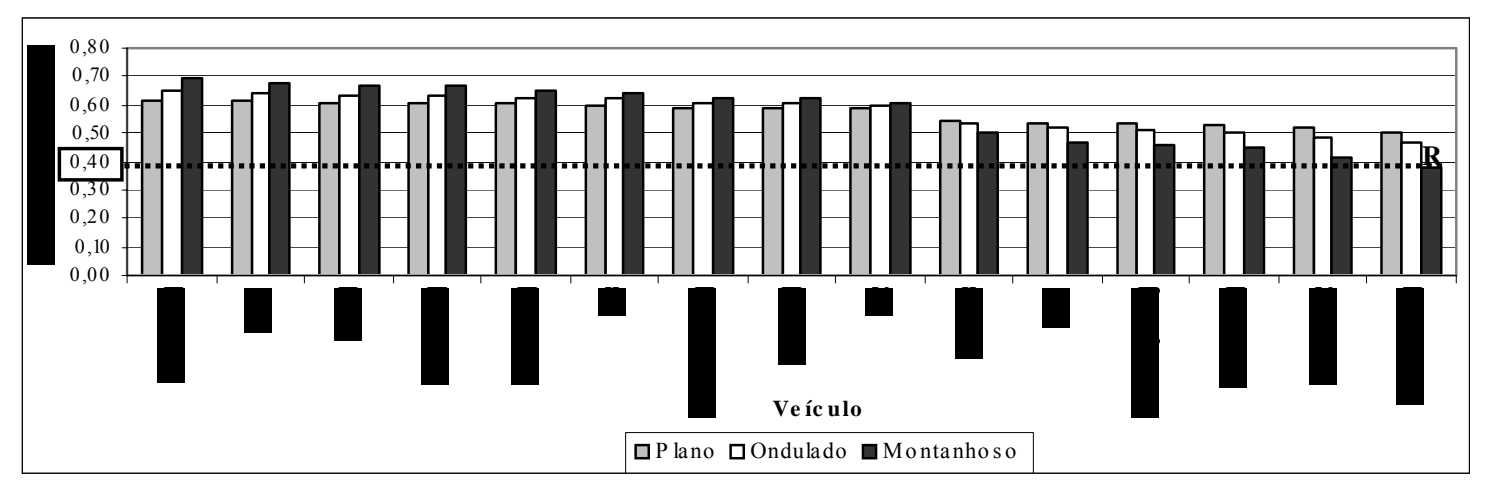

Figura 4.7: Folga Lateral dos Veículos - Classe I - Veículo de Projeto SR

Para os veículos operando numa rodovia de Classe II, os resultados estão apresentados nas Figuras 4.8 a 4.10. No terreno plano, os afastamentos laterais mínimos são atendidos para todos os veículos, independentemente do veículo de projeto. No terreno ondulado, são observados valores abaixo do limite de $0,40 \mathrm{~m}$, quando é utilizado o veículo $\mathrm{CO}$, a partir da CVC 2S1 e para o veículo de projeto O nas CVC 2S2A2S2 e 2S2 $(22,4)$ com pequena utilização do acostamento. No terreno montanhoso, são observados valores negativos no gráfico, que indicam um déficit de sobrelargura que ultrapassa os espaços de segurança na largura das faixas de tráfego. Nestes casos, a varredura do veículo na curva ultrapassa a largura total da pista, ocorrendo a invasão física dos acostamentos. Para o veículo de projeto $\mathrm{CO}$, a utilização dos acostamentos é necessária a partir do veículo O2(ROD).

Todos os demais veículos utilizam o acostamento, sendo o maior uso, de aproximadamente $1,0 \mathrm{~m}$, ainda compatível com a largura mínima de acostamento da Classe II, que é de $2,0 \mathrm{~m}$.

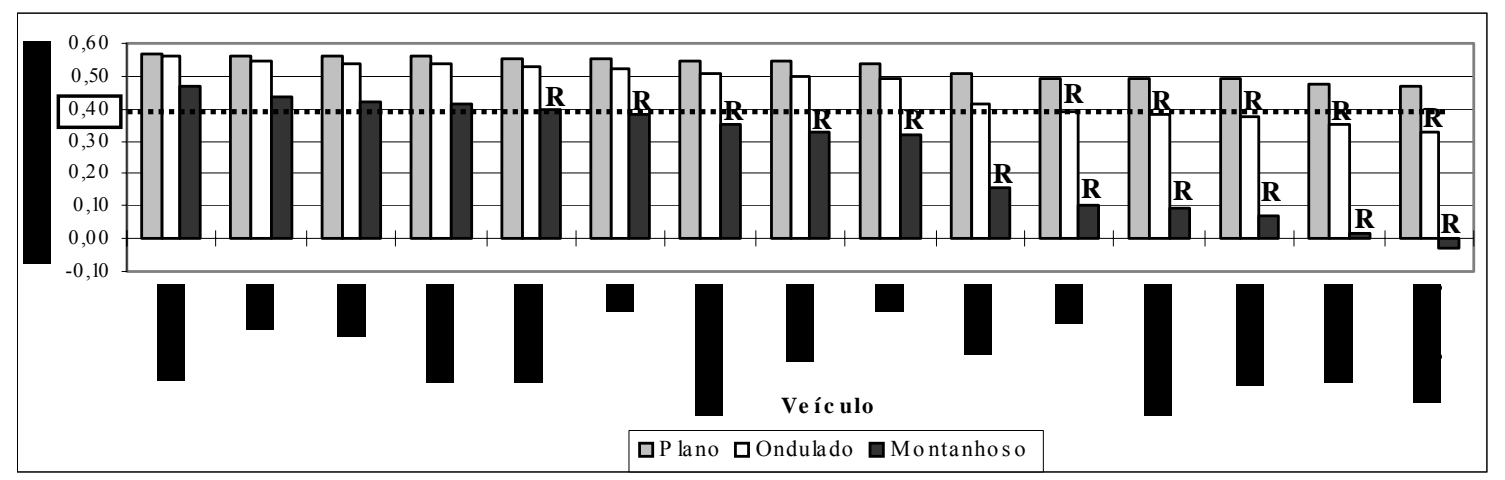

Figura 4.8: Folga Lateral dos Veículos - Classe II - Veículo de Projeto CO. 


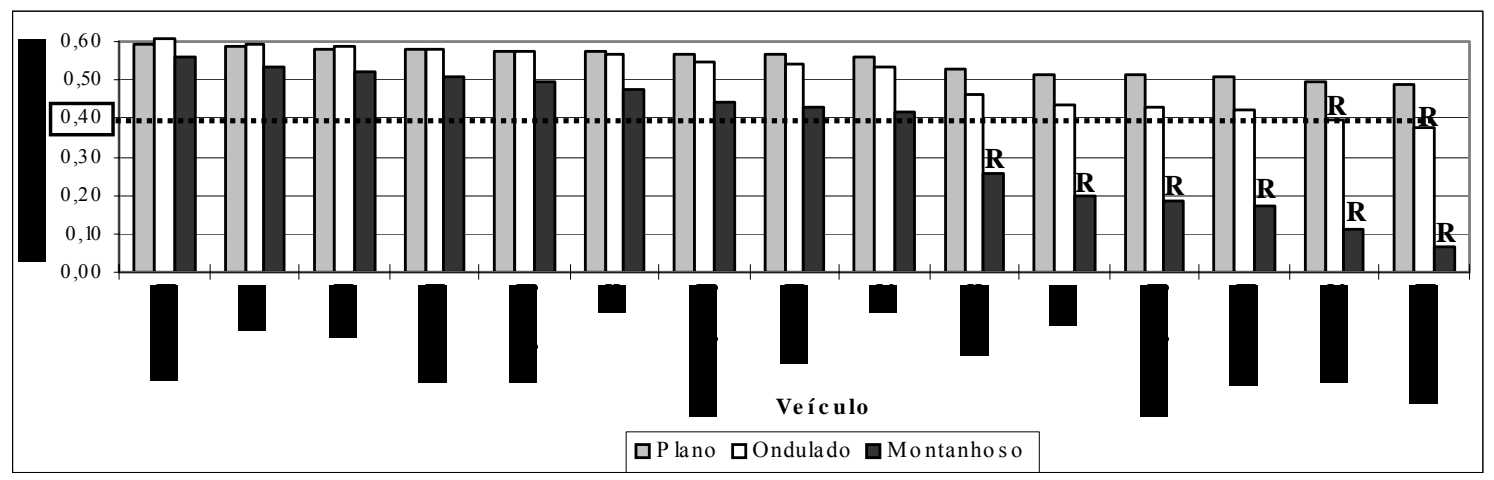

Figura 4.9: Folga Lateral dos Veículos - Classe II - Veículo de Projeto O.

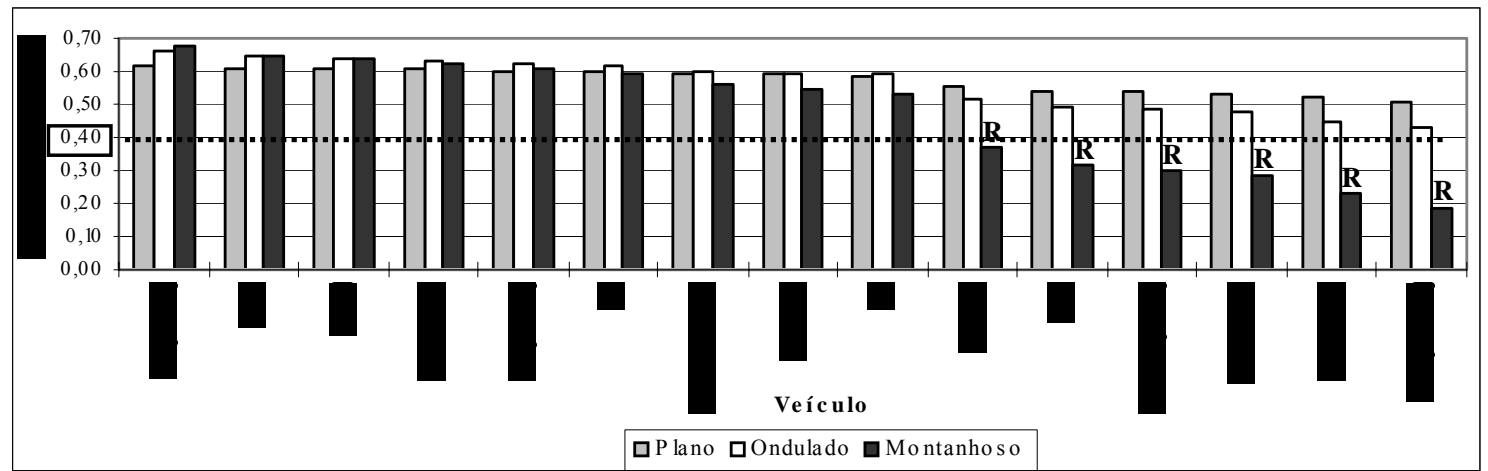

Figura 4.10: Folga Lateral dos Veículos - Classe II - Veículo de Projeto SR.

As Figuras 4.11 a 4.13 mostram os valores de folga lateral efetiva observados nos veículos na Classe III. Para o relevo plano, todos os veículos atendem o valor de espaçamento lateral mínimo sem invasão do acostamento. Nos demais terrenos, vários veículos utilizam o acostamento, sendo que na situação mais crítica, verificada com o veículo $2 \mathrm{~S} 2(22,4 \mathrm{~m})$, veículo de projeto $\mathrm{CO}$ e terreno montanhoso, é observado o único caso de incompatibilidade para a Classe III. Neste caso, mesmo com a utilização total do acostamento, não se obtém uma folga lateral efetiva de $0,40 \mathrm{~m}$.

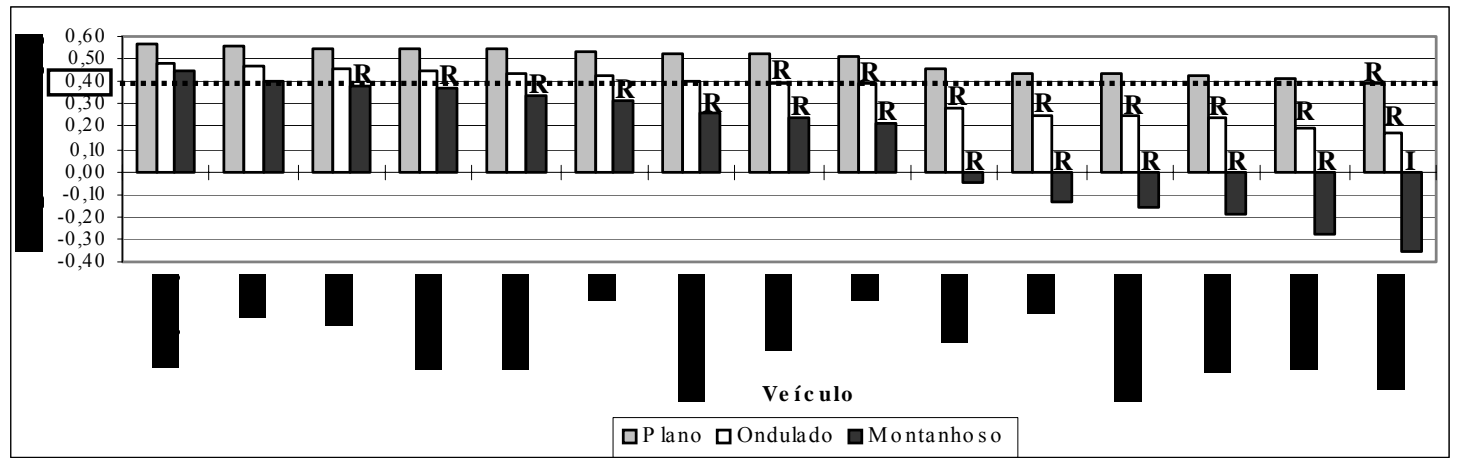

Figura 4.11: Folga Lateral dos Veículos - Classe III - Veículo de Projeto CO. 


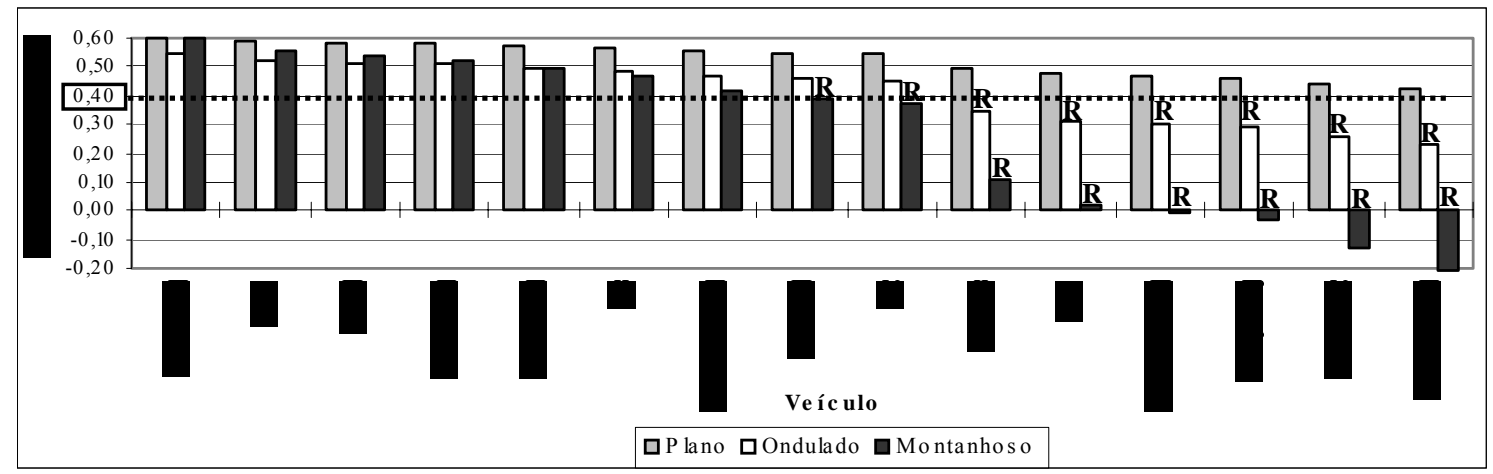

Figura 4.12: Folga Lateral dos Veículos - Classe III - Veículo de Projeto O.

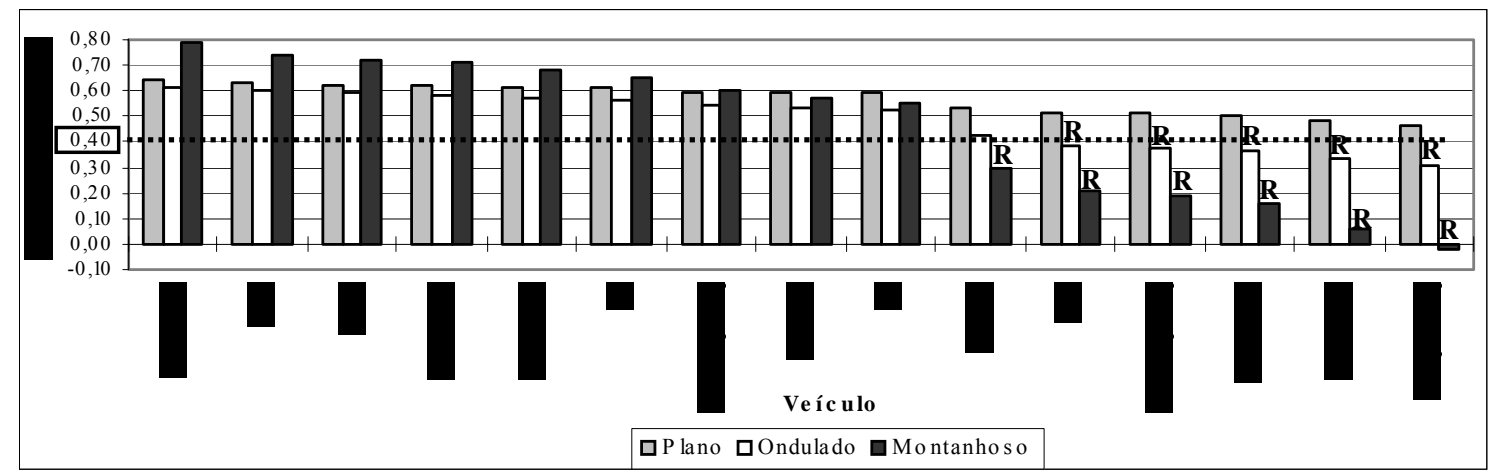

Figura 4.13: Folga Lateral dos Veículos - Classe III - Veículo de Projeto SR.

Para uma rodovia de Classe IV, com veículo de projeto CO, mostrado na Figura 4.14, apenas o veículo O2(URB) no terreno plano não faz uso dos acostamentos, condição necessária nos demais veículos neste relevo.

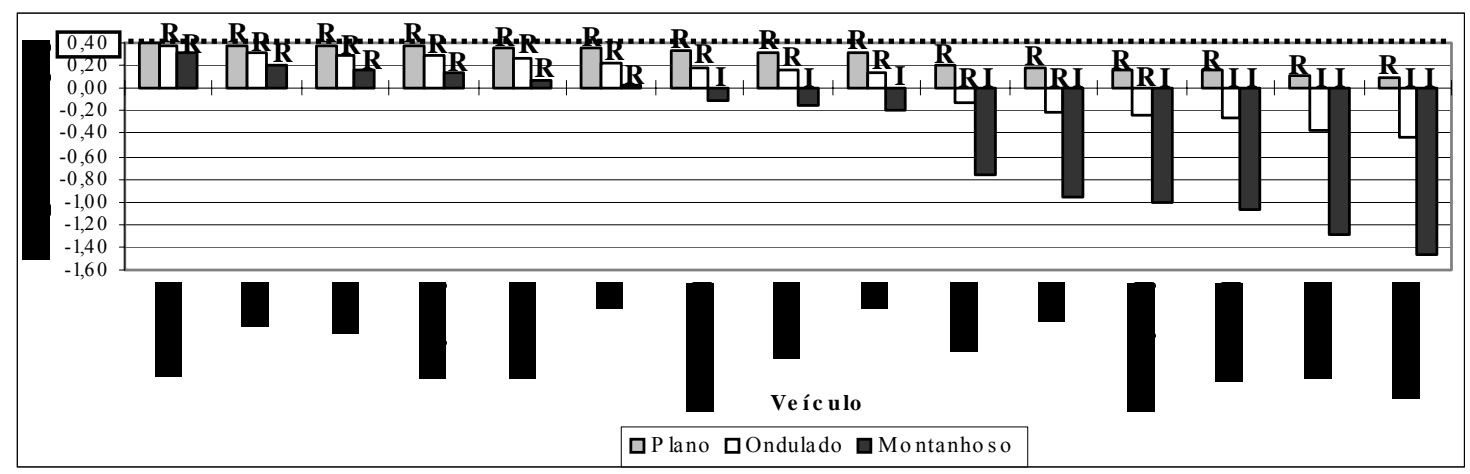

Figura 4.14: Folga Lateral dos Veículos - Classe IV - Veículo de Projeto CO.

No terreno ondulado, a partir do veículo $2 \mathrm{~S} 2(20 \mathrm{~m})$ e demais veículos que demandam maiores sobrelarguras, a largura mínima do acostamento da Classe IV, que é 
de 1,3 m, é insuficiente para acolher estes veículos, sendo sua operação considerada incompatível. No terreno montanhoso, onde a largura mínima dos acostamentos é de 0,8 m, a incompatibilidade ocorre a partir da CVC 3S2B2(20m).

Nas Figuras 4.15 e 4.16, estão as folgas laterais observadas nos veículos da Classe IV para os demais veículos de projeto. A incompatibilidade no terreno ondulado, quando é utilizado o veículo de projeto $\mathrm{O}$, foi verificada apenas para o veículo 2S2(22,4m). No terreno montanhoso, ocorre incompatibilidade a partir do veículo 3S3B3, seja para o veículo de projeto O ou SR.

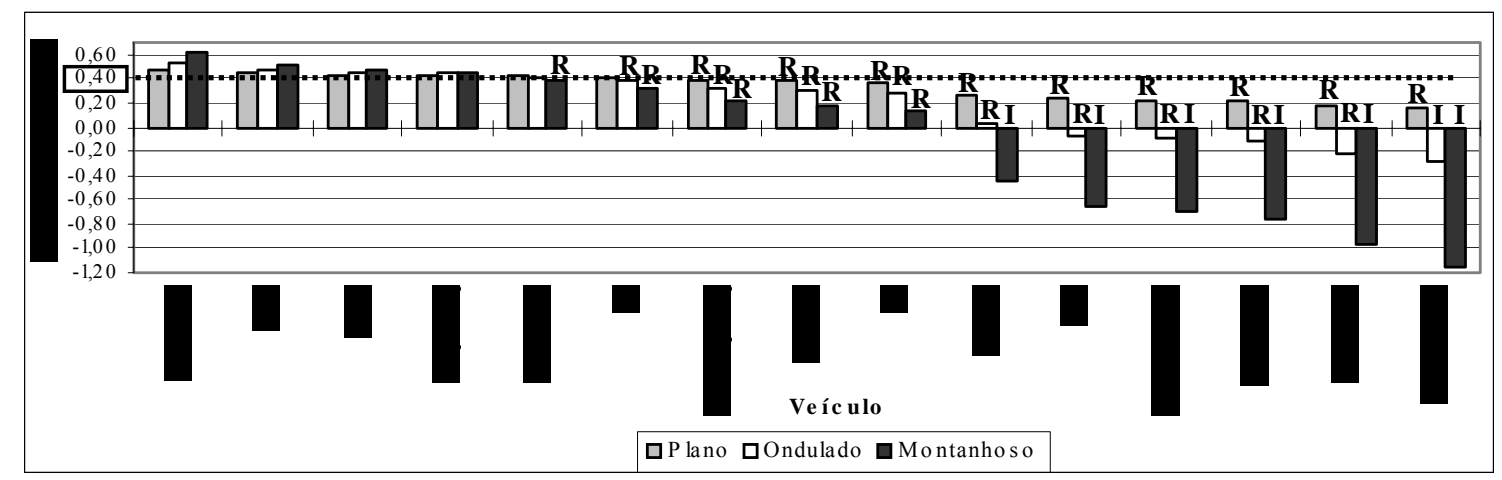

Figura 4.15: Folga Lateral dos Veículos - Classe IV - Veículo de Projeto O.

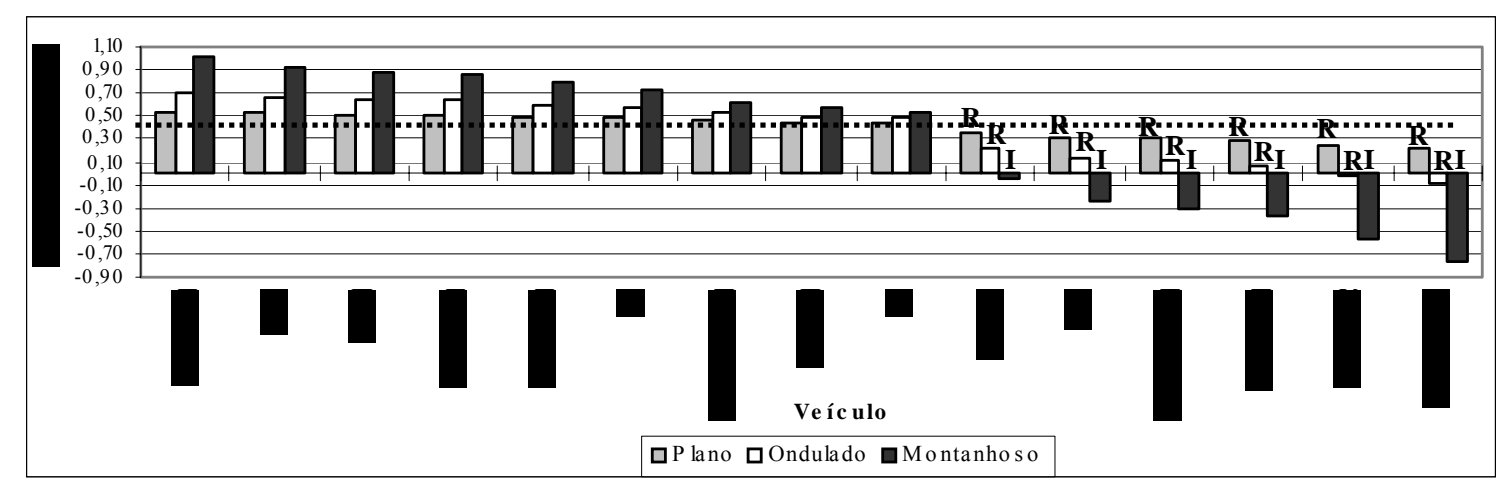

Figura 4.16: Folga Lateral dos Veículos - Classe IV - Veículo de Projeto SR.

A Tabela 4.3 apresenta um resumo dos resultados obtidos, indicando as situações de Compatibilidade (C), Tráfego Restrito (R) e Incompatibilidade (I). 
Tabela 4.3: Compatibilidade das Sobrelarguras Calculadas com Base nos Veículos de Projeto do DNER, por Classe de Rodovia e Terreno (Plano (P), Ondulado (O) e Montanhoso (M)).

\begin{tabular}{|c|c|c|c|c|c|c|c|c|c|c|c|c|c|c|c|}
\hline \multicolumn{16}{|c|}{ VEÍCULO DE PROJETO CO } \\
\hline Classe Técnica & \multicolumn{3}{|c|}{ Classe 0} & \multicolumn{3}{|c|}{ Classe I } & \multicolumn{3}{|c|}{ Classe II } & \multicolumn{3}{|c|}{ Classe III } & \multicolumn{3}{|c|}{ Classe IV } \\
\hline Terreno & $\mathrm{P}$ & $\mathrm{O}$ & $\mathrm{M}$ & $\mathrm{P}$ & $\mathrm{O}$ & $\mathrm{M}$ & $\mathrm{P}$ & $\mathrm{O}$ & $\mathrm{M}$ & $\mathrm{P}$ & $\mathrm{O}$ & $\mathrm{M}$ & $\mathrm{P}$ & $\mathrm{O}$ & $\bar{M}$ \\
\hline $\mathrm{O} 2$ (URB) & $\mathrm{C}$ & $\mathrm{C}$ & $\mathrm{C}$ & $\mathrm{C}$ & $\mathrm{C}$ & $\mathrm{C}$ & $\mathrm{C}$ & $\mathrm{C}$ & $\mathrm{C}$ & $\mathrm{C}$ & $\mathrm{C}$ & $\mathrm{C}$ & $\mathrm{C}$ & $\mathrm{R}$ & $\mathrm{R}$ \\
\hline $2 \mathrm{~S} 3$ & $\mathrm{C}$ & $\mathrm{C}$ & $\mathrm{C}$ & $\mathrm{C}$ & $\mathrm{C}$ & $\mathrm{C}$ & $\mathrm{C}$ & $\mathrm{C}$ & $\mathrm{C}$ & $\mathrm{C}$ & $\mathrm{C}$ & $\mathrm{C}$ & $\mathrm{R}$ & $\mathrm{R}$ & $\mathrm{R}$ \\
\hline $\mathrm{O} 2 \mathrm{~S} 1$ & $\mathrm{C}$ & $\mathrm{C}$ & $\mathrm{C}$ & $\mathrm{C}$ & $\mathrm{C}$ & $\mathrm{C}$ & $\mathrm{C}$ & $\mathrm{C}$ & $\mathrm{C}$ & $\mathrm{C}$ & $\mathrm{C}$ & $\mathrm{R}$ & $\mathrm{R}$ & $\mathrm{R}$ & $\mathrm{R}$ \\
\hline$\overline{\mathrm{O} 3(\mathrm{ROD})}$ & $\mathrm{C}$ & $\mathrm{C}$ & $\mathrm{C}$ & $\mathrm{C}$ & $\mathrm{C}$ & $\mathrm{C}$ & $\mathrm{C}$ & $\mathrm{C}$ & $\mathrm{C}$ & $\mathrm{C}$ & $\mathrm{C}$ & $\mathrm{R}$ & $\overline{\mathrm{R}}$ & $\mathrm{R}$ & $\mathrm{R}$ \\
\hline O2(ROD) & $\mathrm{C}$ & $\mathrm{C}$ & $\mathrm{C}$ & $\mathrm{C}$ & $\mathrm{C}$ & $\mathrm{C}$ & $\mathrm{C}$ & $\mathrm{C}$ & $\mathrm{R}$ & $\mathrm{C}$ & $\mathrm{C}$ & $\mathrm{R}$ & $\mathrm{R}$ & $\mathrm{R}$ & $\mathrm{R}$ \\
\hline U3 & $\mathrm{C}$ & $\mathrm{C}$ & $\mathrm{C}$ & $\mathrm{C}$ & $\mathrm{C}$ & $\mathrm{C}$ & $\mathrm{C}$ & $\mathrm{C}$ & $\mathrm{R}$ & $\mathrm{C}$ & $\mathrm{C}$ & $\mathrm{R}$ & $\bar{R}$ & $\mathrm{R}$ & $\mathrm{R}$ \\
\hline 3S2B2(20m) & $\mathrm{C}$ & $\mathrm{C}$ & $\mathrm{C}$ & $\mathrm{C}$ & $\mathrm{C}$ & $\mathrm{C}$ & $\mathrm{C}$ & $\mathrm{C}$ & $\mathrm{R}$ & $\mathrm{C}$ & $\mathrm{C}$ & $\mathrm{R}$ & $\mathrm{R}$ & $\mathrm{R}$ & $\mathrm{I}$ \\
\hline O2S1B1 & $\mathrm{C}$ & $\mathrm{C}$ & $\mathrm{C}$ & $\mathrm{C}$ & $\mathrm{C}$ & $\mathrm{C}$ & $\mathrm{C}$ & $\mathrm{C}$ & $\mathrm{R}$ & $\mathrm{C}$ & $\mathrm{R}$ & $\mathrm{R}$ & $\mathrm{R}$ & $\mathrm{R}$ & I \\
\hline $\mathrm{U} 2$ & $\mathrm{C}$ & $\mathrm{C}$ & $\mathrm{C}$ & $\mathrm{C}$ & $\mathrm{C}$ & $\mathrm{C}$ & $\mathrm{C}$ & $\mathrm{C}$ & $\mathrm{R}$ & $\mathrm{C}$ & $\mathrm{R}$ & $\mathrm{R}$ & $\mathrm{R}$ & $\mathrm{R}$ & I \\
\hline 3S3B3 & $\mathrm{C}$ & $\mathrm{C}$ & $\mathrm{C}$ & $\mathrm{C}$ & $\mathrm{C}$ & $\mathrm{R}$ & $\mathrm{C}$ & $\mathrm{C}$ & $\mathrm{R}$ & $\mathrm{C}$ & $\mathrm{R}$ & $\mathrm{R}$ & $\mathrm{R}$ & $\mathrm{R}$ & I \\
\hline $2 \mathrm{~S} 1$ & $\mathrm{C}$ & $\mathrm{C}$ & $\mathrm{C}$ & $\mathrm{C}$ & $\mathrm{C}$ & $\mathrm{R}$ & $\mathrm{C}$ & $\mathrm{R}$ & $\mathrm{R}$ & $\mathrm{C}$ & $\mathrm{R}$ & $\mathrm{R}$ & $\mathrm{R}$ & $\mathrm{R}$ & I \\
\hline 3S2B2 $(26 \mathrm{~m})$ & $\mathrm{C}$ & $\mathrm{C}$ & $\mathrm{C}$ & $\mathrm{C}$ & $\mathrm{C}$ & $\mathrm{R}$ & $\mathrm{C}$ & $\mathrm{R}$ & $\mathrm{R}$ & $\mathrm{C}$ & $\mathrm{R}$ & $\mathrm{R}$ & $\mathrm{R}$ & $\mathrm{R}$ & $\mathrm{I}$ \\
\hline $2 \mathrm{~S} 2(20 \mathrm{~m})$ & $\mathrm{C}$ & $\mathrm{C}$ & $\mathrm{C}$ & $\mathrm{C}$ & $\mathrm{C}$ & $\mathrm{R}$ & $\mathrm{C}$ & $\mathrm{R}$ & $\mathrm{R}$ & $\mathrm{C}$ & $\mathrm{R}$ & $\mathrm{R}$ & $\mathrm{R}$ & I & I \\
\hline $3 \mathrm{~S} 2 \mathrm{~A} 2 \mathrm{~S} 2$ & $\mathrm{C}$ & $\mathrm{C}$ & $\mathrm{C}$ & $\mathrm{C}$ & $\mathrm{C}$ & $\mathrm{R}$ & $\mathrm{C}$ & $\mathrm{R}$ & $\mathrm{R}$ & $\mathrm{C}$ & $\mathrm{R}$ & $\mathrm{R}$ & $\mathrm{R}$ & I & I \\
\hline $2 \mathrm{~S} 2(2$ & $\mathrm{C}$ & $\mathrm{C}$ & $\mathrm{R}$ & $\mathrm{C}$ & $\mathrm{R}$ & $\mathrm{R}$ & $\mathrm{C}$ & $\mathrm{R}$ & $\mathrm{R}$ & $\mathrm{R}$ & $\mathrm{R}$ & $\mathrm{I}$ & $\mathrm{R}$ & I & $\mathrm{I}$ \\
\hline \multicolumn{16}{|c|}{ VEÍCULO DE PROJETO O } \\
\hline Classe Técnica & \multicolumn{3}{|c|}{ Classe 0} & \multicolumn{3}{|c|}{ Classe I } & \multicolumn{3}{|c|}{ Classe II } & \multicolumn{3}{|c|}{ Classe III } & \multicolumn{3}{|c|}{ Classe IV } \\
\hline Terreno & $\mathrm{P}$ & $\mathrm{O}$ & M & $\mathrm{P}$ & $\mathrm{O}$ & $\mathrm{M}$ & $\mathrm{P}$ & $\mathrm{O}$ & M & $\mathrm{P}$ & $\mathrm{O}$ & $\mathrm{M}$ & $\mathrm{P}$ & $\mathrm{O}$ & M \\
\hline O2 (URB) & $\mathrm{C}$ & $\mathrm{C}$ & $\mathrm{C}$ & $\mathrm{C}$ & $\mathrm{C}$ & $\mathrm{C}$ & $\mathrm{C}$ & $\mathrm{C}$ & $\mathrm{C}$ & $\mathrm{C}$ & $\mathrm{C}$ & $\mathrm{C}$ & $\mathrm{C}$ & $\mathrm{C}$ & $\mathrm{C}$ \\
\hline $2 \mathrm{~S} 3$ & $\mathrm{C}$ & $\mathrm{C}$ & $\mathrm{C}$ & $\mathrm{C}$ & $\mathrm{C}$ & $\mathrm{C}$ & $\mathrm{C}$ & $\mathrm{C}$ & $\mathrm{C}$ & $\mathrm{C}$ & $\mathrm{C}$ & $\mathrm{C}$ & $\mathrm{C}$ & $\mathrm{C}$ & $\mathrm{C}$ \\
\hline $\mathrm{O} 2 \mathrm{~S} 1$ & $\mathrm{C}$ & $\mathrm{C}$ & $\mathrm{C}$ & $\mathrm{C}$ & $\mathrm{C}$ & $\mathrm{C}$ & $\mathrm{C}$ & $\mathrm{C}$ & $\mathrm{C}$ & $\mathrm{C}$ & $\mathrm{C}$ & $\mathrm{C}$ & $\bar{C}$ & $\mathrm{C}$ & $\mathrm{C}$ \\
\hline O3(ROD) & $\mathrm{C}$ & $\mathrm{C}$ & $\mathrm{C}$ & $\mathrm{C}$ & $\mathrm{C}$ & $\mathrm{C}$ & $\mathrm{C}$ & $\mathrm{C}$ & $\mathrm{C}$ & $\mathrm{C}$ & $\mathrm{C}$ & $\mathrm{C}$ & $\mathrm{C}$ & $\mathrm{C}$ & $\mathrm{C}$ \\
\hline $\mathrm{O} 2$ (ROD) & $\mathrm{C}$ & $\mathrm{C}$ & $\mathrm{C}$ & $\mathrm{C}$ & $\mathrm{C}$ & $\mathrm{C}$ & $\mathrm{C}$ & $\mathrm{C}$ & $\mathrm{C}$ & $\mathrm{C}$ & $\mathrm{C}$ & $\mathrm{C}$ & $\mathrm{C}$ & $\mathrm{C}$ & $\mathrm{R}$ \\
\hline U3 & $\mathrm{C}$ & $\mathrm{C}$ & $\mathrm{C}$ & $\mathrm{C}$ & $\mathrm{C}$ & $\mathrm{C}$ & $\mathrm{C}$ & $\mathrm{C}$ & $\mathrm{C}$ & $\mathrm{C}$ & $\mathrm{C}$ & $\mathrm{C}$ & $\mathrm{C}$ & $\mathrm{R}$ & $\mathrm{R}$ \\
\hline $3 \mathrm{~S} 2 \mathrm{~B} 2(20 \mathrm{~m})$ & $\mathrm{C}$ & $\mathrm{C}$ & $\mathrm{C}$ & $\mathrm{C}$ & $\mathrm{C}$ & $\mathrm{C}$ & $\mathrm{C}$ & $\mathrm{C}$ & $\mathrm{C}$ & $\mathrm{C}$ & $\mathrm{C}$ & $\mathrm{C}$ & $\mathrm{R}$ & $\mathrm{R}$ & $\mathrm{R}$ \\
\hline O2S1B1 & $\mathrm{C}$ & $\mathrm{C}$ & $\mathrm{C}$ & $\mathrm{C}$ & $\mathrm{C}$ & $\mathrm{C}$ & $\mathrm{C}$ & $\mathrm{C}$ & $\mathrm{C}$ & $\mathrm{C}$ & $\mathrm{C}$ & $\mathrm{R}$ & $\mathrm{R}$ & $\mathrm{R}$ & $\mathrm{R}$ \\
\hline $\mathrm{U} 2$ & $\mathrm{C}$ & $\mathrm{C}$ & $\mathrm{C}$ & $\mathrm{C}$ & $\mathrm{C}$ & $\mathrm{C}$ & $\mathrm{C}$ & $\mathrm{C}$ & $\mathrm{C}$ & $\mathrm{C}$ & $\mathrm{C}$ & $\mathrm{R}$ & $\mathrm{R}$ & $\mathrm{R}$ & $\mathrm{R}$ \\
\hline 3S3B3 & $\mathrm{C}$ & $\mathrm{C}$ & $\mathrm{C}$ & $\mathrm{C}$ & $\mathrm{C}$ & $\mathrm{C}$ & $\mathrm{C}$ & $\mathrm{C}$ & $\mathrm{R}$ & $\mathrm{C}$ & $\mathrm{R}$ & $\mathrm{R}$ & $\mathrm{R}$ & $\mathrm{R}$ & I \\
\hline $2 \mathrm{~S} 1$ & $\mathrm{C}$ & $\mathrm{C}$ & $\mathrm{C}$ & $\mathrm{C}$ & $\mathrm{C}$ & $\mathrm{R}$ & $\mathrm{C}$ & $\mathrm{C}$ & $\mathrm{R}$ & $\mathrm{C}$ & $\mathrm{R}$ & $\mathrm{R}$ & $\mathrm{R}$ & $\mathrm{R}$ & I \\
\hline $3 \mathrm{~S} 2 \mathrm{~B} 2(26 \mathrm{~m})$ & $\mathrm{C}$ & $\mathrm{C}$ & $\mathrm{C}$ & $\mathrm{C}$ & $\mathrm{C}$ & $\mathrm{R}$ & $\mathrm{C}$ & $\mathrm{C}$ & $\mathrm{R}$ & $\mathrm{C}$ & $\mathrm{R}$ & $\mathrm{R}$ & $\mathrm{R}$ & $\mathrm{R}$ & I \\
\hline $2 \mathrm{~S} 2(2$ & $\mathrm{C}$ & $\mathrm{C}$ & $\mathrm{C}$ & $\mathrm{C}$ & $\mathrm{C}$ & $\mathrm{R}$ & $\mathrm{C}$ & $\mathrm{C}$ & $\mathrm{R}$ & $\mathrm{C}$ & $\mathrm{R}$ & $\mathrm{R}$ & $\mathrm{R}$ & $\mathrm{R}$ & $\mathrm{I}$ \\
\hline & $\mathrm{C}$ & $\mathrm{C}$ & $\mathrm{C}$ & $\mathrm{C}$ & $\mathrm{C}$ & $\mathrm{R}$ & $\mathrm{C}$ & $\mathrm{R}$ & $\mathrm{R}$ & $\mathrm{C}$ & $\mathrm{R}$ & $\mathrm{R}$ & $\mathrm{R}$ & $\mathrm{R}$ & $\mathrm{I}$ \\
\hline $2 \mathrm{~S} 2(2)$ & $\mathrm{C}$ & $\mathrm{C}$ & $\mathrm{C}$ & $\mathrm{C}$ & $\mathrm{C}$ & $\mathrm{R}$ & $\mathrm{C}$ & $\mathrm{R}$ & $\mathrm{R}$ & $\mathrm{C}$ & $\mathrm{R}$ & $\mathrm{R}$ & $\mathrm{R}$ & I & I \\
\hline \multicolumn{16}{|c|}{ VEÍCULO DE PROJETO SR } \\
\hline Classe Técni & & lasse & & & lasse & & & asse & & & asse & & & sse & \\
\hline Terreno & $\mathrm{P}$ & $\mathrm{O}$ & $\mathrm{M}$ & $\mathrm{P}$ & $\mathrm{O}$ & $\mathrm{M}$ & $\mathrm{P}$ & $\mathrm{O}$ & $\mathrm{M}$ & $\mathrm{P}$ & $\mathrm{O}$ & $\mathrm{M}$ & $\mathrm{P}$ & & $\bar{M}$ \\
\hline O2 (URB) & $\mathrm{C}$ & $\mathrm{C}$ & $\mathrm{C}$ & $\mathrm{C}$ & $\mathrm{C}$ & $\mathrm{C}$ & $\mathrm{C}$ & $\mathrm{C}$ & $\mathrm{C}$ & $\mathrm{C}$ & $\mathrm{C}$ & $\mathrm{C}$ & $\mathrm{C}$ & $\mathrm{C}$ & $\mathrm{C}$ \\
\hline $2 \mathrm{~S} 3$ & $\mathrm{C}$ & $\mathrm{C}$ & $\mathrm{C}$ & $\mathrm{C}$ & $\mathrm{C}$ & $\mathrm{C}$ & $\mathrm{C}$ & $\mathrm{C}$ & $\mathrm{C}$ & $\mathrm{C}$ & $\mathrm{C}$ & $\mathrm{R}$ & $\mathrm{C}$ & $\mathrm{C}$ & $\mathrm{C}$ \\
\hline $\mathrm{O} 2 \mathrm{~S} 1$ & $\mathrm{C}$ & $\mathrm{C}$ & $\mathrm{C}$ & $\mathrm{C}$ & $\mathrm{C}$ & $\mathrm{C}$ & $\mathrm{C}$ & $\mathrm{C}$ & $\mathrm{C}$ & $\mathrm{C}$ & $\mathrm{C}$ & $\mathrm{C}$ & $\mathrm{C}$ & $\mathrm{C}$ & $\mathrm{C}$ \\
\hline O3(ROD) & $\mathrm{C}$ & $\mathrm{C}$ & $\mathrm{C}$ & $\mathrm{C}$ & $\mathrm{C}$ & $\mathrm{C}$ & $\mathrm{C}$ & $\mathrm{C}$ & $\mathrm{C}$ & $\mathrm{C}$ & $\mathrm{C}$ & $\mathrm{C}$ & $\mathrm{C}$ & $\mathrm{C}$ & $\mathrm{C}$ \\
\hline $\mathrm{O} 2$ (ROD) & $\mathrm{C}$ & $\mathrm{C}$ & $\mathrm{C}$ & $\mathrm{C}$ & $\mathrm{C}$ & $\mathrm{C}$ & $\mathrm{C}$ & $\mathrm{C}$ & $\mathrm{C}$ & $\mathrm{C}$ & $\mathrm{C}$ & $\mathrm{C}$ & $\mathrm{C}$ & $\mathrm{C}$ & $\mathrm{C}$ \\
\hline U3 & $\mathrm{C}$ & $\mathrm{C}$ & $\mathrm{C}$ & $\mathrm{C}$ & $\mathrm{C}$ & $\mathrm{C}$ & $\mathrm{C}$ & $\mathrm{C}$ & $\mathrm{C}$ & $\mathrm{C}$ & $\mathrm{C}$ & $\mathrm{C}$ & $\mathrm{C}$ & $\mathrm{C}$ & $\mathrm{C}$ \\
\hline $3 \mathrm{~S} 2 \mathrm{~B} 2(20 \mathrm{~m})$ & $\mathrm{C}$ & $\mathrm{C}$ & $\mathrm{C}$ & $\mathrm{C}$ & $\mathrm{C}$ & $\mathrm{C}$ & $\mathrm{C}$ & $\mathrm{C}$ & $\mathrm{C}$ & $\mathrm{C}$ & $\mathrm{C}$ & $\mathrm{C}$ & $\mathrm{C}$ & $\mathrm{C}$ & $\mathrm{C}$ \\
\hline O2S1B1 & $\mathrm{C}$ & $\mathrm{C}$ & $\mathrm{C}$ & $\mathrm{C}$ & $\mathrm{C}$ & $\mathrm{C}$ & $\mathrm{C}$ & $\mathrm{C}$ & $\mathrm{C}$ & $\mathrm{C}$ & $\mathrm{C}$ & $\mathrm{C}$ & $\mathrm{C}$ & $\mathrm{C}$ & $\mathrm{C}$ \\
\hline $\mathrm{U} 2$ & $\mathrm{C}$ & $\mathrm{C}$ & $\mathrm{C}$ & $\mathrm{C}$ & $\mathrm{C}$ & $\mathrm{C}$ & $\mathrm{C}$ & $\mathrm{C}$ & $\mathrm{C}$ & $\mathrm{C}$ & $\mathrm{C}$ & $\mathrm{C}$ & $\mathrm{C}$ & $\mathrm{C}$ & $\mathrm{C}$ \\
\hline 3S3B3 & $\mathrm{C}$ & $\mathrm{C}$ & $\mathrm{C}$ & C & C & $\mathrm{C}$ & $\mathrm{C}$ & $\mathrm{C}$ & $\mathrm{R}$ & $\mathrm{C}$ & $\mathrm{C}$ & $\mathrm{R}$ & $\mathrm{R}$ & $\mathrm{R}$ & I \\
\hline $2 \mathrm{~S} 1$ & $\mathrm{C}$ & $\mathrm{C}$ & $\mathrm{C}$ & $\mathrm{C}$ & $\mathrm{C}$ & $\mathrm{C}$ & $\mathrm{C}$ & $\mathrm{C}$ & $\mathrm{R}$ & $\mathrm{C}$ & $\mathrm{R}$ & $\mathrm{R}$ & $\mathrm{R}$ & $\mathrm{R}$ & I \\
\hline 3S2B2 (26m) & $\mathrm{C}$ & $\mathrm{C}$ & $\mathrm{C}$ & $\mathrm{C}$ & $\mathrm{C}$ & $\mathrm{C}$ & $\mathrm{C}$ & $\mathrm{C}$ & $\mathrm{R}$ & $\mathrm{C}$ & $\mathrm{R}$ & $\mathrm{R}$ & $\mathrm{R}$ & $\mathrm{R}$ & I \\
\hline $2 \mathrm{~S} 2(20 \mathrm{~m})$ & $\mathrm{C}$ & $\mathrm{C}$ & $\mathrm{C}$ & $\mathrm{C}$ & $\mathrm{C}$ & $\mathrm{C}$ & $\mathrm{C}$ & $\mathrm{C}$ & $\mathrm{R}$ & $\mathrm{C}$ & $\mathrm{R}$ & $\mathrm{R}$ & $\mathrm{R}$ & $\mathrm{R}$ & I \\
\hline $3 \mathrm{~S} 2 \mathrm{~A} 2 \mathrm{~S} 2$ & $\mathrm{C}$ & $\mathrm{C}$ & $\mathrm{C}$ & $\mathrm{C}$ & $\mathrm{C}$ & $\mathrm{C}$ & $\mathrm{C}$ & $\mathrm{C}$ & $\mathrm{R}$ & $\mathrm{C}$ & $\mathrm{R}$ & $\mathrm{R}$ & $\mathrm{R}$ & $\mathrm{R}$ & I \\
\hline $2 \mathrm{~S} 2(22,4 \mathrm{~m})$ & $\mathrm{C}$ & $\mathrm{C}$ & $\mathrm{C}$ & $\mathrm{C}$ & $\mathrm{C}$ & $\mathrm{R}$ & $\mathrm{C}$ & $\mathrm{C}$ & $\mathrm{R}$ & $\mathrm{C}$ & $\mathrm{R}$ & $\mathrm{R}$ & $\mathrm{R}$ & $\mathrm{R}$ & I \\
\hline
\end{tabular}

A pesquisa rodoviária realizada pela Confederação Nacional do Transporte (CNT, 2006), que cobre a totalidade da malha rodoviária pavimentada federal e grande 
parte das rodovias pavimentadas estaduais, revelou que $40,5 \%$ dos trechos percorridos não possuem acostamento e ainda que 5,8\% da extensão pesquisada possuem acostamentos tomados por vegetação. Com relação aos trechos providos de acostamento, foi verificado ainda que apenas $62 \%$ são de acostamentos pavimentados e em boas condições. Este diagnóstico revela que, dada a atual situação da malha rodoviária brasileira, existem muitas ressalvas quanto à utilização dos acostamentos para suprir a deficiência das sobrelarguras das faixas de tráfego. Diante do diagnóstico atual da malha rodoviária brasileira, os veículos que foram enquadrados na condição de tráfego restritivo (R) apresentam dificuldades operacionais significativas, comprometendo a segurança viária.

Como pode ser observado, para as Classes 0 e I prevalece a indicação de compatibilidade com o tráfego das CVCs nas suas mais diversas configurações, mesmo com comprimentos de $30 \mathrm{~m}$, como é o caso do 3S2A2S2. As larguras das faixas de tráfego e os raios mínimos impostos nestas classes garantem a operação da maioria dos veículos sem utilização dos acostamentos e, nos poucos casos em que ela ocorre, é de pequena monta, com $40 \mathrm{~cm}$ no caso mais crítico. Para as demais classes, as condições operacionais se tornam mais desfavoráveis. Considerando, por exemplo, o veículo de projeto CO nas Classes II e III, há restrições em quase todas as CVCs nos relevos ondulado e montanhoso e na Classe IV existe restrição ou incompatibilidade para estes veículos em todos os tipos de terreno. Mesmo quando é utilizado o veículo de projeto mais complexo do DNER, o SR, persiste a necessidade de utilização dos acostamentos para o tráfego de boa parte das CVCs nas Classes III e IV. Como é comum nas classes de rodovia com hierarquia inferior à existência de rodovias com acostamento não pavimentado ou mesmo sem acostamento, pode-se concluir que nestes casos existem restrições significativas ao tráfego de CVCs.

Constata-se, portanto, que a adoção de um veículo de projeto do tipo CVC onde haja uma participação expressiva destes veículos na frota circulante é uma medida importante para garantir a existência de faixas de tráfego com larguras compatíveis. Vale ressaltar que esta conclusão está associada à análise há pouco proposta, onde a rodovia atende apenas aos parâmetros mínimos da classe técnica a que pertencem. Nas demais situações, onde estes parâmetros de projeto superam seus limites inferiores, a 
solução para compatibilizar o tráfego destas CVCs pode ser obtida através da utilização de outras medidas como a adoção de raios mais elevados ou de uma pista com faixas de tráfego com maior largura.

Para investigar o impacto de calcular as sobrelarguras com a utilização de outros veículos mais complexos do que os veículos do Manual do DNER, foi simulada a utilização de alguns dos veículos investigados como veículo de projeto e observada a incidência de utilização dos acostamentos e os casos de incompatibilidade. O resumo dos resultados está apresentado na Tabela 4.4, que mostra também os resultados quando utilizados os atuais veículos de projeto.

Tabela 4.4: Compatibilidade das Sobrelarguras em Curvas Horizontais, Considerando as Simulações de Alguns Veículos de Projeto

\begin{tabular}{ccc}
\hline \multirow{2}{*}{$\begin{array}{c}\text { VEÍCULO DE } \\
\text { PROJETO SIMULADO }\end{array}$} & \multicolumn{2}{c}{ COMPORTAMENTO DOS DEMAIS VEÍCULOS } \\
\cline { 2 - 3 } & $\begin{array}{c}\text { Número de Ocorrências de } \\
\text { Uso do Acostamento (R) }\end{array}$ & $\begin{array}{c}\text { Número de Ocorrências de } \\
\text { Incompatibilidade (I) }\end{array}$ \\
\hline CO(DNER) & 77 & 13 \\
\hline O(DNER) & 50 & 7 \\
\hline SR(DNER) & 31 & 2 \\
\hline 3S3B3 & 19 & 1 \\
\hline 2S1 & 10 & 0 \\
\hline 3S2B2(26m) & 9 & 0 \\
\hline 2S2(20m) & 7 & 0 \\
\hline 3S2A2S2 & 2 & 0 \\
\hline 2S2(22,4m) & 0 & \\
\hline
\end{tabular}

O veículo $2 \mathrm{~S} 2(22,4 \mathrm{~m})$, por ser o mais crítico, naturalmente estabeleceria um padrão geométrico sem restrições para o restante de frota, mas sua utilização como veículo de projeto resulta em sobrelarguras de até $10 \mathrm{~m}$ para as rodovias de Classe IV. Com relação ao uso dos acostamentos, é observado um desempenho semelhante para os veículos 2S1, 3S2B2(26m) e 2S2(20m), havendo a necessidade de utilização dos acostamentos em poucas situações pelos demais veículos, a maioria delas em rodovias de Classe IV. Desta forma, poderia ser recomendada a utilização de qualquer uma destas três configurações de veículos como um novo veículo de projeto para o cálculo de sobrelarguras nas rodovias rurais e também em interseções. Vale ressaltar que, destas três CVCs, a 2S2(20m) oferece a vantagem de permitir o tráfego do veículo 2S2(22,4m), ainda que com a utilização de acostamentos. 
Considerando que boa parte dos projetos de rodovias utiliza o CO como veículo de projeto e que uma parcela importante da malha rodoviária nacional se enquadra nas Classes II, III e IV, pode-se afirmar que há condições restritivas ao tráfego tanto de veículos comerciais unitários de transporte de pessoas e carga, como de CVCs, sendo importante uma mudança no critério de escolha do veículo de projeto para a determinação das sobrelarguras. Os resultados revelam a importância que os acostamentos possuem para impedir a invasão das faixas de tráfego adjacentes, sendo a manutenção de seu estado de conservação uma medida relevante para evitar a ocorrência de acidentes.

\subsubsection{Estabilidade nas Curvas Horizontais}

Como mencionado no Capítulo 3, a estabilidade dos veículos é considerada nos projetos das curvas horizontais em função da ocorrência de escorregamento dos veículos de passeio. Para tanto, são estabelecidos fatores de atrito admissíveis, valores estes abaixo dos valores máximos disponíveis, havendo assim determinada margem de segurança para a derrapagem dos veículos. Mediante análise de sensibilidade, conforme proposta em Harwood e Mason (1994), serão comparadas as margens de segurança observadas em automóveis e veículos de carga, tanto para o fenômeno do escorregamento como do tombamento. Para a análise proposta, foram admitidas as seguintes suposições:

(a) foram adotados os fatores de atrito longitudinal admissíveis $(f)$ assumidos pelo DNER para a situação de pavimento molhado (Pav. Mol.) e rodas travadas, que variam de 0,40 a 0,27 (DNER,1999) para as velocidades de 30 e $120 \mathrm{~km} / \mathrm{h}$, respectivamente. Para a situação de pavimento seco (Pav. Sec.) foi admitido o valor único de 0,65 para o fator de atrito longitudinal (HARWOOD e MASON, 1994);

(b) foi considerado um fator de atrito lateral máximo $\left(f_{\text {Lat max }}\right)$ equivalente a 1,45 vez os fatores de atrito longitudinal (f) acima citados (OLSON et al., 1984). Portanto, no caso de pavimento seco, este fator de atrito apresenta valor único igual a 0,94 ; 
(c) o atrito da interface pneu-pavimento nos caminhões corresponde a $70 \%$ do valor encontrado nos automóveis (OLSON et al., 1984);

(d) o atrito lateral efetivo demandado por caminhões corresponde a um valor $10 \%$ superior ao atrito lateral admitido para os automóveis. MacAdam, Fancher e Segel (1985) observaram que, enquanto nos automóveis o atrito lateral é aproximadamente o mesmo para os quatro pneus, são verificadas variações significativas entre os pneus de veículos do tipo semi-reboque, e esta distribuição desigual resulta na necessidade de maiores valores de atrito para o veículo atingir a condição de equilíbrio na curva. Este maior valor de atrito aplica-se apenas para a análise do escorregamento do veículo, permanecendo, no caso do tombamento, a utilização de fatores de atrito lateral iguais para automóveis ou caminhões; e

(e) foi adotado um valor de $a c_{\max }$ para os automóveis de $1,2 \mathrm{~g}$, enquanto nos caminhões foram simulados valores entre $0,25 \mathrm{~g} \mathrm{e} 0,40 \mathrm{~g}$.

As Tabelas 4.5 e 4.6 apresentam os resultados obtidos para as ocorrências de escorregamento e tombamento, respectivamente, mostrando as margens de segurança por classe de rodovia, considerando os parâmetros de projeto mínimos das classes técnicas do DNER. Os resultados foram ordenados das rodovias que apresentaram maiores margens de segurança, para aquelas com os piores resultados. Tomando como exemplo a ocorrência do escorregamento (Tabela 4.5), para uma rodovia de Classe 0 terreno plano - tem-se uma velocidade de projeto de $120 \mathrm{~km} / \mathrm{h}$. Nessa velocidade, o fator de atrito longitudinal adotado pelo DNER é igual a 0,27. Multiplicando este valor por 1,45 (OLSON et al., 1984), é determinado o fator de atrito lateral máximo para a condição de pavimento molhado, igual a 0,39 . Subtraindo este valor do atrito lateral admissível $\left(f_{\max }\right)$ utilizado no projeto da curva horizontal, que é de 0,11 para esta faixa de velocidade, tem-se um resultado igual a 0,28 g. Este valor corresponde à margem de segurança existente e indica que, admitidas as condições mencionadas, um veículo de passeio derrapará caso surjam fatores que elevem a aceleração lateral do veículo em um valor superior a $0,28 \mathrm{~g}$, ou seja, em aproximadamente $2,75 \mathrm{~m} / \mathrm{s}^{2}$. Dentre os motivos que podem ocasionar esta elevação, pode-se mencionar a utilização de velocidades acima do valor de projeto, assim como caso o motorista percorra uma trajetória mais fechada que o traçado da curva horizontal. 
Tabela 4.5: Margens de Segurança para a Ocorrência de Escorregamento em Curvas Horizontais, Dados os Parâmetros Mínimos das Classes Técnicas do DNER.

\begin{tabular}{|c|c|c|c|c|c|c|c|c|c|c|c|}
\hline \multirow{3}{*}{$\begin{array}{c}\text { CLASSE } \\
\text { DE } \\
\text { RODOVIA } \\
\text { (TERRENO) }\end{array}$} & \multirow{3}{*}{$\begin{array}{c}\mathrm{V}_{\mathrm{p}} \\
(\mathrm{km} / \mathrm{h})\end{array}$} & \multirow{3}{*}{$\begin{array}{c}\mathrm{R}_{\min } \\
(\mathrm{m})\end{array}$} & \multirow{3}{*}{$\begin{array}{l}e_{\max } \\
(\%)\end{array}$} & \multicolumn{4}{|c|}{ AUTO } & \multicolumn{4}{|c|}{ CAMINHÕES } \\
\hline & & & & \multirow{2}{*}{$f_{\max }$} & \multirow{2}{*}{$\begin{array}{c}f_{\text {Lat max }} \\
\text { Pav } \\
\text { Mol. }\end{array}$} & \multicolumn{2}{|c|}{$\begin{array}{c}\text { Margem de } \\
\text { Segurança (g) }\end{array}$} & \multirow{2}{*}{$f_{\max }$} & \multirow{2}{*}{$\begin{array}{c}f_{\text {Lat max }} \\
\text { Pav } \\
\text { Mol. }\end{array}$} & \multicolumn{2}{|c|}{$\begin{array}{c}\text { Margem de } \\
\text { Segurança (g) }\end{array}$} \\
\hline & & & & & & $\begin{array}{l}\text { Pav. } \\
\text { Sec. }\end{array}$ & $\begin{array}{l}\text { Pav. } \\
\text { Mol. }\end{array}$ & & & $\begin{array}{l}\text { Pav. } \\
\text { Sec. }\end{array}$ & $\begin{array}{l}\text { Pav. } \\
\text { Mol. }\end{array}$ \\
\hline $0(\mathrm{P})$ & 120 & 540 & 10 & 0,11 & 0,39 & 0,83 & 0,28 & 0,12 & 0,27 & 0,54 & 0,15 \\
\hline II (P) & 100 & 375 & 8 & 0,13 & 0,41 & 0,81 & 0,28 & 0,14 & 0,28 & 0,52 & 0,14 \\
\hline $0(\mathrm{O})$ e $\mathrm{I}(\mathrm{P})$ & 100 & 345 & 10 & 0,13 & 0,41 & 0,81 & 0,28 & 0,14 & 0,28 & 0,52 & 0,14 \\
\hline III (P) & 80 & 230 & 8 & 0,14 & 0,44 & 0,80 & 0,30 & 0,15 & 0,30 & 0,51 & 0,15 \\
\hline $0(\mathrm{M})$ e I $(\mathrm{O})$ & 80 & 210 & 10 & 0,14 & 0,44 & 0,80 & 0,30 & 0,15 & 0,30 & 0,51 & 0,15 \\
\hline II $(\mathrm{O})$ & 70 & 170 & 8 & 0,15 & 0,45 & 0,79 & 0,30 & 0,17 & 0,31 & 0,49 & 0,15 \\
\hline III (O) e IV (P) & 60 & 125 & 8 & 0,15 & 0,48 & 0,79 & 0,33 & 0,17 & 0,33 & 0,49 & 0,17 \\
\hline $\mathrm{I}(\mathrm{M})$ & 60 & 115 & 10 & 0,15 & 0,48 & 0,79 & 0,33 & 0,17 & 0,33 & 0,49 & 0,17 \\
\hline II (M) & 50 & 80 & 8 & 0,16 & 0,51 & 0,78 & 0,35 & 0,18 & 0,36 & 0,48 & 0,18 \\
\hline III (M) e IV (O) & 40 & 50 & 8 & 0,18 & 0,54 & 0,76 & 0,36 & 0,20 & 0,38 & 0,46 & 0,18 \\
\hline IV (M) & 30 & 25 & 8 & 0,20 & 0,58 & 0,74 & 0,38 & 0,22 & 0,41 & 0,44 & 0,19 \\
\hline
\end{tabular}

Tabela 4.6: Margens de Segurança para a Ocorrência da Tombamento em Curvas Horizontais, Dados Parâmetros Mínimos das Classes Técnicas do DNER

\begin{tabular}{|c|c|c|c|c|c|c|c|c|c|}
\hline \multirow{3}{*}{$\begin{array}{c}\text { RODOVIA } \\
\text { CLASSE } \\
\text { (TERRENO) }\end{array}$} & \multirow{3}{*}{$\begin{array}{c}\mathrm{V}_{\mathrm{p}} \\
(\mathrm{km} / \mathrm{h})\end{array}$} & \multirow{3}{*}{$\begin{array}{l}\mathrm{R}_{\min } \\
(\mathrm{m})\end{array}$} & \multirow{3}{*}{$\begin{array}{l}e_{\max } \\
(\%)\end{array}$} & \multirow[b]{3}{*}{$f_{\max }$} & \multicolumn{5}{|c|}{ MARGEM DE SEGURANÇA (g) } \\
\hline & & & & & \multirow{2}{*}{$\begin{array}{l}\text { Auto } \\
a c_{\max } \\
1,20 \mathrm{~g}\end{array}$} & \multicolumn{4}{|c|}{ Caminhões } \\
\hline & & & & & & $\begin{array}{c}a c_{\max } \\
0,25 \mathrm{~g}\end{array}$ & $\begin{array}{c}a c_{\max } \\
0,30 \mathrm{~g}\end{array}$ & $\begin{array}{c}a c_{\max } \\
0,35 \mathrm{~g}\end{array}$ & $\begin{array}{c}a c_{\max } \\
0,40 \mathrm{~g}\end{array}$ \\
\hline $0(\mathrm{P})$ & 120 & 540 & 10 & 0,11 & 1,09 & 0,14 & $\mathbf{0 , 1 9}$ & 0,24 & 0,29 \\
\hline II $(\mathrm{P})$ & 100 & 375 & 8 & 0,13 & 1,07 & 0,12 & 0,17 & 0,22 & 0,27 \\
\hline $0(\mathrm{O})$ e $\mathrm{I}(\mathrm{P})$ & 100 & 345 & 10 & 0,13 & 1,07 & 0,12 & 0,17 & 0,22 & 0,27 \\
\hline III (P) & 80 & 230 & 8 & 0,14 & 1,06 & 0,11 & 0,16 & 0,21 & 0,26 \\
\hline $0(\mathrm{M})$ e I $(\mathrm{O})$ & 80 & 210 & 10 & 0,14 & 1,06 & $\mathbf{0 , 1 1}$ & 0,16 & 0,21 & 0,26 \\
\hline II (O) & 70 & 170 & 8 & 0,15 & 1,05 & 0,10 & 0,15 & 0,20 & 0,25 \\
\hline III (O) e IV (P) & 60 & 125 & 8 & 0,15 & 1,05 & 0,10 & 0,15 & 0,20 & 0,25 \\
\hline $\mathrm{I}(\mathrm{M})$ & 60 & 115 & 10 & 0,15 & 1,05 & 0,10 & 0,15 & 0,20 & 0,25 \\
\hline II (M) & 50 & 80 & 8 & 0,16 & 1,04 & 0,09 & 0,14 & 0,19 & 0,24 \\
\hline III (M) e IV (O) & 40 & 50 & 8 & 0,18 & 1,02 & 0,07 & 0,12 & 0,17 & 0,22 \\
\hline IV (M) & 30 & 25 & 8 & 0,2 & 1,00 & 0,05 & 0,10 & 0,15 & 0,20 \\
\hline
\end{tabular}

Considerando a ocorrência de escorregamento em pavimento molhado, observase que as classes de rodovia com menor velocidade de projeto apresentam maiores margens de segurança. Este resultado decorre da perda de atrito na superfície pneupavimento, à medida que são elevados os valores de velocidade. Já para a situação de pavimento seco, em que é admitido um fator de atrito único para todas as velocidades, enquanto a curva é projetada com os valores de $f$ para pavimento molhado, com valores decrescentes à medida que se elevam as velocidades, foram obtidas margens de 
segurança maiores nas rodovias de maior velocidade. Como esperado, as margens de segurança se mostraram mais elevadas para os automóveis do que para os caminhões, e esta tendência se mostrou mais acentuada na condição de pavimento molhado. Quanto ao tombamento, as rodovias de velocidade diretriz mais baixa, onde são admitidos valores de $f_{\max }$ mais elevados, apresentaram menores margens de segurança.

A Tabela 4.7 apresenta os valores limites de velocidade, onde são atingidas as margens de segurança mostradas nas Tabelas 4.5 e 4.6, ocorrendo o escorregamento ou tombamento do veículo para as velocidades acima destes níveis.

Tabela 4.7: Margens de Segurança para a Ocorrência de Escorregamento e Tombamento em Curvas Horizontais, Dados os Parâmetros Mínimos das Classes Técnicas do DNER

\begin{tabular}{|c|c|c|c|c|c|c|c|c|c|c|}
\hline \multirow{4}{*}{$\begin{array}{c}\text { RODOVIA } \\
\text { CLASSE } \\
\text { (TERRENO) }\end{array}$} & \multirow{4}{*}{$\begin{array}{c}\mathrm{V}_{\mathrm{p}} \\
(\mathrm{km} / \mathrm{h})\end{array}$} & \multicolumn{9}{|c|}{ VELOCIDADE LIMITE $(\mathrm{km} / \mathrm{h})$} \\
\hline & & \multicolumn{4}{|c|}{ Escorregamento } & \multicolumn{5}{|c|}{ Tombamento } \\
\hline & & \multicolumn{2}{|c|}{ Auto } & \multicolumn{2}{|c|}{ Caminhão } & \multirow{2}{*}{$\begin{array}{c}\text { Auto } \\
a c_{\max } \\
1,20\end{array}$} & \multicolumn{4}{|c|}{ Caminhão } \\
\hline & & $\begin{array}{l}\text { Pav. } \\
\text { Sec. }\end{array}$ & $\begin{array}{l}\text { Pav. } \\
\text { Mol. }\end{array}$ & $\begin{array}{l}\text { Pav. } \\
\text { Sec. }\end{array}$ & $\begin{array}{l}\text { Pav. } \\
\text { Mol. }\end{array}$ & & $\begin{array}{c}a c_{\text {max }} \\
0,25\end{array}$ & $\begin{array}{c}a c_{\max } \\
0,30\end{array}$ & $\begin{array}{c}a c_{\max } \\
0,35\end{array}$ & $\begin{array}{c}a c_{\text {max }} \\
0,40\end{array}$ \\
\hline $0(\mathrm{P})$ & 120 & 267 & 184 & 227 & 158 & 299 & 155 & 166 & 176 & 185 \\
\hline II (P) & 100 & 221 & 152 & 186 & 129 & 247 & 125 & 135 & 143 & 151 \\
\hline $0(\mathrm{O})$ e $\mathrm{I}(\mathrm{P})$ & 100 & 214 & 149 & 181 & 128 & 239 & 124 & 132 & 140 & 148 \\
\hline III (P) & 80 & 173 & 123 & 146 & 104 & 193 & 98 & 105 & 112 & 118 \\
\hline $0(\mathrm{M})$ e I $(\mathrm{O})$ & 80 & 167 & 119 & 141 & 102 & 186 & 97 & 103 & 110 & 115 \\
\hline II $(\mathrm{O})$ & 70 & 149 & 107 & 125 & 91 & 166 & 84 & 91 & 96 & 102 \\
\hline III (O) e IV (P) & 60 & 127 & 94 & 107 & 80 & 143 & 72 & 78 & 83 & 87 \\
\hline $\mathrm{I}(\mathrm{M})$ & 60 & 123 & 92 & 104 & 78 & 138 & 71 & 76 & 81 & 85 \\
\hline II (M) & 50 & 102 & 77 & 86 & 65 & 114 & 58 & 62 & 66 & 70 \\
\hline III (M) e IV (O) & 40 & 81 & 63 & 68 & 53 & 90 & 46 & 49 & 52 & 55 \\
\hline IV (M) & 30 & 57 & 46 & 48 & 38 & 64 & 32 & 35 & 37 & 39 \\
\hline
\end{tabular}

A análise destes valores permite as seguintes conclusões:

(a) todos os resultados revelaram que os automóveis atingem o escorregamento a uma velocidade mais baixa do que o tombamento. Assim, tanto no pavimento seco como molhado, os automóveis são alvos preferencialmente do escorregamento, qualquer que seja a classe de rodovia;

(b) considerando as velocidades-limites para os automóveis, se confirma uma elevada margem de segurança, tanto para o escorregamento como o tombamento. Considerando a situação mais crítica, o escorregamento de um automóvel em uma rodovia Classe IV (M), onde a velocidade de projeto é de 30 
$\mathrm{km} / \mathrm{h}$, o veículo escorregaria a uma velocidade de $57 \mathrm{~km} / \mathrm{h}$, valor $91 \%$ superior à velocidade diretriz;

(c) foi observado que, para a condição de pavimento seco, os caminhões com qualquer um dos valores de $a c_{\max }$ considerados tombam a uma velocidade inferior ao limiar do escorregamento e que, no caso dos caminhões com $a c_{\max }$ de $0,25 \mathrm{~g}$, esta tendência é verificada também no pavimento molhado. Para o pavimento seco, o escorregamento só é verificado a velocidades mais elevadas do que o tombamento em caminhões com $a c_{\max }$ igual ou superior a $0,65 \mathrm{~g}$;

(d) avaliando, então, para a condição de pavimento seco a ocorrência do tombamento, os caminhões com $a c_{\max }$ de $0,25 \mathrm{~g}$ apresentam na maioria das classes técnicas margens de segurança abaixo de $20 \mathrm{~km} / \mathrm{h}$. Nas rodovias de Classes II(M), III(M), IV(O) e IV(M), todos os veículos considerados apresentam margens de segurança abaixo de $20 \mathrm{~km} / \mathrm{h}$, sendo que, para a Classe $\mathrm{IV}(\mathrm{M})$, este valor não chega a $10 \mathrm{~km} / \mathrm{h}$. Apenas os caminhões com $a c_{\max }$ de 0,70 g ou superior têm uma margem de segurança de $20 \mathrm{~km} / \mathrm{h}$ na Classe IV(M). Como foi observado na Tabela 4.6, as rodovias de classe mais inferior apresentam as menores margens de segurança, e, como estas rodovias possuem baixa velocidade de projeto, pequenos incrementos de velocidade podem ocasionar o tombamento dos veículos;

(e) considerando o pavimento molhado, os caminhões com $a c_{\max }$ de $0,35 \mathrm{~g}$ ou maior escorregam antes da condição de tombamento para a maioria das classes simuladas. Considerando estes casos de ocorrência de escorregamento, têm-se os limites de velocidade em torno de $30 \%$ superiores aos valores de projeto, cujos casos mais críticos são as rodovias de Classe III (M) e IV $(\mathrm{O})$, onde a velocidade de projeto é $40 \mathrm{~km} / \mathrm{h}$ e o limiar de escorregamento ocorre a $53 \mathrm{~km} / \mathrm{h}$ e as rodovias de Classe IV (M), onde a velocidade de projeto é $30 \mathrm{~km} / \mathrm{h}$ e o limiar de escorregamento ocorre a uma velocidade de $38 \mathrm{~km} / \mathrm{h}$;

(f) já para os caminhões com $a c_{\max }$ de $0,30 \mathrm{~g}$, nas classes de maior padrão técnico, $0(\mathrm{P}), 0(\mathrm{O}), \mathrm{I}(\mathrm{P})$ e II $(\mathrm{P})$, permanece a tendência de se verificar preferencialmente o escorregamento ao tombamento, mas com uma velocidade-limite em torno de $30 \mathrm{~km} / \mathrm{h}$ superior à velocidade de projeto destas rodovias. Nas rodovias de padrão intermediário, as velocidades-limites para $\mathrm{o}$ escorregamento e 
tombamento são semelhantes, com margens de segurança em torno de $20 \mathrm{~km} / \mathrm{h}$. Para as rodovias de Classe III (M), IV (O) e IV (M), é observada uma tendência maior de ocorrência de tombamento, revelando situações mais críticas de segurança, com margens de segurança abaixo de $15 \mathrm{~km} / \mathrm{h}$, apresentando como caso mais crítico a Classe IV(M), com uma folga de apenas $5 \mathrm{~km} / \mathrm{h}$.

Alguns países, como Austrália e Nova Zelândia, têm determinado padrões mínimos de desempenho para os veículos quanto ao limiar de tombamento, limites estes obtidos com base em estudos das estatísticas de acidentes. Os valores recomendados nesses estudos estão situados entre 0,35 g e 0,40 g (ERVIN; MACADAM; BURNES, 1986; FANCHER et al., 1989; WINKLER; FANCHER, 1992). Por meio de projeto desenvolvido pela AUSTROADS e pela National Road Transport Commission (NRTC), denominado Performance Based Standards (PBS), foram estabelecidos como parâmetros mínimos os valores $0,40 \mathrm{~g}$ para caminhões-tanque e ônibus e $0,35 \mathrm{~g}$ para os demais veículos de carga (PREM et al., 2001).

Considerando a análise procedida há pouco, os valores $0,35 \mathrm{~g}$ e $0,40 \mathrm{~g}$ podem ser recomendados também como limite mínimo para os caminhões que trafegam em rodovias com o padrão técnico proposto pelo DNER. Uma ressalva deve ser feita para as rodovias de classe mais inferior. Apesar de haver margens de segurança superiores a $20 \%$, se observados os valores absolutos, estes limites são alcançados com pequenos acréscimos de velocidade. Nessas rodovias, é necessário ressaltar a relevância da existência de sinalização dos limites de velocidade e a implantação de dispositivos de segurança nas curvas horizontais, como barreiras e defensas, especialmente nas rodovias em terreno montanhoso e ondulado, onde a existência de abismos potencializa a severidade dos acidentes.

No Brasil não há estudos que indiquem com precisão os valores de $a c_{\max }$ encontrados na frota. Este é um desafio árduo, uma vez que esta frota é marcada por intensa heterogeneidade de veículos, produzidos por montadoras, fabricantes e fornecedores de implementos rodoviários e pneus, sem que haja um controle do produto final, e, portanto, sem a mensuração de sua performance. No estudo de caso proposto neste trabalho, serão pesquisados trechos heterogêneos de rodovias, sendo medidas em 
campo as superelevações implantadas nas curvas, que, junto com as informações do projeto geométrico das curvas, permitirão verificar a condição de estabilidade proporcionada aos veículos e as margens de segurança, admitindo os valores de $a c_{\max }$ utilizados há instantes.

\subsubsection{Rampas Ascendentes}

Para determinação dos comprimentos críticos das rampas, foram realizadas simulações com a utilização do software TRUPER (DEMARCHI, 2004) para determinar o desempenho de alguns caminhões. Foram definidas cargas para os veículos simulados, atendendo ao que estabelece a Resolução $\mathrm{n}^{\circ} 210$ do CONTRAN (BRASIL, 2006a), sendo utilizados limites máximos de PBTC e motores que resultaram em relações potência/massa de caminhões típicos brasileiros. Quanto ao perfil longitudinal da via, foram simuladas rampas com as declividades máximas estabelecidas pelo DNER para as classes técnicas de projeto. As configurações de motor, câmbio e diferencial dos veículos foram obtidas a partir de consultas aos catálogos dos fabricantes de veículos, que apresentam a ficha técnica dos caminhões. Estes dados estão apresentados no Apêndice B.

O parâmetro principal para esta análise é a relação potência/massa. A escolha deste valor, assim como os limites admissíveis de perda de velocidade considerados nesta simulação foram definidos tomando como base a pesquisa de Melo (2002). A Tabela 4.8 apresenta os comprimentos críticos de rampa obtidos na simulação para cada classe técnica de rodovia, considerando a velocidade do veículo no início da rampa igual à velocidade de projeto. Vale ressaltar que algumas destas velocidade de projeto são superiores à velocidade de equilíbrio dos veículos simulados dada a condição de greide nulo. Velocidade de equilíbrio é aquela em que o esforço trator do veículo é igual à resistência ao movimento, ou seja, o somatório das forças que atuam no veículo se igualam, resultando numa aceleração nula. Nos casos onde a velocidade de equilíbrio dos veículos se mostrou inferior à velocidade de projeto, se admitiu que o veículo procedesse de um trecho em rampa descendente, permitindo assim o ganho de velocidade necessário. 
Tabela 4.8: Comprimentos Críticos Calculados para as Rampas Máximas das Classes de Projeto do DNER, Considerando Caminhões Típicos Brasileiros (em metros).

\begin{tabular}{|c|c|c|c|c|c|c|c|c|c|}
\hline \multirow{2}{*}{$\begin{array}{c}\text { CLASSE } \\
\text { DA } \\
\text { RODOVIA }\end{array}$} & \multirow{2}{*}{ TERRENO } & \multirow{2}{*}{$\begin{array}{c}\text { DECLIVIDADE } \\
(\%)\end{array}$} & \multirow{2}{*}{$\begin{array}{c}\text { VELOCIDADE } \\
\text { DE PROJETO } \\
(\mathrm{km} / \mathrm{h})\end{array}$} & \multicolumn{6}{|c|}{ RELAÇÃO POTÊNCIA / MASSA (cv/t) } \\
\hline & & & & 3,16 & 4,67 & 6,97 & 7,42 & 9,76 . & 13,15 \\
\hline \multirow{3}{*}{ Classe 0} & Plano & 3 & 120 & 660 & 750 & 780 & 850 & 960 & 1040 \\
\hline & Ondulado & 4 & 100 & 460 & 520 & 580 & 680 & 780 & 1260 \\
\hline & Montanhoso & 5 & 80 & 320 & 360 & 450 & 540 & 710 & - \\
\hline \multirow{3}{*}{$\begin{array}{c}\text { Classe } \\
\text { I-A }\end{array}$} & Plano & 3 & 100 & 590 & 670 & 810 & 990 & - & - \\
\hline & Ondulado & 4,5 & 80 & 350 & 400 & 520 & 660 & 960 & - \\
\hline & Montanhoso & 6 & 60 & 200 & 240 & - & - & - & - \\
\hline \multirow{3}{*}{$\begin{array}{c}\text { Classe } \\
\text { I-B }\end{array}$} & Plano & 3 & 100 & 350 & 400 & 450 & 510 & 600 & 980 \\
\hline & Ondulado & 4,5 & 80 & 210 & 240 & 290 & 340 & 410 & 780 \\
\hline & Montanhoso & 6 & 60 & 130 & 150 & 190 & 240 & 320 & - \\
\hline \multirow{3}{*}{ Classe II } & Plano & 3 & 100 & 350 & 400 & 450 & 510 & 600 & 980 \\
\hline & Ondulado & 5 & 70 & 170 & 200 & 250 & 300 & 390 & - \\
\hline & Montanhoso & 7 & 50 & 90 & 110 & 150 & 200 & - & - \\
\hline \multirow{3}{*}{ Classe III } & Plano & 4 & 80 & 240 & 270 & 330 & 400 & 510 & 720 \\
\hline & Ondulado & 6 & 60 & 130 & 150 & 190 & 240 & 320 & - \\
\hline & Montanhoso & 8 & 40 & 60 & 80 & - & - & - & - \\
\hline \multirow{3}{*}{$\begin{array}{l}\text { Classe } \\
\text { IV-A }\end{array}$} & Plano & 4 & 60 & 190 & 240 & 380 & - & - & - \\
\hline & Ondulado & 6 & 40 & 90 & 120 & - & - & - & - \\
\hline & Montanhoso & 8 & 30 & - & - & - & - & - & - \\
\hline \multirow{3}{*}{$\begin{array}{l}\text { Classe } \\
\text { IV-B }\end{array}$} & Plano & 6 & 60 & 130 & 150 & 190 & 240 & 320 & - \\
\hline & Ondulado & 8 & 40 & 60 & 80 & - & - & - & - \\
\hline & Montanhoso & 10 & 30 & - & - & - & - & - & - \\
\hline
\end{tabular}

Os campos desta tabela preenchidos com hífen indicam situações onde o veículo simulado atinge uma velocidade de equilíbrio na rampa que é superior à redução máxima estipulada de $20 \mathrm{~km} / \mathrm{h}$. Sendo assim, nestes casos, os veículos não possuem um comprimento crítico para estas declividades de rampa. Os resultados obtidos se mostraram próximos às distâncias obtidas quando consultadas as curvas de desempenho propostas no trabalho de Melo (2002) para caminhões típicos brasileiros. O objetivo desta simulação é verificar para as características impostas pelas classes técnicas de projeto (declividade de rampa e velocidade de projeto) como se comportam veículos com diferentes valores de relação potência/massa, sendo utilizado o conceito de comprimento crítico de rampa. As diretrizes para a implantação de faixas adicionais, por sua vez, envolve vários outros aspectos, como o fluxo de veículos no aclive, a participação de caminhões neste fluxo, nível de serviço, além de análises econômicas (KABBACH JÚNIOR, 1993; MELO, 2002).

De modo geral, todas as classes de rodovia com baixas velocidades diretrizes, iguais ou inferiores a $40 \mathrm{~km} / \mathrm{h}$, apresentaram a tendência dos veículos atingirem a 
velocidade de equilíbrio antes de haver uma redução de $20 \mathrm{~km} / \mathrm{h}$, fenômeno verificado para quase todas as relações potência/massa pesquisadas. A redução admissível de velocidade, da ordem de $35 \mathrm{~km} / \mathrm{h}$, considerada nas Classes 0 e I-A, permitiram comprimentos críticos bem mais elevados ou mesmo a inexistência de limites para o mesmo em algumas situações nos veículos com relação potência/massa igual ou superior a 7,4 cv/t, mesmo diante das elevadas velocidades de projeto destas classes de rodovia. Os resultados mostraram claramente a influência da relação potência/massa nos comprimentos críticos das rampas, confirmando a importância de considerar este parâmetro na escolha do veículo de projeto a ser considerado no projeto do perfil longitudinal de uma rodovia.

Voltando a considerar a questão da velocidade de equilíbrio dos veículos, pode ser observado um resultado importante. Para a situação de greide nulo, foram obtidas velocidades de equilíbrio de $60 \mathrm{~km} / \mathrm{h}$ e $75 \mathrm{~km} / \mathrm{h}$ para os veículos de 3,16 e 4,67 cv/t, respectivamente. Estes resultados denotam que, para as rodovias de pista simples com maior velocidade de projeto, isto é, rodovias das classes I-B e II no terreno plano, cuja velocidade é de $100 \mathrm{~km} / \mathrm{h}$, estes veículos, e em especial o veículo de 3,16 cv/t, apresenta condições operacionais restritivas. Neste caso, o veículo só consegue operar com uma redução máxima de velocidade de $20 \mathrm{~km} / \mathrm{h}$ nos greides descendentes, indicando que, se considerado apenas o critério da velocidade, seriam necessários extensos trechos de faixa adicional para mitigar os impactos do veículo de 3,16 cv/t no tráfego destas rodovias. Para os outros veículos simulados, foram obtidas velocidades de equilíbrio entre 86 e $105 \mathrm{~km} / \mathrm{h}$, atendendo ao critério de redução de velocidade considerado.

\subsubsection{Distância de Visibilidade em Interseções}

Para a determinação das distâncias de visibilidade em interseções, foi utilizado o TRUPER, sendo simulado o tempo necessário para o veículo na via secundária transpor este tipo de interseção. Foram consideradas as mesmas relações potência/massa dos veículos utilizados para a simulação realizada nos aclives das rampas. Quanto à extensão da travessia considerada, foi tomado o esquema simplificado ilustrado na Figura 4.17, sendo admitidas as seguintes hipóteses para as condições de travessia: 


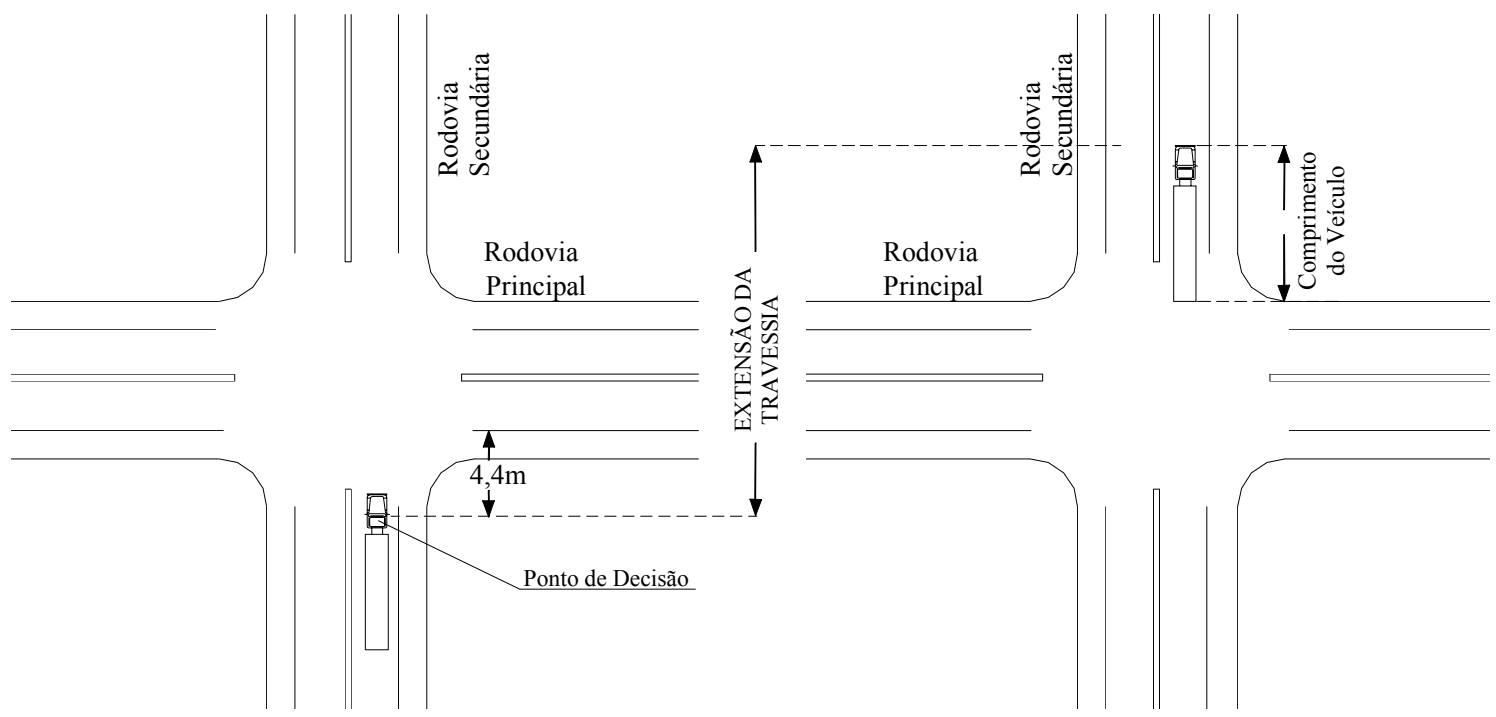

Figura 4.17: Extensão de Travessia Considerada na Simulação para Cálculo da Distância de Visibilidade em Interseções.

(a) para o comprimento dos veículos, foram considerados vários valores, desde 9,1 $\mathrm{m}$, que corresponde ao comprimento do veículo de projeto CO do DNER até 30 $\mathrm{m}$, valor referente ao comprimento máximo de CVC estabelecido pelo CONTRAN, incluindo ainda os comprimentos de veículos apresentados na Tabela 4.1;

(b) o ponto inicial da travessia considerado correspondeu ao ponto de decisão definido pela AASHTO, e sua localização foi definida a uma distância de 4,4 m da borda da pista da rodovia principal;

(c) o ponto final da travessia adotado correspondeu à posição em que o caminhão desobstrui completamente a via principal, incluindo seu acostamento;

(d) a largura da plataforma considerada, isto é, a largura das faixas de tráfego e acostamentos utilizados, correspondeu aos valores mínimos estabelecidos para as classes técnicas do DNER;

(e) quanto às declividades das plataformas, foram simuladas três situações: 1\%, 2\% e 3\%, sendo considerada a primeira metade da distância de travessia em aclive e a segunda metade em declive; e

(f) foi acrescentado aos tempos obtidos na simulação um valor correspondente ao tempo de percepção e reação, sendo adotados 2,5 seg, valor de referência utilizado nos manuais de projeto para representar o comportamento dos motoristas. 
Apenas para ilustrar o problema da travessia de veículos e seu impacto no tráfego dos segmentos rodoviários, será considerado um dos dispositivos utilizados em rodovias no Brasil, denominado de trevo vazado simples e ou provido de faixas de aceleração, como ilustra a Figura 4.18. Este tipo de dispositivo faz uso de ilhas de canalização, sendo o controle de tráfego realizado mediante placas de sinalização "PARE" na via secundária. Sua utilização apresenta algumas vantagens em virtude da desobstrução da via principal, quando os veículos pretendem realizar conversões à esquerda, que são canalizadas para a aproximação da via secundária. Outra vantagem observada neste dispositivo é o melhor posicionamento do veículo procedente da via secundária para se inserir na via principal, permitindo que ele fique parado no acostamento, aguardando uma brecha no fluxo de tráfego.

Este tipo de interseção, porém, apresenta desvantagens, como a presença de interferências entre as correntes de tráfego, potencializadas em função do elevado diferencial de velocidade entre os veículos que trafegam na via principal e aqueles que pretendem cruzá-la ou nela se inserir. Além deste fato, existe a necessidade de o motorista estar atento às duas correntes de tráfego da via principal para realizar a manobra de travessia (XEREZ, 2002). A existência de faixas de aceleração e desaceleração nestes dispositivos eleva o nível de segurança da interseção, uma vez que permite aos veículos que irão se inserir na faixa de tráfego da via principal um menor diferencial de velocidade com relação à corrente de tráfego.
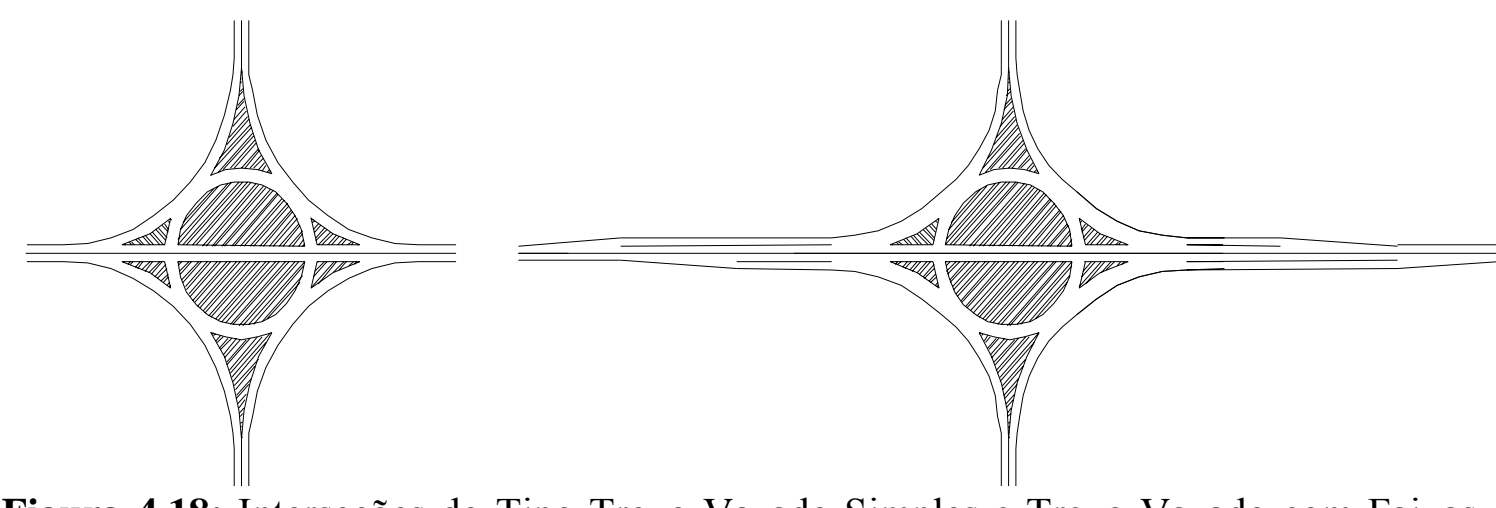

Figura 4.18: Interseções do Tipo Trevo Vazado Simples e Trevo Vazado com Faixas de Aceleração e Desaceleração.

Os resultados obtidos na simulação do TRUPER para o tempo de travessia das interseções foram comparados com os valores admitidos pelos manuais de 
projeto geométrico mencionados no Capítulo 3. A análise das situações envolvendo a realização de conversões pelo veículo da via secundária e sua inserção na via principal será tratada mais adiante, quando será considerada a utilização de faixas de aceleração. Como o enfoque dado nesta pesquisa é verificar o impacto de veículos procedentes de vias secundárias e que irão se inserir na via principal, as faixas de desaceleração não serão tratadas nesta pesquisa. A investigação destes dispositivos está intrinsecamente relacionada à geometria das interseções, envolvendo questões que não estão inseridas no escopo deste trabalho.

Considerando inicialmente a extensão total de travessia direta, dadas as hipóteses assumidas para as condições de travessia, foram obtidas extensões que variaram entre 20,4 e 44,6 m. Em função da grande quantidade de valores obtidos, foram simulados os valores entre 20 e $45 \mathrm{~m}$, com incrementos a cada $1 \mathrm{~m}$. As Tabelas 4.9, 4.10 e 4.11 apresentam os tempos de travessia encontrados na simulação com valores arredondados para intervalos de $0,5 \mathrm{seg}$.

Tabela 4.9: Intervalo de Tempo na Via Principal Aceito para Manobra de Travessia de Veículos Parados na Via Secundária - Greide de 1\%

\begin{tabular}{ccccccc}
\hline \multirow{2}{*}{ EXTENSÃO DE } & \multicolumn{5}{c}{ TEMPO DE TRAVESSIA (seg) } \\
\cline { 2 - 6 } TRAVESSIA (m) & Veículo 1 & Veículo 2 & Veículo 3 & Veículo 4 & Veículo 5 & Veículo 6 \\
& $3,16 \mathrm{cv} / \mathrm{t}$ & $4,67 \mathrm{cv} / \mathrm{t}$ & $6,97 \mathrm{cv} / \mathrm{t}$ & $7,42 \mathrm{cv} / \mathrm{t}$ & $9,76 \mathrm{cv} / \mathrm{t}$ & $13,15 \mathrm{cv} / \mathrm{t}$ \\
\hline 20 & 11,0 & 10,0 & 8,5 & 8,0 & 7,5 & 7,5 \\
21 & 11,0 & 10,0 & 8,5 & 8,5 & 8,0 & 7,5 \\
22 & 11,5 & 10,0 & 8,5 & 8,5 & 8,0 & 7,5 \\
23 & 11,5 & 10,5 & 8,5 & 8,5 & 8,0 & 8,0 \\
24 & 11,5 & 10,5 & 9,0 & 8,5 & 8,5 & 8,0 \\
25 & 12,0 & 11,0 & 9,0 & 9,0 & 8,5 & 8,0 \\
26 & 12,0 & 11,0 & 9,0 & 9,0 & 8,5 & 8,0 \\
27 & 12,5 & 11,0 & 9,5 & 9,0 & 8,5 & 8,5 \\
28 & 12,5 & 11,5 & 9,5 & 9,5 & 9,0 & 8,5 \\
29 & 13,0 & 11,5 & 9,5 & 9,5 & 9,0 & 8,5 \\
30 & 13,0 & 11,5 & 10,0 & 9,5 & 9,0 & 8,5 \\
31 & 13,5 & 12,0 & 10,0 & 9,5 & 9,0 & 9,0 \\
32 & 13,5 & 12,0 & 10,0 & 10,0 & 9,5 & 9,0 \\
33 & 13,5 & 12,5 & 10,0 & 10,0 & 9,5 & 9,0 \\
34 & 14,0 & 12,5 & 10,5 & 10,0 & 9,5 & 9,0 \\
35 & 14,0 & 12,5 & 10,5 & 10,0 & 9,5 & 9,0 \\
36 & 14,5 & 13,0 & 10,5 & 10,5 & 10,0 & 9,5 \\
37 & 14,5 & 13,0 & 11,0 & 10,5 & 10,0 & 9,5 \\
38 & 14,5 & 13,0 & 11,0 & 10,5 & 10,0 & 9,5 \\
39 & 15,0 & 13,5 & 11,0 & 10,5 & 10,0 & 9,5 \\
40 & 15,0 & 13,5 & 11,0 & 11,0 & 10,5 & 9,5 \\
41 & 15,5 & 13,5 & 11,5 & 11,0 & 10,5 & 10,0 \\
42 & 15,5 & 14,0 & 11,5 & 11,0 & 10,5 & 10,0 \\
43 & 15,5 & 14,0 & 11,5 & 11,0 & 10,5 & 10,0 \\
44 & 16,0 & 14,0 & 11,5 & 11,5 & 11,0 & 10,0 \\
45 & 16,0 & 14,0 & 12,0 & 11,5 & 11,0 & 10,5 \\
\hline
\end{tabular}


Tabela 4.10: Intervalo de Tempo na Via Principal Aceito para Manobra de Travessia de Veículos Parados na Via Secundária - Greide de 2\%

\begin{tabular}{|c|c|c|c|c|c|c|}
\hline \multirow{2}{*}{$\begin{array}{l}\text { EXTENSÃO DE } \\
\text { TRAVESSIA (m) }\end{array}$} & \multicolumn{6}{|c|}{ TEMPO DE TRAVESSIA (seg) } \\
\hline & Veículo 1 & Veículo 2 & Veículo 3 & Veículo 4 & Veículo 5 & Veículo 6 \\
\hline 20 & $\frac{3.10 \mathrm{cV} / \mathrm{l}}{11,0}$ & $\frac{4.6 / \mathrm{cV} / \mathrm{t}}{10,0}$ & $\frac{0.9 / \mathrm{cV} / \mathrm{t}}{8.5}$ & $\frac{7.42 \mathrm{cv} / \mathrm{t}}{8.0}$ & $\frac{9.76 \mathrm{cv} / \mathrm{t}}{8.0}$ & $\frac{13.15 \mathrm{cv} / \mathrm{t}}{7.5}$ \\
\hline 21 & 11,5 & 10,5 & 8,5 & 8,5 & 8,0 & 7,5 \\
\hline 22 & 11,5 & 10,5 & 8,5 & 8,5 & 8,0 & 8,0 \\
\hline 23 & 12,0 & 10,5 & 9,0 & 8,5 & 8,0 & 8,0 \\
\hline 24 & 12,0 & 11,0 & 9,0 & 9,0 & 8,5 & 8,0 \\
\hline 25 & 12,5 & 11,0 & 9,0 & 9,0 & 8,5 & 8,0 \\
\hline 26 & 12,5 & 11,5 & 9,5 & 9,0 & 8,5 & 8,5 \\
\hline 27 & 13,0 & 11,5 & 9,5 & 9,0 & 9,0 & 8,5 \\
\hline 28 & 13,0 & 11,5 & 9,5 & 9,5 & 9,0 & 8,5 \\
\hline 29 & 13,5 & 12,0 & 10,0 & 9,5 & 9,0 & 8,5 \\
\hline 30 & 13,5 & 12,0 & 10,0 & 9,5 & 9,0 & 9,0 \\
\hline 31 & 13,5 & 12,5 & 10,0 & 10,0 & 9,5 & 9,0 \\
\hline 32 & 14,0 & 12,5 & 10,5 & 10,0 & 9,5 & 9,0 \\
\hline 33 & 14,0 & 12,5 & 10,5 & 10,0 & 9,5 & 9,0 \\
\hline 34 & 14,5 & 13,0 & 10,5 & 10,0 & 9,5 & 9,5 \\
\hline 35 & 14,5 & 13,0 & 10,5 & 10,5 & 10,0 & 9,5 \\
\hline 36 & 15,0 & 13,0 & 11,0 & 10,5 & 10,0 & 9,5 \\
\hline 37 & 15,0 & 13,5 & 11,0 & 10,5 & 10,0 & 9,5 \\
\hline 38 & 15,5 & 13,5 & 11,0 & 10,5 & 10,0 & 9,5 \\
\hline 39 & 15,5 & 13,5 & 11,5 & 11,0 & 10,5 & 10,0 \\
\hline 40 & 15,5 & 14,0 & 11,5 & 11,0 & 10,5 & 10,0 \\
\hline 41 & 16,0 & 14,0 & 11,5 & 11,0 & 10,5 & 10,0 \\
\hline 42 & 16,0 & 14,5 & 11,5 & 11,0 & 10,5 & 10,0 \\
\hline 43 & 16,5 & 14,5 & 12,0 & 11,5 & 11,0 & 10,5 \\
\hline 44 & 16,5 & 14,5 & 12,0 & 11,5 & 11,0 & 10,5 \\
\hline 45 & 16,5 & 14,5 & 12,0 & 11,5 & 11,0 & 10,5 \\
\hline
\end{tabular}

Tabela 4.11: Intervalo de Tempo na Via Principal Aceito para Manobra de Travessia de Veículos Parados na Via Secundária - Greide de 3\%

\begin{tabular}{ccccccc}
\hline \multirow{2}{*}{ EXTENSÃO DE } & \multicolumn{5}{c}{ TEMPO DE TRAVESSIA (seg) } \\
\cline { 2 - 6 } TRAVESSIA (m) & Veículo 1 & Veículo 2 & Veículo 3 & Veículo 4 & Veículo 5 & Veículo 6 \\
& $3,16 \mathrm{cv} / \mathrm{t}$ & $4,67 \mathrm{cv} / \mathrm{t}$ & $6,97 \mathrm{cv} / \mathrm{t}$ & $7,42 \mathrm{cv} / \mathrm{t}$ & $9,76 \mathrm{cv} / \mathrm{t}$ & $13,15 \mathrm{cv} / \mathrm{t}$ \\
\hline 20 & 11,5 & 10,5 & 8,5 & 8,0 & 8,0 & 7,5 \\
21 & 11,5 & 10,5 & 8,5 & 8,5 & 8,0 & 8,0 \\
22 & 12,0 & 11,0 & 9,0 & 8,5 & 8,0 & 8,0 \\
23 & 12,0 & 11,0 & 9,0 & 8,5 & 8,5 & 8,0 \\
24 & 12,5 & 11,5 & 9,0 & 9,0 & 8,5 & 8,0 \\
25 & 12,5 & 11,5 & 9,5 & 9,0 & 8,5 & 8,5 \\
26 & 13,0 & 11,5 & 9,5 & 9,0 & 8,5 & 8,5 \\
27 & 13,5 & 12,0 & 9,5 & 9,5 & 9,0 & 8,5 \\
28 & 13,5 & 12,0 & 10,0 & 9,5 & 9,0 & 8,5 \\
29 & 13,5 & 12,5 & 10,0 & 9,5 & 9,0 & 9,0 \\
30 & 14,0 & 12,5 & 10,0 & 9,5 & 9,0 & 9,0 \\
31 & 14,0 & 12,5 & 10,5 & 10,0 & 9,5 & 9,0 \\
32 & 14,5 & 13,0 & 10,5 & 10,0 & 9,5 & 9,0 \\
33 & 14,5 & 13,0 & 10,5 & 10,0 & 9,5 & 9,5 \\
34 & 15,0 & 13,5 & 10,5 & 10,5 & 10,0 & 9,5 \\
35 & 15,0 & 13,5 & 11,0 & 10,5 & 10,0 & 9,5 \\
36 & 15,5 & 13,5 & 11,0 & 10,5 & 10,0 & 9,5 \\
37 & 15,5 & 14,0 & 11,0 & 10,5 & 10,0 & 9,5 \\
38 & 16,0 & 14,0 & 11,5 & 11,0 & 10,5 & 10,0 \\
39 & 16,0 & 14,5 & 11,5 & 11,0 & 10,5 & 10,0 \\
40 & 16,5 & 14,5 & 11,5 & 11,0 & 10,5 & 10,0 \\
41 & 16,5 & 14,5 & 11,5 & 11,0 & 10,5 & 10,0 \\
42 & 17,0 & 15,0 & 12,0 & 11,5 & 10,5 & 10,5 \\
43 & 17,0 & 15,0 & 12,0 & 11,5 & 11,0 & 10,5 \\
44 & 17,5 & 15,0 & 12,0 & 11,5 & 11,0 & 10,5 \\
45 & 17,5 & 15,5 & 12,5 & 11,5 & 11,0 & 10,5 \\
\hline
\end{tabular}


Os tempos de travessia obtidos na simulação se mostraram coerentes com resultados de coletas de campo realizadas no trabalho de Demarchi, Setti e Widmer (1994). Considerando os três greides simulados, os resultados se mostraram bastante próximos, com diferenças de no máximo $1 \mathrm{seg}$ entre si, sendo que, para os veículos com relação potência /massa de $6,97 \mathrm{cv} / \mathrm{t}$ ou superior, a maior diferença entre os resultados foi de $0,5 \mathrm{seg}$.

Serão considerados os resultados para o greides de 3\% como valor de referência para o cálculo das distâncias de visibilidade em interseções e comparação com as distâncias de travessia obtidas a partir dos intervalos de tempo (gaps) propostos pelo AASHTO e recomendados pelo DNIT (2005).

Como conclusão geral da simulação, observa-se que veículos com maior relação potência/massa podem compensar seus maiores comprimentos e, portanto, suas maiores extensões de travessia, demandando gaps semelhantes ou até inferiores aos gaps de veículos de menor comprimento. Tomando como exemplo os resultados da Tabela 4.11, observa-se veículos com relação potência/massa de 9,76 e 13,15 cv/t nas extensões de travessia entre 30 e $45 \mathrm{~m}$ apresentando gaps iguais ou inferiores ao demandado por veículos de 3,16 e 4,67 cv/t para as extensões de travessia entre 20 e $30 \mathrm{~m}$.

Para a determinação das distâncias de visibilidade em interseções (DVIs), foram considerados os tempos apresentados na Tabela 4.11, utilizando a equação 3.21. A Tabela 4.12 mostra os resultados obtidos para veículos com diferentes relações potência/massa e comprimento de $12,2 \mathrm{~m}$, comparando à distância de visibilidade proposta pelo DNIT para o veículo de projeto O(DNER). Como observado, a distância de visibilidade demandada pelo veículo O(DNER) é semelhante aos valores encontrados para o veículo de 9,76 cv/t. Os veículos de menor relação potência/massa, em função de seus maiores tempos de travessia, exigiram maiores distâncias de visibilidade. Este déficit é mais acentuado nas rodovias de mais elevado padrão, uma vez que estas possuem velocidades de projeto mais elevadas e também plataformas de maior extensão. A situação mais crítica é verificada no veículo de 3,16 cv/t para a Classe I-Plano, cujo déficit é de aproximadamente $140 \mathrm{~m}$. 
Tabela 4.12: Distância de Visibilidade em Interseções, segundo o Veículo de Projeto O (DNER) e Veículos Simulados com Comprimento de 12,2 m.

\begin{tabular}{|c|c|c|c|c|c|c|c|c|}
\hline \multirow{3}{*}{ CLASSE } & \multirow{3}{*}{ TERRENO } & \multicolumn{7}{|c|}{ DISTÂNCIA DE VISIBILIDADE NA INTERSEÇÃO (m) } \\
\hline & & \multicolumn{7}{|c|}{ Veículo Simulado } \\
\hline & & O (DNER) & $3,16 \mathrm{cv} / \mathrm{t}$ & $4,67 \mathrm{cv} / \mathrm{t}$ & $6,97 \mathrm{cv} / \mathrm{t}$ & $7,42 \mathrm{cv} / \mathrm{t}$ & $9,76 \mathrm{cv} / \mathrm{t}$ & $13,15 \mathrm{cv} / \mathrm{t}$ \\
\hline \multirow{3}{*}{ I } & $\mathrm{P}$ & 236 & 375 & 334 & 264 & 264 & 250 & 236 \\
\hline & $\mathrm{O}$ & 189 & 289 & 256 & 211 & 200 & 189 & 189 \\
\hline & M & 142 & 217 & 192 & 158 & 150 & 142 & 142 \\
\hline \multirow{3}{*}{ II } & $\mathrm{P}$ & 236 & 361 & 320 & 264 & 250 & 236 & 236 \\
\hline & $\mathrm{O}$ & 165 & 253 & 224 & 185 & 175 & 165 & 165 \\
\hline & M & 118 & 174 & 160 & 132 & 125 & 118 & 118 \\
\hline \multirow{3}{*}{ III } & $\mathrm{P}$ & 189 & 289 & 256 & 211 & 200 & $\begin{array}{ll}189 \\
\end{array}$ & 189 \\
\hline & $\mathrm{O}$ & 142 & 209 & 192 & 158 & 150 & 142 & 142 \\
\hline & M & 95 & 139 & 128 & 106 & 100 & 95 & 95 \\
\hline \multirow{3}{*}{ IV } & $P$ & 142 & 209 & 192 & 150 & 150 & 142 & 133 \\
\hline & $\mathrm{O}$ & 95 & 139 & 128 & 100 & 100 & 95 & 89 \\
\hline & $\mathrm{M}$ & 71 & 100 & 92 & 75 & 71 & 71 & 67 \\
\hline
\end{tabular}

A Tabela 4.13 mostra a comparação entre as DVIs do veículo de projeto RE(DNIT) e os demais veículos simulados, com 19,8 m de comprimento. Neste caso os resultados dos gaps propostos para o veículo RE(DNIT) se mostraram adequados para a maioria das relações potência/massa simuladas, havendo necessidade de maiores distâncias de visibilidade apenas para os veículos de 3,16 cv/t e 4,67 cv/t.

Tabela 4.13: Distância de Visibilidade em Interseções, segundo o Veículo de Projeto RE (DNIT) e Veículos Simulados.com Comprimento de 19,8 m

\begin{tabular}{|c|c|c|c|c|c|c|c|c|}
\hline \multirow{3}{*}{ CLASSE } & \multirow{3}{*}{ TERRENO } & \multirow{2}{*}{\multicolumn{7}{|c|}{ DISTÂNCIA DE VISIBILIDADE NA INTERSECCÃO (m) }} \\
\hline & & & & & & & & \\
\hline & & RE (DNIT) & $3,16 \mathrm{cv} / \mathrm{t}$ & $4,67 \mathrm{cv} / \mathrm{t}$ & $6,97 \mathrm{cv} / \mathrm{t}$ & $7,42 \mathrm{cv} / \mathrm{t}$ & $9,76 \mathrm{cv} / \mathrm{t}$ & $13,15 \mathrm{cv} / \mathrm{t}$ \\
\hline \multirow{3}{*}{ I } & $\mathrm{P}$ & 292 & 417 & 375 & 292 & 292 & 278 & 264 \\
\hline & $\mathrm{O}$ & 234 & 334 & 300 & 234 & 234 & 222 & 211 \\
\hline & M & 175 & 250 & 225 & 175 & 175 & 167 & 158 \\
\hline \multirow{3}{*}{ II } & $\mathrm{P}$ & 292 & 417 & 375 & 292 & 292 & 278 & 264 \\
\hline & $\mathrm{O}$ & 204 & 292 & 263 & 204 & 204 & 195 & 185 \\
\hline & M & 146 & 202 & 181 & 146 & 139 & 132 & 132 \\
\hline \multirow{3}{*}{ III } & $P$ & 234 & 334 & 300 & 234 & 234 & 222 & 211 \\
\hline & $\mathrm{O}$ & 175 & 242 & 217 & 175 & 167 & 158 & 158 \\
\hline & $\mathrm{M}$ & 117 & 161 & 145 & 117 & 111 & 106 & 100 \\
\hline \multirow{3}{*}{ IV } & $\mathrm{P}$ & 175 & 242 & 217 & 175 & 167 & 158 & 150 \\
\hline & $\mathrm{O}$ & 117 & 161 & 145 & 117 & 111 & 106 & 100 \\
\hline & M & 88 & 117 & 104 & 88 & 83 & 79 & 75 \\
\hline
\end{tabular}

As Tabelas 4.14 e 4.15 mostram as DVIs obtidas para o veículo de projeto RE(DNIT), representando o maior veículo considerado pelo Manual do DNIT, em comparação a veículos com comprimento de 25 e 30 m, respectivamente. Para o veículo com comprimento de $25 \mathrm{~m}$, as distâncias máximas de visibilidade propostas no Manual 
do DNIT, referentes à travessia de um veículo de 19,8 m, se mostraram compatíveis apenas para a operação de veículos com relação potência/massa de 9,76 e 13,15 cv/t.

Tabela 4.14: Distância de Visibilidade em Interseções Segundo o Veículo de Projeto RE (DNIT) e Veículos Simulados com Comprimento de $25 \mathrm{~m}$.

\begin{tabular}{|c|c|c|c|c|c|c|c|c|}
\hline \multirow{3}{*}{ CLASSE } & \multirow{3}{*}{ TERRENO } & \multicolumn{7}{|c|}{ DISTÂNCIA DE VISIBILIDADE NA INTERSECCÃO (m) } \\
\hline & & & & & culo Simul & & & \\
\hline & & RE (DNIT) & $3,16 \mathrm{cv} / \mathrm{t}$ & $4,67 \mathrm{cv} / \mathrm{t}$ & $6,97 \mathrm{cv} / \mathrm{t}$ & $7,42 \mathrm{cv} / \mathrm{t}$ & $9,76 \mathrm{cv} / \mathrm{t}$ & $13,15 \mathrm{cv} / \mathrm{t}$ \\
\hline \multirow{3}{*}{ I } & $\mathrm{P}$ & 292 & 459 & 403 & 320 & 306 & 292 & 278 \\
\hline & $\mathrm{O}$ & 234 & 356 & 322 & 256 & 245 & 234 & 222 \\
\hline & M & 175 & 267 & 242 & 192 & 183 & 175 & 167 \\
\hline \multirow{3}{*}{ II } & $P$ & 292 & 445 & 403 & 320 & 306 & 292 & 278 \\
\hline & $\mathrm{O}$ & 204 & 311 & 282 & 224 & 214 & 204 & 195 \\
\hline & $\mathrm{M}$ & 146 & 222 & 195 & 160 & 153 & 146 & 139 \\
\hline \multirow{3}{*}{ III } & $P$ & 234 & 356 & 322 & 256 & 245 & 234 & 222 \\
\hline & $\mathrm{O}$ & 175 & 267 & 234 & 192 & 183 & 175 & 167 \\
\hline & $\mathrm{M}$ & 117 & 178 & 156 & 128 & 122 & 117 & 111 \\
\hline \multirow{3}{*}{ IV } & $\mathrm{P}$ & 175 & 259 & 234 & 183 & 175 & 167 & 158 \\
\hline & $\mathrm{O}$ & 117 & 172 & 156 & 122 & 117 & 111 & 106 \\
\hline & $\mathrm{M}$ & 88 & 129 & 113 & 92 & 88 & 83 & 79 \\
\hline
\end{tabular}

Para o veículo de $30 \mathrm{~m}$, esta condição é atendida apenas pelo veículo de 13,15 cv/t. Nestes dois exemplos, vê-se que a compatibilidade da operação de veículos mais longos operarem em interseções cuja DVI foi determinada para veículos menores ocorreu graças a estes veículos apresentarem maior relação potência/massa e, portanto, maior capacidade de aceleração e ganho de velocidade.

Tabela 4.15: Distância de Visibilidade em Interseções Segundo o Veículo de Projeto RE (DNIT) e Veículos Simulados com Comprimento de $30 \mathrm{~m}$.

\begin{tabular}{|c|c|c|c|c|c|c|c|c|}
\hline \multirow{3}{*}{ CLASSE } & \multirow{3}{*}{ TERRENO } & \multicolumn{7}{|c|}{ DISTÂNCIA DE VISIBILIDADE NA INTERSECCÃO (m) } \\
\hline & & & & & culo Simu & & & \\
\hline & & RE(DNIT) & $3,16 \mathrm{cv} / \mathrm{t}$ & $4,67 \mathrm{cv} / \mathrm{t}$ & $6,97 \mathrm{cv} / \mathrm{t}$ & $7,42 \mathrm{cv} / \mathrm{t}$ & $9,76 \mathrm{cv} / \mathrm{t}$ & $13,15 \mathrm{cv} / \mathrm{t}$ \\
\hline \multirow{3}{*}{ I } & $\mathrm{P}$ & 292 & 487 & 431 & 348 & 320 & 306 & 292 \\
\hline & $\mathrm{O}$ & 234 & 389 & 334 & 267 & 256 & 245 & 234 \\
\hline & $\mathrm{M}$ & 175 & 292 & 250 & 200 & 192 & 183 & 175 \\
\hline \multirow{3}{*}{ II } & $\mathrm{P}$ & 292 & 487 & 417 & 334 & 320 & 306 & 292 \\
\hline & $\mathrm{O}$ & 204 & 341 & 292 & 234 & 224 & 214 & 204 \\
\hline & $\mathrm{M}$ & 146 & 236 & 209 & 167 & 160 & 153 & 146 \\
\hline \multirow{3}{*}{ III } & $\mathrm{P}$ & 234 & 389 & 334 & 267 & 256 & 245 & 234 \\
\hline & $\mathrm{O}$ & 175 & 284 & 250 & 200 & 192 & 183 & 175 \\
\hline & $\mathrm{M}$ & 117 & 189 & 167 & 133 & 128 & 122 & 117 \\
\hline \multirow{3}{*}{ IV } & $\mathrm{P}$ & 175 & 284 & 250 & 200 & 192 & 175 & 175 \\
\hline & $\mathrm{O}$ & 117 & 189 & 167 & 133 & 128 & 117 & 117 \\
\hline & $\mathrm{M}$ & 88 & 138 & 121 & 96 & 92 & 88 & 83 \\
\hline
\end{tabular}

Para analisar estes resultados, é importante observar as relações potência/massa dos veículos. Tome-se como referência a pesquisa de caracterização da frota de 
caminhões brasileiros desenvolvida por Cunha et al. (2005) em rodovias do Estado de São Paulo. Esse estudo indicou uma elevação nos valores de relação potência/massa dos veículos se comparado a levantamentos anteriores (DEMARCHI E SETTI, 1999). Se considerados os veículos do tipo 3S2B2, no entanto, foi observado que mais de $50 \%$ da amostra pesquisada apresentavam uma relação potência/massa inferior a 7,6 cv/t. Desta forma, parte significativa dos veículos pesados de maior comprimento demandam gaps mais elevados do que os valores propostos no atual Manual do DNIT, sendo recomendado considerar maiores DVI's onde houver operação de veículos com extensão de $25 \mathrm{~m}$ ou superior.

\section{$\underline{\text { Inserção de Veículos na Via Principal }}$}

Para analisar a adequação das distâncias de visibilidade, para o caso da conversão de veículos procedentes da via secundária, e que se inserem na via principal, foram calculadas as velocidades atingidas por veículos realizando estes movimentos, durante os intervalos de tempo apresentados na Tabela 4.11, ou seja, admitindo o mesmo gap necessário para transpor a via. Na simulação realizada, foi considerada a condição de greide nulo, com o veículo partindo do repouso. Os resultados obtidos estão apresentados na Tabela 4.16. Pode-se observar que são atingidas baixas velocidades neste intervalo de tempo, especialmente para aqueles veículos com menor relação potência/massa, causando interferências na corrente de tráfego e o risco da ocorrência de acidentes. Estes resultados revelam a importância da utilização de faixas de aceleração para reduzir estes impactos, especialmente em situações mais críticas, como em rodovias com elevado volume de tráfego e quando a participação de veículos de carga realizando conversões é significativa. Para o caso das conversões à esquerda, os manuais de projeto geométrico (AASHTO, 2004; DNIT, 2005) acrescem 1 seg aos tempos admitidos para a transposição da via e conversão à direita. Mesmo acrescendo este valor, entretanto, não haveria mudanças significativas nos valores apresentadas na Tabela 4.16, permanecendo a importância de prover faixas de aceleração nas interseções críticas. No caso das interseções do tipo trevo vazado, o veículo da via secundária não realiza a conversão à esquerda de forma direta, sendo inicialmente realizada a transposição da via principal, seguida de uma conversão à direita. Esta será a configuração de interseção considerada na análise a seguir. 
Tabela 4.16: Velocidade Atingida por Veículo que se Inseriu na Via Principal, após um Intervalo equivalente ao Gap Necessário para a Transposição da Via.

\begin{tabular}{ccccccc}
\hline \multirow{2}{*}{ EXTENSÃO DE } & \multicolumn{5}{c}{ VELOCIDADE DO VEÍCULO $(\mathrm{km} / \mathrm{h})$} \\
\cline { 2 - 6 } TRAVESSIA (m) & Veículo 1 & Veículo 2 & Veículo 3 & Veículo 4 & Veículo 5 & Veículo 6 \\
& $3,16 \mathrm{cv} / \mathrm{t}$ & $4,67 \mathrm{cv} / \mathrm{t}$ & $6,97 \mathrm{cv} / \mathrm{t}$ & $7,42 \mathrm{cv} / \mathrm{t}$ & $9,76 \mathrm{cv} / \mathrm{t}$ & $13,15 \mathrm{cv} / \mathrm{t}$ \\
\hline 20 & 17 & 19 & 23 & 24 & 26 & 28 \\
21 & 17 & 19 & 23 & 25 & 26 & 29 \\
22 & 17 & 20 & 24 & 25 & 27 & 29 \\
23 & 17 & 20 & 24 & 25 & 27 & 29 \\
24 & 18 & 20 & 24 & 26 & 27 & 30 \\
25 & 18 & 20 & 25 & 26 & 28 & 30 \\
26 & 18 & 21 & 25 & 26 & 28 & 31 \\
27 & 18 & 21 & 25 & 27 & 29 & 31 \\
28 & 18 & 21 & 26 & 27 & 29 & 32 \\
29 & 19 & 22 & 26 & 27 & 29 & 32 \\
30 & 19 & 22 & 26 & 28 & 30 & 32 \\
31 & 19 & 22 & 26 & 28 & 30 & 33 \\
32 & 19 & 22 & 27 & 28 & 30 & 33 \\
33 & 19 & 23 & 27 & 29 & 31 & 33 \\
34 & 20 & 23 & 27 & 29 & 31 & 34 \\
35 & 20 & 23 & 27 & 29 & 31 & 34 \\
36 & 20 & 23 & 28 & 29 & 31 & 34 \\
37 & 20 & 23 & 28 & 30 & 32 & 35 \\
38 & 20 & 24 & 28 & 30 & 32 & 35 \\
39 & 21 & 24 & 28 & 30 & 32 & 35 \\
40 & 21 & 24 & 29 & 31 & 33 & 36 \\
41 & 21 & 24 & 29 & 31 & 33 & 36 \\
42 & 21 & 24 & 29 & 31 & 33 & 36 \\
43 & 21 & 25 & 29 & 31 & 33 & 37 \\
44 & 21 & 25 & 29 & 31 & 34 & 37 \\
45 & 22 & 25 & 30 & 32 & 34 & 37 \\
\hline
\end{tabular}

Para verificar a adequação das faixas de aceleração em interseções, foi simulado o comportamento dos veículos pesados com diferentes relações potência/massa, sendo comparando-se aos valores recomendados pelo DNIT e pela AASHTO, ambos baseados no comportamento de veículos de passeio. Antes de simular o comportamento destes veículos para diversas declividades de rampa e velocidades de entrada nestas rampas, é importante atentar para a velocidade de equilíbrio destes veículos para as declividades a serem consideradas, como forma de identificar que níveis de velocidade estes veículos conseguem desenvolver. Estas velocidades estão apresentadas na Tabela 4.17.

Tabela 4.17: Velocidade de Equilíbrio dos Veículos Simulados para o Terreno Plano e algumas Rampas Ascendentes.

\begin{tabular}{ccccccc}
\hline \multirow{2}{*}{ GREIDE } & \multicolumn{6}{c}{ VELOCIDADE DE EQUILÍBRIO $(\mathrm{km} / \mathrm{h})$} \\
\cline { 2 - 7 } & Veículo 1 & Veículo 2 & Veículo 3 & Veículo 4 & Veículo 5 & Veículo 6 \\
& $3,16 \mathrm{cv} / \mathrm{t}$ & $4,67 \mathrm{cv} / \mathrm{t}$ & $6,97 \mathrm{cv} / \mathrm{t}$ & $7,42 \mathrm{cv} / \mathrm{t}$ & $9,76 \mathrm{cv} / \mathrm{t}$ & $13,15 \mathrm{cv} / \mathrm{t}$ \\
\hline $0 \%$ & 60 & 75 & 86 & 95 & 105 & 100 \\
$2 \%$ & 25 & 35 & 50 & 56 & 67 & 66 \\
$4 \%$ & 15 & 22 & 30 & 36 & 45 & 54 \\
$6 \%$ & 10 & 16 & 25 & 25 & 35 & 35 \\
\hline
\end{tabular}


Considerando que a velocidade dos veículos admitida no final da rampa de aceleração seja $20 \mathrm{~km} / \mathrm{h}$ inferior à velocidade de projeto da via, e tomando-se como exemplo uma rodovia com velocidade de projeto de $80 \mathrm{~km} / \mathrm{h}$, tem-se que:

(a) para o greide nulo, apenas o veículo de 3,16 cv/t não consegue atingir a velocidade estabelecida para o final da rampa de aceleração $(60 \mathrm{~km} / \mathrm{h})$, entretanto alcança uma velocidade próxima deste valor;

(b) para o greide de 2\%, os veículos de 7,42 cv/t, 9,76 cv/t e 13,15 cv/t conseguirão desenvolver velocidades próximas ou superiores a $60 \mathrm{~km} / \mathrm{h}$ no final de uma rampa de aceleração; e

(c) para o greide de 4\%, apenas o veículo $13,15 \mathrm{cvt} / \mathrm{se}$ aproxima da velocidade de $60 \mathrm{~km} / \mathrm{h}$ e, no greide de $6 \%$, nenhum dos veículos simulados atinge este patamar de velocidade.

Estes resultados mostram que, nas rodovias com velocidades de projeto mais elevadas, a concepção de interseções em trechos com greides ascendentes de $4 \%$ ou superiores compromete o ganho de velocidade da maioria dos veículos de carga, devendo ser evitada. A utilização de faixas de aceleração em greides desta magnitude constitui solução inócua para os veículos com baixa relação potência/massa. Nesses casos, este dispositivo deveria ter sua extensão prolongada até a suavização do greide, assumindo na verdade a configuração de uma faixa adicional para trechos ascendentes.

Para analisar a adequação dos comprimentos das faixas de aceleração nas interseções, foram calculadas as extensões necessárias para que os veículos atinjam uma velocidade adequada ao final destas faixas. Foi admitido como velocidade compatível um valor $20 \mathrm{~km} / \mathrm{h}$ inferior à velocidade de projeto da via, seguindo o mesmo critério utilizado para a implantação de faixas adicionais em rampas ascendentes. Os resultados da simulação foram comparados aos valores propostos pelo DNIT e pela AASHTO, apresentados anteriormente nas Tabelas de 3.11 a 3.16. Os veículos foram simulados para três situações de greide ascendente - 2\%, 4\% e 6\% - além de duas situações de greides descendentes - 3\% e 5\%. Essas declividades representam os valores mais críticos para os intervalos propostos pelos manuais consultados para a definição dos comprimentos das faixas de aceleração. 
Os resultados obtidos estão nas Tabelas de 4.18 a 4.26, sendo apresentados em negrito os valores que ultrapassam os comprimentos propostos pelo DNIT. Os valores sublinhados, por sua vez, representam os comprimentos que, apesar de superarem os valores propostos no Manual do DNIT, se mantêm abaixo das extensões propostas no Manual da AASHTO. Os resultados simulados para a condição dos veículos partindo do repouso nas rampas ascendentes superiores a $2 \%$ e nas rampas descendentes não foram comparados com as extensões propostas pelo DNIT e pela AASHTO, pois, para estas situações, os manuais consultados não propõem comprimentos para as faixas de aceleração. Nestes casos, a AASHTO também não propõe comprimentos de faixa adicional para as velocidades de projeto inferiores a $60 \mathrm{~km} / \mathrm{h}$, assim como para velocidades no início da faixa adicional inferiores a $40 \mathrm{~km} / \mathrm{h}$.

Tabela 4.18: Comprimento da Faixa de Aceleração para os Veículos de Carga, Incluindo Taper - Rampas Ascendentes de 2\% (em metros).

\begin{tabular}{|c|c|c|c|c|c|c|c|c|}
\hline \multirow{2}{*}{$\begin{array}{l}\text { VELOCIDADE } \\
\text { DIRETRIZ }(\mathrm{km} / \mathrm{h})\end{array}$} & \multicolumn{8}{|c|}{ VELOCIDADE NO INÍCIO DA FAIXA DE ACELERAÇÃO $(\mathrm{km} / \mathrm{h})$} \\
\hline & 0 & 20 & 30 & 40 & 50 & 60 & 70 & 80 \\
\hline \multicolumn{9}{|l|}{ Veículo $1-3,16 \mathrm{cv} / \mathrm{t}$} \\
\hline 40 & 778 & - & - & - & - & - & - & - \\
\hline \multicolumn{9}{|l|}{ Veículo $2-4,67 \mathrm{cv} / \mathrm{t}$} \\
\hline 40 & 40 & - & - & - & - & - & - & - \\
\hline 50 & 45 & 194 & - & - & - & - & - & - \\
\hline \multicolumn{9}{|l|}{ Veículo $3-6,97 \mathrm{cv} / \mathrm{t}$} \\
\hline 40 & 40 & - & - & - & - & - & - & - \\
\hline 50 & 89 & 70 & - & - & - & - & - & - \\
\hline 60 & 276 & 258 & 187 & - & - & - & - & - \\
\hline \multicolumn{9}{|l|}{ Veículo $4-7,42 \mathrm{cv} / \mathrm{t}$} \\
\hline 40 & 40 & - & - & - & - & - & - & - \\
\hline 50 & 57 & 45 & - & - & - & - & - & - \\
\hline 60 & 175 & 161 & 118 & - & - & - & - & - \\
\hline 70 & $\overline{530}$ & $\overline{486}$ & $\overline{443}$ & 326 & - & - & - & - \\
\hline \multicolumn{9}{|l|}{ Veículo $5-9,76 \mathrm{cv} / \mathrm{t}$} \\
\hline 40 & 40 & - & - & - & - & - & - & - \\
\hline 50 & 45 & 45 & - & - & - & - & - & - \\
\hline 60 & 120 & 109 & 78 & - & - & - & - & - \\
\hline 70 & 301 & 290 & 259 & 182 & - & - & - & - \\
\hline 80 & 794 & 782 & 751 & $\overline{674}$ & 494 & - & - & - \\
\hline \multicolumn{9}{|l|}{ Veículo $6-13,15 \mathrm{cv} / \mathrm{t}$} \\
\hline 40 & 40 & - & - & - & - & - & - & - \\
\hline 50 & 45 & 45 & - & - & - & - & - & - \\
\hline 60 & 78 & 69 & 55 & - & - & - & - & - \\
\hline 70 & 175 & 166 & 145 & 97 & - & - & - & - \\
\hline 80 & 354 & $\overline{344}$ & $\overline{323}$ & 276 & 180 & - & - & - \\
\hline
\end{tabular}

Os resultados da Tabela 4.18 indicam faixas de aceleração com extensões superiores aos valores propostos pelo DNIT em todos os veículos simulados em 
rodovias com velocidade diretriz de $80 \mathrm{~km} / \mathrm{h}$. A adoção de valores mais elevados como os comprimentos propostos pela AASHTO, mostrou-se compatível com algumas extensões requeridas pelos veículos de 7,42 cv/t, 9,76 cv/t e 11,35 cv/t. Para as velocidades entre $90 \mathrm{~km} / \mathrm{h}$ e $120 \mathrm{~km} / \mathrm{h}$, os veículos simulados não conseguem atingir as velocidades propostas, uma vez que suas velocidades de equilíbrio estão abaixo de 70 $\mathrm{km} / \mathrm{h}$ para o greide de $2 \%$. Nestes casos, para garantir que o veículo se insira na rodovia com este patamar de velocidade, as faixas adicionais devem se estender até uma mudança de greide que favoreça o ganho de velocidade dos veículos.

Se consideradas as rampas ascendestes de $4 \%$ como mostram os resultados da Tabela 4.19, apenas os veículos de 9,76 e 13,15 cv/t conseguem vencer rampas desta magnitude e atingir a velocidade compatível com a velocidade diretriz de $60 \mathrm{~km} / \mathrm{h}$. Se considerada uma velocidade diretriz de $70 \mathrm{~km} / \mathrm{h}$, apenas o veículo de $13,15 \mathrm{cv} / \mathrm{t}$ atinge a velocidade de $50 \mathrm{~km} / \mathrm{h}$, requerendo ainda maiores comprimentos para as faixas de aceleração do que o proposto pelo DNIT e pela AASHTO. Para as rampas com 6\% de declividade, apenas os veículos de 9,76 e 13,15 cv/t atingem a velocidade considerada compatível para se inserir em rodovias com velocidade diretriz de $50 \mathrm{~km} / \mathrm{h}$, como mostra a Tabela 4.20 .

Tabela 4.19: Comprimento da Faixa de Aceleração para os Veículos de Carga, Incluindo Taper - Rampas Ascendentes de 4\% (em metros).

\begin{tabular}{ccccccccc}
\hline VELOCIDADE & \multicolumn{7}{c}{ VELOCIDADE NO INÍCIO DA FAIXA DE ACELERAÇÃO $(\mathrm{km} / \mathrm{h})$} \\
\cline { 2 - 10 } DIRETRIZ $(\mathrm{km} / \mathrm{h})$ & 0 & 20 & 30 & 40 & 50 & 60 & 70 & 80 \\
\hline Veículo 2-4,67 cv/t & & & & & & & & \\
\hline 40 & 134 & - & - & - & - & - & - & - \\
\hline Veículo 3-6,97 cv/t & & & & & & & & \\
\hline 40 & 40 & - & - & - & - & - & - & - \\
\hline Veículo 4-7,42 cv/t & & & & & & & & \\
\hline 40 & 40 & - & - & - & - & - & - & - \\
50 & 98 & 80 & - & - & - & - & - & - \\
\hline Veículo 5-9,76 cv/t & & & & & & & & \\
\hline 40 & 40 & - & - & - & - & - & - & - \\
50 & 61 & 47 & - & - & - & - & - & - \\
60 & 249 & $\mathbf{2 3 5}$ & $\mathbf{1 8 8}$ & - & - & - & - & - \\
\hline Veículo 6-13,15 cv/t & & & & & & & & \\
\hline 40 & 40 & - & - & - & - & - & - & - \\
50 & 45 & 45 & - & - & - & - & - & - \\
60 & 113 & 102 & 75 & - & - & - & - & - \\
70 & 341 & $\mathbf{3 3 0}$ & $\mathbf{3 0 4}$ & $\mathbf{2 3 0}$ & - & - & - & - \\
\hline
\end{tabular}


Tabela 4.20: Comprimento da Faixa de Aceleração para os Veículos de Carga, Incluindo Taper - Rampas Ascendentes de 6\% (em metros).

\begin{tabular}{|c|c|c|c|c|c|c|c|c|}
\hline \multirow{2}{*}{$\begin{array}{l}\text { VELOCIDADE } \\
\text { DIRETRIZ }(\mathrm{km} / \mathrm{h})\end{array}$} & \multicolumn{8}{|c|}{ VELOCIDADE NO INÍCIO DA FAIXA DE ACELERAÇÃO $(\mathrm{km} / \mathrm{h})$} \\
\hline & 0 & 20 & 30 & 40 & 50 & 60 & 70 & 80 \\
\hline \multicolumn{9}{|l|}{ Veículo $3-6,97 \mathrm{cv} / \mathrm{t}$} \\
\hline 40 & 44 & - & - & - & - & - & - & - \\
\hline \multicolumn{9}{|l|}{ Veículo $4-7,42 \mathrm{cv} / \mathrm{t}$} \\
\hline 40 & 40 & - & - & - & - & - & - & - \\
\hline \multicolumn{9}{|l|}{ Veículo $5-9,76 \mathrm{cv} / \mathrm{t}$} \\
\hline 40 & 40 & - & - & - & - & - & - & - \\
\hline 50 & 118 & 101 & - & - & - & - & - & - \\
\hline \multicolumn{9}{|l|}{ Veículo $6-13,15 \mathrm{cv} / \mathrm{t}$} \\
\hline 40 & 40 & - & - & - & - & - & - & - \\
\hline 50 & 49 & 45 & - & - & - & - & - & - \\
\hline
\end{tabular}

Nas rampas descendentes, conforme apresentado nas Tabelas de 4.21 a 4.26, a influência dos greides de 3 e 5\% permitiu a todos os veículos simulados atingirem as velocidades necessárias para se inserir na via principal. Foram, entretanto, obtidas extensões bem superiores aos comprimentos propostos pelo DNIT, sobretudo para os casos de a velocidade diretriz da via estar acima de $80 \mathrm{~km} / \mathrm{h}$. Se considerados os comprimentos propostos pela AASHTO para as rampas de aceleração nos declives, foi observada compatibilidade em algumas situações, mesmo para os veículos de menor relação potência-massa.

Nas menores faixas de velocidade diretriz, entre 40 e $60 \mathrm{~km} / \mathrm{h}$, a simulação dos veículos com relação potência/massa igual ou superior a $6,97 \mathrm{cv} / \mathrm{t}$ resultou em comprimentos das faixas de aceleração dentro dos limites propostos pelo DNIT. Nestes casos, a maioria dos resultados apresentou valores inferiores aos comprimentos mínimos estabelecidos pelo DNIT (2005) para a extensão dos taper, sendo utilizados esses comprimentos como extensão mínima da faixa de aceleração. Para a velocidade diretriz de $70 \mathrm{~km} / \mathrm{h}$, apenas os veículos com relação potência/massa de 9,76 cv/t e 13,15 cv/t atingiram a velocidade de $50 \mathrm{~km} / \mathrm{h}$ dentro do comprimento da faixa de aceleração proposta pelo DNIT. Para a velocidade diretriz de $80 \mathrm{~km} / \mathrm{h}$, esta condição só foi atendida pelo veículo de $13,15 \mathrm{cv} / \mathrm{t}$. 
Tabela 4.21: Comprimento da Faixa de Aceleração para os Veículos de Carga em Rampas Descendentes, Incluindo Taper - Veículo 1 - 3,16 cv/t (em metros).

\begin{tabular}{|c|c|c|c|c|c|c|c|c|}
\hline \multirow{2}{*}{$\begin{array}{l}\text { VELOCIDADE } \\
\text { DIRETRIZ }(\mathrm{km} / \mathrm{h})\end{array}$} & \multicolumn{8}{|c|}{ VELOCIDADE NO INÍCIO DA FAIXA DE ACELERAÇÃO $(\mathrm{km} / \mathrm{h})$} \\
\hline & 0 & 20 & 30 & 40 & 50 & 60 & 70 & 80 \\
\hline \multicolumn{9}{|c|}{ Rampas Descendentes de 3\% } \\
\hline 40 & 40 & - & - & - & - & - & - & - \\
\hline 50 & 68 & 45 & - & - & - & - & - & - \\
\hline 60 & 141 & 117 & 73 & - & - & - & - & - \\
\hline 70 & 253 & 230 & 186 & $\underline{113}$ & - & - & - & - \\
\hline 80 & 400 & 377 & 333 & 260 & 147 & - & - & - \\
\hline 90 & 600 & 577 & 533 & 460 & 348 & 201 & - & - \\
\hline 100 & 853 & 829 & 785 & 713 & 601 & 454 & 252 & - \\
\hline 110 & 1165 & 1142 & 1097 & 1025 & 913 & 766 & 567 & 314 \\
\hline 120 & 1477 & 1453 & 1409 & 1336 & 1224 & 1078 & 878 & 630 \\
\hline \multicolumn{9}{|c|}{ Rampas Descendentes de 5\% } \\
\hline 40 & 40 & - & - & - & - & - & - & - \\
\hline 50 & 49 & 45 & - & - & - & - & - & - \\
\hline 60 & 96 & 79 & 55 & - & - & - & - & - \\
\hline 70 & 165 & 147 & 116 & 69 & - & - & - & - \\
\hline 80 & 252 & 234 & 204 & $\underline{156}$ & $\underline{89}$ & - & - & - \\
\hline 90 & 365 & 347 & 317 & 270 & 201 & $\underline{114}$ & - & - \\
\hline 100 & 501 & 483 & 453 & 405 & 337 & 249 & $\underline{138}$ & - \\
\hline 110 & 662 & 644 & 613 & 566 & 497 & 410 & 298 & 163 \\
\hline 120 & 815 & 800 & 770 & 720 & 655 & 565 & 455 & 320 \\
\hline
\end{tabular}

Tabela 4.22: Comprimento da Faixa de Aceleração para os Veículos de Carga em Rampas Descendentes, Incluindo Taper - Veículo 2 - 4,67 cv/t (em metros).

\begin{tabular}{|c|c|c|c|c|c|c|c|c|}
\hline \multirow{2}{*}{$\begin{array}{l}\text { VELOCIDADE } \\
\text { DIRETRIZ }(\mathrm{km} / \mathrm{h})\end{array}$} & \multicolumn{8}{|c|}{ VELOCIDADE NO INÍCIO DA FAIXA DE ACELERAÇÃO $(\mathrm{km} / \mathrm{h})$} \\
\hline & 0 & 20 & 30 & 40 & 50 & 60 & 70 & 80 \\
\hline \multicolumn{9}{|c|}{ Rampas Descendentes de 3\% } \\
\hline 40 & 40 & - & - & - & - & - & - & - \\
\hline 50 & 52 & 45 & - & - & - & - & - & - \\
\hline 60 & 111 & 93 & 60 & - & - & - & - & - \\
\hline 70 & 198 & 181 & 147 & $\underline{88}$ & - & - & - & - \\
\hline 80 & 322 & 305 & 271 & $\overline{212}$ & 124 & - & - & - \\
\hline 90 & 485 & 468 & 434 & 375 & $\overline{288}$ & $\underline{164}$ & - & - \\
\hline 100 & 694 & 676 & 643 & 584 & 496 & $\overline{373}$ & 211 & - \\
\hline 110 & 949 & 932 & 898 & 839 & 751 & 628 & 466 & 258 \\
\hline 120 & 1261 & 1243 & 1210 & 1151 & 1063 & 940 & 778 & 567 \\
\hline \multicolumn{9}{|c|}{ Rampas Descendentes de 5\% } \\
\hline 40 & 40 & - & - & - & - & - & - & - \\
\hline 50 & 45 & 45 & - & - & - & - & - & - \\
\hline 60 & 81 & 67 & 55 & - & - & - & - & - \\
\hline 70 & 140 & 126 & 101 & 60 & - & - & - & - \\
\hline 80 & 218 & 204 & 179 & $\underline{138}$ & $\underline{80}$ & - & - & - \\
\hline 90 & 318 & 304 & 279 & 238 & $\underline{179}$ & $\underline{101}$ & - & - \\
\hline 100 & 439 & 425 & 400 & 359 & $\overline{300}$ & $\overline{222}$ & $\underline{123}$ & - \\
\hline 110 & 586 & 572 & 547 & 505 & 447 & 368 & $\overline{270}$ & $\underline{147}$ \\
\hline 120 & 755 & 741 & 716 & 675 & 616 & 537 & 439 & $\overline{316}$ \\
\hline
\end{tabular}


Tabela 4.23: Comprimento da Faixa de Aceleração para os Veículos de Carga em Rampas Descendentes, Incluindo Taper - Veículo 3 - 6,97 cv/t (em metros).

\begin{tabular}{|c|c|c|c|c|c|c|c|c|}
\hline \multirow{2}{*}{$\begin{array}{l}\text { VELOCIDADE } \\
\text { DIRETRIZ }(\mathrm{km} / \mathrm{h})\end{array}$} & \multicolumn{8}{|c|}{ VELOCIDADE NO INÍCIO DA FAIXA DE ACELERAÇÃO $(\mathrm{km} / \mathrm{h})$} \\
\hline & 0 & 20 & 30 & 40 & 50 & 60 & 70 & 80 \\
\hline \multicolumn{9}{|c|}{ Rampas Descendentes de 3\% } \\
\hline 40 & 40 & - & - & - & - & - & - & - \\
\hline 50 & 45 & 45 & - & - & - & - & - & - \\
\hline 60 & 78 & 67 & 55 & - & - & - & - & - \\
\hline 70 & 147 & 135 & 111 & 69 & - & - & - & - \\
\hline 80 & 240 & 228 & 204 & 162 & 93 & - & - & - \\
\hline 90 & 370 & 359 & 334 & $\overline{292}$ & 224 & $\underline{130}$ & - & - \\
\hline 100 & 537 & 526 & 501 & 459 & 391 & 297 & 169 & - \\
\hline 110 & 758 & 747 & 723 & 680 & 612 & 519 & 389 & 222 \\
\hline 120 & 1038 & 1027 & 1003 & 961 & 892 & 799 & 669 & 503 \\
\hline \multicolumn{9}{|c|}{ Rampas Descendentes de 5\% } \\
\hline 40 & 40 & - & - & - & - & - & - & - \\
\hline 50 & 45 & 45 & - & - & - & - & - & - \\
\hline 60 & 62 & 55 & 55 & - & - & - & - & - \\
\hline 70 & 111 & 101 & 82 & 60 & - & - & - & - \\
\hline 80 & 176 & 166 & 147 & $\underline{115}$ & 70 & - & - & - \\
\hline 90 & 263 & 253 & 234 & $\overline{201}$ & $\underline{152}$ & $\underline{87}$ & - & - \\
\hline 100 & 369 & 360 & 340 & $\overline{308}$ & $\overline{259}$ & $\overline{193}$ & $\underline{108}$ & - \\
\hline 110 & 502 & 492 & 473 & 441 & 391 & 326 & $\overline{240}$ & $\underline{134}$ \\
\hline 120 & 664 & 654 & 634 & 602 & 553 & 488 & 402 & $\overline{295}$ \\
\hline
\end{tabular}

Tabela 4.24: Comprimento da Faixa de Aceleração para os Veículos de Carga em Rampas Descendentes, Incluindo Taper - Veículo 4 - 7,42 cv/t (em metros).

\begin{tabular}{ccccccccc}
\hline VELOCIDADE & \multicolumn{7}{c}{ VELOCIDADE NO INÍCIO DA FAIXA DE ACELERAÇÃO $(\mathrm{km} / \mathrm{h})$} \\
\cline { 2 - 10 } DIRETRIZ $(\mathrm{km} / \mathrm{h})$ & 0 & 20 & 30 & 40 & 50 & 60 & 70 & 80 \\
\hline Rampas Descendentes de $3 \%$ & 40 & - & - & - & - & - & - & - \\
\hline 40 & 45 & 45 & - & - & - & - & - & - \\
50 & 67 & 58 & 55 & - & - & - & - & - \\
60 & 125 & $\mathbf{1 1 6}$ & 95 & 60 & - & - & - & - \\
70 & 208 & $\mathbf{1 9 8}$ & $\mathbf{1 7 8}$ & $\underline{\mathbf{1 4 1}}$ & 83 & - & - & - \\
80 & 322 & $\mathbf{3 1 2}$ & $\mathbf{2 9 1}$ & $\mathbf{2 5 4}$ & $\underline{\mathbf{1 9 7}}$ & $\mathbf{1 1 5}$ & - & - \\
90 & 466 & $\mathbf{4 5 6}$ & $\mathbf{4 3 6}$ & $\mathbf{3 9 8}$ & $\mathbf{3 4 1}$ & $\mathbf{2 5 9}$ & $\mathbf{1 4 6}$ & - \\
100 & 657 & $\mathbf{6 4 8}$ & $\mathbf{6 2 7}$ & $\mathbf{5 9 0}$ & $\mathbf{5 3 3}$ & $\mathbf{4 5 1}$ & $\mathbf{3 3 8}$ & $\mathbf{1 9 2}$ \\
110 & 902 & $\mathbf{8 9 4}$ & $\mathbf{8 7 2}$ & $\mathbf{8 3 5}$ & $\mathbf{7 7 6}$ & $\mathbf{6 9 4}$ & $\mathbf{5 8 0}$ & $\mathbf{4 3 5}$ \\
120 & 40 & - & - & - & - & - & - & - \\
\hline Rampas Descendentes de 5\% & & & & & & - & - \\
40 & 45 & 45 & - & - & - & - & - & - \\
50 & 55 & 55 & 55 & - & - & - & - & - \\
60 & 98 & 89 & 73 & 60 & - & - & - & - \\
70 & 158 & $\mathbf{1 5 0}$ & $\mathbf{1 3 3}$ & 104 & 70 & - & - & - \\
90 & 236 & $\mathbf{2 2 7}$ & $\mathbf{2 1 1}$ & $\mathbf{1 8 1}$ & $\mathbf{1 3 8}$ & 80 & - & - \\
100 & 334 & $\mathbf{3 2 5}$ & $\mathbf{3 0 9}$ & $\mathbf{2 8 0}$ & $\mathbf{2 3 6}$ & $\mathbf{1 7 7}$ & $\underline{\mathbf{9 8}}$ & - \\
110 & 455 & $\mathbf{4 4 6}$ & $\mathbf{4 2 9}$ & $\mathbf{4 0 0}$ & $\mathbf{3 5 7}$ & $\mathbf{2 9 7}$ & $\mathbf{2 1 9}$ & $\underline{\mathbf{1 2 3}}$ \\
120 & 605 & $\mathbf{5 9 4}$ & $\mathbf{5 7 7}$ & $\mathbf{5 4 8}$ & $\mathbf{5 0 4}$ & $\mathbf{4 4 2}$ & $\mathbf{3 6 4}$ & $\mathbf{2 6 8}$ \\
\hline
\end{tabular}


Tabela 4.25: Comprimento da Faixa de Aceleração para os Veículos de Carga em Rampas Descendentes, Incluindo Taper - Veículo 5 - 9,76 cv/t (em metros).

\begin{tabular}{|c|c|c|c|c|c|c|c|c|}
\hline \multirow{2}{*}{$\begin{array}{l}\text { VELOCIDADE } \\
\text { DIRETRIZ }(\mathrm{km} / \mathrm{h})\end{array}$} & \multicolumn{8}{|c|}{ VELOCIDADE NO INÍCIO DA FAIXA DE ACELERAÇÃO $(\mathrm{km} / \mathrm{h})$} \\
\hline & 0 & 20 & 30 & 40 & 50 & 60 & 70 & 80 \\
\hline \multicolumn{9}{|c|}{ Rampas Descendentes de 3\% } \\
\hline 40 & 40 & - & - & - & - & - & - & - \\
\hline 50 & 45 & 45 & - & - & - & - & - & - \\
\hline 60 & 58 & 55 & 55 & - & - & - & - & - \\
\hline 70 & 109 & 100 & 83 & 60 & - & - & - & - \\
\hline 80 & 181 & 173 & 156 & $\underline{124}$ & 73 & - & - & - \\
\hline 90 & 281 & 273 & 255 & 224 & $\underline{173}$ & $\underline{100}$ & - & - \\
\hline 100 & 415 & 407 & 389 & 357 & 307 & 234 & $\underline{135}$ & - \\
\hline 110 & 588 & 579 & 562 & 530 & 480 & 407 & 307 & 173 \\
\hline 120 & 807 & 799 & 782 & 750 & 699 & 626 & 527 & 392 \\
\hline \multicolumn{9}{|c|}{ Rampas Descendentes de 5\% } \\
\hline 40 & 40 & - & - & - & - & - & - & - \\
\hline 50 & 45 & 45 & - & - & - & - & - & - \\
\hline 60 & 55 & 55 & 55 & - & - & - & - & - \\
\hline 70 & 88 & 81 & 66 & 60 & - & - & - & - \\
\hline 80 & 143 & 135 & 121 & 95 & 70 & - & - & - \\
\hline 90 & 214 & 206 & 191 & $\underline{166}$ & $\underline{126}$ & 80 & - & - \\
\hline 100 & 307 & 299 & 284 & 259 & $\underline{219}$ & $\underline{165}$ & $\underline{93}$ & - \\
\hline 110 & 420 & 413 & 398 & 372 & $\overline{333}$ & 279 & $\overline{207}$ & $\underline{116}$ \\
\hline 120 & 558 & 550 & 536 & 510 & 470 & 416 & 344 & 253 \\
\hline
\end{tabular}

Tabela 4.26: Comprimento da Faixa de Aceleração para os Veículos de Carga em Rampas Descendentes, Incluindo Taper - Veículo 6 - 13,15 cv/t (em metros).

\begin{tabular}{|c|c|c|c|c|c|c|c|c|}
\hline \multirow{2}{*}{$\begin{array}{l}\text { VELOCIDADE } \\
\text { DIRETRIZ }(\mathrm{km} / \mathrm{h})\end{array}$} & \multicolumn{8}{|c|}{ VELOCIDADE NO INÍCIO DA FAIXA DE ACELERAÇÃO $(\mathrm{km} / \mathrm{h})$} \\
\hline & 0 & 20 & 30 & 40 & 50 & 60 & 70 & 80 \\
\hline \multicolumn{9}{|c|}{ Rampas Descendentes de 3\% } \\
\hline 40 & 40 & - & - & - & - & - & - & - \\
\hline 50 & 45 & 45 & - & - & - & - & - & - \\
\hline 60 & 55 & 55 & 55 & - & - & - & - & - \\
\hline 70 & 87 & 80 & 66 & 60 & - & - & - & - \\
\hline 80 & 146 & 139 & 125 & 100 & 70 & - & - & - \\
\hline 90 & 226 & 219 & 206 & $\underline{180}$ & 140 & 81 & - & - \\
\hline 100 & 335 & 328 & 314 & $\overline{289}$ & $\overline{248}$ & 189 & 109 & - \\
\hline 110 & 472 & 465 & 451 & 426 & $\overline{386}$ & 327 & $\overline{246}$ & 140 \\
\hline 120 & 666 & 658 & 645 & 619 & 579 & 520 & 439 & $\overline{330}$ \\
\hline \multicolumn{9}{|c|}{ Rampas Descendentes de 5\% } \\
\hline 40 & 40 & - & - & - & - & - & - & - \\
\hline 50 & 45 & 45 & - & - & - & - & - & - \\
\hline 60 & 55 & 55 & 55 & - & - & - & - & - \\
\hline 70 & 73 & 67 & 60 & 60 & - & - & - & - \\
\hline 80 & 120 & 114 & 102 & 81 & 70 & - & - & - \\
\hline 90 & 180 & 174 & 162 & $\underline{141}$ & 108 & 80 & - & - \\
\hline 100 & 260 & 253 & 241 & $\underline{220}$ & 187 & $\underline{141}$ & 85 & - \\
\hline 110 & 357 & 350 & 338 & $\overline{317}$ & $\overline{284}$ & $\underline{238}$ & $\underline{176}$ & $\underline{99}$ \\
\hline 120 & 484 & 477 & 465 & 444 & 411 & $\overline{365}$ & $\overline{303}$ & $\overline{227}$ \\
\hline
\end{tabular}




\subsection{Considerações Finais}

Os resultados apresentados ao longo do Capitulo 4 revelaram uma série de restrições ao tráfego de veículos longos, se considerados padrões mínimos de projeto propostos no Manual brasileiro. No Capitulo 5 será apresentado um estudo de caso realizado em trechos de rodovias brasileiras, sendo verificada a compatibilidade dos veículos para alguns dos parâmetros estudados. 


\section{ESTUDO DE CASO}

\subsection{Considerações Iniciais}

Como parte da pesquisa proposta, foram selecionados trechos de rodovias brasileiras com o objetivo de investigar a compatibilidade do tráfego de veículos unitários e CVCs, dadas as restrições operacionais. A escolha dos trechos procurou abranger rodovias com características técnicas diversas, localizadas em regiões de topografia plana, ondulada e montanhosa, sendo utilizadas estradas dos Estados de São Paulo e Ceará. Apesar da existência de um manual que estabelece um padrão técnico de classificação para as rodovias no Brasil, as diferenças regionais, sobretudo aquelas de caráter econômico nesses dois Estados, determinam sua capacidade de investimento, refletindo nas condições técnicas da infra-estrutura. Estas duas realidades são representativas da heterogeneidade observada na malha rodoviária brasileira, servindo como objeto de estudo da investigação proposta.

Os dados necessários para caracterização dos trechos pesquisados foram obtidos a partir de consulta ao projeto geométrico destas rodovias, mediante suas representações em planta e perfil longitudinal. Em virtude da inexistência de alguns parâmetros de projeto importantes para o estudo da compatibilidade nos dados obtidos junto ao Departamento de Estradas de Rodagem do Estado de São Paulo (DER-SP) e ao Departamento de Edificações, Rodovias e Transportes (DERT-CE), a maioria projetada na década de 1960, foram necessárias visitas a campo e a realização de levantamentos complementares para a obtenção de alguns parâmetros, como, por exemplo, os valores de sobrelargura e superelevação existente nas curvas horizontais, bem como informações quanto à condição geral dos acostamentos. 


\subsection{Localização dos Trechos Selecionados}

Foram selecionados os seguintes trechos de rodovias, com suas localizações apresentadas nas Figuras 5.1 a 5.6:

(a) SP 310 - Rodovia de Pista Dupla concessionada, entre as localidades de Rio Claro e São Carlos, numa extensão de $63 \mathrm{~km}$.

(b) SP 225 - Rodovia de Pista Simples concessionada, entre a SP 310 e a SP 255, numa extensão de $85 \mathrm{~km}$.

(c) SP 333 - Rodovia de Pista Simples administrada pelo DER-SP, entre as rodovias SP 304 e SP 300, numa extensão de $57 \mathrm{~km}$.

(d) SP 333 - Rodovia de Pista Simples administrada pelo DER-SP, entre as localidades de Serrana e Cajuru, numa extensão de $37 \mathrm{~km}$.

(e) SP 147 - Rodovia de Pista Simples administrada pelo DER-SP, entre as localidades de Socorro e Itapira, numa extensão de $39 \mathrm{~km}$.

(f) SP 304 - Rodovia de Pista Simples administrada pelo DER-SP, entre as localidades de Ibitinga e Novo Horizonte, numa extensão de 48 km.

(g) CE 040 - Rodovia de Pista Simples administrada pelo DERT-CE, entre as localidades de Cascavel e Beberibe, numa extensão de $19 \mathrm{~km}$.

(h) CE 232 - Rodovia de Pista Simples administrada pelo DERT-CE, entre as localidades de Viçosa do Ceará e Padre Vieira (Divisa CE/PI) numa extensão de $36 \mathrm{~km}$.

(i) CE 377 - Rodovia de Pista Simples administrada pelo DERT-CE, entre as localidades de Limoeiro do Norte e Quixeré, numa extensão de 16 km.

(j) CE 456 - Rodovia de Pista Simples administrada pelo DERT-CE, entre as localidades de Choró e entroncamento com a CE 060, numa extensão de 13 km. 


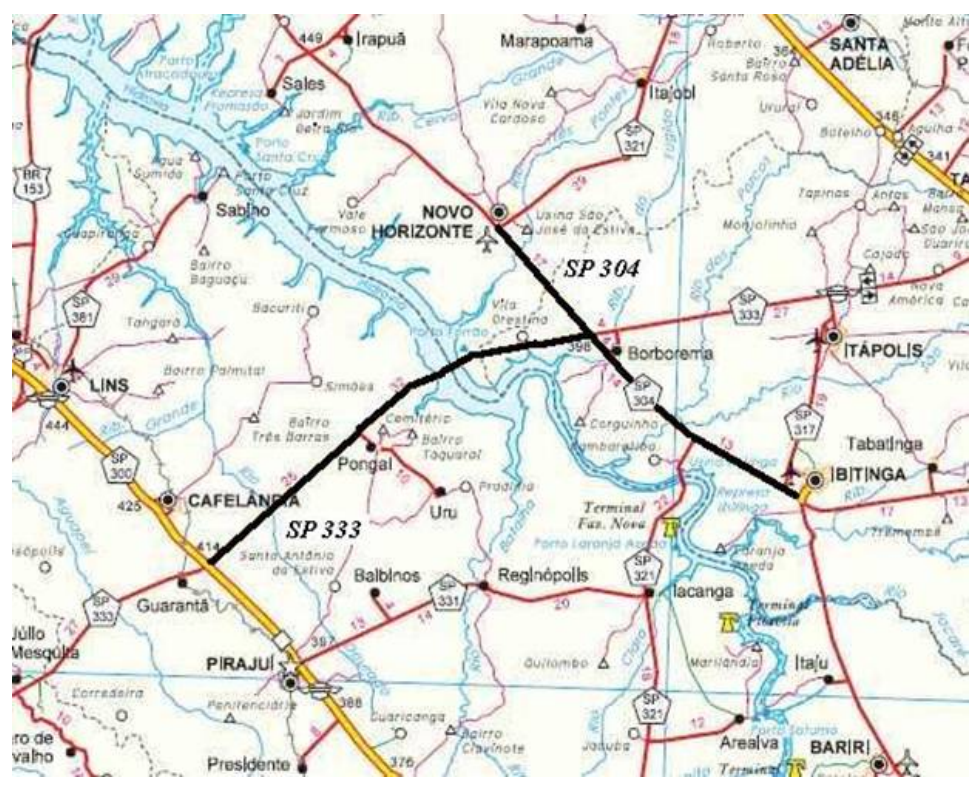

Figura 5.1: Localização do Trecho das Rodovias SP 333 (entre SP 300 e SP 304) e SP304.

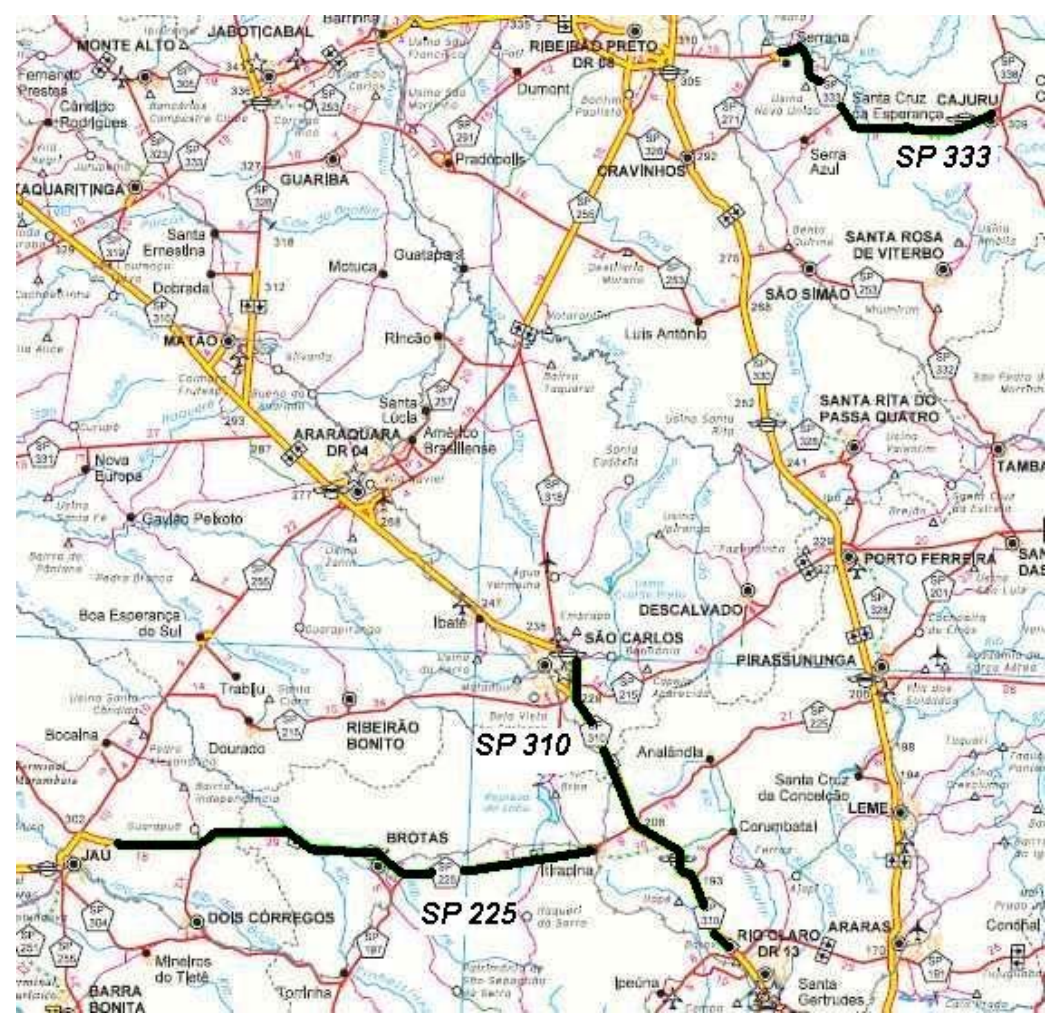

Figura 5.2: Localização do Trecho das Rodovias SP 333 (Serrana - Cajuru), SP 225 e SP 310. 


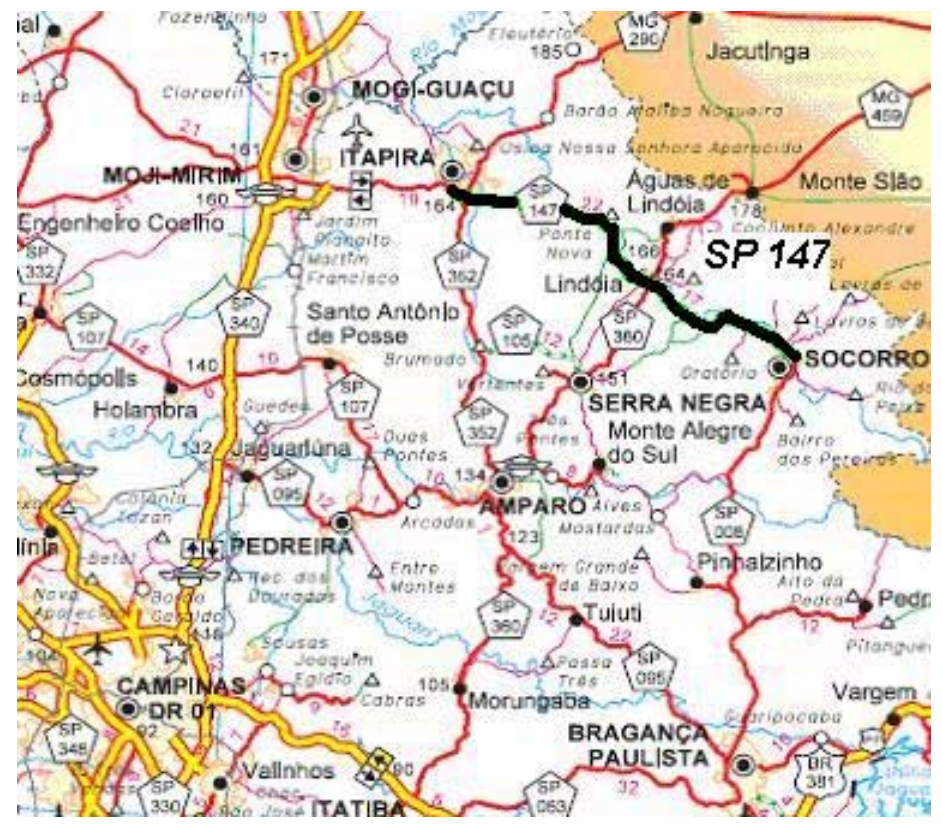

Figura 5.3: Localização do Trecho da Rodovia SP 147.

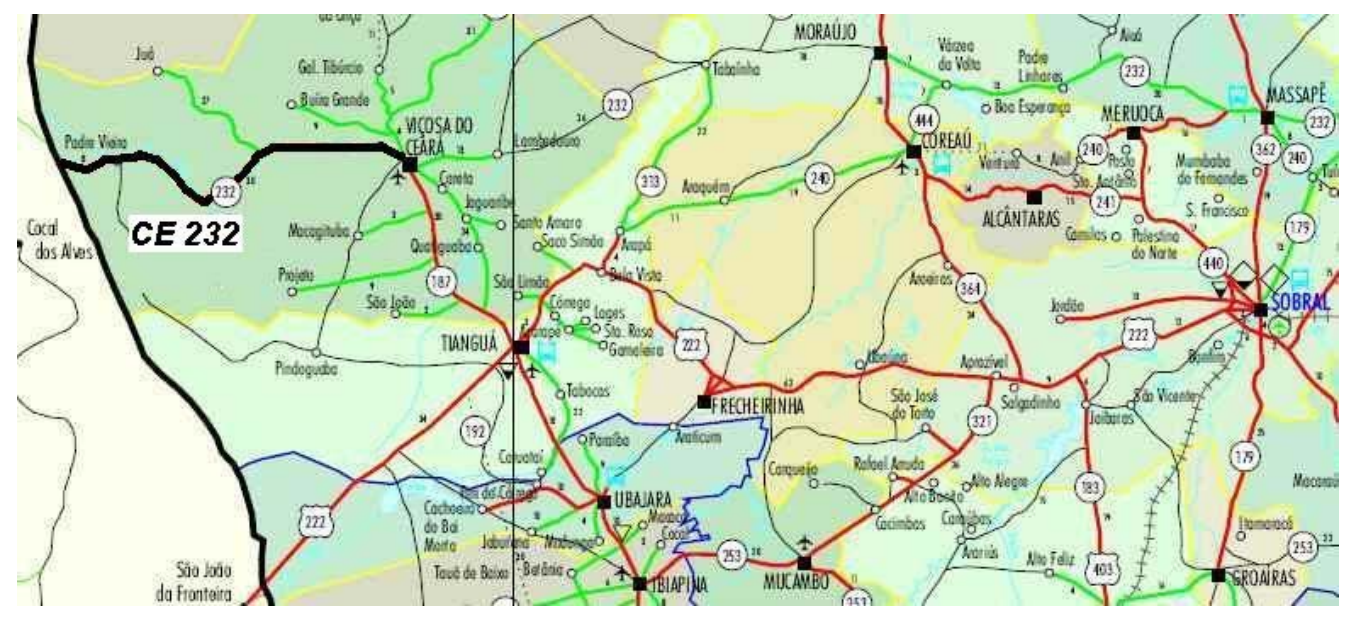

Figura 5.4: Localização do Trecho da Rodovia CE 232.

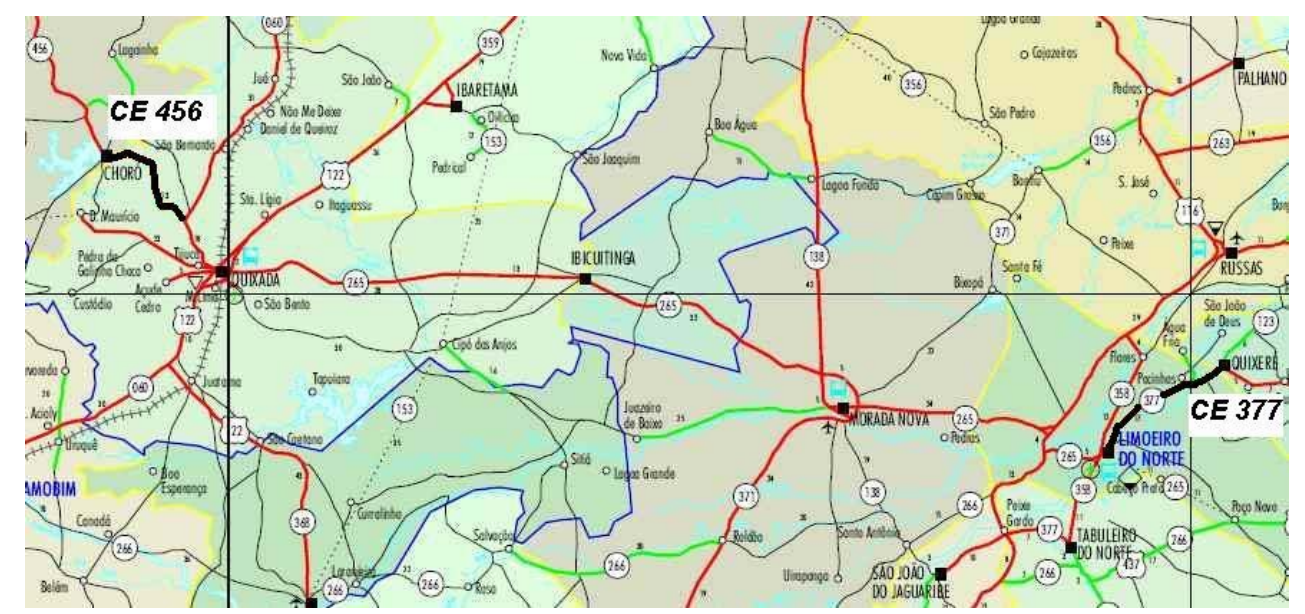

Figura 5.5: Localização do Trecho das Rodovias CE 456 e CE 377. 


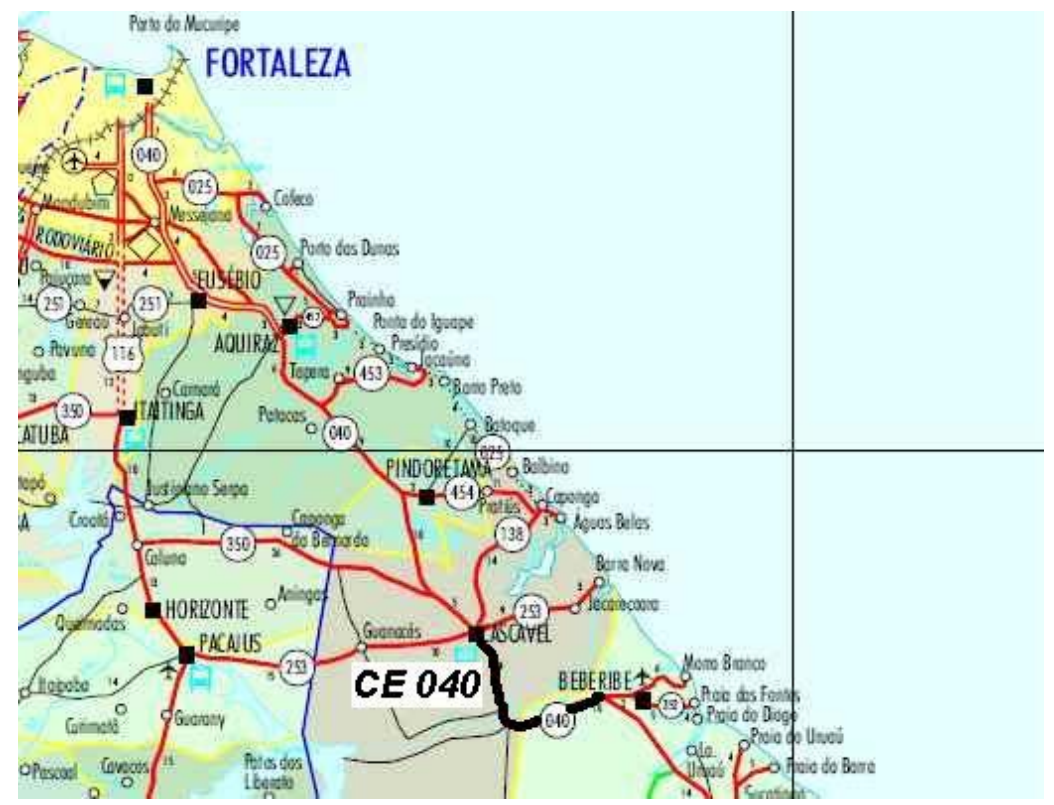

Figura 5.6: Localização do Trecho da Rodovia CE 040.

\subsection{Características Técnicas dos Trechos Selecionados}

A Tabela 5.1 apresenta as principais características técnicas de cada trecho. Comparando os parâmetros da maioria das rodovias pesquisadas, percebe-se claramente a dificuldade de enquadramento nas classes de projeto do DNER. Os resultados indicaram que, para a maioria dos trechos pesquisados, a velocidade de projeto, que deveria reger a concepção geométrica da via, possui valor inadequado com alguns dos demais parâmetros técnicos. Em várias situações, foi observado o fato de que a concordância horizontal foi projetada com raios e superelevações que não permitem aos veículos trafegar com a velocidade diretriz da via, podendo ocasionar situações que comprometem sua estabilidade e segurança. Quanto à concordância vertical, foram encontradas rampas máximas acima dos limites admissíveis para a velocidade diretriz da via. 
Tabela 5.1: Características Técnicas dos Trechos Pesquisados.

\begin{tabular}{|c|c|c|c|c|c|c|c|}
\hline \multirow{2}{*}{ RODOVIA } & \multirow{2}{*}{ TERRENO } & \multirow{2}{*}{$\begin{array}{c}\mathrm{V}_{\mathrm{P}} \\
(\mathrm{km} / \mathrm{h})\end{array}$} & \multicolumn{2}{|c|}{$\begin{array}{l}\text { CONCORDÂNCIA } \\
\text { HORIZONTAL }\end{array}$} & \multicolumn{2}{|c|}{ SEÇÃO TRANSVERSAL } & \multirow{2}{*}{$\begin{array}{c}\text { RAMPA } \\
\text { MÁXIMA } \\
(\%)\end{array}$} \\
\hline & & & $\begin{array}{l}\text { Raios Curvas } \\
\text { Horizontais (m) }\end{array}$ & $e(\%)$ & $\begin{array}{l}\text { Faixas de } \\
\text { Tráfego (m) }\end{array}$ & Acostamentos & \\
\hline SP 225 & $\mathrm{O} / \mathrm{M}$ & $80 / 60$ & $153,5-3130$ & $2-10$ & 3,6 & $0,8-2,5(2,0)$ & 7 \\
\hline $\begin{array}{c}\text { SP } 310 \\
\text { (Pista Norte) }\end{array}$ & $\mathrm{O} / \mathrm{M}$ & $90 / 60$ & $199,7-5565$ & $2-8$ & 3,6 & $1,0-3,0(2,5)$ & 7 \\
\hline $\begin{array}{c}\text { SP } 310 \\
\text { (Pista Sul) }\end{array}$ & $\mathrm{O} / \mathrm{M}$ & $90 / 60$ & $215,5-10713$ & $2-7$ & 3,6 & $2,5-3,0(2,5)$ & 7 \\
\hline $\begin{array}{c}\text { SP } 333 \\
\text { (SP304 - SP 300) }\end{array}$ & $\mathrm{O}$ & 80 & $2644,5-5729,6$ & $0-2$ & 3,6 & $0-3,5(3,5)$ & 6 \\
\hline $\begin{array}{c}\text { SP } 333 \\
\text { (Serrana Cajuru) }\end{array}$ & $\mathrm{O}$ & 80 & $1000-2000$ & $1-3$ & 3,3 & $0,3-2,6(2,0)$ & 6 \\
\hline SP 147 & M & 60 & $50-1011,1$ & $0-12$ & 3,6 & $0-2,5(2,0)$ & 11 \\
\hline SP 304 & $\mathrm{O}$ & 80 & $1800-5000$ & $0-2$ & 3,6 & $2,0-5,5(3,0)$ & 6 \\
\hline CE 040 & $\mathrm{P}$ & 80 & $286,5-1788,4$ & $0-4$ & 3,3 & 2,0 & - \\
\hline CE 232 & $\mathrm{O}$ & 80 & $133,3-941,3$ & $0-8$ & 3,0 & 1,5 & 12 \\
\hline CE 377 & $\mathrm{P}$ & 80 & $55-1566,8$ & $4-12$ & 3,1 & 1,0 & 2 \\
\hline CE 456 & $\mathrm{O}$ & 80 & $100-1172,8$ & $2-10$ & 3,0 & 1,0 & $9,88 \%$ \\
\hline
\end{tabular}

Considerando a seção transversal da via, tem-se um diferencial importante, pois, enquanto no Estado de São Paulo é adotado normalmente um padrão de rodovias onde as faixas de tráfego possuem 3,6 m, no Estado do Ceará são geralmente construídas rodovias com faixas de tráfego de 3,0 m. Desta forma, as rodovias de São Paulo atendem com folga as larguras mínimas estabelecidas pelo DNER, enquanto as rodovias do Ceará possuem largura inadequada em todos os casos, apresentando valores estabelecidos no Manual apenas para rodovias de Classe IV. A largura dos acostamentos variou bastante ao longo de alguns trechos pesquisados, especialmente naqueles onde o relevo é ondulado ou montanhoso. Os valores de largura de acostamento apresentados entre parênteses na Tabela 5.1 são referentes à moda das observações coletadas em campo. Além dos dados apresentados na Tabela 5.1, outro parâmetro que merece destaque foram os valores de $K_{\min }$ das curvas verticais, que para a maioria das rodovias pesquisadas assumem valores propostos pelo DNER apenas para rodovias de Classe IV.

Em se tratando da função que estas rodovias exercem, os trechos pesquisados se enquadram como vias arteriais ou coletoras primárias, segundo a classificação funcional 
do DNER. Alguns parâmetros de projeto observados nestes trechos atendem apenas ao padrão de rodovias da Classe IV, que é utilizada normalmente apenas para vias locais. Isto demonstra uma incompatibilidade entre o padrão técnico utilizado na concepção da via e a função que esta desempenha, o que pode ser resultado tanto de erros no projeto da via como de falhas no planejamento e estruturação da rede viária. Esta realidade potencializa o problema da incompatibilidade dos veículos de carga, uma vez que estes são alvos de maiores impactos das restrições operacionais existentes.

Para as rodovias projetadas fora do padrão geométrico estabelecido atualmente, o Manual do DNER propõe alguns critérios de melhoramentos. É considerado, porém, o pressuposto do máximo aproveitamento da plataforma, de modo que as intervenções para a reabilitação de vias têm suas ações limitadas. Alguns problemas apresentam solução difícil, como, por exemplo, adequar as distâncias de visibilidade em curvas verticais, uma vez que as correções ocasionariam a necessidade de reconstrução do pavimento. Para outros problemas, como a concordância horizontal das curvas, $\mathrm{o}$ Manual menciona melhorias que vão desde a sinalização de curvas perigosas, até intervenções, tais como a adequação das superelevações e dos raios das curvas. O estudo de caso proposto neste trabalho visa a investigar de que modo os veículos de carga, especialmente as CVCs, se comportam em trechos de rodovias implantadas, identificando onde se encontram as incompatibilidades, apontando suas razões e possíveis soluções, visando à reabilitação destas vias para o tráfego desses veículos.

Com base nos dados de projeto geométrico das rodovias investigadas, e de coletas complementares realizadas em campo, foram realizadas análises que contemplaram três aspectos mostrados na Figura 4.1 - as sobrelarguras, a estabilidade nas curvas horizontais e as rampas ascendentes. Quanto às distâncias de visibilidade em interseções, foi observado que, para os cruzamentos das rodovias pesquisadas com outras rodovias, existem dispositivos como rotatórias e trevos que permitem a travessia segura dos veículos, com distâncias de visibilidade suficientes. Com exceção da Rodovia SP 310, entretanto, que possui maior controle dos acessos, em todas as demais foram encontradas interseções com vias de acesso em locais inapropriados, com visibilidade bastante limitada. 


\subsection{Avaliação das Sobrelarguras dos Trechos Investigados}

Dentre os trechos pesquisados, apenas a SP 310 apresentou curvas horizontais com implantação de sobrelarguras. Em todos os demais trechos, as curvas horizontais possuem o mesmo perfil transversal dos trechos em tangente. A Tabela 5.2 apresenta os resultados da compatibilidade destes trechos com o tráfego das CVCs, conforme método apresentado no Capítulo 4. Para cada trecho pesquisado, os veículos foram divididos em três grupos. No primeiro, estão os veículos cujo arraste nas curvas é devidamente acolhido pelas faixas de tráfego da via; no segundo grupo, estão os casos em que, apesar de a via não possuir faixas de tráfego com largura suficiente, existe acostamento adequado para acomodar o veículo; e no terceiro grupo estão os veículos onde foi verificada incompatibilidade, seja pela inadequação ou inexistência de acostamentos.

Tabela 5.2: Compatibilidade da Largura das Pistas nas Curvas Horizontais para o Tráfego de Veículos.

\begin{tabular}{|c|c|c|c|}
\hline RODOVIA (Trecho) & $\begin{array}{c}\text { VEÍCULOS } \\
\text { COMPATÍVEIS SEM } \\
\text { USO DO } \\
\text { ACOSTAMENTO } \\
\end{array}$ & $\begin{array}{c}\text { VEÍCULOS } \\
\text { COMPATÍVEIS COM } \\
\text { USO DO } \\
\text { ACOSTAMENTO } \\
\end{array}$ & $\begin{array}{c}\text { VEÍCULOS } \\
\text { INCOMPATÍVEIS }\end{array}$ \\
\hline SP 225 & $\begin{array}{l}\mathrm{O} 2(\mathrm{URB})-2 \mathrm{~S} 3- \\
\mathrm{O} 2 \mathrm{~S} 1-\mathrm{O} 3(\mathrm{ROD})\end{array}$ & $\begin{array}{c}\mathrm{O} 2(\mathrm{ROD})-\mathrm{U} 3 \\
\text { 3S2B2(20m)-U2- } \\
\text { 3S3B3-2S1- } \\
\text { 3S2B2(26m)- } \\
\text { 2S2(20m)-3S2A2S2 } \\
-2 \mathrm{~S} 2(22,4 \mathrm{~m})\end{array}$ & - \\
\hline SP 310 - Pista Norte & $\begin{array}{c}\mathrm{O} 2(\mathrm{URB})-2 \mathrm{~S} 3- \\
\mathrm{O} 2 \mathrm{~S} 1-\mathrm{O} 3(\mathrm{ROD}) \\
\mathrm{O} 2(\mathrm{ROD})-\mathrm{U} 3 \\
3 \mathrm{~S} 2 \mathrm{~B} 2(20 \mathrm{~m})-\mathrm{U} 2 \\
\end{array}$ & $\begin{array}{c}3 \mathrm{~S} 3 \mathrm{~B} 3-2 \mathrm{~S} 1- \\
3 \mathrm{~S} 2 \mathrm{~B} 2(26 \mathrm{~m})- \\
2 \mathrm{~S} 2(20 \mathrm{~m})-3 \mathrm{~S} 2 \mathrm{~A} 2 \mathrm{~S} 2 \\
-2 \mathrm{~S} 2(22,4 \mathrm{~m}) \\
\end{array}$ & - \\
\hline SP 310 - Pista Sul & Todos & - & - \\
\hline SP 333 (SP304 - SP 300) & Todos & - & - \\
\hline SP 333 (Serrana - Cajuru) & - & - & Todos \\
\hline SP 147 & - & - & Todos \\
\hline SP 304 & Todos & - & - \\
\hline CE 040 & - & Todos & - \\
\hline CE 232 & - & Todos & - \\
\hline CE 377 & - & - & Todos \\
\hline CE 456 & - & $\begin{array}{c}\mathrm{O} 2(\mathrm{URB})-2 \mathrm{~S} 3- \\
\mathrm{O} 2 \mathrm{~S} 1-\mathrm{O} 3(\mathrm{ROD}) \\
\mathrm{O} 2(\mathrm{ROD})-\mathrm{U} 3 \\
\text { 3S2B2(20m) - U2 }\end{array}$ & $\begin{array}{c}\text { 3S3B3-2S1- } \\
\text { 3S2B2(26m)- } \\
\text { 2S2(20m)- } \\
\text { 3S2A2S2- } \\
\text { 2S2(22,4m) }\end{array}$ \\
\hline
\end{tabular}


Os resultados levaram às seguintes conclusões sobre os trechos pesquisados:

- SP 310 - o trecho localizado em terreno ondulado é provido de curvas horizontais de raio elevado, pistas de tráfego com largura de $3,5 \mathrm{~m}$, mostrandose compatível com o tráfego de todos os veículos pesquisados, capaz de acolher os veículos nas curvas sem a necessidade de sobrelarguras, e sem haver utilização dos acostamentos. $\mathrm{O}$ trecho em terreno montanhoso (proximidades do km 195) possui na pista norte (sentido Rio Claro - São Carlos) curvas horizontais com raios entre $199 \mathrm{~m}$ e $416 \mathrm{~m}$. Esse trecho é provido de três faixas de tráfego com sobrelarguras na pista variando entre 0,40 e $0,60 \mathrm{~m}$, valores suficientes para acomodar alguns dos veículos estudados, sem utilização dos acostamentos (Figura 5.7). Para os demais veículos, é necessária a utilização do acostamento, situação possível nas faixas de tráfego das extremidades das pistas. Na pista sul (sentido São Carlos - Rio Claro), há curvas com raios entre $215 \mathrm{~m}$ e $346 \mathrm{~m}$, com duas faixas de tráfego e uma sobrelargura na pista de 1,0 $\mathrm{m}$, valor suficiente para acomodar todos os veículos pesquisados sem necessidade de invasão dos acostamentos.

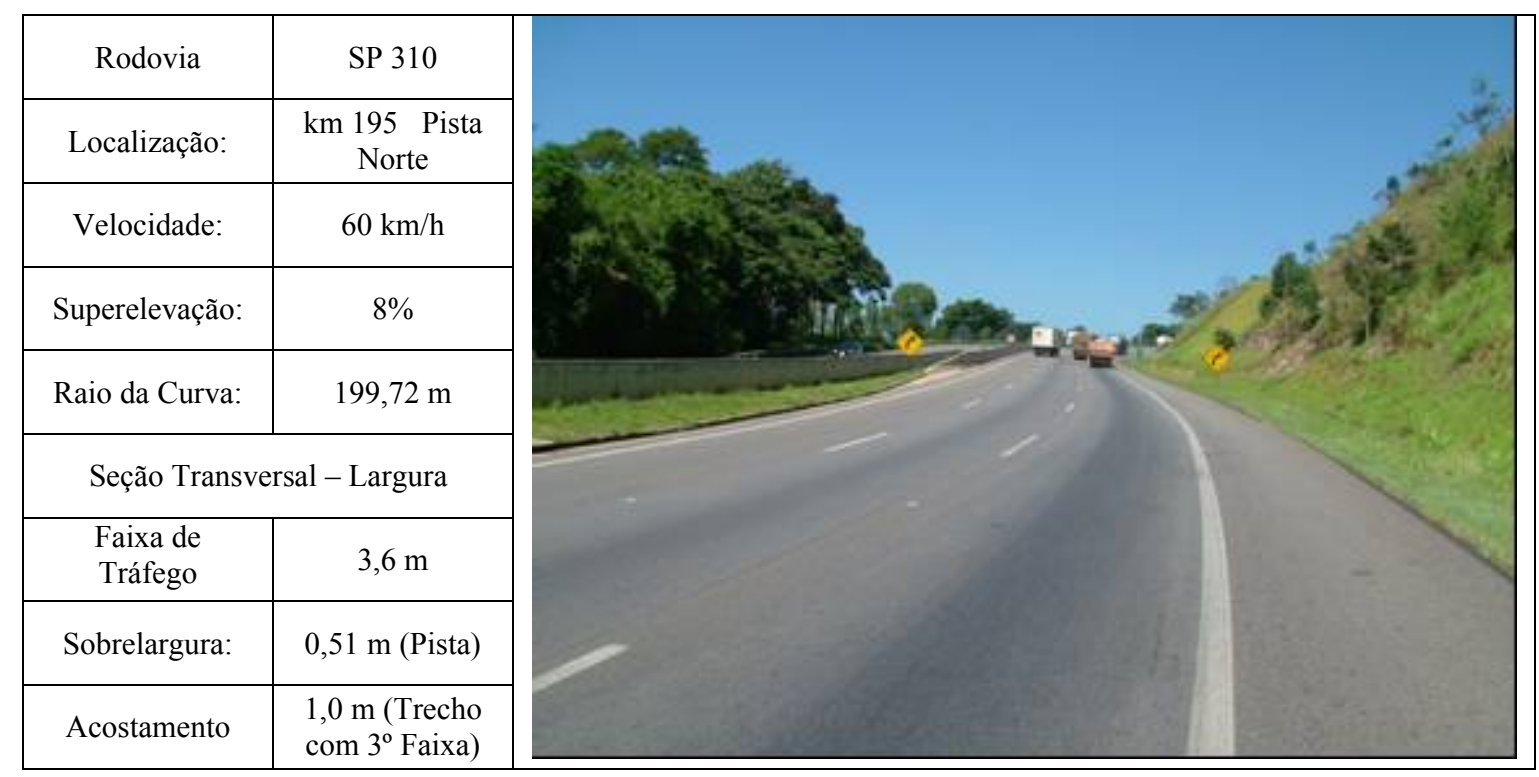

Figura 5.7: SP 310 - Trecho Montanhoso com Sobrelarguras nas Curvas Horizontais. Foto: Autor. 
- SP 225 - Apesar da existência no trecho pesquisado de curvas horizontais de raios pequenos, da ordem de $150 \mathrm{~m}$, a existência de faixas de tráfego com 3,6 m associada à existência de acostamentos de $2 \mathrm{~m}$ nestas curvas, permitiu acomodar os veículos mais complexos, mesmo sem a existência de sobrelarguras. Vale ressaltar, entretanto, que a inexistência de sobrelargura está diferente do que determina o Manual do DNER, uma vez que deveriam ser implantadas sobrelarguras de até $0,75 \mathrm{~m}$ na pista de tráfego (2 faixas), se considerado o veículo de projeto mais simples (CO), enquanto o Manual orienta a implantação de sobrelarguras nas pistas quando este valor atingir $0,40 \mathrm{~m}$.

- SP 333 (SP304 - SP 300) - A existência de curvas horizontais com raios elevados e a utilização de faixas de tráfego com largura de 3,6 m permitiram acomodar todos os veículos pesquisados, sem a necessidade de implantação de sobrelarguras para quaisquer veículos de projeto e mesmo sem a utilização dos acostamentos, que neste trecho apresentam deficiências como o desgaste no revestimento (Figura 5.8) e a existência de degraus (Figura 5.9).

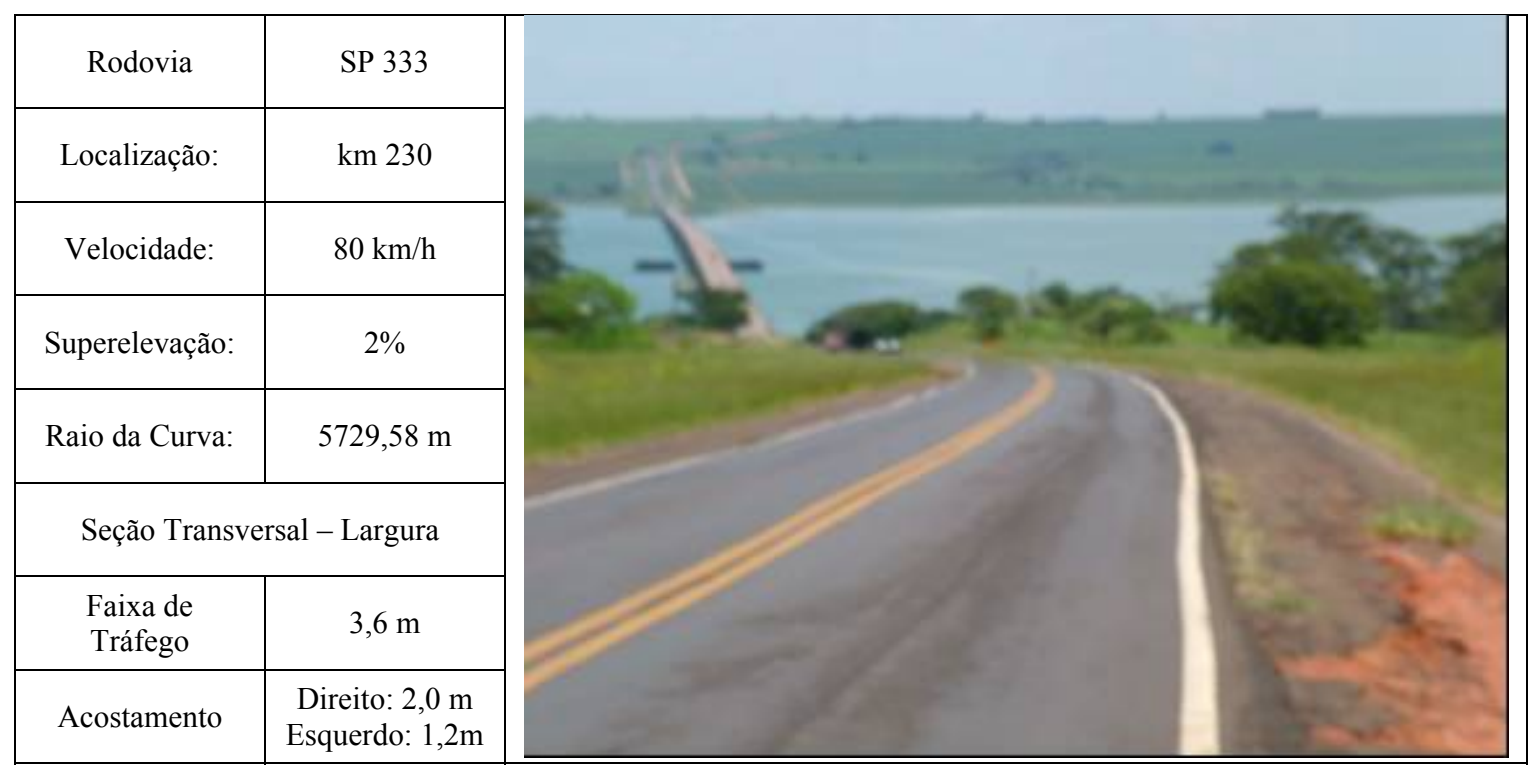

Figura 5.8: SP 333 (SP 300 - SP 304) - Acostamentos em Mal Estado de Conservação. Foto: Autor. 


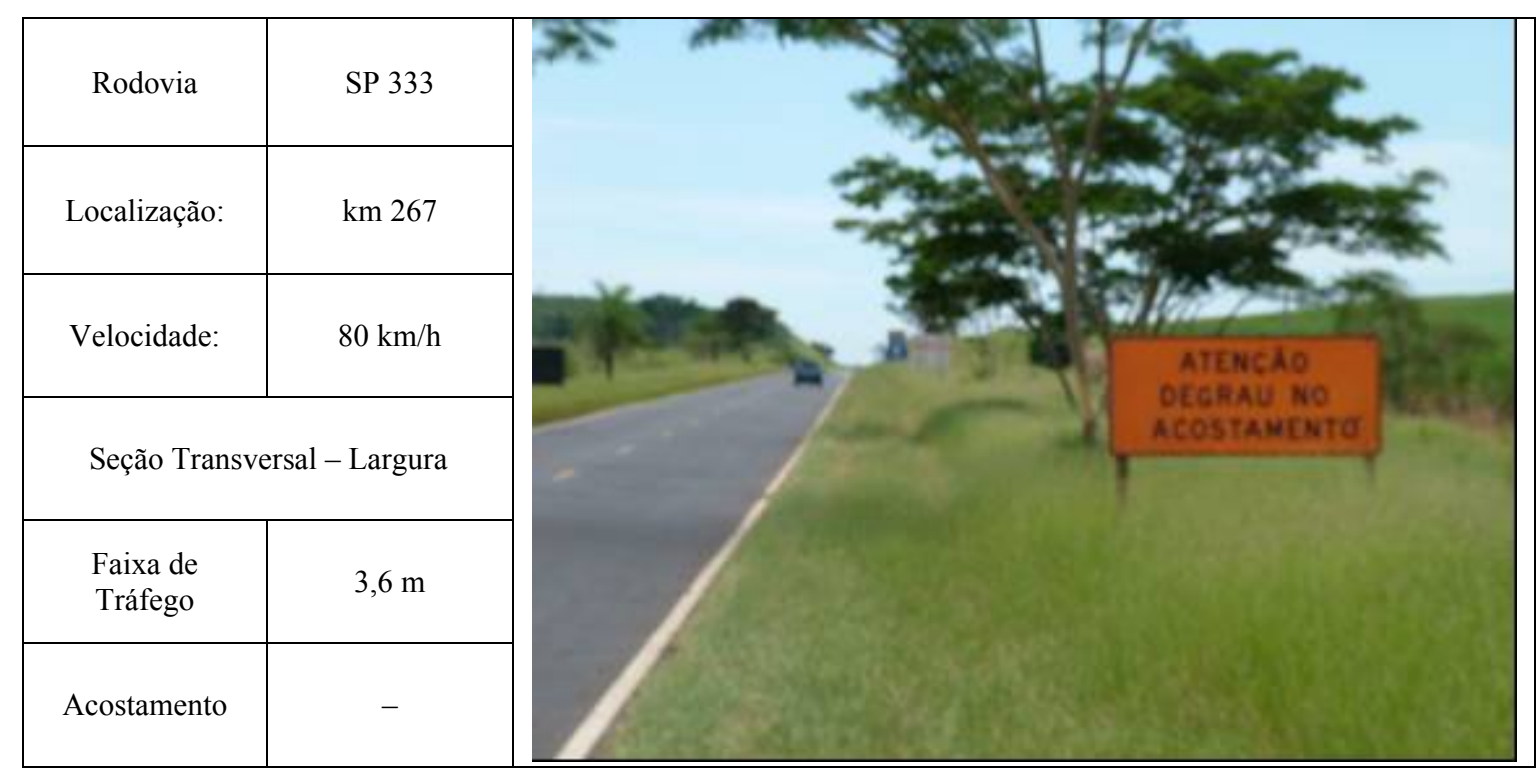

Figura 5.9: SP 333 (SP 300 - SP 304) - Acostamentos com Desnível Acentuado. Foto: Autor.

- SP 333 (Serrana - Cajuru) - O trecho apresenta curvas horizontais com raios elevados, entretanto a adoção de faixas de tráfego com 3,3 m e a inexistência de acostamento na curva de menor raio do trecho (Figura 5.10) resultou na incompatibilidade para todos os veículos estudados. Neste caso, a implantação de sobrelarguras de 0,40 m nos trechos curvos da pista e a reconstrução dos acostamentos ofereceria condições adequadas para acolher todos os veículos.

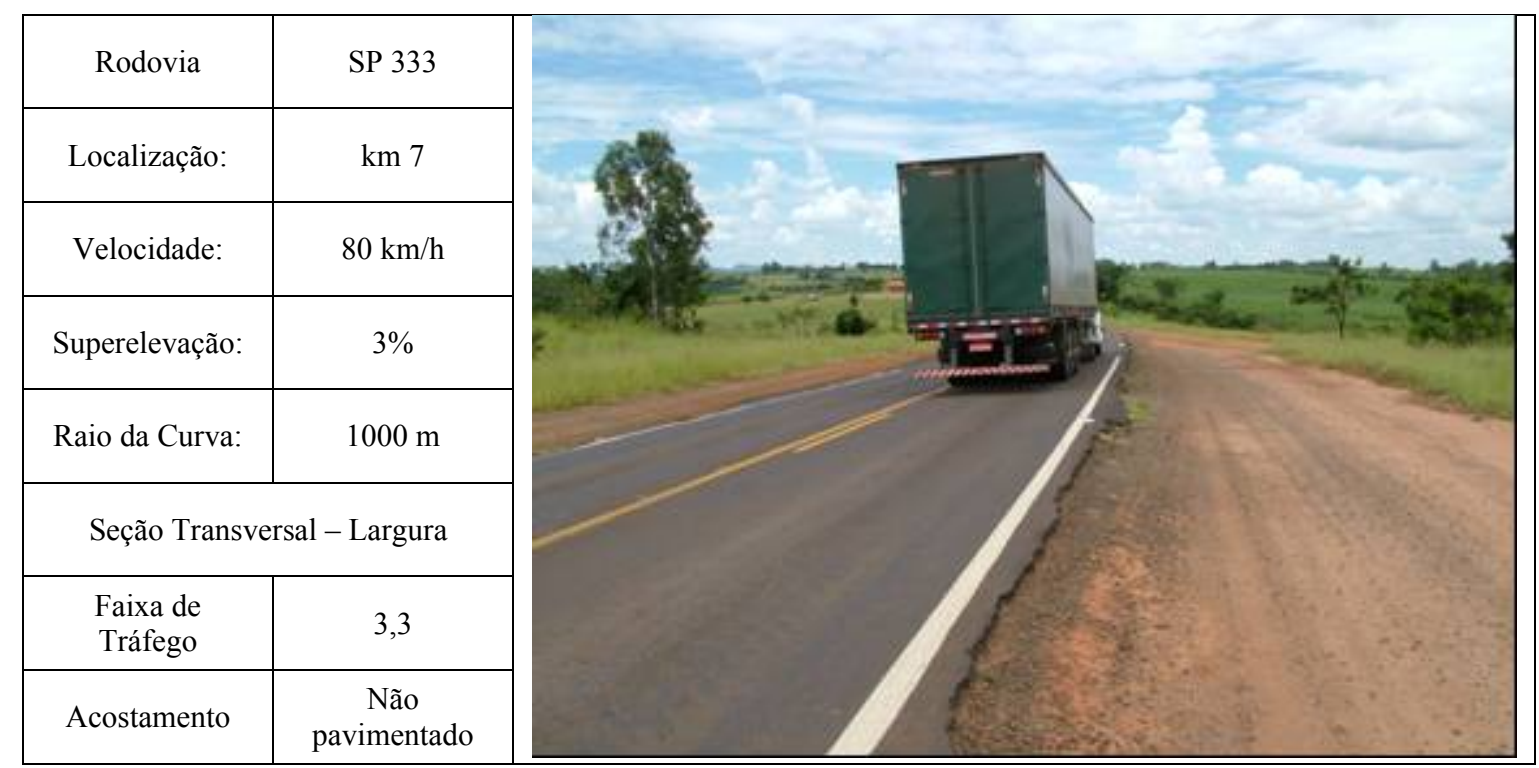

Figura 5.10: SP 333 (Serrana - Cajuru) - Pista com Acostamento sem Pavimento.

Foto: Autor. 
- SP 147 - Apesar de o trecho possuir várias curvas horizontais (32 curvas) com raios inferiores a $100 \mathrm{~m}$, que justificaria implantação de sobrelarguras para o veículo de projeto $\mathrm{CO}$ de até $0,78 \mathrm{~m}$, as faixas de tráfego possuem 3,6 m em toda a extensão da via. Associado a este fato, a ocorrência de trechos sem acostamento ou com acostamentos estreitos tornou o trecho incompatível para o tráfego de todos os veículos pesquisados (Figuras 5.11 a 5.13). Neste caso, a correção destas deficiências se torna mais complexa em função da natureza das intervenções necessárias, que fogem do conceito de reabilitação de via, além dos custos envolvidos, principalmente por se tratar de um trecho construído em terreno montanhoso. As intervenções para adequação da via devem ser analisadas individualmente, definindo quais pontos críticos devem receber intervenções físicas, como alargamento da plataforma ou correção de raios. Restam ainda outras medidas possíveis, como, por exemplo, a restrição parcial de acesso para alguns veículos, limitado a determinados horários com menor volume de tráfego, ou mesmo sua proibição.

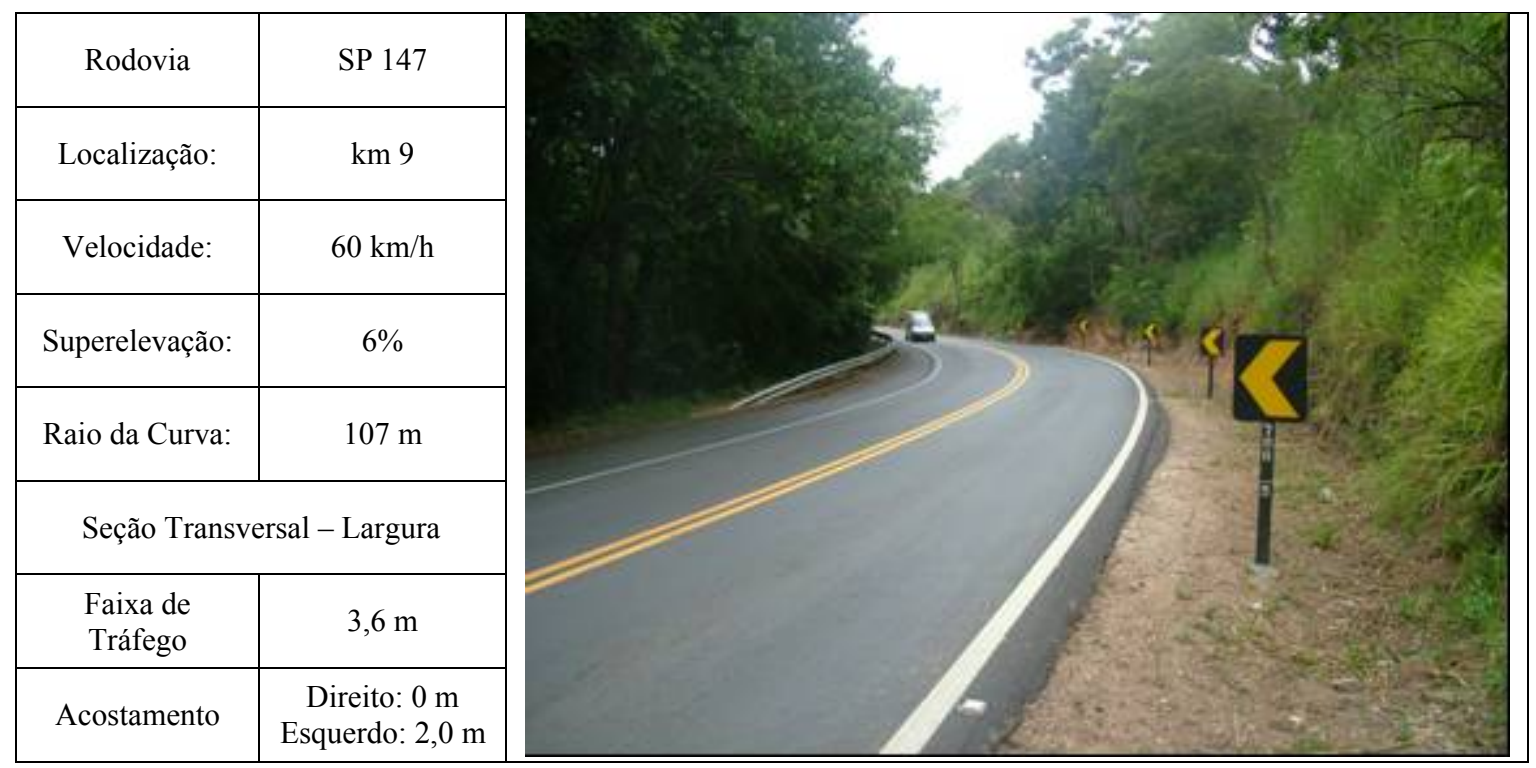

Figura 5.11: SP 147 - Pista sem Acostamento.

Foto: Autor. 


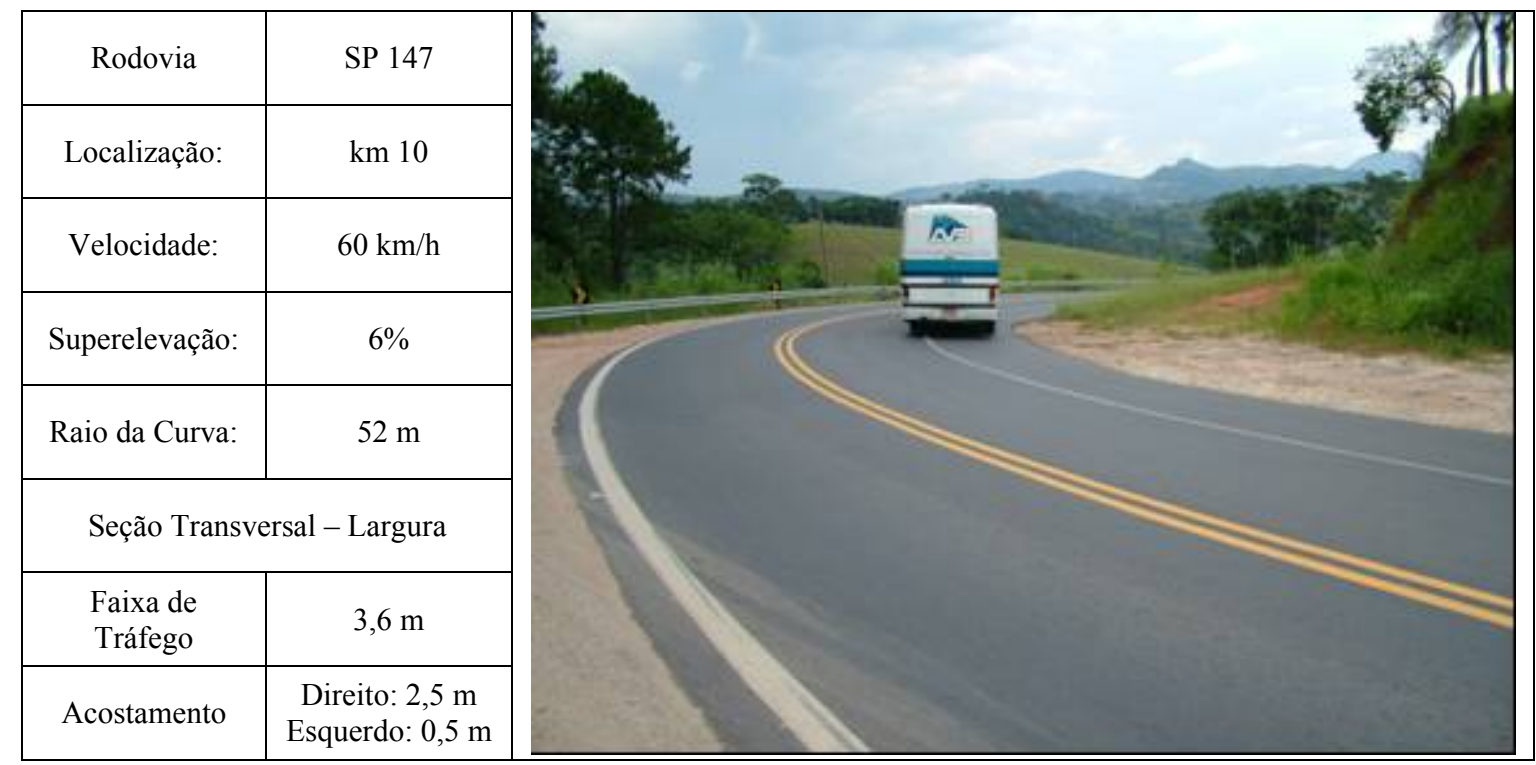

Figura 5.12: SP 147 - Curva com Acostamento Direito Adequado para Acomodar o Veículo sem Invasão da Faixa de Tráfego Oposta, mas Acostamento Esquerdo Insuficiente. Foto: Autor.

\begin{tabular}{|c|c|c|c|}
\hline Rodovia & SP 147 & \\
\hline Localização: & $\mathrm{km} 5$ \\
\hline Velocidade: & $60 \mathrm{~km} / \mathrm{h}$ \\
\hline Superelevação: & $6 \%$ \\
\hline Raio da Curva: & $100 \mathrm{~m}$ \\
\hline Seção Transversal - Largura \\
\hline $\begin{array}{c}\text { Faixa de } \\
\text { Tráfego }\end{array}$ \\
\hline Acostamento
\end{tabular}

Figura 5.13: SP 147 -Trecho Curvo sobre Ponte, sem Acostamento. Foto: Autor.

- SP 304 - A combinação de faixas de tráfego com 3,6 m e curvas horizontais com raios generosos permite acomodar o arraste de todos os veículos pesquisados sem a necessidade de sobrelarguras ou uso dos acostamentos. 
- CE 232 - Apesar de as faixas de tráfego possuírem largura de $3 \mathrm{~m}$ e haver algumas curvas com raios pequenos (até $133 \mathrm{~m}$ ), a existência de acostamento de 1,5 m em boas condições em toda a extensão dos trechos em curva permitiu compensar a inexistência de sobrelarguras e acomodar todos os veículos.

\begin{tabular}{|c|c|}
\hline Rodovia & CE 232 \\
\hline Localização: & $\mathrm{km} 5$ \\
\hline Velocidade: & $80 \mathrm{~km} / \mathrm{h}$ \\
\hline Superelevação: & $1 \%$ \\
\hline Raio da Curva: & $224,77 \mathrm{~m}$ \\
\hline Seção Transversal - Largura \\
\hline $\begin{array}{c}\text { Faixa de } \\
\text { Tráfego }\end{array}$ \\
\hline Acostamento & $\begin{array}{c}\text { Direito: } 1,5 \mathrm{~m} \\
\text { Esquerdo: } 1,5 \mathrm{~m}\end{array}$ \\
\hline
\end{tabular}

Figura 5.14: CE 232 - Rodovia com Acostamento Pavimentado e Largura Suficiente em Todas as Curvas para Acolher o Arraste dos Veículos.

Foto: Autor.

- CE 377 - A existência de curvas de até $55 \mathrm{~m}$ de raio e acostamentos estreitos e não pavimentados compromete a operação de todos os veículos pesquisados. Considerando a utilização dos veículos de projeto do DNER, este trecho deveria possuir sobrelarguras de até $1 \mathrm{~m}$ por faixa de tráfego apenas para garantir a operação de um veículo do tipo $\mathrm{CO}$ e de até $1,75 \mathrm{~m}$ para um veículo SR. O caso dessa rodovia é um exemplo típico de falha no projeto durante a etapa de definição do traçado da via. O terreno plano e a inexistência de pontos obrigados como acidentes geográficos e corpos hídricos permitiriam a adoção de um traçado mais fluente, no entanto existe um traçado sinuoso, com um elevado número de curvas de raio reduzido. Neste caso, o alargamento da plataforma e a readequação de alguns raios são medidas necessárias para compatibilizar o tráfego das CVCs investigadas. 


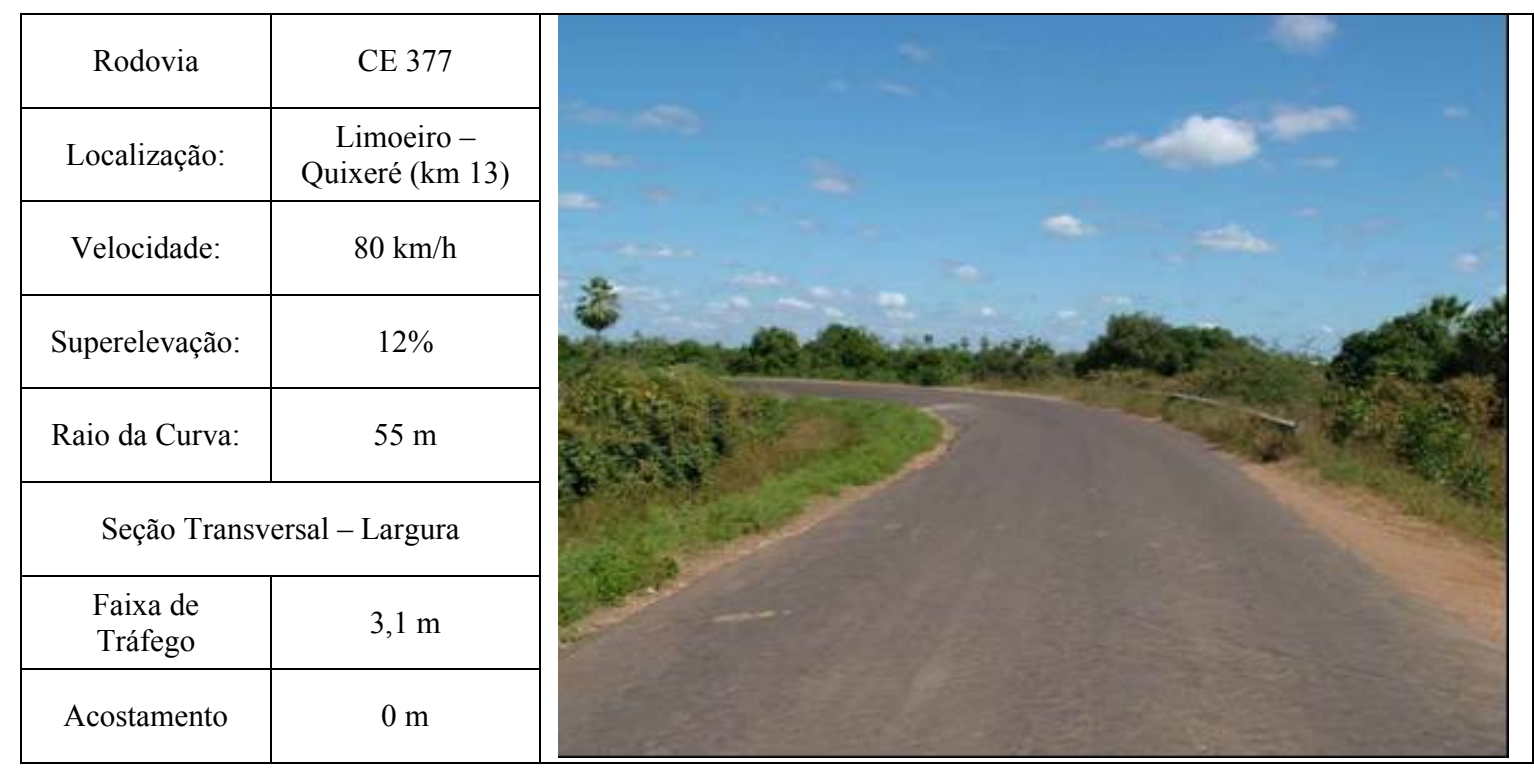

Figura 5.15: CE 377 - Rodovia com Curvas de Raio Reduzido, com Acostamentos Estreitos e sem Pavimento.

Foto: Autor.

- CE 040 - A existência de curvas com raios elevados e acostamentos com largura suficiente, em torno de 2,0 m, e em boas condições, permite a operação de todos os veículos.

- CE 456 - De forma semelhante ao que foi observado na CE 040, o trecho é provido de acostamento pavimentado e em boas condições de uso em toda a sua extensão. Sua largura de apenas 1,0 m, entretanto, é incapaz de compensar a inexistência de sobrelargura nas curvas horizontais para alguns veículos, tornando sua operação incompatível. Apenas uma parte dos veículos mais complexos apresentou incompatibilidade com o tráfego, e alguns são veículos com acesso restrito, operando apenas mediante a concessão de Autorização Especial de Trânsito (AET). Nestas situações é importante que, além da adoção de intervenções físicas na via, também sejam consideradas medidas como a imposição de restrições de acesso.

Como visto, a adequação de uma rodovia para a operação de veículos de forma a receber o arraste dos veículos é decorrência de uma combinação de fatores, como raios das curvas, largura das faixas de tráfego e largura e condição geral dos acostamentos, cabendo investigar caso a caso a implicação destes aspectos para determinar a 
compatibilidade do tráfego, bem como as intervenções a serem propostas para sua adequação.

\subsection{Avaliação da Estabilidade nas Curvas Horizontais dos Trechos Investigados}

Para verificar a condição de estabilidade lateral dos veículos nas curvas horizontais dos trechos pesquisados, foram observados os valores de raio, superelevações e velocidades. Com base nestas informações, foi verificado se os valores de atrito lateral efetivo estão dentro do limite de $f_{\max }$ recomendado pelo DNER (que é de 0,14 para a velocidade de $80 \mathrm{~km} / \mathrm{h}$ e 0,15 para a velocidade de $60 \mathrm{~km} / \mathrm{h}$ ) para as duas faixas de velocidades diretrizes dos trechos pesquisados. Os dados de raio das curvas horizontais foram obtidos em consultas ao projeto geométrico das estradas.

As demais informações foram coletadas diretamente em campo. As superelevações existentes nas curvas foram determinadas com a utilização de um clinômetro. A inexistência desta informação nos arquivos dos projetos da maioria das rodovias, alguns desenvolvidos na década de 1960, e mesmo a alteração das inclinações transversais da pista em decorrência de operações de recapeamento dos pavimentos, justificaram a escolha pela coleta direta em campo e determinação das condições atuais. Quanto à velocidade, foi considerada a velocidade regulamentar nos locais onde havia sinalização e, no caso de inexistência de informação em campo, foi admitida a velocidade de projeto constante do material consultado.

Recorreu-se à equação 3.18, substituindo os valores de $\mathrm{R}_{\min }$ e $e_{\max }$ pelos respectivos raios e superelevações existentes nas curvas, obtendo assim o fator de atrito lateral calculado ( $f$ Lat calc), que corresponde ao valor de atrito demandado para as condições existentes na curva. Foram admitidas as mesmas suposições mencionadas no Capítulo 4, com o objetivo de analisar o comportamento dos veículos de passeio e caminhões sob a condição de pavimento seco (PAV. SEC.) e pavimento molhado (PAV. MOV).

A Tabela 5.3 apresenta o intervalo de valores de $f$ Lat calc das curvas de cada trecho e as velocidades limite para a ocorrência de escorregamento e tombamento na curva onde foi observada a menor margem de segurança. 
Tabela 5.3: Velocidade-Limite Estimada para a Ocorrência de Instabilidade Lateral do Veículo - Curva com Menor Margem de Segurança do Trecho.

\begin{tabular}{|c|c|c|c|c|c|c|c|c|c|c|c|}
\hline \multirow{4}{*}{ RODOVIA } & \multirow{4}{*}{$\begin{array}{c}\mathrm{Vp} \\
(\mathrm{km} / \mathrm{h})\end{array}$} & \multirow{4}{*}{$f$ Lat calc } & \multicolumn{9}{|c|}{$\begin{array}{c}\text { VELOCIDADE LIMITE }(\mathrm{km} / \mathrm{h}) \text { - CURVA COM MENOR } \\
\text { MARGEM DE SEGURANÇA }\end{array}$} \\
\hline & & & \multicolumn{4}{|c|}{ Escorregamento } & \multicolumn{5}{|c|}{ Tombamento } \\
\hline & & & \multicolumn{2}{|c|}{ Auto } & \multicolumn{2}{|c|}{ Caminhão } & \multirow{2}{*}{$\begin{array}{c}\text { Auto } \\
a c_{\text {max }} \\
1,2 \mathrm{~g}\end{array}$} & \multicolumn{4}{|c|}{ Caminhão } \\
\hline & & & $\begin{array}{l}\text { PAV. } \\
\text { SEC. }\end{array}$ & $\begin{array}{l}\text { PAV. } \\
\text { MOL }\end{array}$ & $\begin{array}{l}\text { PAV. } \\
\text { SEC. }\end{array}$ & $\begin{array}{l}\text { PAV. } \\
\text { MOL }\end{array}$ & & $\begin{array}{l}a c_{\max } \\
0,25 \mathrm{~g}\end{array}$ & $\begin{array}{l}a c_{\max } \\
0,30 \mathrm{~g}\end{array}$ & $\begin{array}{l}a c_{\max } \\
0,35 \mathrm{~g}\end{array}$ & $\begin{array}{l}a c_{\max } \\
0,40 \mathrm{~g}\end{array}$ \\
\hline CE040 & 80 & $0-0,18$ & 183 & 119 & 153 & 97 & 221 & 119 & 127 & 134 & 140 \\
\hline CE232 & 80 & $0,11-0,38$ & 124 & 81 & 103 & 63 & 151 & 81 & 86 & 91 & 96 \\
\hline CE377 & 80 & $0,16-0,38$ & 123 & 81 & 102 & 63 & 150 & 81 & 86 & 91 & 95 \\
\hline CE456 & 80 & $0,20-0,50$ & 106 & 71 & 88 & 53 & 130 & 70 & 75 & 79 & 83 \\
\hline SP147 & 60 & $0,04-0,53$ & 77 & 57 & 64 & 45 & 94 & 53 & 56 & 59 & 61 \\
\hline SP225 & 60 & $0,01-0,16$ & 135 & 90 & 112 & 72 & 163 & 89 & 95 & 100 & 104 \\
\hline SP304 & 80 & $0-0,03$ & 463 & 299 & 388 & 249 & 553 & 299 & 317 & 335 & 351 \\
\hline $\begin{array}{c}\text { SP310 } \\
\text { Pista Norte }\end{array}$ & 60 & $0,01-0,06$ & 161 & 119 & 136 & 102 & 190 & 110 & 116 & 121 & 126 \\
\hline $\begin{array}{c}\text { SP310 } \\
\text { Pista Sul }\end{array}$ & 60 & $0,02-0,06$ & 166 & 123 & 141 & 104 & 197 & 113 & 119 & 125 & 130 \\
\hline $\begin{array}{c}\mathrm{SP} 333 \\
(\mathrm{SP} 300-\mathrm{SP} 304)\end{array}$ & 80 & $0-0,02$ & 562 & 363 & 470 & 302 & 671 & 362 & 384 & 406 & 423 \\
\hline $\begin{array}{c}\text { SP333 } \\
\text { (Serrana }- \text { Cajuru) }\end{array}$ & 80 & $0,01-0,03$ & 345 & 223 & 288 & 185 & 413 & 223 & 236 & 250 & 262 \\
\hline
\end{tabular}

Os resultados obtidos mostram que os trechos das Rodovias SP 304, SP 310 e SP 333 apresentam boas condições de estabilidade lateral para os veículos, com todas as curvas horizontais apresentando um fator de atrito lateral bem abaixo do valor de $f_{\max }$, além de baixas taxas de superelevação, em virtude da utilização de curvas com raios elevados. Isto resultou em altas margens de segurança para a ocorrência de escorregamento ou tombamento, como revelam as velocidades apresentadas na Tabela 5.3 .

Observando as velocidades-limites apresentadas, têm-se os automóveis mais propensos ao escorregamento do que ao tombamento, tanto para a condição de pavimento seco como molhado. Os caminhões, dados os valores de $a c_{\max }$ considerados, também estão mais predispostos a escorregar no pavimento molhado. Para a condição de pista seca, porém, o tombamento ocorre a uma velocidade inferior ao limiar de 
escorregamento destes veículos. Nos demais trechos rodoviários, foi observado que a velocidade de projeto não se mostrou adequada para algumas curvas horizontais. Alguns casos estão associados à inexistência de sobrelargura nas curvas e outros à existência de raios muito pequenos para a velocidade de projeto da via.

A segunda situação ocorre normalmente em terrenos de relevo mais acidentado, onde o custo de construção inviabiliza a implantação de raios mais elevados, sendo propostos raios pequenos e ainda outras práticas, como a redução da largura das faixas de tráfego e dos acostamentos. Apesar de indesejável, quando esta prática é utilizada, deve vir acompanhada de uma redução adequada da velocidade de projeto no trecho, devendo ser devidamente sinalizada para orientar o motorista. Alguns dos trechos pesquisados apresentaram inadequações desta natureza e estão detalhados na seqüência, sendo propostas algumas intervenções.

- CE 040 - Apresentou apenas uma curva fora do limite de $f_{\max }$ estabelecido pelo DNER, com $f$ igual a 0,18. A inexistência de superelevação na curva levou a este resultado, reduzindo a margem de segurança, que para o escorregamento de caminhões em pavimento molhado, foi de $97 \mathrm{~km} / \mathrm{h}$, isto é, $20 \%$ acima da velocidade de projeto. A implantação de uma superelevação de 8\% nesta curva elevaria esta velocidade de $97 \mathrm{~km} / \mathrm{h}$ para $112 \mathrm{~km} / \mathrm{h}$.

- CE232 - O trecho analisado apresentou três curvas com velocidades de escorregamento nos caminhões abaixo da velocidade de projeto $(80 \mathrm{~km} / \mathrm{h})$, sendo que na curva mais crítica isto ocorre a uma velocidade de $63 \mathrm{~km} / \mathrm{h} \mathrm{em}$ pavimento molhado. Mesmo para os automóveis, é verificada uma incompatibilidade da velocidade de projeto com a geometria da curva, onde o automóvel derrapa com $81 \mathrm{~km} / \mathrm{h}$. Como pode ser observado pelas velocidades apresentadas da curva mais crítica, os caminhões no pavimento seco são suscetíveis preferencialmente, a tombamento, onde o veículo com $a c_{\max }$ de 0,25 g tomba a uma velocidade de $81 \mathrm{~km} / \mathrm{h}$ e os demais também apresentam baixas margens de segurança. As três curvas apresentam baixas taxas de superelevação, da ordem de $2 \%$. A implantação de superelevação de $8 \%$ elevaria a velocidade de escorregamento nos caminhões para o valor de $76 \mathrm{~km} / \mathrm{h}$ no pavimento molhado e a velocidade de tombamento para $89 \mathrm{~km} / \mathrm{h}$ nos caminhões com $a c_{\max }$ 
de $0,25 \mathrm{~g}$, que consiste na situação mais crítica para a condição de pavimento seco. Como estas medidas ainda não permitem que os caminhões operem a uma velocidade de $80 \mathrm{~km} / \mathrm{h}$, é recomendada a adoção de uma velocidade regulamentar de $60 \mathrm{~km} / \mathrm{h}$ no trecho para garantir condições de segurança.

- CE377 - O trecho analisado apresentou quatro curvas com velocidades de escorregamento nos caminhões abaixo da velocidade de projeto, estando a curva mais crítica em condição operacional semelhante ao verificado na curva crítica do ultimo trecho citado (CE 232). Nas curvas deste trecho, no entanto, as superelevações estão entre $8 \%$ e $10 \%$, correspondendo ao limite estabelecido pelo DNER. A redução da velocidade regulamentar no trecho para $60 \mathrm{~km} / \mathrm{h}$ garante margem de segurança razoável para as outras três curvas, entretanto, para a curva mais crítica, esta medida não é suficiente, uma vez que a velocidade de escorregamento dos caminhões no pavimento molhado é de $63 \mathrm{~km} / \mathrm{h}$. É recomendada neste caso a readequação do raio desta curva.

- $\mathrm{CE} 456$ - O trecho apresentou incompatibilidade em quatorze curvas para o tráfego de caminhões, passíveis de escorregamento abaixo da velocidade de projeto da via, considerando a situação de pavimento molhado. Para a condição de pavimento seco, o tombamento é verificado em oito curvas a uma velocidade inferior ao limite de projeto, se considerados os caminhões com $a c_{\max }$ de 0,25 g. Dos valores de $a c_{\max }$ investigados, apenas os veículos com limiar igual a 0,40 g podem percorrer o trecho com a velocidade de projeto sem tombar, entretanto com uma pequena margem de segurança, entre 3 e $10 \%$. As curvas apresentam superelevação em torno de $8 \%$, restando como medida de segurança a imposição de uma velocidade regulamentar mais baixa, que neste caso não deveria ser superior a $40 \mathrm{~km} / \mathrm{h}$. É recomendado, entretanto, considerar a readequação dos raios para permitir uma velocidade mais próxima da velocidade diretriz da via, que é de $80 \mathrm{~km} / \mathrm{h}$.

- SP 147 - Foi notoriamente o trecho de pior condição operacional para os veículos. Mesmo com a existência de uma velocidade de projeto de $60 \mathrm{~km} / \mathrm{h}$, foi observado que em dezenove curvas os caminhões escorregam a uma velocidade abaixo deste limite, para a condição de pavimento molhado. Além disso, em 
outras quinze curvas, existe pequena margem de segurança. Quando admitida a condição de pavimento seco, os veículos com $a c_{\max }$ de $0,25 \mathrm{~g}$ tombam em doze curvas, e mesmo os caminhões com $a c_{\max }$ de $0,40 \mathrm{~g}$ operam no limiar de tombamento na curva mais crítica, como visto na Tabela 5.3. Algumas destas curvas apresentam superelevações de $4 \%$, podendo ser tomada como medida corretiva a elevação destes valores para $8 \%$. Outras medidas, entretanto, como a redução da velocidade regulamentar para $40 \mathrm{~km} / \mathrm{h}$ e ainda a readequação de alguns raios seriam necessárias para tornar compatível a operação de veículos com $a c_{\max }$ entre 0,25 e $0,40 \mathrm{~g}$.

- SP 225 - O trecho analisado desta rodovia tem sua velocidade regulamentar reduzida de $80 \mathrm{~km} / \mathrm{h}$ para $60 \mathrm{~km} / \mathrm{h}$. Nesta condição, apenas uma curva apresentou um fator de atrito lateral acima do limite de $f_{\max }$ adotado pelo DNER, que resulta num limiar de escorregamento de caminhões na velocidade de 74 $\mathrm{km} / \mathrm{h}$. Essa curva possui apenas $2 \%$ de superelevação, de forma que é recomendada sua elevação para uma taxa de $8 \%$, medida que aumenta a velocidade-limite de escorregamento dos caminhões para $82 \mathrm{~km} / \mathrm{h}$.

\subsection{Avaliação das Rampas Ascendentes dos Trechos Estudados}

O comportamento dos veículos de carga em rampas ascendentes se distingue do observado nos veículos de passeio, substancialmente, em virtude da relação entre sua potência motora e seu peso bruto total. A declividade e a extensão das rampas, por sua vez, tornarão mais ou menos evidente esta diferença de desempenho. À medida que a via possui rampas mais extensas e de maior declividade, os veículos com menor relação potência/massa passam a interferir na corrente de tráfego, ocasionando conflitos com os demais veículos da frota, especialmente nas rodovias de pista simples, exigindo a adoção de medidas como a implantação de faixas de tráfego adicionais. Como mencionado no Capítulo 4, a proposição destas faixas de tráfego é determinada por um conjunto de aspectos, como a redução de velocidade dos veículos de carga, os volumes de tráfego, o nível de serviço, além do aspecto econômico, de importância decisiva, uma vez que este tipo de dispositivo normalmente se faz necessário em terrenos acidentados, onde são mais elevados os custos de construção. 
O objetivo da análise realizada a seguir é conhecer o comportamento de veículos típicos brasileiros, em termos de seu desempenho em rampas ascendentes, para alguns trechos de rodovias de pista simples. Foram utilizados os seis veículos de projeto propostos neste trabalho, sendo realizadas simulações com o TRUPER ao longo do perfil longitudinal destes trechos. Dos trechos de pista simples investigados, três são providos de faixa de tráfego adicional. A simulação de veículos ao longo de todo o greide do trecho foi realizada também para verificar como as rampas adicionais implantadas nestes trechos atendem a veículos de relação potência/massa diferente, indicando onde ocorrem perdas significativas de velocidade e onde os veículos recuperam sua capacidade de aceleração. Para mensurar o desempenho dos veículos nos trechos pesquisados, foi verificada a extensão de via onde o caminhão opera com velocidade $20 \mathrm{~km} / \mathrm{h}$ abaixo da velocidade de projeto.

A escolha deste valor como redução máxima admissível para caminhões operando em rampas segue resultado obtido por Melo (2002), que correlaciona índice de envolvimento de caminhões em acidentes com a diferença de velocidade de veículos. Dos trechos de pista simples pesquisados, existe faixa de tráfego adicional em rampas de aclive nas rodovias SP 147, SP 225 e SP 333 (Serrana - Cajuru).

A Tabela 5.4 apresenta o resultado da simulação dos veículos com suas respectivas relações potência/massa percorrendo o perfil longitudinal dos trechos de aclive e declive das rodovias pesquisadas. A variável apresentada consiste na extensão da via onde o veículo opera com uma redução de velocidade maior do que $20 \mathrm{~km} / \mathrm{h}$, com relação à velocidade de projeto, e está apresentada em valores percentuais. Os campos representados com hífen indicam que o veículo em nenhum instante reduziu sua velocidade abaixo deste limite estipulado. 
Tabela 5.4: Extensão do Trecho onde o Veículo Trafega com uma Redução de Velocidade Superior a $20 \mathrm{~km} / \mathrm{h}(\mathrm{em} \%)$

\begin{tabular}{cccccccc}
\hline \multirow{2}{*}{ RODOVIA } & \multirow{2}{*}{ SENTIDO } & \multicolumn{6}{c}{ VÉ́CULO } \\
\cline { 3 - 8 } & $3,16 \mathrm{cv} / \mathrm{t}$ & $4,67 \mathrm{cv} / \mathrm{t}$ & $6,97 \mathrm{cv} / \mathrm{t}$ & $7,42 \mathrm{cv} / \mathrm{t}$ & $9,76 \mathrm{cv/t}$ & $13,15 \mathrm{cv} / \mathrm{t}$ \\
\hline \multirow{2}{*}{ CE 456 } & Choro - CE 060 & 44 & 23 & 11 & 11 & 4 & - \\
& CE 060 - Choro & 50 & 20 & 4 & 2 & 1 & - \\
\hline \multirow{2}{*}{ CE 377 } & Limoeiro - Quixeré & 81 & - & - & - & - & - \\
& Quixeré - Limoeiro & 79 & - & - & - & - & - \\
\hline \multirow{2}{*}{ CE 232 } & Viçosa - Padre Vieira & 24 & 10 & 3 & 1 & 1 & 0 \\
& Padre Vieira - Viçosa & Veíc. Pára & Veíc. Pára & 37 & 28 & 19 & 14 \\
\hline \multirow{2}{*}{ SP 304 } & Ibitinga - N. Horizonte & 51 & 38 & 24 & 18 & 13 & 5 \\
& N. Horizonte - Ibitinga & 56 & 47 & 34 & 25 & 17 & 4 \\
\hline \multirow{2}{*}{ SP 147 } & Itapira - Socorro & 34 & 25 & 15 & 12 & 7 & - \\
& Socorro - Itapira & 30 & 19 & 12 & 10 & 8 & - \\
\hline \multirow{2}{*}{ SP 333 } & Serrana - Cajuru & 63 & 51 & 38 & 33 & 28 & 14 \\
& Cajuru - Serrana & 41 & 32 & 22 & 17 & 12 & 6 \\
\hline \multirow{2}{*}{ SP 225 } & Itirapina - Jaú & 47 & 30 & 20 & 14 & 8 & 5 \\
& Jaú - Itirapina & 58 & 52 & 28 & 21 & 15 & 7 \\
\hline \multirow{2}{*}{ SP 333 } & SP 304 - SP 300 & 45 & 36 & 23 & 17 & 11 & 6 \\
& SP 300 - SP 304 & 56 & 45 & 29 & 20 & 15 & 4 \\
\hline \multirow{2}{*}{30} & & & & & &
\end{tabular}

O veículo com relação potência/massa de 3,16 cv/t apresentou, para a maioria dos percursos pesquisados, uma redução de velocidade acima de $20 \mathrm{~km} / \mathrm{h}$. A razão principal para este fato não se encontra no perfil dos trechos pesquisados, mas no próprio desempenho do veículo, que atinge uma velocidade de equilíbrio no greide nulo de apenas $48 \mathrm{~km} / \mathrm{h}$. A operação de veículos com esta relação potência/massa em rodovias de pista simples com velocidade diretriz superior a $60 \mathrm{~km} / \mathrm{h}$ acentua a necessidade de haver mais oportunidades de ultrapassagem para os demais veículos. Por outro lado, o melhor resultado, se considerados os valores percentuais apresentados, ocorreu no Trecho da SP 147, notadamente o trecho mais acidentado da pesquisa. Neste caso, a adoção de menor velocidade de projeto, $60 \mathrm{~km} / \mathrm{h}$, permitiu ao veículo com menor capacidade de aceleração ter um desempenho mais próximo dos demais. Este resultado comprova a importância de se compatibilizar a velocidade de projeto da via, sua declividade e extensão dos greides e a relação potência-massa dos veículos representativos da frota. Ainda a respeito do veículo de 3,16 cv/t, foi verificada uma redução de velocidade para valores próximos de $10 \mathrm{~km} / \mathrm{h}$ em doze percursos. Além disto, o veículo pára em uma rampa de 9,11\% no trecho da Rodovia CE 232, demonstrando sua incompatibilidade para operar neste trecho. 
$\mathrm{O}$ veículo de 4,67 cv/t também não conseguiu vencer uma rampa na CE $232 \mathrm{e}$ apresentou reduções significativas de velocidade, que chegaram a $15 \mathrm{~km} / \mathrm{h}$ em nove percursos pesquisados. Nos demais veículos, as velocidades mínimas observadas foram em sua maioria próximas de $30 \mathrm{~km} / \mathrm{h}$ para os veículos de $6,97 \mathrm{cv} / \mathrm{t} \mathrm{e} 7,43 \mathrm{cv} / \mathrm{t}, 35 \mathrm{~km} / \mathrm{h}$ para os veículos de $9,76 \mathrm{cv} / \mathrm{t}$ e $45 \mathrm{~km} / \mathrm{h}$ para os veículos de $13,15 \mathrm{cv} / \mathrm{t}$. Vale destacar o fato de que o veículo de $13,15 \mathrm{cv} / \mathrm{t}$ apresentou seis trechos onde a velocidade se manteve sempre acima do limite de redução de $20 \mathrm{~km} / \mathrm{h}$.

Foi analisado também, por simulação, o comportamento dos veículos nos trechos providos de faixa adicional nos aclives, sendo verificada a velocidade dos veículos no início e no final da faixa adicional. A SP 147 possui dois trechos com faixa adicional no sentido Itapira/Socorro, ambas com $1200 \mathrm{~m}$ de extensão e dois trechos no sentido Socorro/Itapira com extensões de $1500 \mathrm{~m}$ e $1000 \mathrm{~m}$. A simulação nos trechos a montante do inicio das faixas adicionais mostrou que os veículos de todas as relações potência/massa consideradas conseguem iniciar o trecho de faixa adicional com uma velocidade superior a $40 \mathrm{~km} / \mathrm{h}$, isto é, com redução de velocidade menor do que o limite máximo de $20 \mathrm{~km} / \mathrm{h}$. A extensão das faixas adicionais também se mostrou adequada para todos os veículos, que retornam à faixa de tráfego principal com velocidade acima de $40 \mathrm{~km} / \mathrm{h}$.

A SP 225 também é provida de faixa de tráfego adicional, com extensão de 2000 $\mathrm{m}$ no sentido Itirapina/Jaú, em um trecho onde a velocidade regulamentar da via é de 60 $\mathrm{km} / \mathrm{h}$. A simulação mostrou que os veículos de 3,16 cv/t, 4,67 cv/t e 6,97 cv/t iniciam o trecho com faixa adicional a uma baixa velocidade, respectivamente de $13 \mathrm{~km} / \mathrm{h}, 16$ $\mathrm{km} / \mathrm{h}$ e $30 \mathrm{~km} / \mathrm{h}$. Estes veículos percorrem longa extensão após o final da faixa adicional, com uma velocidade abaixo do limite de redução máxima: $1700 \mathrm{~m}$ para o veículo de 3,16 cv/t, $1300 \mathrm{~m}$ para o veículo de 4,67 cv/t e $1100 \mathrm{~m}$ para o veículo de 6,97 cv/t. Para os demais veículos, as extensões das faixas adicionais se mostraram suficientes para permitir o retorno do veículo à faixa principal com uma velocidade acima do limite de redução máxima. A SP 333 possui dois trechos com faixa adicional no sentido Serrana/Cajuru e dois trechos no sentido Cajuru/Serrana. No sentido Serrana/Cajuru, as faixas adicionais possuem extensão de $2800 \mathrm{~m}$ e $3200 \mathrm{~m}$, sendo que todos os veículos simulados apresentaram velocidades compatíveis no início da faixa 
adicional e recuperação de suas velocidades para um patamar acima do limite de redução máxima, antes do término do trecho com terceira faixa. No sentido Cajuru/Serrana, os veículos de 3,16 cv/t iniciam o primeiro trecho de faixa adicional com velocidades de $38 \mathrm{~km} / \mathrm{h}$ e percorrem uma extensão em torno de $1650 \mathrm{~m}$ após o término da faixa adicional, com uma velocidade abaixo do limite de redução máxima, revelando a incapacidade do dispositivo implantado de acomodar adequadamente a restrição deste veículo. Para os demais veículos, a faixa adicional mostrou-se adequada. O segundo trecho de faixa adicional apresentou localização e extensão suficientes para acomodar todos os veículos simulados. 


\section{ANÁLISE DOS RESULTADOS}

\subsection{Considerações Iniciais}

O estudo de caso apresentado no Capítulo 5 revelou a existência de marcante heterogeneidade no padrão das rodovias estudadas, característica que se estende para toda a malha rodoviária nacional. Estas diferenças podem ser justificadas por diversos motivos, despontando como uma das razões principais as diferentes capacidades de investimento dos Estados, que determinam o nível de recursos financeiros disponíveis e, por conseguinte, o padrão técnico da infra-estrutura viária a ser implantado. O advento da concessão de rodovias à iniciativa privada acentuou ainda mais estas disparidades, uma vez que o interesse dos investidores convergiu para os estados com atividade econômica mais intensa, notadamente o Estado de São Paulo.

Outro aspecto que tem uma forte influência no padrão geométrico das vias está relacionado ao relevo do terreno e à presença de outros acidentes naturais, que têm uma importante participação nos custos envolvidos com a implantação da infra-estrutura viária. Como o projeto da via deve atender a uma condição de viabilidade econômica, estes aspectos são muitas vezes determinantes do traçado e padrão da rodovia. Em um país de dimensões continentais como o Brasil, a diversidade de formações de relevo e de condições naturais acentuam ainda mais a heterogeneidade da malha viária. $\mathrm{O}$ resultado que pode ser observado é a ocorrência de níveis de restrição diferentes, que os veículos complexos precisam enfrentar, diferenças estas que se mostram mais acentuadas quando se ultrapassam os limites entre estados.

As análises realizadas no Capítulo 4 tomaram como referência os parâmetros mínimos de projeto das classes técnicas de rodovia e permitiram que fossem identificadas as restrições à operação de veículos que atualmente compõem a frota nacional. Estes resultados podem, assim, orientar o estabelecimento de ajustes nos parâmetros de projeto, de forma que seja assegurada a compatibilidade da via para a 
operação de veículos com maiores restrições. Como visto, estes ajustes podem acontecer através da alteração de parâmetros mínimos das classes de projeto, bem como com a utilização de veículos de projeto mais complexos.

Como diagnosticado no estudo de caso, entretanto, grande parte das rodovias pesquisadas não atende a alguns dos padrões mínimos propostos para as classes de projeto, enquanto, por outro lado, podem superar com folga outros parâmetros. Em trechos de rodovias inseridos em terrenos planos, onde a topografia favoreça o uso de um traçado mais suave, pode-se, por exemplo, obter em alguns casos uma concordância horizontal e vertical que atenda a requisitos bem superiores ao padrão exigido pela classe técnica da rodovia. Neste caso, a investigação da compatibilidade dos veículos deve ser avaliada caso a caso, uma vez que a combinação de parâmetros de projeto, alguns superiores aos parâmetros mínimos das classes técnicas e outros abaixo destes limites pode ensejar uma compensação, algumas vezes resultando numa condição de compatibilidade satisfatória. Como exemplo, pode ser mencionado o resultado observado para a análise de compatibilidade nas curvas horizontais para acomodar a varredura dos veículos. Foi verificado que o trecho da SP 225, que apresenta um padrão semelhante a uma rodovia de Classe II, no terreno ondulado, apresenta raios pequenos, da ordem de $150 \mathrm{~m}$, portanto inferiores ao padrão mínimo desta classe de rodovia. A existência de faixas de tráfego, porém, acima do padrão mínimo da classe técnica permitiu acomodar a varredura dos veículos, mesmo sem a implantação de sobrelargura nas curvas. No caso da CE 040, foi observada uma situação inversa. A existência de raios mais elevados nas curvas horizontais, onde o menor deles foi de $286 \mathrm{~m}$, valor acima do parâmetro mínimo de uma rodovia de velocidade diretriz de $80 \mathrm{~km} / \mathrm{h}$, foi suficiente para compensar a pequena largura das faixas de tráfego, de $3,3 \mathrm{~m}$, permitindo assim, como também foi verificado na SP 225, a operação de todos os veículos investigados com o uso dos acostamentos disponíveis.

\subsection{Procedimentos para Verificar a Adequação de Parâmetros de Geometria de Segmentos Rodoviários}

Para a análise de trechos que não atendem exatamente aos parâmetros mínimos de projeto estabelecidos para as classes técnicas de rodovias, são propostos os 
procedimentos apresentados no fluxograma da Figura 6.1, que visam a garantir a compatibilidade de segmentos rodoviários para a operação dos veículos. Estes procedimentos permitem também auxiliar a concepção de novos projetos, onde há liberdade de ajustar os parâmetros de projeto para atender às demandas dos veículos a serem atendidos pela via, liberdade esta condicionada especialmente pelas características do terreno onde será implantada a infra-estrutura e pela presença de outros condicionantes que amarram o traçado da via como os pontos obrigados de passagem.

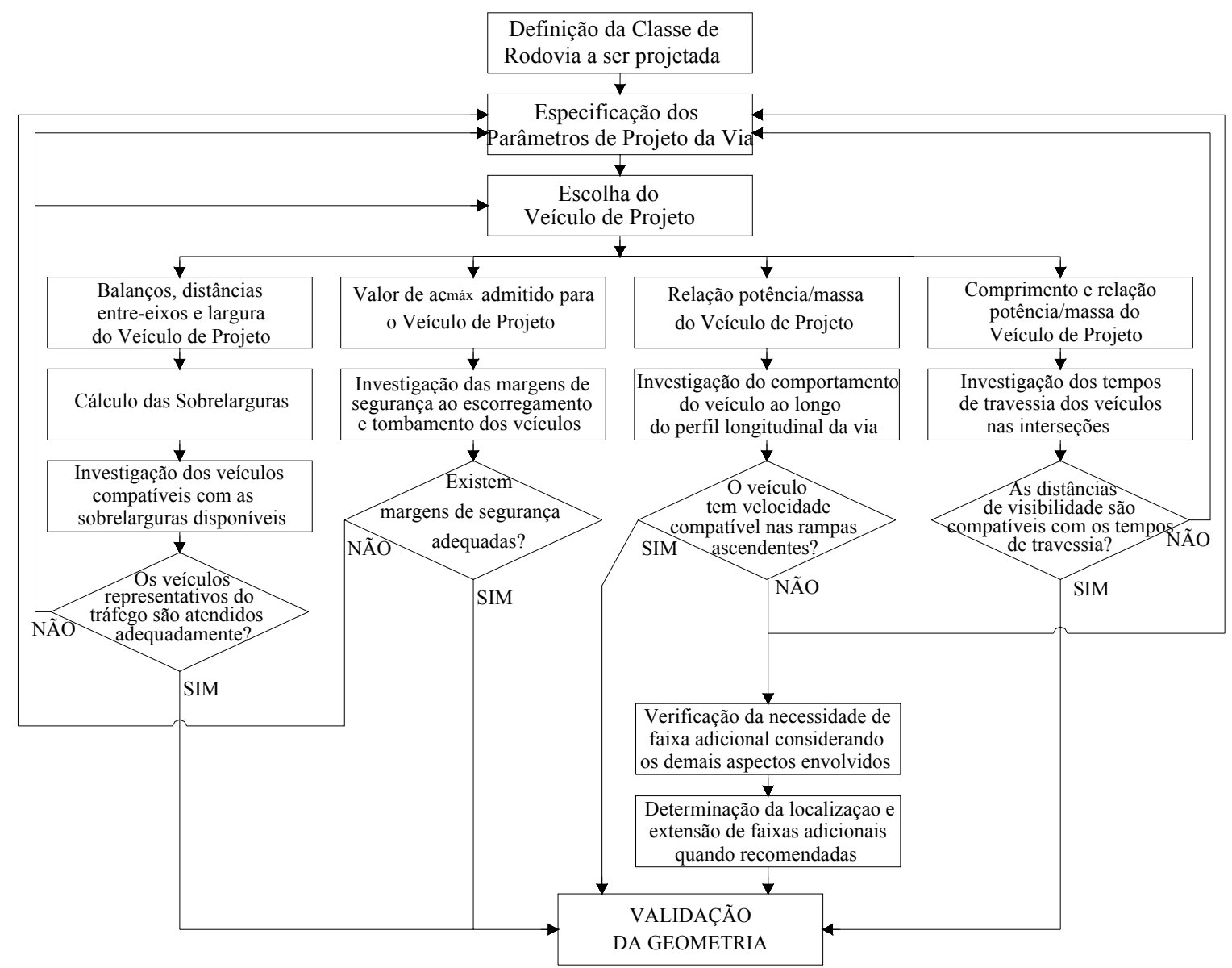

Figura 6.1: Procedimentos para Verificar a Adequação de Parâmetros Importantes da Geometria de Rodovias às Condições dos Veículos.

Esta abordagem está focada no papel do veículo de projeto na concepção da geometria da via, sendo estabelecidas as condições necessárias da via para atender às restrições deste veículo. Como mostra o fluxograma, se for verificada inadequação da geometria à operação de um determinado veículo representativo do tráfego, pode-se recorrer à redefinição de parâmetros de projeto, como também podem ser adotadas 
intervenções contingentes como a alteração de velocidades em trechos críticos ou modificação de raios em certas curvas horizontais. Pode-se também recorrer a mudanças mais abrangentes, como readequar o padrão da rodovia para outra classe técnica de maior padrão. Para o caso das sobrelarguras, a redefinição do veículo de projeto é outra forma de prover esta adequação, uma vez que a escolha de um veículo mais complexo interfere diretamente no cálculo desta variável, permitindo que a adequação seja atingida mesmo sem alterações nos parâmetros de projeto. 


\section{CONCLUSÕES E RECOMENDAÇÕES}

\subsection{Considerações Iniciais}

A compatibilidade dos padrões de uma rodovia com a operação dos veículos é resultado de uma série de aspectos abordados ao longo deste trabalho. Primeiramente, antes mesmo de tratar dos veículos, suas especificações técnicas e restrições, é importante salientar a necessidade de uma consistência entre a função exercida pela via e seu padrão técnico, ou seja, a existência de condições físicas na via que permitam cumprir adequadamente suas atribuições. A existência de uma rede viária bem hierarquizada, com funções bem estabelecidas para cada elemento do sistema, é o primeiro passo neste sentido. Apenas com a estrutura viária organizada é possível planejar as ações de forma a atender os veículos e suas demandas. Os conflitos entre as possíveis funções de uma via, como prover mobilidade, acessibilidade, assim como as inter-relações com o uso do solo e os impactos gerados pelo sistema viário em sua área de entorno e no meio ambiente, são questões complexas e que devem ser tratadas conjuntamente.

A partir da hierarquização das vias, estabelecida na classificação funcional, e da correta escolha das diretrizes técnicas de projeto que darão suporte ao exercício das atribuições destas vias, deve-se então centrar o foco nas questões que envolvem a compatibilidade dos veículos, dadas as características das vias. O ponto-chave desta discussão reside na definição e escolha do veículo de projeto. Este veículo determinará como a via projetada acolherá os demais veículos componentes da frota, sendo sua escolha o principal responsável pelas condições operacionais. 


\subsection{Conclusões Quanto à Investigação de Parâmetros de Projeto Ordinariamente Baseados em Veículos de Passeio.}

Alguns parâmetros de projeto, que são normalmente definidos com base nos veículos de passeio, foram considerados nesta pesquisa, onde as análises realizadas levaram às seguintes conclusões:

(a) a adoção de distâncias de visibilidade de parada com base no desempenho de veículos de carga deve passar a ser considerada no projeto de rodovias brasileiras. A adoção de um tratamento único para automóveis e caminhões como propõe o Manual norte americano não é adequada à realidade brasileira, onde a frota de veículos comerciais possui, quase na totalidade, veículos com sistemas de frenagem convencionais, cujo desempenho é bem inferior ao dos veículos de passeio. Mesmo admitindo que a frota nacional de veículos de carga tenha uma relação potência/massa inferior a outros padrões internacionais, cabe ressaltar que, especialmente nas regiões brasileiras de relevo acidentado, os trechos em declive proporcionam a estes veículos elevadas velocidades, superando inclusive as velocidades de projeto, sendo importante estabelecer distâncias de frenagem adequadas para estas situações. A utilização de distâncias de frenagem mínimas, propostas pelo Manual do DNER, e que considera valores de velocidade média no lugar da velocidade de projeto, deve ser considerada com ressalvas. Nos trechos em declive das rodovias, a distância desejável, expressão utilizada no Manual brasileiro para tratar das distâncias de visibilidade de parada calculadas com base na velocidade de projeto, deve ser entendida como valor mínimo admissível e ainda ter o desempenho de frenagem dos caminhões levado em consideração;

(b) outro parâmetro comumente calculado com base nos veículos de passeio consiste nos comprimentos mínimos das curvas verticais convexas. Foi observado que esta prática não consiste em riscos para o tráfego de caminhões, havendo uma compensação, ainda que não seja em sua plenitude, da maior altura de visão dos motoristas de caminhões diante de seu pior desempenho nos processos de frenagem. Considerando as margens de segurança existentes nas taxas de desaceleração admitidas no projeto das vias, pode-se afirmar que a 
utilização de critérios baseados em automóveis para a determinação deste parâmetro resultam em valores compatíveis com a operação de caminhões;

(c) para as curvas horizontais, é recomendada a utilização de afastamentos laterais, calculados com base em distâncias de visibilidade de parada para caminhões, nos casos em que existam obstáculos capazes de obstruir sua altura de visão, de 2,4 m. Nos demais casos, a determinação dos afastamentos laterais com base nos veículos de passeio não compromete as condições de segurança dos caminhões; e

(d) quanto às distâncias de visibilidade de ultrapassagem, a existência de modelos que consideram veículos longos, como o proposto por Glennon, em contraposição a modelos conservadores, como o modelo de ultrapassagem da AASHTO (que, apesar de considerar apenas automóveis, propõe distâncias mais elevadas que outros modelos), revela a necessidade de serem consideradas outras questões que influenciam a determinação deste parâmetro de projeto. Além do comprimento dos veículos, as condições admitidas no processo de ultrapassagem, como o diferencial de velocidade e os gaps admitidos entre os veículos são aspectos que interferem significativamente nas distâncias de visibilidade obtidas. A partir destas distâncias de visibilidade e considerando ainda a análise dos volumes de tráfego na via, pode ser prevista a existência ou não de condições em trechos de rodovia de pista simples para a liberação do tráfego de veículos longos.

Além destes aspectos, em que os veículos são normalmente tratados apenas em dois grupos - veículos de passeio ou de carga - existem outros, pois diferentes configurações de veículos e, por conseguinte, suas restrições operacionais demandam diferentes níveis de exigência.

\subsection{Conclusões Quanto à Investigação dos Veículos de Projeto Brasileiros.}

O papel do veículo de projeto não se limita à função comumente associada à definição dos raios de giro nas interseções ou as sobrelarguras necessárias nas curvas e em outros dispositivos. Existem outras características dos veículos que devem ser 
destacadas e orientam o projeto das vias. A relação potência/massa é uma destas características, estando intimamente associada à capacidade de aceleração e velocidade dos veículos e que têm importante influência na determinação de parâmetros como comprimentos críticos de rampa e tempos de travessia em interseções, como foi verificado nas simulações realizadas.

\subsubsection{Cálculo de Sobrelarguras}

Considerando inicialmente os veículos de projeto utilizados com a função de determinar as sobrelarguras a serem implantadas nas curvas, dadas as diretrizes do atual Manual de projeto, chegou-se às seguintes conclusões:

(a) inexistem veículos de projeto segundo a classificação do DNIT capazes de representar as demandas por sobrelargura de vários veículos em operação, alguns dos quais gozando de acesso irrestrito na malha viária. Considerando os padrões mínimos de projeto de cada classe técnica de rodovia, foi observada a necessidade de utilização dos acostamentos para suprir a insuficiência de sobrelargura para vários veículos do tipo $\mathrm{CVC}$, mesmo quando utilizado o veículo de projeto mais complexo do Manual do DNER;

(b) os veículos de projeto $\mathrm{CO}$ e $\mathrm{O}$ apresentam dimensões que resultam em sobrelarguras inferiores ao demandado por outros veículos de mesma categoria, como o caminhão unitário U2 de $14 \mathrm{~m}$, conforme foi verificado no Capítulo 4. Uma prática existente em outros manuais, como observado na AASHTO e na TAC, é a utilização de mais de um veículo de projeto para uma mesma categoria de veículo, com diferentes distâncias entre seus pontos notáveis, resultando em diferentes valores de sobrelargura. Esta solução poderia ser utilizada no Manual brasileiro como forma de atender ao nítido crescimento do segmento de veículos longos verificado na frota nacional. Neste caso, recomenda-se a inclusão, como veículo de projeto, de um caminhão unitário, com dimensões semelhantes ao veículo U2 presente neste trabalho. Da mesma forma, a inclusão de uma CVC do tipo 2S1 apresentada é recomendada para substituir ou ser incluída ao veículo SR(DNER). A Resolução $\mathrm{n}^{\circ} 210$ do CONTRAN autoriza a operação destes dois veículos, U2 e $2 \mathrm{~S} 1$, com a configuração mencionada, em todo o Território Nacional, sendo sua inclusão no grupo de veículos de projeto uma 
forma de permitir melhor condição operacional para veículos com circulação garantida por uma determinação legal; e

(c) além do $2 \mathrm{~S} 1$, a inclusão de outra CVC, como a 2S2(20m) ou a 3S2B2(26m) como veículo de projeto poderia ser considerada. Apesar de se tratar de veículos com operação condicionada à emissão de AETs, é importante a existência de um representante desta categoria de veículo, servindo de referência nos projetos de vias que assegurem a participação destes veículos.

\subsubsection{Estabilidade nas Curvas Horizontais}

Quanto à estabilidade lateral dos veículos, outro aspecto considerado no trabalho, os resultados verificados para o padrão das classes de projeto do DNER revelaram que veículos com aceleração lateral limite de tombamento $\left(a c_{\max }\right)$ de $0,25 \mathrm{~g} \mathrm{e}$ 0,30 g apresentam pequena margem se segurança para a ocorrência de tombamento, com a velocidade do veículo chegando ao limiar do tombamento em um valor apenas $8 \%$ superior à velocidade de projeto, se considerada a rodovia de menor padrão técnico. A regulamentação de veículos com padrões mínimos de estabilidade lateral é uma iniciativa necessária para garantir condições mínimas de segurança. Os veículos com $a c_{\max }$ de $0,35 \mathrm{~g}$ e 0,40 g, valores mínimos recomendados internacionalmente, oferecem margens de segurança onde as velocidades-limites de tombamento são de $23 \%$ e $30 \%$ superiores à velocidade de projeto, respectivamente, para o caso mais crítico observado, nas rodovias de Classe IV(M).

\subsubsection{Perfil Longitudinal}

Os resultados das simulações do comportamento dos veículos em rampas ascendentes mostraram a influência significativa da relação potência/massa e da importância de considerar este parâmetro ao longo do perfil longitudinal da via e também nos processos de travessia em interseções. O estudo de implantação de faixas adicionais em rampas ascendentes deve ser proposto, visando a atender a um veículo com determinada relação potência/massa, sendo projetadas faixas adicionais com localização e extensão adequadas para o comportamento deste veículo. 


\subsubsection{Visibilidade nas Interseções}

Quanto à determinação das distâncias de visibilidade em interseções, além da relação potência/massa, o comprimento do veículo e a largura da plataforma são variáveis com importante influência no tempo de travessia dos veículos. Os resultados das simulações levam às seguintes conclusões, quando comparados aos tempos de travessia propostos no Manual do DNIT (2005):

(a) quando considerado o veículo de projeto O(DNER), os tempos propostos no Manual se mostraram insuficientes para os veículos de mesmo comprimento, com relação potência/massa de 3,16 cv/t, 4,67 cv/t, 6,97 cv/t e 7,42 cv/t;

(b) no caso do veículo de projeto RE(DNIT), os tempos propostos no Manual se mostraram insuficientes para os veículos de mesmo comprimento, com relação potência/massa de 3,16 cv/t e 4,67 cv/t; e

(c) as distâncias de visibilidade máximas propostas pelo DNIT, obtidas com base no veículo de projeto RE(DNIT) de 19,8 m se mostraram compatíveis para veículos de $25 \mathrm{~m}$ que possuem relação potência/massa de $9,76 \mathrm{cv} / \mathrm{t}$ ou $13,15 \mathrm{cv} / \mathrm{t}$ e também no veículo de $30 \mathrm{~m}$ e relação potência/massa de 13,15 cv/t. Apesar deste resultado confirmar a hipótese de que veículos longos com maior capacidade de aceleração possam compensar seu maior comprimento nos tempos demandados para manobras de travessia, é importante propor a utilização de maiores DVI's para atender a veículos longos com menores relação potência/massa. Considerando que as rodovias de padrão mais elevado apresentam maiores extensões de travessia e maiores velocidades de projeto, são estas classes de via que apresentam as maiores restrições para estes veículos.

\subsection{Conclusões Obtidas no Estudo de Caso}

O estudo de caso mostrou a existência de rodovias com padrões que não atendem aos parâmetros mínimos de projeto estabelecidos nas classes do DNER, resultando em restrições mais severas, especialmente para os veículos que não possuem representação nos veículos de projeto. A inexistência de sobrelarguras em todos os trechos de rodovias de pista simples, onde os raios mínimos observados chegaram a ser 
de até $50 \mathrm{~m}$, é um exemplo das deficiências. Da mesma forma, foram evidenciados problemas na geometria das curvas horizontais, onde em várias curvas as superelevações implantadas se encontravam bem abaixo dos valores necessários ou eram inexistentes, resultando em elevados valores de atrito lateral, comprometendo a estabilidade dos veículos. Estas inconsistências observadas em campo representam um sério risco para a ocorrência de acidentes e denotam a importância de avaliar as condições de segurança das rodovias não apenas nas questões associadas ao seu estado de conservação, mas também quanto à sua geometria, aspecto que muitas vezes é posto em segundo plano, diante da existência de outros problemas de percepção mais evidente.

As transformações ocorridas na frota de veículos brasileiros, marcadas pelo surgimento de veículos mais longos e de maior capacidade, tornam esta realidade diagnosticada no estudo de caso ainda mais crítica. Mesmo com a liberação do tráfego nas rodovias condicionado à deliberação dos órgãos estaduais, por meio de AETs, os órgãos responsáveis pela emissão destas autorizações muitas vezes não possuem os instrumentos necessários para avaliar se a rodovia é adequada para o tráfego dos veículos. Dentre as dificuldades de se aquilatar esta compatibilidade está a inexistência de cadastros com informações das rodovias. Em muitos casos, só estão disponíveis informações como os raios das curvas horizontais e o perfil longitudinal, faltando dados importantes como as superelevações, sobrelarguras e outros parâmetros necessários de análise, exigindo a coleta direta em campo, que demanda tempo e recursos muitas vezes inexistentes. O estudo de caso revelou também que em algumas situações a compatibilidade dos veículos com a geometria da via está condicionada ao estado de conservação da via, como se observou no caso da utilização dos acostamentos para suprimir a carência de sobrelargura das pistas. Neste caso, não apenas a existência do acostamento é suficiente para este fim, mas sobretudo sua condição geral, tornando a determinação da compatibilidade um caráter dinâmico, o qual exige o conhecimento de informações continuamente atualizadas.

Como se pode perceber, a correta definição e escolha do veículo de projeto é a condição fundamental para permitir a compatibilidade entre o veículo e a infraestrutura viária. Esta tarefa não é fácil, uma vez que o Brasil não possui procedimentos 
de certificação de veículos. A falta deste instrumento de controle traz muitos questionamentos quanto às reais condições operacionais dos veículos que compõem a frota nacional, contribuindo ainda para aumentar sua heterogeneidade, dificultando a definição de veículos representativos a serem utilizados na concepção das vias. É importante a criação deste tipo de mecanismo para controlar como um determinado veículo unitário ou uma CVC está sendo posto no mercado. Juntamente com esta iniciativa é importante também que seja instituída a prática de inspeção veicular, permitindo fiscalizar as condições operacionais dos veículos e garantir maior segurança nas rodovias.

\subsection{Recomendações}

Recomenda-se como temas para trabalhos futuros, que sejam estudadas algumas questões, algumas das quais, em razão da amplitude da pesquisa realizada, não puderam ser abordadas com maior profundidade:

(a) determinar experimentalmente os valores de atrito na interface pneu-pavimento, considerando os tipos de revestimento asfáltico empregados no Brasil em suas diversas regiões e os impactos na frenagem dos veículos de carga, bem como a utilização de pneus do tipo extra-largo;

(b) determinar o limiar de tombamento de veículos de carga brasileiros, considerando especialmente as CVCs e caminhões-tanque;

(c) estabelecer critérios para a liberação do tráfego de CVCs em rodovias com restrições operacionais;

(d) desenvolver um procedimento para a realização de auditoria de geometria viária, reunindo os diversos aspectos abordados nesta pesquisa e em outras fontes, permitindo assim uma avaliação global das condições das rodovias para o atendimento de diferentes tipos de veículo; e

(e) estudar os acidentes em rodovias de pista simples nos processos de ultrapassagem envolvendo caminhões, considerando aspectos como o comprimento dos veículos, o percentual de ultrapassagens abortadas e a adoção de velocidade diferencial para automóveis e caminhões. 


\section{REFERÊNCIAS}

AASHTO. A Policy of Marking and Signing of No-Passing Zones on Two and Three-Lane Roads. Washington: American Association of State Highway and Transportation Officials; 1940.

. A Policy on Geometric Design of Highways and Streets. 3 ed. Washington: American Association of State Highway and Transportation Officials; 1994. 1006p. ISBN: 1-56051-068-4.

. A Policy on Geometric Design of Highways and Streets. 4 ed. Washington: American Association of State Highway and Transportation Officials; 2001. 905p. ISBN: 1-56051-156-7.

. A Policy on Geometric Design of Highways and Streets. 5 ed. Washington: American Association of State Highway and Transportation Officials; 2004. 896p. ISBN: 1-56051-263-6.

ASSOCIAÇÃO BRASILEIRA DE NORMAS TÉCNICAS. NBR 5532: componentes e sistemas de freio para veículos rodoviários. Rio de Janeiro, 1990.

ALBERTA INFRASTRUCTURE. Road Classification Guidelines, Government of Alberta, 1994. Disponível em: <http://www.btre.gov.au>. Acesso em: 20 jul. 2003.

AUSTROADS. Austroads and Standards Australia, Design Vehicles and Turning Path Templates. Sydney: Association of Australian and New Zealand Road Transport and Traffic Authorities; 1995.

. Rural Road Design: a guide to the geometric design of rural roads. $6^{\text {a }}$ Edição. Sydney: Association of Australian and New Zealand Road Transport and Traffic Authorities; 2002. 126p.

BRASIL. Lei n ${ }^{\circ}$ 9.503, de 23 de setembro de 1997. Institui o código de trânsito brasileiro. Lex: nova coletânea de legislação de trânsito, Porto Alegre, p. 9-90, 1999a.

BRASIL. Conselho Nacional de Trânsito. Estabelece os requisitos de segurança necessários a circulação de Combinações para Transporte de Veículos - CTV. Resolução $n^{0}$ 75, 19 de novembro de 1998. Lex: nova coletânea de legislação de trânsito, Porto Alegre, 1999b. 
BRASIL. Conselho Nacional de Trânsito. Estabelece os limites de peso e dimensões para veículos que transitem por vias terrestres e dá outras providências. Resolução $\mathrm{n}^{\mathrm{o}}$ 210, 13 de novembro de 2006. Brasília, 2006a.

BRASIL. Conselho Nacional de Trânsito. Requisitos necessários à circulação de Combinações de Veículos de Carga - CVC, a que se referem os arts. 97, 99 e 314 do Código de Trânsito Brasileiro-CTB. Resolução nº 211, 13 de novembro de 2006. Brasília, 2006b.

BRTE. State Spending on Roads, Bureau of Transport and Regional Economics, Department of Transport and Regional Service, Australia, 2003. Disponível em: $<$ http://www.btre.gov.au>. Acesso em: 25 jul. 2004.

CARDOSO, J.C.; FLOUDA, A.; DIMITROPOULOS, I.; KANELLAIDIS; G. Design Consistency of Horizontal Alignment in Rural Roads. Safety Standards for Road Design and Redesign, 1997

CNT. Boletim Estatístico, Confederação Nacional do Transporte, 2005. Disponível em: $<$ http://www.cnt.org.br>. Acesso em: 04 dez. 2006.

. Pesquisa Rodoviária 2006: Relatório Gerencial. Brasília: Confederação Nacional do Transporte; 2006. 156 p.

COOPERRIDER, N.; THOMAS, T.; HAMMOUND, S. Testing and analysis of vehicle rollover behavior. SAE Research Report, Warrendale, 1990.

COSTA, E.E.S. Análise da compatibilidade do gabarito de caminhões com a geometria das interseções urbanas numa cidade de médio porte. 1997. 91f. Dissertação (Mestrado em Engenharia de Transportes) - Escola de Engenharia de São Carlos, Universidade de São Paulo, São Carlos, 1997.

CUNHA, A.L. B. N.; MON-MA, M. L.; ARAÚJO, J. J.; EGAMI, C. Y.; SETTI, J. R. A. Caracterização da frota de caminhões no sistema Anhanguera-Bandeirantes. In: CONGRESSO BRASILEIRO DE PESQUISA E ENSINO EM TRANSPORTE, 19. 2005, Recife. Anais... Recife: ANPET, 2005. 
DEBS, M. K. E.; MALITE, M.; MUNAIAR NETO, J. Análise das conseqüências do tráfego de combinações de veículos de carga (CVCs) sobre as pontes da rede viária sob jurisdição do DER - SP. Revista Minerva Fipai, São Carlos, v. 1, n. 1, p. 27-35, 2004.

DEMARCHI, S.H; SETTI. Caracterização da relação massa/potência de caminhões em rodovias do Estado de São Paulo. In: CONGRESSO BRASILEIRO DE PESQUISA E ENSINO EM TRANSPORTE, 13., 1999, São Carlos. Anais... São Carlos: ANPET, 1999, v.1, p. 573-584.

DEMARCHI, S.H; SETTI, J. R. A.; WIDMER, J.A. Comportamento de caminhões em interseções em nível. In: CONGRESSO BRASILEIRO DE PESQUISA E ENSINO EM TRANSPORTE, 8., 1994, Recife. Anais... Recife: ANPET, 1994, v.1, p. 269-274.

DEMARCHI, S.H. Influência dos veículos pesados na capacidade de interseções rodoviárias. 1995. 164f. Dissertação (Mestrado em Engenharia de Transportes) Escola de Engenharia de São Carlos, Universidade de São Paulo, São Carlos, 1995.

Influência de veículos pesados na capacidade e nível de serviço de rodovias de pista dupla. 2000. 157f. Tese (Doutorado em Engenharia de Transportes) - Escola de Engenharia de São Carlos, Universidade de São Paulo, São Carlos, 2000a.

. Truper: Simulador de Desempenho de Veículos Rodoviários e

Ferroviários: Versão 2.1e. Universidade Estadual de Maringá, Departamento de Engenharia Civil. Maringá, 2000b.

. Truper: Simulador de Desempenho de Veículos Rodoviários e

Ferroviários. Versão 2.5d. Universidade Estadual de Maringá, Departamento de Engenharia Civil. Maringá, 2004.

DENATRAN. Frota de veículos, por tipo e com placa, segundo as grandes regiões e unidades da Federação, Departamento Nacional de Trânsito, Ministério das Cidades, 2006. Disponível em: < http://www.infoseg.gov.br/renaest>. Acesso em: 20 fev. 2007.

DER-SP. Manual de Sinalização Rodoviária. 2 ed. São Paulo: Departamento de Estradas de Rodagem do Estado de São Paulo; 2006, v.1, 223 p.

DNER. Manual de Projeto de Engenharia Rodoviária: Projeto de Interseções. Rio de Janeiro: IPR; 1974. 
DNER. Manual de Projeto Geométrico de Rodovias Rurais. Rio de Janeiro: IPR; 1999. $195 \mathrm{p}$.

DNER. Manual de Sinalização Rodoviária. 2 ed. Rio de Janeiro: IPR; 2000. 175 p.

DNIT. Manual de Projeto de Interseções. 2 ed. Rio de Janeiro: IPR; 2005. 514 p.

DONALDSON, G.A. Safety of Large Trucks and the Geometric Design of Two-lane, Two-way Roads. Transportation Research Record, Washington, v. 1052, p 10-14, 1986.

DOWNS JUNIOR, H G; WALLACE, D W. (1982) Shoulder Geometrics and Use Guidelines. NCHRP Report, Washington, v. 254, 1982.

EL-GINDY, M.; WOODROOFFE, J.H. The Effects of Tractor Parameter Variations on the Dynamic Performance of B-Train Double. In: ASME SYMPOSIUM ON TRANSPORTATION SYSTEMS, WINTER ANNUAL MEETING, 1990, Dallas. Anais..., 1990, v. 108, p. 99-108.

ERVIN, R.; MACADAM, C.; BURNES, M. Influence of the geometric design of highway ramps on the stability and control of heavy-duty trucks. Transportation Research Record, Washington, v. 1052, p 77-89, 1986.

FABBRI, G.T.P.; FERNANDES JÚNIOR, J.L.; WIDMER, J.A.; SÓRIA, M.H.A. Análise de composições rodoviárias quanto a fatores de destruição de pavimentos. In: REUNIÃO ANUAL DE PAVIMENTAÇÃO DA ABPV, 24, 1990, Belém. Anais... Belém: ABPV, 1990. p. 147-169.

FANCHER, P. S. Sight distance problems related to large trucks. Transportation Research Record, Washington, v. 1052, p. 29-35, 1986.

FANCHER, P.S.; BARETEK, Z.; RUSSO, M.R.A. Truck Length and Weight Issues: Passing and Turning at Intersections. Road Transport Technology, Ann Arbor, p. 397-404, 1995.

FANCHER, P. S; MATHEW, A.; CAMPBELL, K.; BLOWER, D.; WINKLER, C.B. Turner Truck Handling and Stability Properties Affecting Safety: Final Report, v. 
1. Ann Arbor: University of Michigan Transportation Research Institute, 1989. 206 p.

(Relatório Técnico, Nº UMTRI-89-11-1).

FERNANDES JÚNIOR, J.L. Investigação dos efeitos das solicitações do tráfego sobre o desempenho de pavimentos. 1994. 313f. Tese (Doutorado em Engenharia de Transportes) - Escola de Engenharia de São Carlos, Universidade de São Paulo, São Carlos, 1994.

FHWA. Comprehensive truck size and weight study: Scenary Analysis. The U.S. Departament of Transportation's, Volume 3, 2000. Disponível em:

$<$ http://www.fhwa.dot.gov>. Acesso em: 10 fev. 2005.

FHWA. Manual on Uniform Traffic Control Devices for Streets and Highways. Federal Highway. Edição 2003. Washington: Federal Highway Administration; 2003.

FITZPATRICK, K. Geometric Design and Operational Considerations for Trucks. Institute of Transportation Engineers Journal, Washington, p. 12-15, 1992.

FRAMBO, D.B.; FITZPATRICK, K.; KOPPA, R.J. Determination of Stopping Sight Distances. NCHRP Report, Washington, v. 400, 1997.

GATTIS, J.L.; ALGUIRE, M.S.; TOWNSEND, K.; RAO, S. Rural Two-lane Passing Headways and Platooning. Transportation Research Report, Washington, v. 1579, p. 27-34, 1997.

GILLESPIE, T. D. Fundamentals of Vehicle Dynamics. Warrendale: Society of Automotive Engineers;1992. 519p. ISBN: 1-56091-199-9.

GLENNON, J. C. An evaluation of Design Criteria for Operating Trucks Safely on Grades. Highway Research Record, Washington, v. 312, p. 93-112, 1970.

. New and Improved Model of Passing Sight Distance on Two-lane Highways.

Transportation Research Record, Washington, v. 1195, 1988.

HANLEY, P.F.; FORKENBROCK, D.J. Safety of Passing Longer Combination Vehicles on Two-lane Highways. Transportation Research Part A, Kidlington, v. 39, p. 1-15, 2005. 
HARWOOD, D.W.; GLENNON, J. C. Framework for Design and Operation of Passing Zones on Two-Lane Highways. Transportation Research Record, Washington, v. $601,1976$.

HARWOOD, D.W.; MASON JUNIOR, J.M. Horizontal Curve Design for Passanger Cars and Trucks. Transportation Research Record, Washington, v. 1445, 1994.

HARWOOD, D.W.; MASON JUNIOR, J.M.; GLAUZ, D.W.; KULAKOWSKI, T.B.; FITZPATRICK, K. Truck Characteristics for use in Highway Design and Operation, Research Report FHWA, Washington, v. 1-2, 1990.

HARWOOD, D.W.; TORBIC, D.J.; RICHARD, K. R. Review of Truck Characteristics as Factors in Roadway Design. NCHRP Report, Washington, v. 505, 2003.

KABBACH JÚNIOR, F.I. Contribuição para o estudo de implantação de faixas adicionais em rampas ascendentes de rodovias de pista simples. 1993. 333f. Tese (Doutorado em Engenharia de Transportes) - Escola Politécnica, Universidade de São Paulo, São Paulo, 1993.

KAUB, A.R. Passing Operations on a Recreational Two-lane, Two-way Highway. Transportation Research Record, Washington, v. 1280, p. 156-162, 1990.

KREMPEL, G. Experimenteller Beitrag zu Untersuchungen an Kraftfahrzeugreifen. 1965. Tese (Doutorado), Karlsruhe, 1965.

LAMM, R.; PSARIANOS, B.; MAILAENDER, T. Highway Design and Traffic Safety Engineering Handbook. McGraw-Hill; 1999. 1100p. ISBN: 0-07-038295-6.

LEE, S. H. Introdução ao Projeto Geométrico de Rodovias. 2 ed. Florianópolis: Editora da UFSC; 2005. 430p. ISBN: 85-328-0233-8.

LIEBERMAN, E. B. Model for Calculating Safe Passing Distances on Two-Lane Rural Roads.Transportation Research Record, Washington, v. 869, p. 70-76, 1982. 
LIMPERT, R. Brake Design and Safety. SAE Research Report, Warrendale, p. 1-78, 1992.

LIU, C.; HERMAN R. Passing Sight Distance and Dilemma on Two-lane

Roads.Transportation Research Record, Washington, v. 1566, p. 64-70, 1996.

LUCAS, M.J. Faixas adicionais para trechos de rodovias com declives longos considerando os aspectos técnicos da frenagem de veículos de carga. 2004. 92f. Dissertação (Mestrado em Engenharia de Transportes) - Escola de Engenharia de São Carlos, Universidade de São Paulo, São Carlos, 2004.

MACADAM, C.C.; FANCHER P.S.; SEGEL L. Side Friction for Superelevation on Horizontal Curves: Final Report, v. 2. Ann Arbor: University of Michigan

Transportation Research Institute, 1985. (Relatório Técnico, DTFH-6182-C-00019).

MACHADO NETO, E.F. Influência dos veículos pesados na capacidade de rodovias de pista simples. 1995.136f. Dissertação (Mestrado em Engenharia de Transportes) Escola de Engenharia de São Carlos, Universidade de São Paulo, São Carlos, 1995.

MCLEAN, J.; TZIOTS, M.; GUNATILLAKE, T. Geometric Design for trucks: When, Where and How? Sydney: Association of Australian and New Zealand Road Transport and Traffic Authorities; 2002.

MELO, R.A. Faixas adicionais para aclives de rodovias brasileiras. 2002. 178f. Tese (Doutorado em Engenharia de Transportes) - Escola de Engenharia de São Carlos, Universidade de São Paulo, São Carlos, 2002.

NTC. National Heavy Vehicle Standards, Dimensions, Mass Limits \& Registration Charges, National Transportation Commission, 2005. Disponível em:

$<$ http://www.ntc.gov.au>. Acesso em: 20 dez. 2005.

OLSON, P.; CLEVELAND, D.E.; FANCHER, P.S.; KOSTYNIUK, L.P.;

SCHNEIDER, L.W. Parameters Affecting Stopping Sight Distance. NCHRP Report, Washington, v. 270, 1984.

PIMENTA, C.R.T; OLIVEIRA, M.P. Projeto Geométrico de Rodovias. 2 ed. São Carlos: Editora Rima; 2004. 198 p. ISBN: 85-86552-91-7. 
PONTES FILHO, G. Estradas de Rodagem: Projeto Geométrico. São Carlos, 1998. $432 \mathrm{p}$.

PREM, H.; RAMSAY, E.D.; FLETCHER, C.A.; GEORGE, R.M.; GLEESON, B.P. Estimation of Lane Width Requirements for Heavy Vehicles on Straight Paths.

Research Report, Vermont South, v. 342, 1999.

PREM, H.; RAMSAY, E.D; MCLEAN, J.; PEARSON, B.; WOODROOFFE, J.; PONT, J. Definition of Potential Performance Measures and Initial Standards, National Road Transport Commission, Melbourne, 2001.

RILLET, L.R.; HUTCHINSON, B.G.; WHITNEY, M. Mechanics of the Passing Maneuver and the Impact of Large Trucks. Transportation Research Part A, v. 24, p. 121-128, 1990.

ROMANA, M.G. Passing Activity on Two-lane Highways in Spain. Transportation Research Record, Washington, v. 1678, p. 90-95, 1999.

RUSSO, M.R.A. Impacto de manobras de veículos combinados sobre a geometria horizontal de interseções rodoviárias.1995. 131f. Tese (Doutorado em Engenharia de Transportes) - Escola de Engenharia de São Carlos, Universidade de São Paulo, São Carlos, 1995.

SAE. Commercial Truck and Bus SAE Recommended Procedure for Vehicle Performance Prediction and Charting: Procedure J2188. Warrendale: Society of Automotive Engineers; 1996.

SAFWAT, K.N.A.; WALTON, C.M. Expected Performance of Longer Combination Vehicles on Highway Grades. Transportation Research Record, Washington, v. 1052, p. $63-77,1986$.

SARM (1999) Rural Road Classification Report, Saskatchewan Association of Rural Municipalities, Saskatchewan Highways and Transportation, 1999. Disponível em: $<$ http://www.highways.gov.sk.ca>. Acesso em 20 jul. 2003.

SYMPOSIUM ON GEOMETRIC DESIGN FOR LARGE TRUCKS, 1986, Washington. Artigos...Washington: Transportation Research Board, 1986. 
STOKES, R. W.; MCCASLAND, W.R. Truck Operations and Regulations on Urban Freeway in Texas. Institute of Transportation Engineers Journal, Washington, p. 17-21, 1986.

TAC. Geometric Design Guide for Canadian Roads. Ottawa: Transportation Association of Canada; 1999. ISBN: 1-55187-131-9.

TRB. Highway Capacity Manual. Washington: Transportation Research Board; 2000.

TRIGGS, T.J.; HARRIS, W.G. Reaction Times of Drivers to Road Stimuli: Human Factors Report. Victoria: Monash University; 1982.

US DOT. Comprehensive Truck Size and Weight Study: Scenario Analysis; US Department of Transportation, Washington, 2000.

VAN VALKENBURG, G.W.; MICHAEL, H.L. Criteria for No-Passing Zones. Highway Research Record, Washington, v. 366, p. 1 -19, 1971.

WANG, Y.; CARTMELL, M.P. New Model of Passing Sight Distance on Two-lane Highways. Journal of Transportation Engineering, Washington, v. 124, p. 536-545, 1998.

WEAVER, G.D.; GLENNON, J.C. Passing Performance Measurements Related to Sight Distance Design. Texas Transportation Institute, Texas A\&M University, College Station, 1971.

WIDMER, J. A. Compatibilidade de tráfego de bitrens de 25 metros com a infraestrutura viária brasileira. In: COLLOQUIUM DE IMPLEMENTOS RODOVIÁRIOS E MOSTRA DE ENGENHARIA, 1., 2002a, Caxias do Sul. Anais...Caxias do Sul, 2002a, p. 7-12.

. Análise Teórica da Eficiência de Frenagem de Algumas Configurações de Veículos Unitários e Combinações de Veículos Rodoviários de Carga Brasileiros. In: CONGRESSO SAE BRASIL, 11., 2002b, São Paulo. Anais... São Paulo, 2002b.

. Proposta de nomenclatura para caminhões, ônibus, CVCs - Combinações de Veículos de Carga e CVPs - Combinações de Veículos de Passageiros. In: 
CONGRESSO BRASILEIRO DE PESQUISA E ENSINO EM TRANSPORTE, 18., 2004, Florianópolis. Anais... Florianópolis: ANPET, 2004, p. 624-635.

WIDMER, J. A.; SETTI, J. R. Impacts Expected from the Operation of Long Combination Vehicles on Brazilian Two Lane Highways. In: INTERNATIONAL SYMPOSIUM ON HEAVY VEHICLES WEIGHTS AND DIMENSIONS, 5., 1998, Twin-Waters. Anais... Twin-Waters, 1998.

WINKLER, C.B.; FANCHER, P.S. Scenarios for Regulation of Commercial Vehicle Stability in the US. In: INTERNATIONAL HEAVY VEHICLE SEMINAR, 4., 1992, Auckland. Anais...Auckland, 1992.

WINKLER, C.B.; BLOWER, D.; ERVIN,R.D.; CHALSANI, R.M. Rollover of Heavy Commercial Vehicles. SAE Research Report, Warrendale, 2000.

XEREZ, R.S. Método comparativo de desempenho para interseções em nível de rodovias de pista simples. 2002.100. Dissertação (Mestrado em Engenharia de Transportes) - Escola de Engenharia de São Carlos, Universidade de São Paulo, São Carlos, 2002. 


\section{APÊNDICE A}

A seguir são apresentados os pictogramas ilustrativos das configurações dos veículos considerados no presente estudo, seguindo a nomenclatura proposta por Widmer (2004).

Tabela A.1: Representação Pictográfica dos Veículos Estudados.

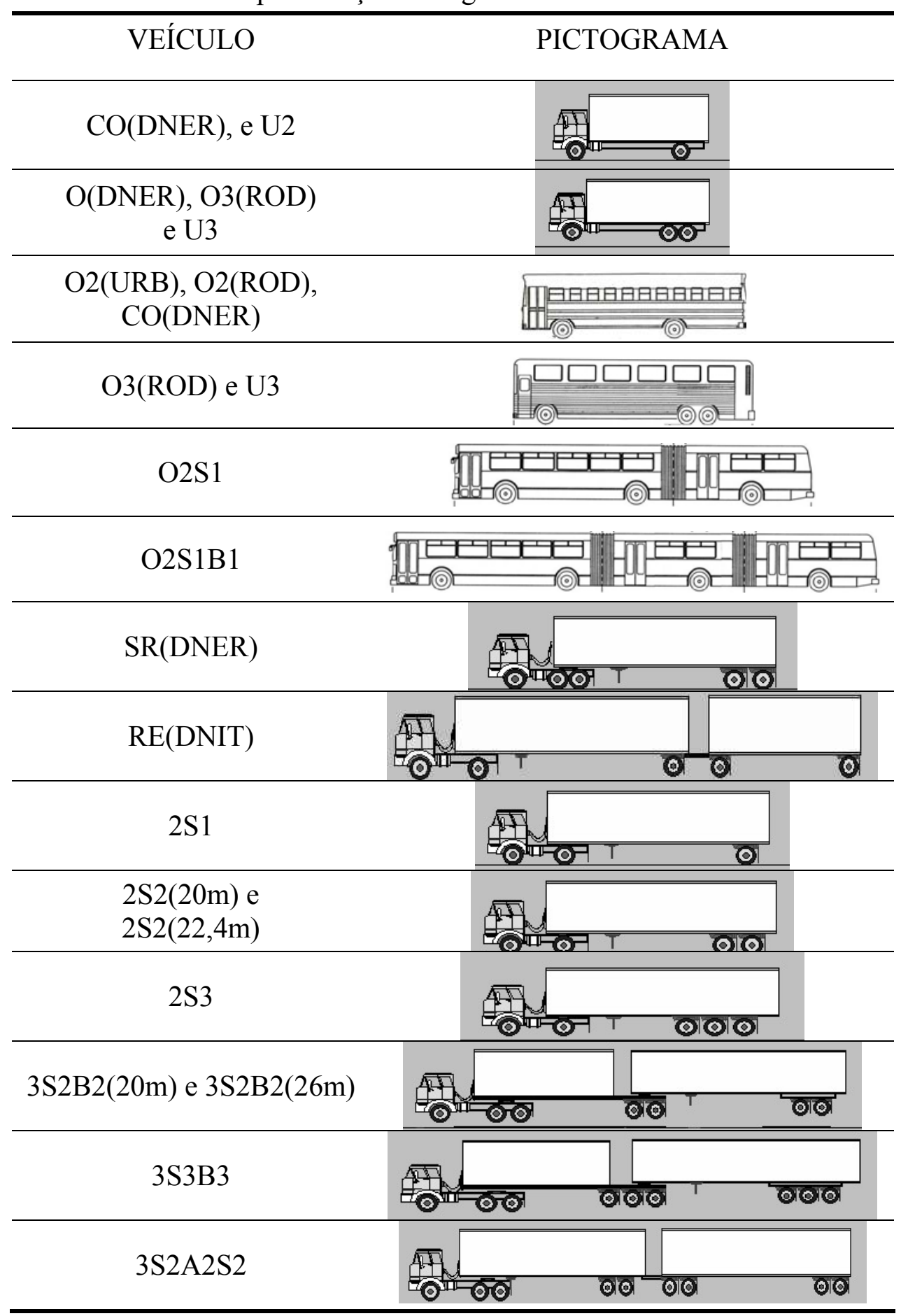


No caso de combinações veiculares, é importante diferenciar o tipo de conexão entre as unidades veiculares. Para o caso da primeira unidade rebocada, esta pode ser acoplada à unidade tratora através de duas formas: através da utilização de uma barra de tração conectada por um pino à extremidade traseira do chassis da unidade tratora, recebendo a denominação de "Tipo A", ou por um acoplamento, através de uma plataforma com encaixe (quinta-roda), fixado na parte superior traseira do chassis da unidade tratora, na qual se encaixa um pino vertical (pino-rei) fixado rigidamente na parte inferior do chassis da unidade rebocada (Widmer, 2004), como é ilustrado na Figura A.1.

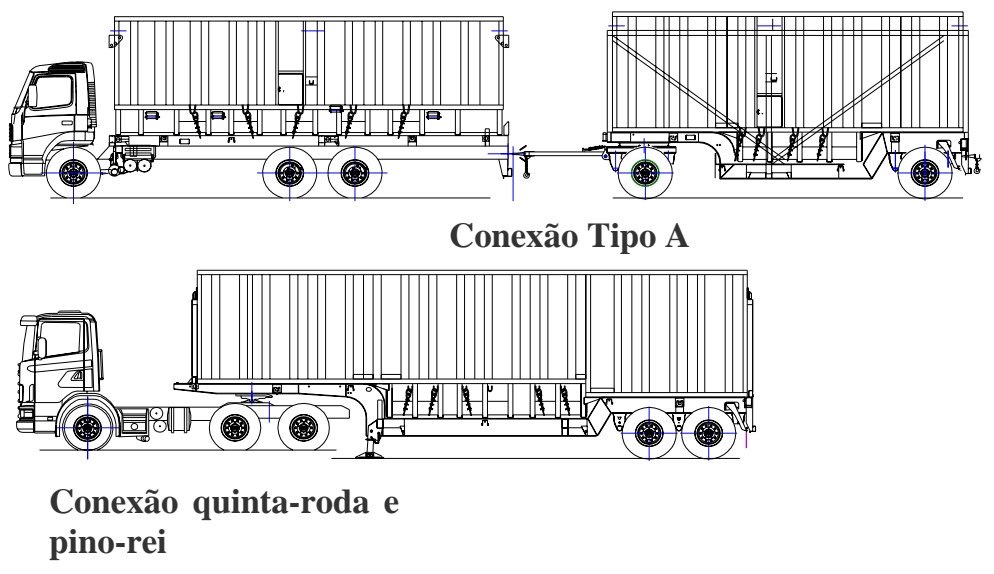

Figura A.1: Tipos Comuns de Conexão entre a Unidade Tratora e a Primeira Unidade Rebocada de CVCs.

As unidades rebocadas subseqüentes podem ser acopladas às unidades dianteiras por: um dispositivo com barras de tração convergentes em um ponto de articulação, conexão tipo A; uma ligação tipo quinta-roda/pino-rei instalada sobre o prolongamento do chassis da unidade dianteira, conexão tipo B; ou ainda por um dispositivo, pouco utilizado na prática, constituído por duas barras paralelas espaçadas conectadas a dois pontos de engate, conexão tipo C" (Widmer, 2004). Estes três tipos de acoplamentos estão ilustrados na Figura A.2. 

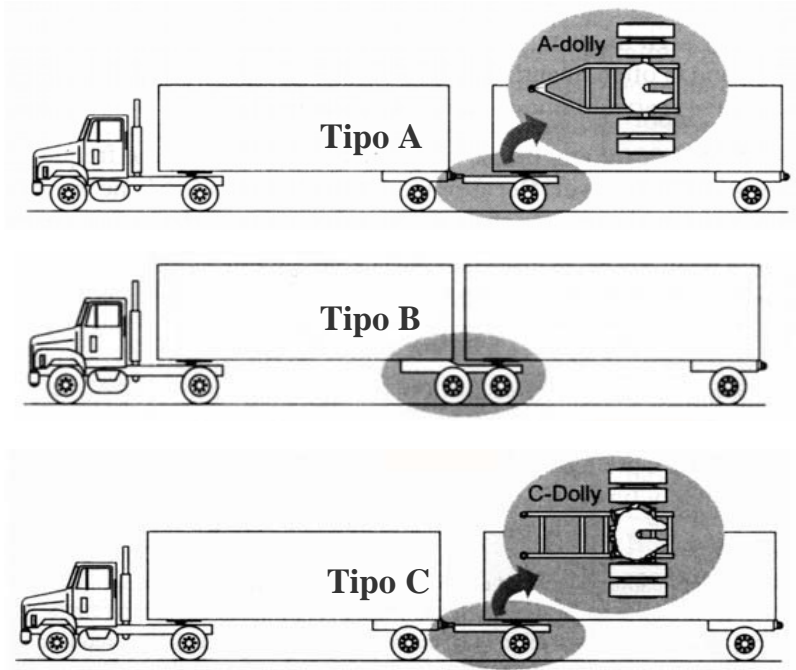

Figura A.2: Tipos de Conexão entre as Unidades Rebocadas de uma CVC 


\section{APÊNDICE B}

Estão apresentadas a seguir as configurações dos veículos utilizados no Simulador Truper para determinar o comportamento dos veículos em rampas.

\begin{tabular}{|c|c|c|c|}
\hline $\begin{array}{l}\text { Veículo } 1 \\
\text { Julieta) }\end{array}$ & 3A1S1 (Romeu e & & \\
\hline 5 eixos & $3,16[\mathrm{cv} / \mathrm{t}]$ & & \\
\hline $\mathbf{P}$ & 136,00 & $\mathrm{cv}$ & potência nominal \\
\hline $\mathbf{h}$ & 0,90 & & eficiência transmissão \\
\hline $\mathbf{W}$ & 43000 & $\mathrm{~kg}$ & PBTC \\
\hline Wta & 8500 & $\mathrm{~kg}$ & peso trator \\
\hline $\mathbf{m}$ & 0,80 & & coef atrito estático \\
\hline $\mathrm{C} 2$ & 0,056 & & cte para o tipo de pneu \\
\hline C3 & 7,6 & & cte para o tipo de pneu \\
\hline $\mathrm{Cr}$ & 1 & & coef. de rolamento \\
\hline Cd & 0,85 & & coef. Aerodinâmico \\
\hline $\mathbf{H}$ & 0 & $\mathrm{~m}$ & altitude média \\
\hline $\mathbf{A}$ & 7,00 & $\mathrm{~m} 2$ & área frontal \\
\hline $\mathrm{r}$ & 0,488 & $\mathrm{~m}$ & raio dinâmico do pneu \\
\hline $\mathrm{gd}$ & 5,25 & & redução no diferencial \\
\hline Ngov & 2400 & $\mathrm{rpm}$ & rotação de governo \\
\hline Npk & 1600 & $\mathrm{rpm}$ & rotação de torque máximo \\
\hline & Resumo do Veícu & & \\
\hline & CVC: & $\mathrm{U} 3 \mathrm{~A}$ & \\
\hline & Configuração: & $4 \times 2 a$ & aptado para 6x2 \\
\hline & Caminhão: & MB I & LK 1414 \\
\hline & Motor: & MB & M366 - marco/89 \\
\hline & Caixa Mudanças: & EAT & N FS 6306 A \\
\hline & Diferencial: & $\mathrm{HL}-4$ & para L/LK1414 \\
\hline & Pneu: & & \\
\hline
\end{tabular}

\begin{tabular}{|c|c|}
\hline $\mathbf{N}$ & $\mathbf{P}$ \\
$\mathbf{r p m}$ & $\mathbf{k W}$ \\
\hline 1000 & 35 \\
1100 & 42 \\
1200 & 47 \\
1300 & 52 \\
1400 & 58 \\
1500 & 63 \\
\hline
\end{tabular} \mid \begin{tabular}{c|c|c|}
\hline \multicolumn{2}{|c|}{ Transmissão } \\
\hline $1^{\mathrm{a}}$ & 47,30 \\
$2^{\mathrm{a}}$ & 27,67 \\
$3^{\mathrm{a}}$ & 16,91 \\
$4^{\mathrm{a}}$ & 10,71 \\
$5^{\mathrm{a}}$ & 7,14 \\
$6^{\mathrm{a}}$ & 5,25 \\
\hline
\end{tabular}

$1600 \quad 67$

$1700 \quad 71$

$1800 \quad 76$

$1900 \quad 80$

$2000 \quad 84$

$2100 \quad 86$

$2200 \quad 90$

$2300 \quad 93$

$2400 \quad 95$

$2500 \quad 96$

$2600 \quad 97$

$2700 \quad 98$

$2800 \quad 100$ 


\begin{tabular}{|l|}
\hline $\begin{array}{l}\text { Veículo 2 - 3A1S1A1S1 } \\
\text { (Treminhão) }\end{array}$ \\
\hline 7 eixos \\
\hline
\end{tabular}

\begin{tabular}{|c|c|c|c|}
\hline $\mathbf{P}$ & 294,00 & $\mathrm{cv}$ & potência nominal \\
\hline $\mathbf{h}$ & 0,90 & & eficiência transmissão \\
\hline $\mathbf{w}$ & 63000 & $\mathrm{~kg}$ & PBTC \\
\hline Wta & 8500 & $\mathrm{~kg}$ & peso trator \\
\hline $\mathbf{m}$ & 0,80 & & coef atrito estático \\
\hline C2 & 0,056 & & cte para o tipo de pneu \\
\hline C3 & 7,6 & & cte para o tipo de pneu \\
\hline $\mathrm{Cr}$ & 1 & & coef. de rolamento \\
\hline Cd & 0,85 & & coef. Aerodinâmico \\
\hline $\mathbf{H}$ & 0 & $\mathrm{~m}$ & altitude média \\
\hline $\mathbf{A}$ & 7,00 & $\mathrm{~m} 2$ & área frontal \\
\hline
\end{tabular}

\begin{tabular}{|c|c|c|c|}
\hline \multirow{2}{*}{$\begin{array}{c}\mathrm{N} \\
\mathrm{rpm}\end{array}$} & \multirow{2}{*}{$\begin{array}{c}\mathrm{P} \\
\mathrm{kW}\end{array}$} & \multicolumn{2}{|c|}{ Transmissão } \\
\hline & & marcha & gtxgd \\
\hline 1000 & 85,87 & $1^{\mathrm{a}}$ & 51,91 \\
\hline 1200 & 142,63 & $2^{\mathrm{a}}$ & 34,77 \\
\hline 1400 & 175,05 & $3^{\mathrm{a}}$ & 25,58 \\
\hline 1600 & 184,31 & $4^{\mathrm{a}}$ & 19,02 \\
\hline 1800 & 196,04 & $5^{\mathrm{a}}$ & 14,02 \\
\hline 2000 & 205,25 & $6^{\mathrm{a}}$ & 10,17 \\
\hline 2200 & 211,95 & $7^{\mathrm{a}}$ & 7,46 \\
\hline 2400 & 221,17 & $8^{a}$ & 5,58 \\
\hline & & $9^{\mathrm{a}}$ & 4,1 \\
\hline
\end{tabular}

\begin{tabular}{|cccl|}
\hline $\mathrm{r}$ & 0,5388 & $\mathrm{~m}$ & raio dinâmico do pneu \\
$\mathrm{gd}$ & 4,10 & & redução no diferencial \\
Ngov & 1800 & $\mathrm{rpm}$ & rotação de governo \\
$\mathrm{Npk}$ & 1400 & $\mathrm{rpm}$ & rotação de torque máximo \\
\hline
\end{tabular}

\section{Resumo do Veículo}

CVC: U3A1S1A1S1

Configuração: $6 \times 4$

Caminhão: VW 35.300

Motor: Cummins 6CTAA-294 (em kW)

Caixa Mudanças: EATON RT 8609 A

Diferencial: Redução 4,1

Pneu: 11.00 R 22 PR 16 


\begin{tabular}{|l|l|}
\hline \multicolumn{2}{|l|}{ Veículo 3-2S2 } \\
\hline 4 eixos & $6,97[\mathrm{cv} / \mathrm{t}]$ \\
\hline
\end{tabular}

\begin{tabular}{|cccl|}
\hline $\mathbf{P}$ & 230,00 & $\mathrm{cv}$ & potência nominal \\
$\mathbf{h}$ & 0,90 & & eficiência transmissão \\
$\mathbf{W}$ & 33000 & $\mathrm{~kg}$ & PBTC \\
$\mathbf{W t a}$ & 10000 & $\mathrm{~kg}$ & peso trator \\
$\mathbf{m}$ & 0,80 & & coef atrito estático \\
$\mathbf{C} 2$ & 0,056 & & cte para o tipo de pneu \\
$\mathbf{C} 3$ & 7,6 & & cte para o tipo de pneu \\
$\mathbf{C r}$ & 1 & & coef. de rolamento \\
$\mathbf{C d}$ & 0,85 & & coef. Aerodinâmico \\
$\mathbf{H}$ & 0 & $\mathrm{~m}$ & altitude média \\
$\mathbf{A}$ & 7,00 & $\mathrm{~m} 2$ & área frontal \\
\hline
\end{tabular}

\begin{tabular}{|cccl|}
\hline $\mathrm{r}$ & 0,50175 & $\mathrm{~m}$ & raio dinâmico do pneu \\
$\mathrm{gd}$ & 3,40 & & redução no diferencial \\
$\mathrm{Ngov}$ & 1800 & $\mathrm{rpm}$ & rotação de governo \\
$\mathrm{Npk}$ & 1100 a 1400 & $\mathrm{rpm}$ & rotação de torque máximo \\
\hline
\end{tabular}

\section{Resumo do Veículo}

CVC: $2 \mathrm{~S} 2$

Configuração: $4 \times 2$

Caminhão: P230 (4x2)

Motor: Scania-DC9 19230

Caixa Mudanças: Scania - GR 801

Diferencial: Scania-R780

Pneu: 295 / 80 R 22,5

\begin{tabular}{|c|c|c|c|}
\hline \multirow{2}{*}{$\begin{array}{c}\mathrm{N} \\
\mathrm{rpm}\end{array}$} & \multirow{2}{*}{$\begin{array}{c}P \\
\mathrm{~kW}\end{array}$} & \multicolumn{2}{|c|}{ Transmissão } \\
\hline & & marcha & gtxgd \\
\hline 1000 & 108 & $1^{\mathrm{a}}$ & 31,11 \\
\hline 1100 & 121 & $2^{\mathrm{a}}$ & 21,49 \\
\hline 1200 & 132 & $3^{\mathrm{a}}$ & 15,95 \\
\hline 1300 & 143 & $4^{a}$ & 12,75 \\
\hline 1400 & 154 & $5^{\mathrm{a}}$ & 8,296 \\
\hline 1500 & 162 & $6^{\mathrm{a}}$ & 5,712 \\
\hline 1600 & 164 & $7^{\mathrm{a}}$ & 4,25 \\
\hline 1700 & 166 & $8^{a}$ & 3,4 \\
\hline 1800 & 167 & & \\
\hline 1900 & 168 & & \\
\hline
\end{tabular}




\begin{tabular}{|l|l|}
\hline \multicolumn{2}{|l|}{ Veículo 4 - 3S3 } \\
\hline 6 eixos & $7,42[\mathrm{cv} / \mathrm{t}]$ \\
\hline
\end{tabular}

\begin{tabular}{|cccl|}
\hline $\mathbf{P}$ & 360,00 & $\mathrm{cv}$ & potência nominal \\
$\mathbf{h}$ & 0,90 & & eficiência transmissão \\
$\mathbf{W}$ & 48500 & $\mathrm{~kg}$ & PBTC \\
$\mathbf{W t a}$ & 17000 & $\mathrm{~kg}$ & peso trator \\
$\mathbf{m}$ & 0,80 & & coef atrito estático \\
$\mathbf{C} 2$ & 0,056 & & cte para o tipo de pneu \\
$\mathbf{C} 3$ & 7,6 & & cte para o tipo de pneu \\
$\mathbf{C r}$ & 1 & & coef. de rolamento \\
$\mathbf{C d}$ & 0,85 & & coef. Aerodinâmico \\
$\mathbf{H}$ & 0 & $\mathrm{~m}$ & altitude média \\
$\mathbf{A}$ & 7,00 & $\mathrm{~m} 2$ & área frontal \\
\hline & & & \\
\hline $\mathrm{r}$ & 0,50175 & $\mathrm{~m}$ & raio dinâmico do pneu \\
gd & 4,27 & & redução no diferencial \\
Ngov & 1800 & $\mathrm{rpm}$ & rotação de governo \\
Npk & $1300 \mathrm{a} 1500$ & $\mathrm{rpm}$ & rotação de torque máximo \\
\hline
\end{tabular}

Resumo do Veículo

CVC: $3 \mathrm{~S} 3$

Configuração: $6 \times 2$

Caminhão: Scania - Carga Geral (6x2)

Motor: Scania-DSC12 02

Caixa Mudanças: Scania - GRS 900

Diferencial: Scania-RBP835+RP835

Pneu: 295 / 80 R 22,5

\begin{tabular}{|c|c|c|c|}
\hline \multirow{2}{*}{$\begin{array}{c}\mathbf{N} \\
\text { rpm }\end{array}$} & \multirow{2}{*}{$\begin{array}{c}P \\
\mathbf{k W} \\
\end{array}$} & \multicolumn{2}{|c|}{ Transmissão } \\
\hline & & marcha & gtxgd \\
\hline 1000 & 173 & $1^{\mathrm{a}}$ & 69,94 \\
\hline 1100 & 190 & $2^{\mathrm{a}}$ & 56,71 \\
\hline 1200 & 208 & $3^{\mathrm{a}}$ & 48,12 \\
\hline 1300 & 227 & $4^{a}$ & 39,03 \\
\hline 1400 & 245 & $5^{\mathrm{a}}$ & 30,62 \\
\hline 1500 & 283 & $6^{\mathrm{a}}$ & 24,81 \\
\hline 1600 & 285 & $7^{\mathrm{a}}$ & 19,7 \\
\hline 1700 & 285 & $8^{a}$ & 16 \\
\hline 1800 & 285 & $9^{a}$ & 12,9 \\
\hline 1900 & 285 & $10^{\mathrm{a}}$ & 10,4 \\
\hline 2000 & 248 & $11^{\mathrm{a}}$ & 8,16 \\
\hline 2100 & 246 & $12^{\mathrm{a}}$ & 6,62 \\
\hline & & $13^{\mathrm{a}}$ & 5,47 \\
\hline & & $14^{\mathrm{a}}$ & 4,27 \\
\hline
\end{tabular}




\begin{tabular}{|c|c|c|c|}
\hline \multicolumn{2}{|c|}{ Veículo 5 - 2S2 } & & \\
\hline 4 eixos & $9,76[\mathrm{cv} / \mathrm{t}]$ & & \\
\hline $\mathbf{P}$ & 322,00 & \multirow[t]{2}{*}{$\mathrm{cv}$} & \multirow{2}{*}{$\begin{array}{l}\text { potência nominal } \\
\text { eficiência transmissão }\end{array}$} \\
\hline h & 0,90 & & \\
\hline $\mathbf{w}$ & 33000 & $\mathrm{~kg}$ & PBTC \\
\hline Wta & 10000 & \multirow[t]{2}{*}{$\mathrm{kg}$} & peso trator \\
\hline $\mathbf{m}$ & 0,80 & & coef atrito estático \\
\hline $\mathrm{C} 2$ & 0,056 & & cte para o tipo de pneu \\
\hline $\mathrm{C} 3$ & 7,6 & & cte para o tipo de pneu \\
\hline $\mathrm{Cr}$ & 1 & & coef. de rolamento \\
\hline Cd & 0,85 & & coef. Aerodinâmico \\
\hline $\mathbf{H}$ & 0 & $\mathrm{~m}$ & altitude média \\
\hline A & 7,00 & $\mathrm{~m} 2$ & área frontal \\
\hline \multirow{4}{*}{$\begin{array}{c}\mathrm{r} \\
\mathrm{gd} \\
\mathrm{Ngov} \\
\mathrm{Npk}\end{array}$} & 0,50175 & \multirow[t]{2}{*}{$\mathrm{m}$} & raio dinâmico do pneu \\
\hline & 3,40 & & redução no diferencial \\
\hline & 1800 & rpm & rotação de governo \\
\hline & 1000 a 1500 & \multicolumn{2}{|r|}{ rotação de torque máximo } \\
\hline \multicolumn{4}{|c|}{ Resumo do Veículo } \\
\hline & CVC: & \multicolumn{2}{|l|}{$2 \mathrm{~S} 2$} \\
\hline & Configuração: & \multicolumn{2}{|c|}{$4 \times 2$} \\
\hline & Caminhão: & \multicolumn{2}{|c|}{$\mathrm{P} 230(4 \mathrm{x} 2)$} \\
\hline & Motor: & \multicolumn{2}{|c|}{ Scania - DC11 07} \\
\hline & Caixa Mudanças: & \multicolumn{2}{|c|}{ Scania - GRS 900} \\
\hline & Diferencial: & \multirow{2}{*}{\multicolumn{2}{|c|}{$\begin{array}{l}\text { Scania - R780 } \\
295 / 80 \text { R } 225\end{array}$}} \\
\hline & Pneu: & & \\
\hline
\end{tabular}

\begin{tabular}{|c|c|c|c|}
\hline $\mathbf{N}$ & $\mathbf{P}$ \\
& & $\mathbf{k W}$ \\
$\mathbf{r p m}$ & $\mathbf{k}$ & \multicolumn{2}{|c|}{ Transmissão } \\
1000 & 157 & & \\
1100 & 173 \\
1200 & 187 \\
1300 & 205 \\
1400 & 220 \\
1500 & 235 \\
1600 & 236 \\
1700 & 236 \\
1800 & 236 \\
1900 & 236 \\
2000 & 225 \\
2100 & 220 \\
\hline & & $1^{\mathrm{a}}$ & 55,69 \\
$2^{\mathrm{a}}$ & 45,15 \\
$3^{\mathrm{a}}$ & 38,32 \\
$4^{\mathrm{a}}$ & 31,08 \\
$5^{\mathrm{a}}$ & 24,38 \\
$6^{\mathrm{a}}$ & 19,75 \\
$7^{\mathrm{a}}$ & 15,71 \\
$8^{\mathrm{a}}$ & 12,75 \\
$9^{\mathrm{a}}$ & 10,23 \\
$10^{\mathrm{a}}$ & 8,296 \\
$11^{\mathrm{a}}$ & 6,494 \\
$12^{\mathrm{a}}$ & 5,27 \\
$13^{\mathrm{a}}$ & 4,352 \\
$14^{\mathrm{a}}$ & 3,4 \\
\hline
\end{tabular}




\begin{tabular}{|c|c|}
\hline \multicolumn{2}{|l|}{ Veículo 6 - 2S2 } \\
\hline 4 eixos & $13.15[\mathrm{cv} / \mathrm{t}]$ \\
\hline
\end{tabular}

\begin{tabular}{|c|c|c|c|}
\hline $\begin{array}{l}\mathbf{P} \\
\mathbf{h}\end{array}$ & $\begin{array}{c}420.00 \\
0.90\end{array}$ & $\mathrm{cV}$ & $\begin{array}{l}\text { potência nominal } \\
\text { eficiência transmissão }\end{array}$ \\
\hline $\mathbf{W}$ & 31950 & $\mathrm{~kg}$ & PBTC \\
\hline Wta & 8500 & $\mathrm{~kg}$ & peso trator \\
\hline $\mathbf{m}$ & 0.80 & & coef atrito estático \\
\hline $\mathrm{C} 2$ & 0.056 & & cte para o tipo de pneu \\
\hline C3 & 7.6 & & cte para o tipo de pneu \\
\hline Cr & 1 & & coef. de rolamento \\
\hline Cd & 0.85 & & coef. Aerodinâmico \\
\hline $\mathbf{H}$ & 0 & $\mathrm{~m}$ & altitude média \\
\hline A & 7.00 & $\mathrm{~m} 2$ & área frontal \\
\hline $\mathrm{r}$ & 0.50175 & $\mathrm{~m}$ & raio dinâmico do pneu \\
\hline gd & 3.76 & & redução no diferencial \\
\hline Ngov & 1700 & $\mathrm{rpm}$ & rotação de governo \\
\hline $\mathrm{Npk}$ & 1300 & $\mathrm{rpm}$ & rotação de torque máximo \\
\hline
\end{tabular}

\begin{tabular}{|c|c|}
\hline $\mathbf{N}$ & $\mathbf{P}$ \\
$\mathbf{r p m}$ & $\mathbf{k W}$ \\
\hline 1000 & 200 \\
1100 & 230 \\
1200 & 250 \\
1300 & 270 \\
1400 & 290 \\
1500 & 309 \\
1600 & 309 \\
1700 & 309 \\
1800 & 309 \\
1900 & 280 \\
2000 & 220 \\
\hline
\end{tabular}

\begin{tabular}{|c|c|}
\hline \multicolumn{2}{|c|}{ Transmissão } \\
\hline marcha & gtxgd \\
\hline $1^{\mathrm{a}}$ & 63.39 \\
$2^{\mathrm{a}}$ & 50.80 \\
$3^{\mathrm{a}}$ & 41.85 \\
$4^{\mathrm{a}}$ & 33.54 \\
$5^{\mathrm{a}}$ & 26.92 \\
$6^{\mathrm{a}}$ & 21.58 \\
$7^{\mathrm{a}}$ & 17.60 \\
$8^{\mathrm{a}}$ & 14.10 \\
$9^{\mathrm{a}}$ & 11.17 \\
$10^{\mathrm{a}}$ & 8.95 \\
$11^{\mathrm{a}}$ & 7.18 \\
$12^{\mathrm{a}}$ & 5.75 \\
$13^{\mathrm{a}}$ & 4.70 \\
$14^{\mathrm{a}}$ & 3.76 \\
\hline
\end{tabular}

\begin{tabular}{|c|c|}
\hline \multicolumn{2}{|c|}{ Resumo do Veículo } \\
\hline CVC: & $2 \mathrm{~S} 2$ \\
\hline Configuração: & $6 \times 2$ \\
\hline Caminhão: & Volvo - NH12 (6x2) \\
\hline Motor: & Volvo - D12D 420 \\
\hline $\begin{array}{r}\text { Caixa } \\
\text { Mudancas: }\end{array}$ & Volvo - VT2214 e VT2214B \\
\hline Diferencial: & Volvo - RAN 471 \\
\hline Pneu: & Firestone - 295 \\
\hline
\end{tabular}

